\author{
UNIVERSIDADE DE SÃO PAULO \\ ESCOLA DE ENGENHARIA DE SÃO CARLOS \\ DEPARTAMENTO DE ENGENHARIA MECÂNICA
}

\title{
SINTETIZAÇÃO DOS \\ ERROS TERMICAMENTE INDUZIDOS EM \\ Máquinas de Medir a Três CoORdenadAs
}

RosendA VALDÉs ARENCIBIA

Tese apresentada à Escola de Engenharia de São Carlos da Universidade de São Paulo, como parte dos requisitos para obtenção do título de Doutor em Engenharia Mecânica.

ORIENTADOR: Prof. Dr. Benedito Di Giacomo

São Carlos

2003 
Ficha catalográfica preparada pela Seção de Tratamento da Informação do Serviço de Biblioteca - EESC/USP

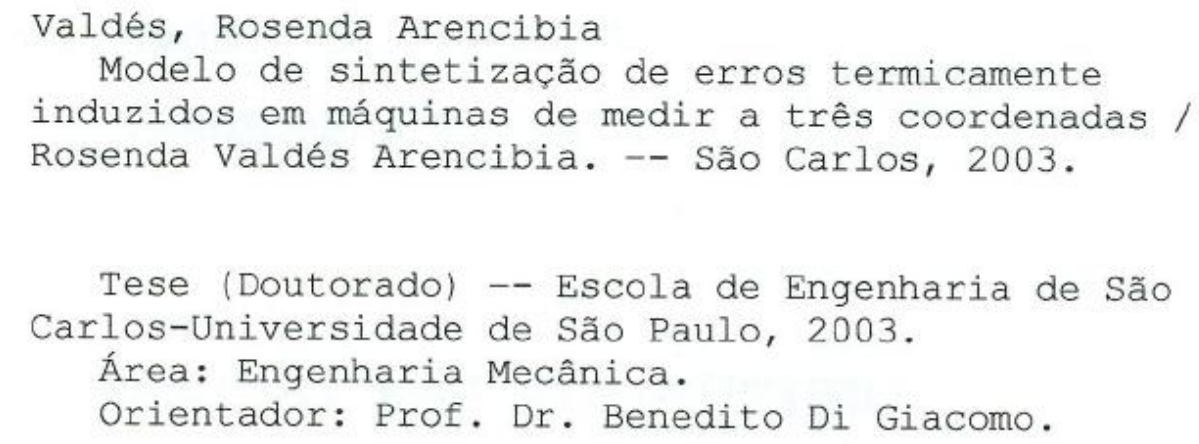

1. Drift térmico. 2. Erros termicamente induzidos. 3. Estados térmicos. 4. Gradientes térmicos espaciais.

5. Transformações homogêneas. I. Título. 

Aos meus pais GERALDO e NILDA.

Às minhas filhas WENDY e AMANDA. 
Decidí que trabajaría de una forma más precisa que cualquiera de los otros aprendices y que cuando lo consiguiera, entonces aprenderia a hacerlo de una forma aún más precisa que antes. A lo largo de mi vida esta ha sido mi única idea.

Lucian Sharpe 


\section{Agradecimentos}

Ao final deste trabalho, gostaria de expressar meus mais sinceros agradecimentos ao Prof. Dr. Benedito Di Giacomo pelos ensinamentos, orientação, apoio, incentivo, paciência e amizade durante a realização deste trabalho.

À Denise Pizarro Vieira Sato e Rosamel Melita Muños pela amizade, pela ajuda, pelo incentivo e força.

À Luis Carlos Neves, José Cláudio Pinto de Azevedo e Eraldo dos Santos Junior pela ajuda na realização dos experimentos e pela amizade.

Aos colegas de pós-graduação Márcia, Renata, Alessandro, Fabrício, Roberto, Alexandre, Alessandra, Andréa, Rita e Marcela pela amizade e apoio manifestado durante o transcorrer do trabalho.

Aos funcionários da Oficina do LAMAFE Adão S. Bolsan, José Carlos Botelho e José Risardi pela amizade.

A meus pais, irmãos e à Cecília pelo amor, incentivo e esperança, embora distantes.

À Dona Angélica e ao Senhor Nivaldo pela amizade e ajuda durante todos estes anos.

À Ilda, Osmar, Tálitta e Yazmin pela amizade.

Agradecimento especial a minhas filhas Amanda e Wendy, motivo de alegria e força para vencer os obstáculos.

A você Sam por me ensinar o caminho das estrelas.

À FAPESP pela bolsa concedida durante o desenvolvimento do projeto e ao Departamento de Engenharia Mecânica, Comissão de Pós Graduação e corpo administrativo.

Ao povo brasileiro pela hospitalidade com que fui recebida e acolhida.

$\mathrm{E}$ a todos aqueles que por esquecimento ou ausência deixaram de ser citados, os nossos agradecimentos. 


\section{SUMÁRIO}

Lista de Figuras

V

Lista de Tabelas

$\mathrm{X}$

xi

Lista de Símbolos

xiii

Glossário

xiv

RESUMO

XV

ABSTRACT

1. INTRODUÇÃO

2. Efeitos Térmicos em Máquinas de Medir a Três CoORdenadas

2.1. Erros térmicos. Considerações gerais

2.2. Efeitos térmicos em MM3Cs

2.2.1. Formas de transferência de calor em Máquinas de Medir

2.2.2. Distribuições uniformes e não uniformes das temperaturas

2.2.3. Influências térmicas na Estrutura, Escala e Peça 16

2.3. Métodos e Técnicas utilizados para equacionamento dos erros térmicos

2.4. Novas tendências

3. Ferramentas Matemáticas Utilizadas na Modelagem e no CÁlCUlo da InCERTEZA de MEDiÇÃo.

3.1. Modelagem Matemática. Transformações Homogêneas 30

3.1.1. Considerações Gerais 
3.2. Tratamento estatístico de dados. Conceitos básicos 38

3.2.1. Conceitos básicos 39

3.2.2. Regressão linear 41

3.3. Erro e Incerteza de Medição 44

3.3.1. Incerteza Padrão 46

3.3.2. Incerteza Padrão Combinada 49

3.3.3. Incerteza Expandida 50

3.3.4. Incerteza Tridimensional 52

4. Equacionamento dos ERros Termicamente Induzidos Em $\begin{array}{ll}\text { MM3Cs } & 57\end{array}$

4.1. Estudo do Sistema de Medição 58

4.2. Desenvolvimento do modelo da máquina 59

4.3. Calibração da máquina. 62

4.4. Avaliação do Modelo Proposto 62

4.5. Determinação da incerteza associada às componentes do erro volumétrico 63

5. DescriçÃo dA MEtodologia PARA Equacionamento dos ERROS TERMICAMENTE INDUZIDOS NA MM3C 64

5.1. Estudo do sistema de medição 64

5.1.1. Identificação dos Pontos Quentes da estrutura da máquina 65

5.2. Desenvolvimento do modelo geométrico-térmico da MM3C

5.2.1. Equacionamento do comportamento geométrico $\begin{array}{ll}\text { da máquina } & 67\end{array}$

5.3. Calibração da MM3C. 77

5.3.1. Levantamento dos erros geométricos 78

5.3.2. Desenvolvimento do sistema de monitoramento das temperaturas $\quad 78$

5.3.3. Levantamento dos dados de drift 84

5.4. Avaliação do modelo proposto 86 
5.5. Determinação da incerteza

5.5.1. Determinação da incerteza associada às componentes do erro volumétrico Ex, Ey e Ez.

5.5.2. Estimativa da incerteza associada à medição de erros utilizando o esquadro mecânico.

5.5.3. Estimativa da incerteza associada aos erros de posição medidos com o interferômetro laser

5.5.4. Incerteza associada aos erros de retitude e angulares pitch e yaw medidos com o Interferômetro laser

5.5.5. Incerteza associada aos erros roll medidos com o nivel eletrônico

5.5.6. Incerteza associada aos braços fixos

6. Resultados e Discussões

6.1. Resultados da análise do sistema 98

6.1.1. Fontes de calor 99

6.1.2. Pontos quentes da estrutura 100

6.1.3. Gradientes térmicos espaciais

6.1.4. Distribuição da temperatura na estrutura da máquina

6.1.5. Resultados preliminares do levantamento do drift

6.2. Resultados da Medição e Modelagem dos Erros Geométricos

6.2.1. Erro de Posição do eixo $X$

6.2.2. Erro de posição do eixo $Y$

6.2.3. Erro de posição do eixo $Z$

6.2.4. Erros de Retitude do eixo $X$

6.2.5. Erros de Retitude do eixo $Y$

6.2.6. Erros de Retitude do eixo $Z$ 
6.2.8. Erro angular pitch do eixo $Y$

6.2.9. Erro angular pitch do eixo $Z \quad 132$

6.2.10. Erro angular yaw do eixo $X \quad 132$

6.2.11. Erro angular yaw do eixo $Y \quad 133$

6.2.12. Erro angular yaw do eixo $Z \quad 134$

6.2.13. Erro angular roll do eixo $X \quad 135$

6.2.14. Erro angular roll do eixo $Y \quad 135$

6.2.15. Erros de perpendicularidade 137

6.3. Avaliação do modelo 138

6.4. Cálculo da Incerteza associada às componentes do erro volumétrico

7. Conclusões e Propostas para TRabalhos Futuros

REFERÊNCIAS BIBLIOGRÁFICAS

APÊNDICES

APÊNDICE A. Procedimento estatístico para escolha de variáveis na regressão (VIEIRA SATO, 1998) 158

APÊNDICE B. Medição dos erros geométricos 160

APÊNDICE C. Especificações técnicas dos instrumentos utilizados na calibração da máquina

APÊNDICE D. Temperaturas durante a medição dos erros geométricos

APÊNDICE E. Cálculo das características do círculo 175

APÊNDICE F. Curvas de drift dos erros de retitude e angulares $\quad 178$

APÊNDICE G. Estudo do principio de montagem escala-guia 185

APÊNDICE H. Cálculo do coeficiente de correção do laser 189 


\section{LISTA DE FIGURAS}

$\begin{array}{lll}\text { Figura 2.1 Fontes de erros em MM3Cs } & 6\end{array}$

Figura 2.2 Aumento do significado dos aspectos térmicos (GROBMANN e JUNGNICKEL, 2002)

Figura 2.3 Diagrama de influências térmicas em Máquinas de Medir (BRYAN, 1990)

Figura 3.1 Sistemas de coordenadas cartesianas

Figura 3.2 Translação em $X$

Figura 3.3 Translação em Y 34

Figura 3.4 Translação em $Z$

Figura 3.5 Rotação $\alpha$ do sistema $(X i, Y i, Z i)$ em torno do eixo $X$

Figura 3.6 Rotação $\beta$ do sistema $(X i, Y i, Z i)$ em torno do eixo $Y \quad 37$

Figura 3.7 Rotação $\gamma$ do sistema $(X i, Y i, Z i)$ em torno do eixo $Z \quad 38$

Figura 3.8 Distribuições de Probabilidade 45

Figura 3.9 Representação da Incerteza padronizada combinada $\left(u_{c}\right)$ e da incerteza expandida com 95\% (U95) e 99\% (U99) de confiança

Figura 5.1 Arranjo experimental para identificação de pontos quentes

Figura 5.2 Representação da MM3C com os sistemas de coordenadas

Figura 5.3 Representação vetorial dos caminhos real e ideal

Figura 5.4 Localização física dos termopares

Figura 5.5 Termopares destinados para monitoramento dos gradientes térmicos espaciais

Figura 5.6 Esquema de montagem do termopar

Figura 5.7 Termopar conectado ao voltímetro e circuito equivalente (OMEGA ENGINEERING, 1995)

Figura 5.8 Montagem do termopar de referência (OMEGA ENGINEERING, 1995) 
$\begin{array}{lll}\text { Figura 6.1 Imagens de diferentes componentes } & 100\end{array}$

Figura 6.2 Imagem das peças de alumínio e de aço inox 101

Figura 6.3 Gradiente térmico vertical à direita da máquina 102

Figura 6.4 Gradiente térmico vertical atrás da máquina 103

Figura 6.5 Gradiente térmico vertical à esquerda da máquina 104

Figura 6.6 Curvas da variação da temperatura dos elementos fixos da máquina e do ambiente $\quad 105$

Figura 6.7 Distribuição das temperaturas para $20^{\circ} \mathrm{C} \quad 105$

Figura 6.8 Drift do erro de posição do eixo $Y$ no ponto zero 106

Figura 6.9 Curvas de drift do erro de posição do eixo $X$ na retificadora cilindrica 107

Figura 6.10 Erro de posição do eixo $X$, para $20{ }^{\circ} \mathrm{C} \quad 109$

Figura 6.11 Curvas do erro de posição do eixo $X$ para 20, 22, 24 e $26^{\circ} \mathrm{C} \quad 109$

Figura 6.12 Curvas de drift do erro de posição do eixo $X \quad 110$

Figura 6.13 Princípio de montagem da ponte móvel 111

Figura 6.14 Temperatura dos elementos fixos no drift do erro de posição do eixo $X$

Figura 6.15 Temperatura dos termopares dos elementos móveis na posição $X=0 \quad 112$

Figura 6.16 Erro de posição do eixo $Y$, para $20^{\circ} \mathrm{C} \quad 114$

Figura 6.17 Curvas do erro de posição do eixo $Y$ para 20, 22, 24 e $26^{\circ} \mathrm{C}$

Figura 6.18 Curvas de drift do erro de posição do eixo $Y \quad 115$

Figura 6.19 Temperatura dos termopares em $Y=0 \quad 116$

Figura 6.20 Erro de posição do eixo $Z$ para $20^{\circ} \mathrm{C} \quad 118$

Figura 6.21 Curvas do erro de posição do eixo $Z$ para 20, 22, 24 e $26^{\circ} \mathrm{C}$. 118

$\begin{array}{lll}\text { Figura 6.22 Curvas de drift do erro de posição do eixo } Z & 119\end{array}$

Figura 6.23 Variação de temperatura dos termopares fixos durante o drift do erro de posição $Z \quad 119$

Figura 6.24 Duas formas diferentes de montagem de escalas em guias 
Figura 6.25 Erros de expansão diferencial para ambos princípios de montagem

Figura 6.26 Erro de retitude $X y$ para $20^{\circ} \mathrm{C}$.

Figura 6.27 Erro de retitude $\mathrm{Xz}$ para $20^{\circ} \mathrm{C}$

Figura 6.28 Curvas de drift do erro de retitude $X y$

Figura 6.29 Erro de retitude horizontal do eixo $Y$ para $20^{\circ} \mathrm{C}$

Figura 6.30 Erro de retitude $Y z$ para $20^{\circ} \mathrm{C}$

Figura 6.31 Erro de retitude $Z x$ para $20^{\circ} \mathrm{C}$

Figura 6.32 Erro de retitude $Z y$ para $20^{\circ} \mathrm{C}$

Figura 6.33 Curvas de drift dos erros de posição $X$ e de retitude dos eixos $Y$ e $Z$ na direção $X$

Figura 6.34 Curvas de drift dos erros posição do eixo $Y$ e de retitude dos eixos $X$ e $Z$ na direção $Y$

Figura 6.35 Curvas de drift dos erros posição do eixo $Z$ e de retitude dos eixos $X$ e $Y$ na direção $Z$

Figura 6.36 Erro angular pitch do eixo $X$ para $20^{\circ} \mathrm{C}$

Figura 6.37 Erro angular pitch do eixo $Y$ para $20^{\circ} \mathrm{C}$

Figura 6.38 Erro angular pitch do eixo $Z$ para $20^{\circ} \mathrm{C}$

Figura 6.39 Erro angular yaw do eixo $X$ para $20^{\circ} \mathrm{C}$

Figura 6.40 Erro angular yaw do eixo $Y$ para $20^{\circ} \mathrm{C}$

Figura 6.41 Erro angular yaw do eixo $Z$ para $20^{\circ} \mathrm{C}$

Figura 6.42 Erro angular roll do eixo $X$ para $20^{\circ} \mathrm{C}$

Figura 6.43 Erro angular roll do eixo $Y$ para $20^{\circ} \mathrm{C}$

Figura 6.44 Curvas de drift dos erros yaw dos eixos $X$ e $Y$

Figura 6.45 Curvas de drift dos erros roll de $X$ e pitch de $Y$

Figura 6.46 Erros de medição e residuais para $20^{\circ} \mathrm{C}$

Figura 6.47 Posições de medição do anel padrão

Figura 6.48 Erros de medição e residuais para $26^{\circ} \mathrm{C}$

Figura B.1 Montagem do sistema interferométrico para medição do erro de posição dos eixos $X$ e $Y$

Figura B.2 Montagem do sistema interferométrico para medição do erro de posição do eixo $Z$ 
Figura B.3 Montagem do sistema interferométrico para medição do erro de posição do eixo $Y \quad 162$

$\begin{array}{lll}\text { Figura B.4 Interferômetro laser com o prisma de Wollaston } & 164\end{array}$

Figura B.5 Efeitos de desalinhamento na medição dos erros de retitude (VIEIRA SATO, 1998) 164

Figura B.6 Montagem experimental para a calibração do erro de retitude do eixo $Y$ na direção $X \quad 165$

Figura B.7 Interferômetro angular laser (BARREIRA, 1998) 166

$\begin{array}{lll}\text { Figura B.8 Sistema de medição do erro angular yaw do eixo } X \quad 167 & 168\end{array}$

Figura B.9 Medição com o nível eletrônico 168

Figura B.10 Esquema básico de medição do erro de perpendicularidade entre dos eixos $\quad 170$

Figura B.11 Montagem do sistema para medir o erro de perpendicularidade entre os eixos $X$ e $Z \quad 171$

Figura B.12 Montagem do sistema para medir o erro de perpendicularidade entre os eixos $Y$ e $Z$

Figura B.13 Arranjo experimental para levantamento do erro de perpendicularidade usando o esquadro óptico $\quad 172$

$\begin{array}{lll}\text { Figura F.1 Curvas de drift do erro de retitude } X z & 179\end{array}$

$\begin{array}{lll}\text { Figura F.2 Curvas de drift do erro de retitude } Y x & 179\end{array}$

Figura F.3 Curvas de drift do erro de retitude $Y z \quad 180$

Figura F.4 Curvas de drift do erro de retitude $Z x \quad 180$

Figura F.5 Curvas de drift do erro de retitude $Z y \quad 181$

Figura F.6 Curvas de drift do erro pitch do eixo $X \quad 181$

Figura F.7 Curvas de drift do erro pitch do eixo $Y \quad 182$

Figura F.8 Curvas de drift do erro angular pitch do eixo $Z \quad 182$

$\begin{array}{lll}\text { Figura F.9 Curvas de drift do erro angular yaw do eixo } X & 182\end{array}$

Figura F.10 Curvas de drift do erro angular yaw do eixo $Y \quad 183$

Figura F.11 Curvas de drift do erro yaw do eixo $Z \quad 183$

Figura F.12 Curvas de drift do erro roll do eixo $X$

Figura F.13 Curvas de drift do erro roll do eixo $Y \quad 184$

Figura G.1 Curvas do erro de posição do eixo $Y \quad 185$

Figura G.2 Curvas representando a distância entre interceptos 186

$\begin{array}{lll}\text { Figura G.3 Posição relativa entre componentes } & 187\end{array}$ 


\section{LISTA DE TABELAS}

Tabela 5.1 Movimentos e matrizes entre sistemas de coordenadas 70

Tabela 5.2 Procedimento experimental para coleta do drift 85

Tabela 5.3 Dados resultantes do levantamento do drift térmico

Tabela 5.4 Resultados da calibração do anel padrão

Tabela 5.5 Parâmetros para determinar a incerteza da medição dos erros de Perpendicularidade

Tabela 5.6 Parâmetros para determinar a incerteza da medição dos erros de Posição

Tabela 5.7 Parâmetros para determinar a incerteza da medição dos erros de Retitude e angulares pitch e yaw

Tabela 7.8 Parâmetros para determinar a incerteza da medição dos erros roll

Tabela 7.9 Parâmetros para determinar a incerteza da medição dos braços fixos

Tabela 6.1 Erros de perpendicularidade

Tabela 6.2 Erros de perpendicularidade $\mathrm{XZ}$ para diferentes estados térmicos

Tabela 6.3 Resultados da avaliação do modelo geométrico

Tabela 6.4 Resultados da avaliação do modelo geométricotérmico para $26^{\circ} \mathrm{C}$

Tabela 6.5 Erros termicamente induzidos

Tabela 6.6 Incerteza do erro de posição do eixo $\mathrm{X}_{275}$ para $20{ }^{\circ} \mathrm{C}$

Tabela 6.7 Incerteza associada às componentes do erro volumétrico

Tabela C.1 Características dos instrumentos utilizados para calibrar a MM3C (BARREIRA, 1998)

Tabela D.1 Temperatura durante a medição dos erros geométricos 


\section{NOTAÇÃo}

EED - Erro de Expansão Diferencial

IET - Índice de Erro Térmico

CNC - Controle Numérico Computadorizado

$\alpha$ - Coeficiente de Dilatação Volumétrico

$\mathrm{q}$ - ponto no espaço

$\mathbb{R}^{\mathrm{n}}-$ Espaço Euclidiano

$\overrightarrow{\mathrm{v}}-$ vetor

$\vec{i}, \vec{j}, \vec{k}$ - vetores unitários de direção nos eixos $X, Y, Z$, respectivamente

$\mathrm{w}$ - fator de escala

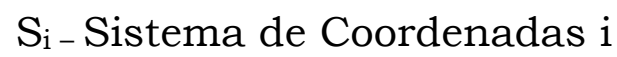

$P_{x}, P_{y}, P_{z}$ - Vetor coluna

$\left[{ }^{(i-1)} M_{i}\right]$ - Matriz de transformação homogênea. Matriz que indica a posição e orientação do $i$-ésimo sistema em relação ao (i-1)-ésimo sistema

$\alpha$ - ângulo de rotação em torno do eixo $X$

$\beta$ - ângulo de rotação em torno do eixo $Y$

$\gamma$ - ângulo de rotação em torno do eixo $Z$

$E v$ - Erro volumétrico da MM3C

$E x, E y, E z$ - Componentes do erro volumétrico da MM3C, na direção

dos eixos $X, Y$ e $Z$

$\sigma^{2}$ - variância do resíduo experimental

$\mathrm{t}$ - variável aleatória padronizada $t$ de Student

$\bar{x}$ - média de uma amostra

$\mathrm{s}$ - desvio padrão amostral

$\mu$ - média de uma população

$\sigma$ - desvio padrão de uma população

n - número de observações de uma amostra

$\mathrm{N}$ - número de observações de uma população 
$\mathrm{m}_{\mathrm{t}}$ - momento centrado de uma amostra, de ordem $\mathrm{t}$

$a_{3}$ - coeficiente de skewness

$\mathrm{a}_{4}$ - coeficiente de Kurtosis

$\varepsilon_{\mathrm{i}}$ - resíduos de regressão

$v$ - graus de liberdade

$v_{\text {ef-grau de liberdade efetivo }}$

$\beta_{\mathrm{i}}$ - coeficientes de regressão

$r^{2}$ - coeficiente de correlação amostral

$u_{c}$ - Incerteza padrão combinada

Up - termo incerteza expandida

$\mathrm{k}$ - fator de abrangência

$a_{i}$ - constante

$b_{j}$ - constante

Erro $_{i}$ - erro geométrico

$p$ - posição de medição

(M)Mov - Matriz de Movimento

(V)sonda - vetor que descreve o caminho da sonda

(V)peça -vetor que descreve o caminho da peça 


\section{GLOSSÁRIO}

Erro -

Erro volumétrico -

Exatidão -

Repetibilidade -

Calibração -

Compensação -

Estado de temperatura

Estado de equilíbrio térmico

Teste de drift -

Tempo de Equilíbrio

Zerodur

Aerodur

Invar
Diferença entre o valor medido de uma grandeza e o valor verdadeiro da mesma.

Erro total de uma máquina que possui movimentação nos três eixos coordenados.

Grau de concordância entre o valor medido e o valor verdadeiro do mensurado. Exatidão (INMETRO, 1995).

Grau de concordância entre os resultados de medições sucessivas de um mesmo mensurando efetuadas sob as mesmas condições de medição. Repetitividade (INMETRO, 1995).

Determinação do grau de concordância da grandeza que está sendo avaliada, entre os valores indicados por um instrumento de medição e o valor verdadeiro dado por um padrão, reconhecido internacionalmente.

Procedimento de correção de erros

Conjunto de leituras das temperaturas dos vários termopares acoplados à máquina num dado instante de tempo $\mathrm{t}_{\mathrm{i}}$.

Estado em que a temperatura dos componentes da máquina esta em equilíbrio térmico, porém não necessariamente homogênea.

Observação da variação do erro, em uma dada posição dos carros de movimentação até a estabilização.

Intervalo de tempo necessário para que a peça entre em equilíbrio térmico com o ambiente.

Vidro cerâmico aplicado em ótica, opto-eletrônica e na engenharia de precisão. Material com expansão térmica extremamente baixa, em determinadas escalas de temperatura pode mesmo ser zero ou ligeiramente negativa (vidro e quartzo).

Aço revestido com ouro

Liga de Ferro e Níquel (Ni-Ni-Fe) com a expansão térmica mais baixa entre todos os metais e ligas na escala da temperatura de quartzo até aproximadamente $230{ }^{\circ} \mathrm{C}$. O coeficiente médio da expansão térmica (CTE) do invar de 20$100{ }^{\circ} \mathrm{C}$ é menor que $1,3 \times 10-6{ }^{\circ} \mathrm{C}^{-1}$. 


\section{RESUMO}

VALDÉS, A.R. (2003). Sintetização de erros termicamente induzidos em Máquinas de Medir a Três Coordenadas. Tese (Doutorado) - Escola de Engenharia de São Carlos, Universidade de São Paulo, São Carlos, 2003. 209p.

O desempenho das Máquinas de Medir a Três Coordenadas (MM3Cs) fica limitado por diversos fatores, que atuam de maneira conjunta gerando os denominados erros volumétricos. Para a temperatura de $20^{\circ} \mathrm{C}$ os erros geométricos podem ser considerados constantes, uma vez que variam muito lentamente com o tempo. Porém, se a temperatura é alterada estes erros mudam em grandeza e comportamento, gerando os denominados erros térmicos. Alguns trabalhos têm sido desenvolvidos com o objetivo de estudar e modelar os erros térmicos, porém os resultados alcançados são, ainda, incipientes. Este trabalho apresenta o equacionamento das componentes do erro volumétrico das MM3Cs considerando as influências térmicas. A medelagem foi aplicada a uma MM3C do tipo "Ponte Móvel" e combina transformações homogêneas, técnicas de regressão e mínimos quadrados. As grandezas dos erros geométricos e das variações termicamente induzidas destes erros foram coletadas utilizando-se do interferômetro laser, do esquadro mecânico, do nivel eletrônico, etc. Os valores das temperaturas foram monitorados através de termopares do tipo $\mathrm{T}$ (Cobre-Constantan). Verificou-se que a Máquina não experimenta deformações, além, das provocadas pela livre dilatação dos seus componentes. A partir do modelo proposto foram sintetizadas as componentes do erro volumétrico, os resultados foram discutidos e comparados com aqueles obtidos através da medição de um anel padrão, constatando-se a excelente capacidade do modelo na previsão do erro volumétrico da máquina. No caso, erros da ordem de grandeza de $10 \mu \mathrm{m}$ foram reduzidos em pelo menos $75 \%$, enquanto que para erros maiores que $10 \mu \mathrm{m}$ a eficiência do modelo foi de $90 \%$.

Palavras-chaves: drift térmico, erros termicamente induzidos, estados térmicos, gradientes térmicos espaciais. 


\section{AbSTRACT}

VALDÉS, A.R. (2003). Synthesization of thermally induced errors in coordinate measuring machines. Tese (Doutorado) - Escola de Engenharia de São Carlos, Universidade de São Paulo, São Carlos, 2003. 209p.

Performance of coordinate measuring machines (CMMs) is limited by numerous factors that operate simultaneously and generate volumetric errors. The most significant portion of the volumetric error is produced by geometric errors. At the temperature of $20{ }^{\circ} \mathrm{C}$, geometric errors can be considered at steady states, once their variation in time is considerably slow. However, if temperature is modified, these errors change in magnitude and behaviour, generating the thermal induced errors. Some work has been developed aiming to study and model the thermal errors, but the achieved results are still incipient. This work presents the derivation of the components of the volumetric error considering its thermal influences. The method was employed and applied to moving bridge CMM and combines homogeneous transformation, regression techniques and least squares methods. The magnitudes of the geometric errors and its thermally induced variations were collected by means of a laser interferometer system, mechanical square, electronic level, etc. Temperature data were monitored by means of T-type thermocouples (copper-constantan). It was verified that the CMM was not susceptible to deformations other than the ones due to the dilatation of its components. From the proposed model, the components of volumetric error were synthesized; the results were discussed and compared to the ones obtained from the measurement of a ring plug, observing the outstanding ability of the model to predict the volumetric error of the machine. Errors of $10 \mu \mathrm{m}$ in magnitude were reduced in at least $75 \%$, whilst errors greater than $10 \mu \mathrm{m}$, presented a reduction efficiency of $90 \%$. It was verified that the CMM was not susceptible to deformations other than the ones due to the dilatation of its components.

Keywords: Thermal drift, thermally induced errors, thermal states, spatial thermal gradients. 


\section{Capítulo 1}

\section{INTRODUÇÃO}

A nova era da manufatura está caracterizada pela combinação de um número cada vez maior de operações tornando as Máquinas Ferramentas multifuncionais e capazes de executar a usinagem completa de uma peça em apenas uma fixação. Isto unido à utilização de motores mais potentes, deslocamentos mais rápidos, menores cursos de deslocamento para carga e descarga de peças e para a troca de ferramentas, permite que as peças sejam usinadas em tempo recorde, além, reduzidos os tempos mortos.

Assim sendo, a produção de peças vem-se tornando mais rápida, precisa e barata, exigindo um controle de qualidade eficiente. Na área de inspeção, as Máquinas de Medir a Três Coordenadas (MM3Cs) aparecem como candidatas em potencial para as operações integradas com os sistemas modernos de manufatura, pois elas podem medir os mais variados tipos de peças com rapidez e precisão. Com as MM3Cs junto às linhas de produção os erros podem ser identificados com rapidez o que pode reduzir o índice de peças refugadas. Além disso, se reduz o tempo de máquina parada à espera da inspeção da peça. 
Porém, diversas características das MM3Cs atuais fazem com que elas sejam muito susceptiveis ao calor, a umidade e contaminantes, tornando-as impróprias para serem instaladas no chão de fábrica. Dentre estas características tem-se: a utilização de materiais diferentes na fabricação dos componentes mecânicos; a utilização de motores e sistemas eletrônicos, a presença de um operador para máquinas manuais e a necessidade de um sistema de iluminação para o operador trabalhar, etc.

Somam-se a estas características a interação entre componentes geometricamente imperfeitos; a dificuldade de montagem de eixos perfeitamente ortogonais e a presença inevitável dos braços de Abbé. Assim sendo, devido ao fenômeno de dilatação e ao efeito do gradiente térmico, quando a temperatura é alterada, acontecem variações nos comprimentos das escalas de medição, na peça a ser medida e na estrutura da Máquina de Medir em sentido geral. Como conseqüência, os valores dos erros geométricos não permanecem fixos. A variação experimentada pelos erros geométricos devido às variações de temperatura convencionou-se chamar de erros térmicos ou erros termicamente induzidos.

Os erros térmicos são, atualmente, os que mais influenciam a exatidão das Máquinas de Medir. Isto ocorre porque a influência dos demais erros tem sido largamente estudada e, portanto, gradativamente minimizados. Assim sendo, o significado dos erros térmicos torna-se cada vez mais evidente.

A diminuição dos erros termicamente induzidos a um nivel considerado pequeno, na fase de projeto, envolve custos impraticáveis. A concepção e construção de Máquinas de Medir com uma distribuição de massa mais conveniente, com elementos de alta precisão, construídos com materiais especiais com coeficiente de dilatação térmica próximos de zero demandam, além de pessoal qualificado, tempo e equipamentos sofisticados. Mesmo que a prática fosse viável, o envelhecimento dos componentes da máquina geraria, ainda, erros ao longo do tempo. Diante do exposto a compensação de erros através de métodos computacionais 
tem-se tornado a via mais utilizada para corrigir os efeitos das variações de temperatura. Assim sendo, torna-se fundamental para fins de compensação conhecer, previamente, a grandeza e o comportamento dos erros induzidos termicamente.

Muitos estudos têm sido desenvolvidos neste sentido, revelando a complexidade do fenômeno térmico e os custos elevados que envolve o estudo do mesmo. Por este motivo estes erros ficaram durante muito tempo no esquecimento. Portanto, este assunto embora não seja recente apresenta grande atualidade e cientistas do mundo todo trabalham procurando minimizar os efeitos das variações de temperatura nas Máquinas de Medir.

O maior desafio encontrado no estudo e modelagem do comportamento térmico das MM3Cs é a previsão dos erros durante os transientes de temperatura, uma vez que pode ser atribuído um caráter dinâmico às deformações termicamente induzidas. Enquanto a temperatura ambiente varia a estrutura da máquina tenta acompanhar essa variação até alcançar o equilíbrio térmico. Durante esta fase a geometria dos componentes da máquina muda continuamente, assim como, as coordenadas dos pontos no volume de trabalho, aumentando a complexidade do fenômeno térmico.

Desta forma, o presente trabalho tem como objetivo estudar e modelar o comportamento de uma MM3C, do tipo Ponte Móvel, quando submetida a variações de temperatura ambiente.

Inicialmente, foi efetuado um amplo estudo sobre os principais aspectos relacionados ao funcionamento térmico destas máquinas, isto é: materiais, fontes de calor, distribuição das temperaturas e gradientes térmicos espaciais. Em seguida foi desenvolvido um modelo de sintetização para previsão das grandezas e comportamento das componentes do erro volumétrico para qualquer posição e qualquer temperatura. O modelo foi obtido utilizando-se as transformações homogêneas, garantindo facilidade de adaptação e elevado poder de diagnóstico. Durante a modelagem foi efetuada a superposição dos efeitos dos erros geométricos e de suas variações termicamente induzidas, 
partindo da hipótese de que ambos os efeitos podem ser considerados como variáveis independentes.

O estudo e a modelagem matemática foram aplicados a uma Máquina de Medir a Três Coordenadas, tipo Ponte Móvel, instalada no Laboratório de Metrologia, da Escola de Engenharia de São Carlos Universidade de São Paulo.

Assim o presente trabalho está estruturado conforme descrito a seguir:

No capítulo dois apresenta-se uma ampla revisão bibliográfica sobre erros térmicos, suas causas e efeitos. Assim como, o estado da arte, os métodos para medição e as técnicas de modelagem dos erros termicamente induzidos, são apresentadas.

O terceiro capítulo oferece as considerações gerais sobre transformações homogêneas e técnicas de regressão. Também, são apresentados alguns conceitos básicos sobre incerteza de medição e diferentes critérios para determinação da mesma, de acordo com os requisitos propostos pelo Guia para Expressão das Incertezas de Medição (GUM).

O quarto capítulo apresenta a proposta do trabalho, isto é, o desenvolvimento e a aplicação da metodologia para modelar o comportamento térmico das componentes do erro volumétrico da Máquina de Medir. Em seguida, no capítulo cinco, estão descritas de forma detalhada cada uma das etapas de obtenção do modelo matemático, os experimentos realizados para levantamento dos dados e o procedimento de cálculo da incerteza de medição.

No capítulo seis são apresentados e discutidos os resultados experimentais. O método proposto é avaliado através da comparação dos valores sintetizados e aqueles resultados da medição de um artefato padrão em diferentes posições do volume de trabalho da máquina e para diferentes temperaturas. Como encerramento do trabalho, no sétimo capítulo, são apresentadas as conclusões relativas ao trabalho desenvolvido, além de algumas sugestões para trabalhos futuros. 


\section{Capítulo 2}

\section{EFEITOS TÉRMICOS EM \\ MÁQUINAS DE MEDIR A TRÊS COORDENADAS}

A fabricação de produtos com tolerâncias cada vez mais estreitas e em maiores quantidades levou à necessidade de desenvolver meios de controle de qualidade mais rápidos, precisos, flexíveis e confiáveis. Neste contexto surgem as Máquinas de Medir a Três Coordenadas.

Apesar de suas conhecidas vantagens, o desempenho destas máquinas fica limitado por vários fatores, que atuam de maneira conjunta, combinando-se de forma complexa por todo o volume de trabalho da máquina, gerando o denominado erro volumétrico, Figura 2.1.

A parcela mais significativa do erro volumétrico é constituída pelos erros geométricos (BOSCH, 1995). Estes erros têm origem nos desvios geométricos dos diferentes componentes da Máquina de Medir e se materializam durante a movimentação dos eixos coordenados, devido à interação entre os componentes. 
Os erros geométricos interferem no posicionamento relativo entre sonda e peça, comprometendo o resultado das medições.

Para o estudo dos erros geométricos, os elementos móveis da MM3C são considerados corpos rígidos. A posição de um corpo rígido no espaço pode ser definida através de seis graus de liberdade. Como a cada grau de liberdade pode ser associado um erro, associam-se seis erros geométricos para cada eixo preferencial da máquina. Isto é; um erro de posição, dois erros de retitude e três erros de rotação (pitch, yaw e roll) somando um total de 18 erros geométricos.

$\mathrm{Na}$ maioria das vezes estes erros são apresentados na forma paramétrica, isto é, parametrizados na posição, e por isso, eles são freqüentemente chamados de erros paramétricos.

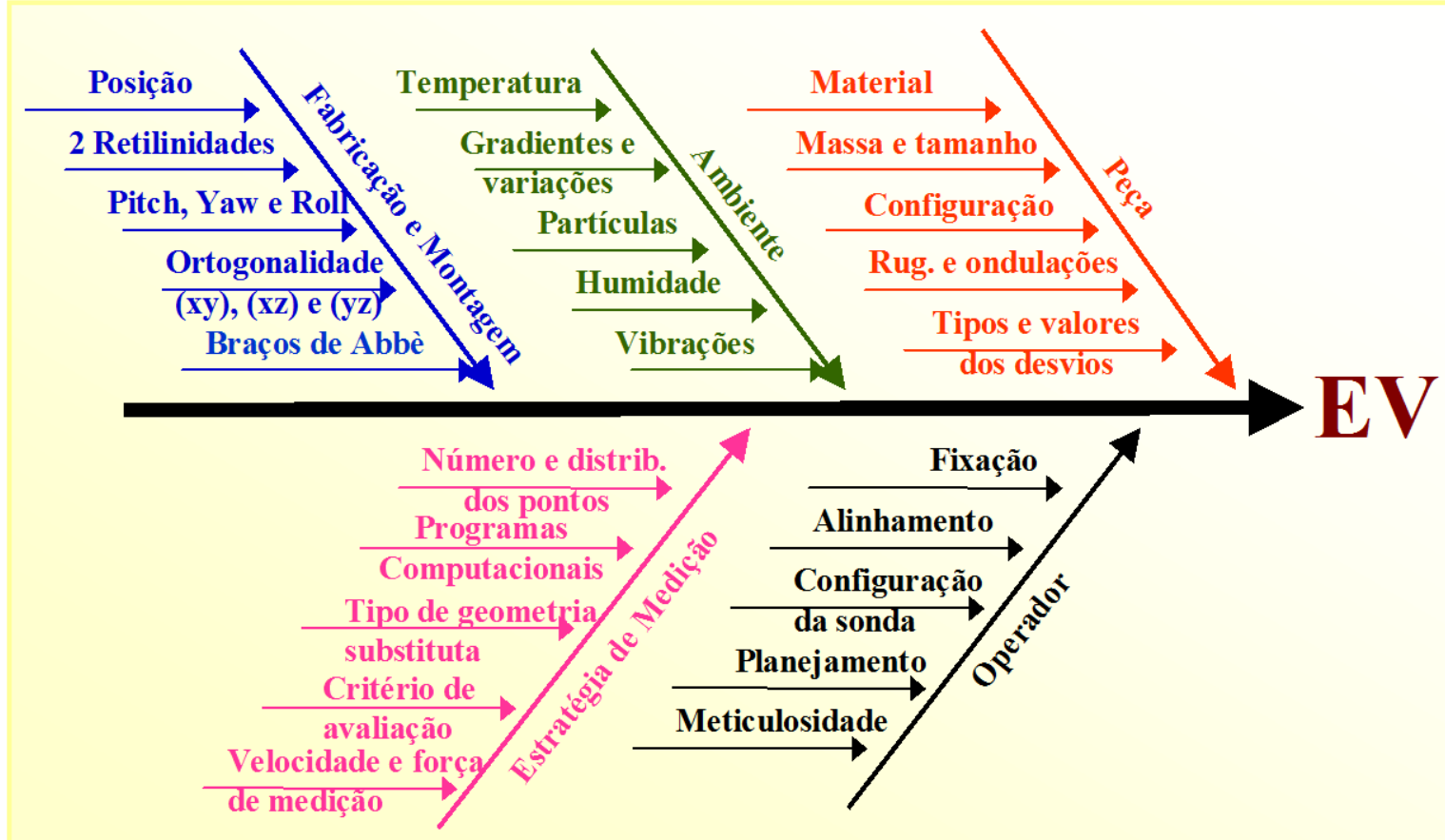

Figura 2.1 - Fontes de erros em MM3Cs (WECKENMANN; KNAUER; KILLMAIER, 2001).

Somam-se a estes erros outros três gerados pela impossibilidade da montagem de três eixos perfeitamente ortogonais, que são denominados erros de perpendicularidade ou erros não paramétricos, dependentes da relação entre componentes. Dessa maneira totalizam-se 21 erros geométricos em MM3Cs. 
Para a temperatura de $20{ }^{\circ} \mathrm{C}$ os erros geométricos podem ser considerados constantes, uma vez que variam muito lentamente com o tempo. Porém, se a temperatura for diferente de $20^{\circ} \mathrm{C}$ estes erros mudam em grandeza e comportamento devido às deformações experimentadas pela estrutura da máquina em sentido geral. São induzidos, assim, os denominados erros térmicos, que comprometem a precisão e a repetibilidade das Máquinas de Medir (BRYAN, 1995; KUNZMANN et al., 1995).

\subsection{ERros TÉrmicos. Considerações Gerais}

Muitos estudos têm sido desenvolvidos com o objetivo de conhecer as características, grandezas e fontes dos erros termicamente induzidos, para assim poder minimizar seus efeitos. Se analisados cronologicamente os trabalhos publicados sobre erros térmicos nota-se que estes têm sido estudados por mais de 40 anos. Apesar dos esforços dedicados, pouco progresso foi observado até a metade da década de 80 , onde houve um incremento substancial do número de trabalhos publicados, especificamente, sobre compensação de erros. Porém, os avanços alcançados nesta área permanecem muito distantes dos desejados.

Os erros térmicos, seus custos e fontes ficaram e continuam praticamente esquecidos. Por tal motivo, ainda hoje, presta-se a eles uma atenção especial por serem considerados uma das fontes de erros mais importantes em máquinas ferramenta e de Medir (BRYAN, 1995).

$\mathrm{Na}$ literatura estudada sobre o assunto destacam-se dois artigos publicados por Bryan em 1967 e 1990, respectivamente. Estes artigos marcaram pautas importantes na evolução do entendimento dos erros termicamente induzidos. Bryan teve o mérito de reunir, em poucas páginas, a experiência e os resultados alcançados por muitos pesquisadores, durante longos anos de trabalho.

O primeiro trabalho, publicado em 1967, aborda o estado da arte e a importância dos erros termicamente induzidos. Segundo Bryan na maioria dos casos os erros causados pelas variações de temperatura têm a 
mesma grandeza ou são maiores que os erros cinemáticos, estáticos e dinâmicos. Os erros térmicos são responsáveis por uma porcentagem significativa do erro total em Máquinas Ferramentas (40 a 70\%). Assim sendo, o significado econômico dos erros térmicos é elevado (BRYAN, 1967).

BRYAN (1990) apresentou uma avaliação dos avanços alcançados no período 1967-1990. Na ocasião o autor escreveu que o problema relacionado aos erros térmicos é um dos mais importantes na metrologia dimensional e na engenharia de precisão. É preciso trabalhar para reduzir a sensibilidade térmica das Máquinas Ferramentas. As deformações geométricas que a Máquina Ferramenta experimenta devido ao efeito estático e dinâmico das temperaturas é um dos fatores que mais afeta a exatidão. Geralmente, as deformações térmicas influenciam mais na precisão das peças usinadas que a rigidez mecânica da máquina.

No período analisado (1967-1990) foram introduzidos os computadores, o interferômetro laser, o torneamento com diamante, a usinagem a altas velocidades. As tolerâncias de fabricação foram diminuídas, os erros geométricos foram estudados e seus efeitos minimizados. Diante do desenvolvimento da indústria nestes anos, a pouca atenção dada aos erros térmicos não tem explicação clara. Aparentemente este fato é justificado pela complexidade do fenômeno térmico e pelos custos que envolve seu estudo.

Dando continuidade à obra de Bryan, RAMESH et al. (2000) publicaram um artigo sobre erros térmicos em Máquinas Ferramentas. Este artigo discute, basicamente, os trabalhos publicados na década dos anos 90 sobre estudo, medição, modelagem e compensação dos erros termicamente induzidos. Os autores destacam que apesar dos avanços alcançados o problema das influências térmicas em Máquinas Ferramentas continua sem solução, constituindo um desafio para a comunidade científica internacional.

Outros autores têm-se manifestado com relação à importância dos erros térmicos. MURTHY (1980) escreveu: "As crescentes velocidades de corte, que aumentam a geração de calor, somadas à diminuição do 
tamanho das máquinas, ou seja, há uma menor quantidade de massa para distribuir e dissipar mais calor, o que em geral, contribui para que as influências térmicas sejam cada vez mais evidentes".

GROBMANN e JUNGNICKEL (2002) escreveram: "O comportamento térmico das máquinas-ferramenta ganhou duplo significado no domínio e aprimoramento da precisão oferecida na manufatura. A fração relativa de erros provocados por efeitos térmicos está crescendo em função da redução da fração de erros geométricocinemáticos e estáticos no resultado global, enquanto, a fração absoluta dos aspectos térmicos aumenta em função do aumento de potência e elevação dos requisitos de precisão obtidos ao longo do desenvolvimento de técnicas de manufatura" Figura 2.2.

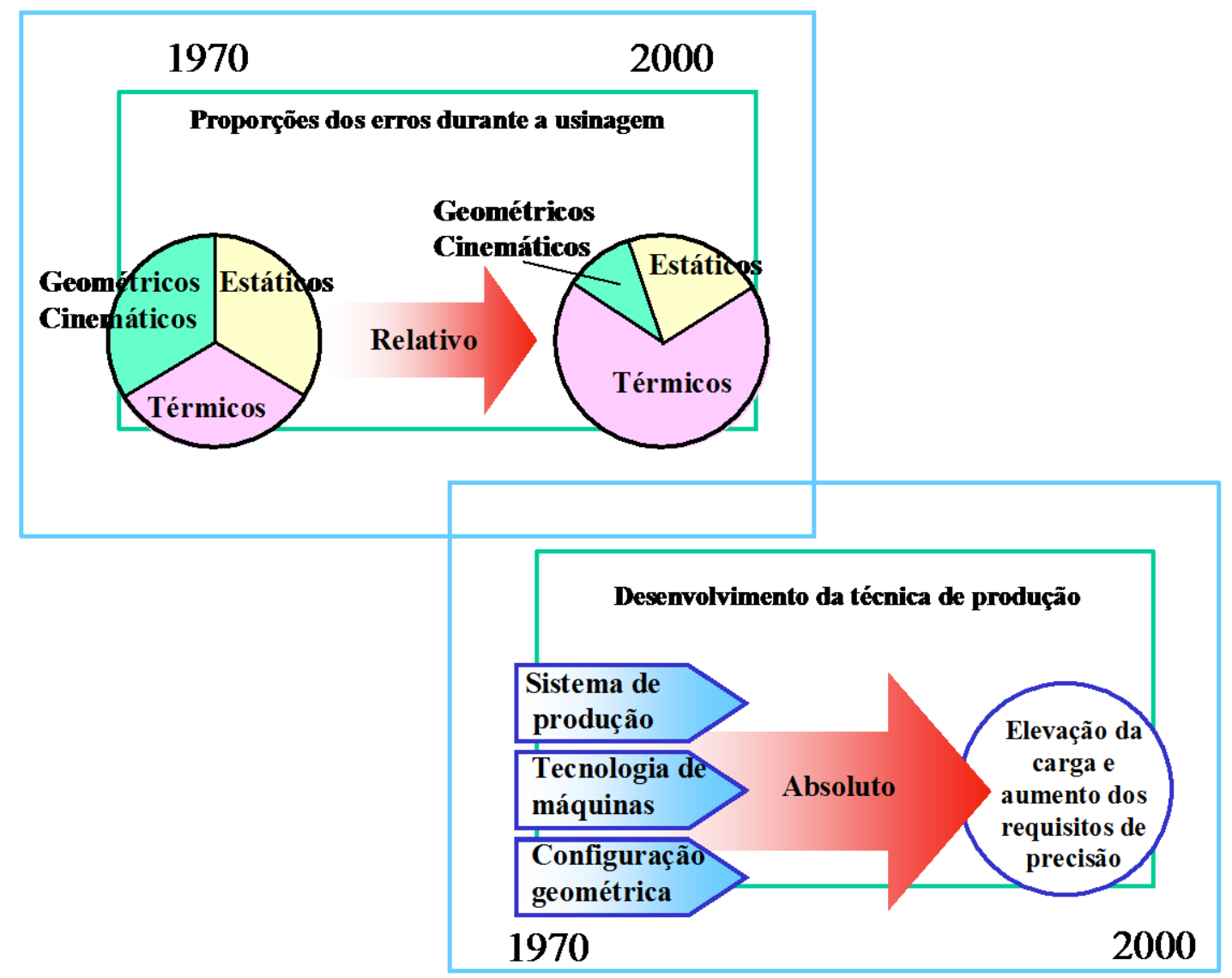

Figura 2.2 - Aumento do significado dos aspectos térmicos (GROBMANN e JUNGNICKEL, 2002).

Para Máquinas de Medir a Três Coordenadas o problema das influências térmicas é, ainda mais crítico, devido a pouca disponibilidade 
de trabalhos e a insipiência dos resultados já publicados. Assim sendo, este assunto, embora não seja recente representa grande atualidade.

\subsection{EFeITOS TÉRMICOS EM MM3Cs}

BRYAN (1990) apresentou um diagrama com os efeitos térmicos em Máquinas Ferramentas, Figura 2.3. Este diagrama agrupa de forma resumida e simples as fontes de erros térmicos, as possiveis causas e os efeitos das variações de temperatura.

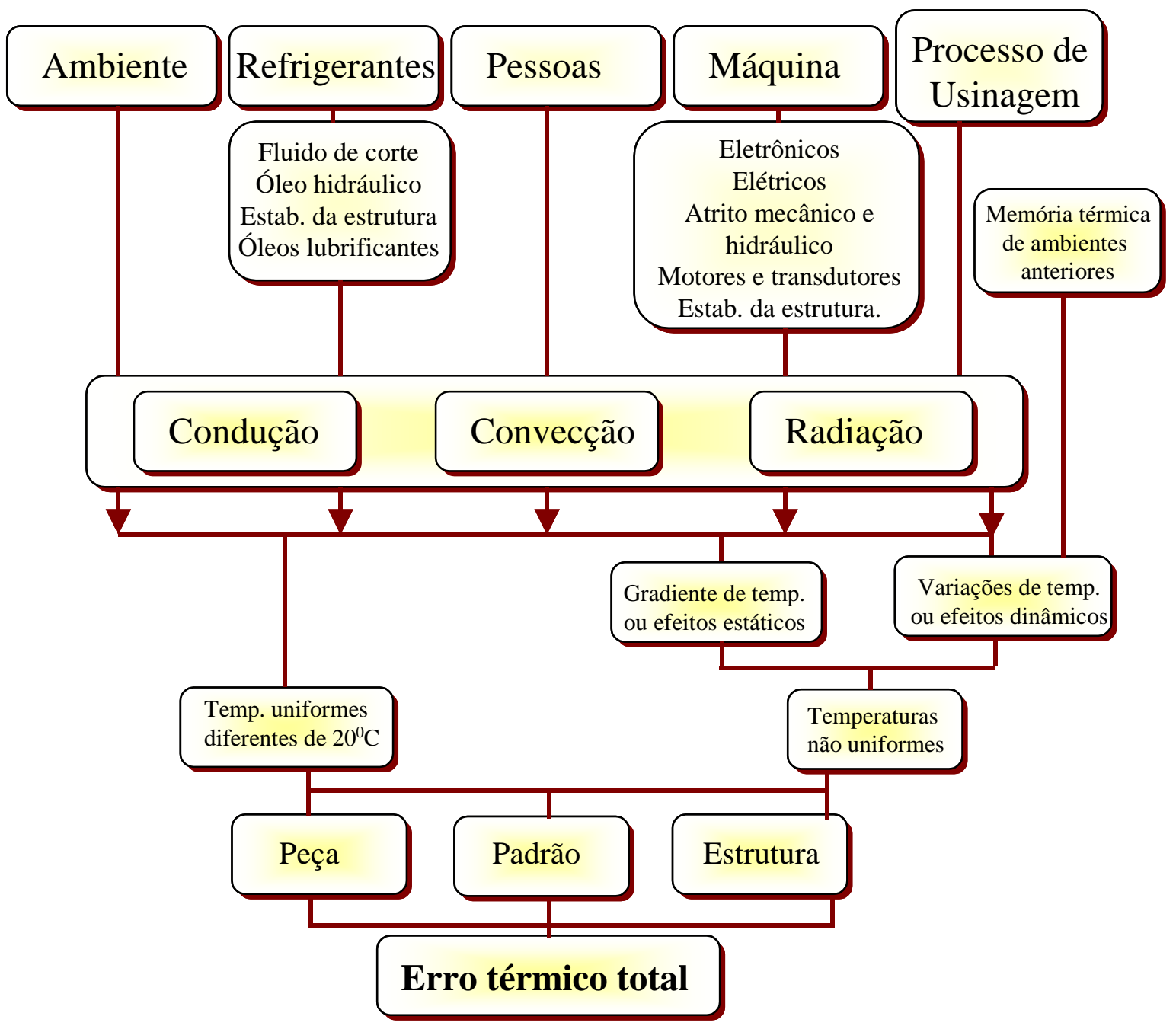

Figura 2.3 - Diagrama de influências térmicas (BRYAN, 1990).

Aplicando as considerações apresentadas por Bryan, no diagrama de influências térmicas, às MM3Cs pode-se dizer que nestas máquinas estão presentes diferentes fontes de calor, descritas a seguir. 
a- Ambiente: depende da climatização ou não do ambiente e da temperatura externa. Para ambientes com temperatura controlada de $20 \pm 1{ }^{\circ} \mathrm{C}$ os efeitos térmicos presentes nas medições são mínimos. Quando a temperatura ambiente não for controlada as variações térmicas constituem uma grande preocupação.

b- Pessoas: A presença de pessoas próximas à máquina contribui para a alteração da temperatura ambiente. A temperatura do corpo humano é de, aproximadamente, $36,8^{\circ} \mathrm{C}$ e transmite calor através dos três mecanismos sendo que a radiação é o mais significativo. O operador da máquina deve manipular de forma adequada tanto a máquina quanto a peça a ser medida. Além disso, sempre que possivel, as medições devem ser efetuadas sem a presença do operador ou este deve usar roupas que impeçam a radiação.

c- Atrito nas Guias e Mancais: Para Máquinas de Medir com mancais de contato e movimentos dos carros rápidos, com velocidade de movimentação grande, o calor associado às guias de deslizamento é considerável. Já para velocidades de movimentação menores e movimentos mais lentos ou quando utilizados mancais aerostáticos o atrito e o calor gerado são despreziveis.

d- Motores e Sistemas Eletrônicos: Os motores e sistemas eletrônicos encarregados de produzir os movimentos dos carros, nas máquinas automáticas, constituem fontes geradoras de calor (BREYER e PRESSEL, 1991).

e- Outras Máquinas: As máquinas existentes nas proximidades, além de outros equipamentos, contribuem na geração de calor e modificam o comportamento térmico dos componentes da MM3C durante o seu funcionamento. Dentre estas máquinas e equipamentos têm-se: computadores, monitores, processadores de sinais, lâmpadas, etc.

f- Memória térmica: As Máquinas de Medir são fabricadas de diferentes materiais, os quais respondem de forma diferenciada às variações de temperatura e necessitam de intervalos de tempo diferentes para entrar em equilíbrio térmico com o ambiente. Durante este período, o 
elemento pode ter sua geometria modificada e sofrer temporariamente distorções.

A quantidade de fontes de calor presentes em uma determinada Máquina de Medir e seus efeitos dependem do projeto e do local de instalação.

\subsubsection{Formas de Transferência de Calor em Máquinas de Medir}

O calor gerado pelas fontes descritas afeta o sistema por meio das três formas possiveis de transferência de calor: condução, convecção e radiação. NI (1995) apresenta algumas práticas comuns para reduzir a influência das fontes localizadas de calor. Estas deveriam ser adotadas como procedimentos rotineiros, unidos às recomendações para melhoramento do projeto.

A radiação pode ser evitada protegendo-se as paredes e o chão, provendo filtros para luminárias e colocando-se capas protetoras nas janelas.

Durante as medições de precisão é aconselhável evitar a presença de pessoas no local da máquina ou os operadores de MM3Cs devem usar roupas que evitem a radiação.

As MM3Cs devem ser colocadas a uma distância de 1,5 m pelo menos das paredes exteriores.

No caso da condução deve-se isolar termicamente a estrutura da máquina das fundações. O contato manual direto do operador com a peça e a máquina deve ser evitado, quando necessário, luvas térmicas devem ser usadas.

A convecção, por sua vez, exige o uso de um sistema de ventilação capaz de dissipar o calor gerado pelos computadores, unidades de controle e outras fontes. O sistema de condicionamento de ar deve ser projetado de forma a produzir uma distribuição uniforme da temperatura para eliminar a influência das fontes localizadas de calor.

A peça a ser medida deve estar em equilíbrio térmico com a MM3C e com o meio ambiente. 
O operador deve obedecer às especificações acima e, muito mais importante do que isso deve efetuar as medições a uma temperatura de 20 ${ }^{\circ} \mathrm{C}$, conhecida como a temperatura de referência ou padrão.

A temperatura de referência ou padrão $\left(20^{\circ} \mathrm{C}\right)$ foi adotada pelo Comitê Internacional de Pesos e Medidas no dia 15 de Abril de 1931 depois de longos anos de estudos e negociações (ISO R-1, 1975). A razão desta escolha justifica-se pelo amplo uso dos blocos padrões, na indústria. Na última década do século XIX, Carl Edvard Johansson concebeu e implementou a idéia de fabricar Blocos Padrões para garantir a intercambiabilidade de peças. No desenvolvimento de seus blocos, Johansson fixou a temperatura de $20{ }^{\circ} \mathrm{C}$ como sendo a temperatura básica para calibração dos mesmos, pois esta era a temperatura média registrada nas suas oficinas, na Suécia, sendo também um valor que resulta em um número inteiro na conversão para a escala Farenheit $\left(68^{\circ} \mathrm{F}\right)$. Assim sendo, Johansson foi o primeiro a adotar esta temperatura de referência, a qual, posteriormente, viria a se tornar um padrão mundial em metrologia dimensional.

A maior preocupação com relação à temperatura de $20{ }^{\circ} \mathrm{C}$ é o desconforto que gera para os operadores de máquinas. Por esta razão, em Janeiro de 1994, os integrantes do comitê ISO pensaram na possibilidade de mudar a temperatura de referência. No entanto, eles desistiram da idéia pelos custos que acarretaria tal mudança. Assim sendo, as medições são corretas somente se o sistema de medição estiver, aproximadamente, a $20^{\circ} \mathrm{C}$.

Vale destacar que a influência de temperaturas diferentes de $20{ }^{\circ} \mathrm{C}$ é muito significativa no resultado das medições. Pois com algumas exceções, os volumes de todos os corpos aumentam quando a temperatura cresce, se a pressão externa permanece constante. Esta variação é caracterizada pelo Coeficiente de Dilatação Volumétrico.

Em qualquer estrutura sujeita a mudanças de temperatura deve-se levar em conta a dilatação. É preciso deixar uma margem que permita aos elementos mecânicos dilatarem-se ou contraírem-se sob a influência das variações de temperatura. Se isto não for possivel, tensões de tração ou 
compressão, chamadas de tensões térmicas, serão induzidas nos elementos da máquina.

As tensões térmicas geradas devido às variações de temperatura podem ser tão grandes a ponto de tencionar os elementos mecânicos além de seus limites elásticos chegando às vezes a ruptura.

$\mathrm{Na}$ construção das Máquinas de Medir são utilizados materiais com coeficientes de expansão térmica distintos, tais como aço, alumínio e granito, além disso, são medidas peças fabricadas dos mais diversos materiais. Desta forma, quando o sistema de medição é submetido a variações de temperatura seus componentes dilatam-se ou contraem-se diferentemente, gerando um erro denominado Erro de Expansão Diferencial (EED).

Segundo BRYAN (1995), é possivel corrigir os efeitos da expansão diferencial, no entanto, ela é geralmente ignorada no mundo todo.

O coeficiente de expansão nominal é uma estimativa do coeficiente de dilatação de um corpo. Como toda estimativa ele tem associada uma incerteza, denominada de Incerteza de Expansão Nominal (IEN) (BRYAN, 1967).

Segundo a Norma ANSI B 89.6 .2 (1973), a Incerteza de Expansão Nominal é igual a zero para a temperatura de $20^{\circ} \mathrm{C}$ e aumenta na medida em que a temperatura se afasta deste valor. Esta incerteza no coeficiente varia para diferentes materiais.

BREYER e PRESSEL (1991) verificaram a IEN de dois jogos de blocos padrões de aço. Os resultados obtidos mostraram que o coeficiente de expansão térmica pode variar em até 20\%, dentro de um determinado jogo de blocos padrões. Esta diferença se deve a erros experimentais, anisotropia, variação na composição química e tratamento térmico do material.

\subsubsection{Distribuições uniformes e não uniformes das temperaturas}

Fazendo referência ao diagrama de influências térmicas apresentado por Bryan (Figura 2.3) pode-se dizer que nas MM3Cs a única 
fonte de calor que pode criar temperaturas uniformes diferentes de $20{ }^{\circ} \mathrm{C}$ é o ambiente. Fontes de calor tais como pessoas, máquinas e sistemas eletrônicos criam temperaturas não uniformes.

Segundo BÁLSAMO et al. (1990), diferentes técnicas têm sido aplicadas para minimizar os efeitos da distribuição não uniforme de temperaturas. Dentre elas: o melhoramento do projeto da estrutura e da localização das fontes de calor; controle térmico do meio ambiente em volta da máquina (fontes externas) e correção das deformações em tempo real através da utilização de programas computacionais.

As temperaturas não uniformes englobam gradientes e variações de temperatura (BRYAN, 1995). A influência dos gradientes térmicos está estreitamente relacionada aos materiais utilizados para fabricação das MM3Cs e ao projeto (BREYER e PRESSEL, 1991).

TRAPET e WÄLDELE (1989) muito contribuíram para o entendimento dos gradientes térmicos. Eles induziram gradientes, arbitrários, em uma Máquina de Medir com carenagem e observaram a correlação entre os cálculos analíticos e o erro levantado, através da medição de uma placa de esferas, de zerodur.

O problema relacionado à variação da temperatura é muito mais complexo que o problema relacionado aos gradientes térmicos (BRYAN, 1995). Quando o sistema atinge o equilíbrio térmico para uma dada temperatura, diferente da temperatura de referência, apresenta um estado deformado, porque os diferentes materiais dilataram-se quantidades diferentes. Ainda pode acontecer que dentro de um mesmo estado estacionário a temperatura dos diferentes pontos não seja homogênea devido à influência de fontes localizadas de calor.

Para estados de temperatura transientes a complexidade dos efeitos térmicos cresce, ainda mais, pois para cada instante de tempo origina-se um novo estado de deformação.

Uma das ferramentas mais simples e poderosa para avaliar a influência da variação da temperatura em máquinas de qualquer dimensão ou complexidade é o drift. Os testes de drift permitem 
determinar a variação do erro, em uma dada posição para diferentes estados de temperatura, até a estabilização (VIEIRA SATO, 1998).

KRUTH et al. (2001) coletaram os valores de drift a partir da medição sucessiva de esferas padrões. As esferas são idealmente apropriadas para este tipo de medição, pois permitem monitorar um único ponto de modo seguro (centro da esfera). Durante um mesmo teste podem ser medidas múltiplas referências e estas podem ser montadas em apoios ficando a alturas diferentes com relação ao desempeno da máquina.

Se utilizadas várias esferas as medições serão efetuadas em um período de tempo menor, evitando assim, o efeito das variações de temperatura dentro de um mesmo ciclo de medição (KRUTH et al., 2001). Segundo os autores este procedimento de medição apresenta algumas vantagens, dentre elas:

$>$ Assemelha-se ao funcionamento da máquina durante as medições;

> Movimenta os três eixos coordenados, simultaneamente;

$>$ As coordenadas dos centros das esferas são determinadas a partir da medição de cinco pontos alcançando-se elevada repetibilidade;

> Não é necessário usar equipamentos adicionais, a própria máquina faz as medições;

Apresenta baixo custo.

Mas, a utilização de esferas padrões para coletar os valores de drift térmico apresenta limitações quanto ao poder de diagnóstico.

\subsubsection{Influências térmicas na Estrutura, na Escala e na Peça}

Um aspecto muito importante, quando estudadas as influências térmicas, é a memória térmica. A peça transportada de um lugar para outro precisa de um intervalo de tempo até alcançar o equilíbrio térmico 
com o novo ambiente. Durante este período a peça muda de tamanho e pode sofrer distorções geométricas temporárias. O intervalo de tempo necessário para que a peça entre em equilíbrio térmico com o novo ambiente é chamado de tempo de equilíbrio. Somente depois de "esquecido" o ambiente anterior é que pode ser dito que a peça está em equilíbrio com o novo ambiente (ANSI B 89.6.2, 1973). Vale ressaltar que a memória térmica é característica de todos os objetos. Se forem feitas medições durante o tempo de equilíbrio podem resultar erros sérios já que a resposta do sistema e as dimensões da peça são variáveis no tempo.

$\mathrm{O}$ erro térmico total pode ser determinado como sendo a soma do erro causado pelas temperaturas diferentes de $20{ }^{\circ} \mathrm{C}$ e o erro devido às variações de temperatura (BRYAN, 1967).

A norma ANSI B 89.1.12 (1990), "Métodos para avaliação do desempenho de MMCs" tornou-se um documento de trabalho para os usuários e fabricantes de tais máquinas. Nesta norma está incorporada a B 89.6.2 (1973) em cuja base está o conceito de índice de erro térmico (IET). Em adição, a citada norma exige correções obrigatórias da expansão diferencial entre a escala da máquina e qualquer padrão de comprimento que seja usado para testes (interferômetro, blocos-padrão, etc.). Ao fabricante, também, é exigido declarar o coeficiente efetivo de expansão térmica da escala da máquina com a finalidade de fazer a correção dos efeitos da Expansão Diferencial.

A adoção do conceito do índice de erro térmico pela ISO em janeiro de 1994 foi de grande valia, chamando atenção a este modo simples de pensamento sobre as conseqüências de fabricar e medir peças a temperaturas diferentes da temperatura de referência $\left(20^{\circ} \mathrm{C}\right)$. O IET é expresso como uma porcentagem da tolerância de fabricação da peça.

O IET está relacionado com as variáveis que criam a necessidade de controlar a temperatura ambiente, elas são, tolerância e dimensões da peça; coeficientes de expansão térmica da peça e da escala; correção dos efeitos da expansão diferencial e dos efeitos térmicos. O IET pode ser reduzido através da compensação dos efeitos térmicos na máquina, na peça e através do controle direto da temperatura. 
a- Compensação dos efeitos térmico na máquina: SARTORI et al., (1989) escreveram que todas as precauções e métodos descritos na literatura podem ser adotados no sentido de reduzir os efeitos térmicos. Porém, ele chamou a atenção num ponto muito importante:

“Acreditar que a compensação, em tempo real, das deformações térmicas elimine os defeitos de projeto, relacionados com o fenômeno térmico, é de fato um engano. Para definir procedimentos de correção das deformações térmicas através de programas computacionais é preciso garantir algumas condições prévias, essenciais, tais como: projeto de estruturas simétricas termicamente capazes de distribuir, de forma rápida e uniforme, o calor produzido e o uso de fluídos com temperatura controlada".

A solução mais efetiva para evitar ou diminuir os efeitos térmicos é a otimização do desenho das máquinas. As técnicas de compensação são necessárias para incrementar a precisão das Máquinas de Medir a partir de projetos já otimizados.

b- Compensação dos efeitos térmicos na peça: o problema da compensação dos efeitos térmicos na peça é o desafio do futuro. Quando o número de peças a medir for considerável é praticamente impossivel obter um modelo matemático para cada uma delas, e até mesmo se a modelagem for possivel, está fora de questão instrumentar a peça o necessário para determinar o seu estado da temperatura.

Quanto à compensação dos efeitos térmicos na peça existem alguns critérios um tanto pessimistas. Na maioria das MM3Cs e das peças a medir a influência das temperaturas se torna mais complexa em função das características do local e devido à distribuição, no tempo, das temperaturas causadas por fontes internas e externas à máquina. Assim sendo, as deformações da MM3C e da peça, objeto de medição, dependem de tantos parâmetros que não há nenhum método simples que permita fazer uma correção completa do erro total.

Para efetivar a compensação são usados coeficientes de expansão, geralmente, tabelados. Estes coeficientes são aproximados e estão baseados em algumas hipóteses, tais como: homogeneidade e pureza dos 
materiais, temperatura uniforme ao longo do material, geometria simples além de se desprezar, por hipótese, as mudanças de configuração das peças. Porém, é sabido que paredes mais finas das peças respondem mais rapidamente que as partes mais grossas às mudanças de temperatura, isto pode provocar deformações nos elementos da máquina. Por outro lado, as peças a serem medidas geralmente são complexas e fabricadas dos mais diversos materiais, provocando dessa forma erros devido às distorções induzidas termicamente. Ainda, freqüentemente, durante a compensação assume-se que a superficie e o centro da peça têm a mesma temperatura. Sabe-se que é preciso aguardar um intervalo de tempo até a peça alcançar o equilíbrio térmico, caso contrário a compensação não pode ser considerada boa.

Os efeitos térmicos induzem tensões e deformações na peça e na Máquina de Medir. Tendo em conta o anteriormente escrito o operador deve conhecer os limites da compensação térmica. Saber que a compensação não é a melhor forma para minimizar os efeitos térmicos, ela deve ser usada para melhorar a precisão dos processos tanto de medição quanto de usinagem.

Apesar destes pontos um tanto quanto pessimistas, os cientistas concordam que as pesquisas deveriam continuar na procura do entendimento dos efeitos térmicos nas estruturas mecânicas. Tais pesquisas devem focar o desenvolvimento de sistemas de medição de temperatura que sejam precisos, fidedignos, fáceis de instalar e baratos.

c- Controle direto da temperatura: $O$ controle do meio ambiente é um modo efetivo para eliminar muitas fontes de erros ou minimizar seus efeitos. Assim sendo é preciso controlar um conjunto de fatores, tais como a temperatura no ponto de controle; a variação temporal e espacial da temperatura. Com relação ao ambiente, especificamente a temperatura, pode-se dizer que este é um dos mais óbvios e menos compreendidos dos componentes do sistema de medição (NI, 1995).

Algumas máquinas modernas com controle numérico computadorizado ( $\mathrm{CNC}$ ) podem estar dotadas de carenagem, permitindo o controle da temperatura com uma variação de $\pm 1{ }^{\circ} \mathrm{C}$ com custo 
relativamente baixo. Assim sendo, incrementa-se a precisão e a repetibilidade dos processos de medição. Estas máquinas conhecidas como termicamente otimizadas, apresentam um controle de temperatura similar ao usado nos aeroportos, shopping pequenos, hotéis, oficinas e restaurantes. Onde a temperatura é, aproximadamente, $(24 \pm 3){ }^{\circ} \mathrm{C}$ dependendo da preferência dos empregados.

Este tipo de controle de temperatura elimina o desconforto humano produzido pela temperatura de $20{ }^{\circ} \mathrm{C}$, melhora o estado de ânimo, a produtividade e a saúde dos operadores de máquinas; motiva os engenheiros a ficarem mais tempo no local de trabalho; controla a temperatura do ar e permite a remoção de fontes localizadas de calor tais como motores e sistemas de controle.

As Máquinas de Medir requerem a implantação de ambientes com temperatura controlada. Porém, a necessidade de integrá-las às linhas automatizadas de produção obriga a compensação dos efeitos térmicos.

\subsection{MÉtodos e Técnicas Utilizados para Equacionamento dos ERROS TÉrmicos}

Inúmeras pesquisas foram desenvolvidas com o objetivo de conhecer as fontes, características, grandezas e comportamento dos erros termicamente induzidos. Dentre as ferramentas matemáticas empregadas para descrever o comportamento de tais erros tem-se: Transformações Homogêneas, Elementos Finitos e Técnicas Estatísticas.

\section{Modelos que utilizam Transformações Homogêneas}

As transformações homogêneas têm sido largamente usadas para descrever erros em Máquinas Ferramentas e de Medir. A seguir, alguns trabalhos são citados para reafirmar a ampla utilização e potencial desta ferramenta matemática. 
DONMEZ et al. (1986) utilizaram a técnica das transformações homogêneas no modelamento de Máquinas Ferramentas para determinação da relação espacial entre ferramenta e peça. A metodologia foi aplicada em um centro de torneamento de dois eixos. Durante a modelagem, os autores fizeram algumas considerações, dentre elas: a máquina ferramenta é uma estrutura com muitos graus de liberdade; a cada elemento móvel da máquina podem ser associados seis graus de liberdade; o efeito de um eixo pode ser afetado pelo movimento de outro eixo; o efeito final de todas as componentes dos erros individuais é uma translação e rotação da ferramenta em torno de um eixo arbitrário no espaço. Na formulação proposta, o erro individual foi escrito como sendo a soma de dois polinômios. O primeiro, expressa a variação do erro geométrico em função da posição do carro de movimentação, enquanto que o segundo descreve a variação do erro em função da temperatura, isto é, o erro termicamente induzido. Os coeficientes do modelo foram determinados através do método dos mínimos quadrados. $\mathrm{O}$ equacionamento proposto pode ser modificado e aplicado a outros tipos de Máquinas Ferramentas, como centros de usinagem de múltiplos eixos.

SHIVASWAMY (1992) apresentou um modelo para uma máquina de três eixos utilizando a teoria de coordenadas homogêneas. Para descrever o modelo, um levantamento cuidadoso dos erros geométricos e térmicos da máquina foi realizado. Usando o modelo, pôde-se implementar uma compensação dos erros e conjeturar a melhor geometria para minimizá-los.

FERREIRA e LIUa (1986) propuseram um modelo analítico para a previsão de erros geométricos em Máquinas Ferramentas. Utilizaram matrizes de transformações homogêneas e apresentaram um método para estimar os coeficientes do modelo, através de expressões para os erros individuais. O modelo apresenta características interessantes, pois permite avaliar a variação das componentes de erro; modela retitude em função da variação dos erros angulares. Além disso, os coeficientes do modelo podem ser obtidos pela observação do vetor erro em poucos pontos (nove) no espaço de trabalho da máquina. 
No trabalho de FERREIRA e LIUb (1986) foi apresentada uma aplicação do modelo descrito por FERREIRA e LIUa (1986) em uma máquina com dois eixos de movimentação. O cálculo dos parâmetros do modelo foi efetuado a partir das medições realizadas em nove pontos distribuídos no domínio de trabalho da máquina. O experimento foi realizado monitorando a temperatura de termopares localizados em pontos distintos da estrutura da máquina, até que o estado de equilíbrio térmico fosse atingido. A máquina foi avaliada em duas condições: aquecimento e resfriamento. Com os dados levantados e introduzidos, adequadamente, nas expressões o erro total pode ser previsto em todo o seu plano de trabalho.

KRENG et al. (1994) apresentaram um modelo para expressar o erro no volume de trabalho de um centro de usinagem de três eixos. Foram utilizadas na modelagem a cinemática do corpo rígido e as transformações em coordenadas homogêneas. Os coeficientes do modelo de erro foram calculados a partir de medições em dez pontos distribuídos no volume de trabalho da máquina, cinco destes pontos estavam na mesa de trabalho e os outros cinco no plano perpendicular a ela. Com a metodologia e a instrumentação convencional foram levantados os erros com a máquina fria e com a máquina aquecendo. O modelo não previu adequadamente o erro da máquina fria, mas apresentou bons resultados durante o período de aquecimento, onde erros da ordem de $100 \mu \mathrm{m}$ foram previstos em pelo menos 75\%. Dentre as possiveis razões da ineficiência do modelo para descrever os erros da máquina fria estão, segundo os autores, a pouca exatidão do sistema de apalpamento e do artefato mecânico utilizado para levantamento dos valores de drift térmico, além, do equacionamento inadequado do erro através de uma aproximação quadrática.

PEREIRA (1995) através do uso das transformações homogêneas modelou uma retificadora cilíndrica $\mathrm{CNC}$, considerando a influência dos gradientes térmicos atuantes na máquina. Através do modelo foram descritos os movimentos dos elementos da máquina e os respectivos erros, além de previsto o erro de posicionamento relativo entre ferramenta e 
peça. O modelo permitiu obter o erro total da máquina levando em consideração as influências térmicas. Como conclusão do trabalho destaca-se a influência significativa das variações de temperatura no comportamento de quase todos os erros individuais da máquina.

VIEIRA SATO (1998) utilizando transformações homogêneas desenvolveu o modelo cinemático de uma retificadora cilíndrica $\mathrm{CNC}$, considerando a influência das variações térmicas. Os resultados sintetizados com o modelo foram avaliados, discutidos e comparados com os erros medidos em peças usinadas pela máquina, constatando-se a excelente capacidade do método na previsão do erro planar da retificadora avaliada. A partir do modelo proposto é possivel corrigir pelo menos $80 \%$ dos erros dimensionais na direção do eixo $X$.

WANG et al. (1998) utilizaram transformações homogêneas para modelar e estudar o comportamento de um centro de usinagem de três eixos. Para o desenvolvimento do trabalho os autores partiram da suposição de que cada eixo apresenta seis erros, um de posicionamento, dois de retitude e três angulares. Assim sendo, foram estudadas 21 fontes de erros incluindo os três erros de perpendicularidade.

YUAN e NI (1998) desenvolveram um procedimento geral para compensação dos erros geométricos, térmicos e dos induzidos pelas forças de corte. O modelo de sinterização dos erros geométricos e térmicos está baseado na suposição do corpo rígido. Usando matrizes de transformações homogêneas foi determinado o vetor do erro volumétrico para qualquer posição.

LO et al. (1995) desenvolveram um modelo de sintetização para descrever os erros de posicionamento de um centro de torneamento vertical de quatro eixos e dois fusos. No modelo utilizaram matrizes de transformações homogêneas e foram introduzidas onze componentes de erros. 


\section{Modelos que utilizam Elementos Finitos}

Uma das técnicas usadas para modelar os efeitos térmicos é o método denominado elementos finitos (SATA et al., 1972; SATA et al., 1973; SHIVASWAMY, 1992; KRENG et al., 1994). Este método consiste na determinação da distribuição de temperatura de uma estrutura através da solução de equações de transferência de calor do sistema. Essa distribuição pode, então, ser usada para calcular tensões e deformações térmicas. Outros modelos também foram propostos por OKUSHIMA e KAKINO (1975); SATA et al. (1975); WECK e ZANG (1975); VENUGOPAL e BARASH (1986) e SPUR et al. (1988). Porém a exatidão prevista por estes modelos está limitada pelas condições de contorno da máquina e pelo comportamento termoelástico complicado dos elementos da máquina.

SARTORI et al., (1989) usando elementos finitos modelaram os erros induzidos por gradientes quase-estáticos em tempo real, numa Máquina de Medir SIP 560M. Para tanto, foram induzidos gradientes de até $10{ }^{\circ} \mathrm{C}$ por metro utilizando-se de um aquecedor, de aproximadamente $2 \mathrm{~kW}$ de potência, colocado a um metro de distância da máquina. No caso, as deformações da peça com respeito à máquina e as deformações, entre si, dos elementos da máquina constituíram as fontes de erros não corrigidos mais significativas. Como um dos resultados do estudo ficou comprovado que 80 a $85 \%$ das deformações podem ser explicadas através do modelo. As correções feitas automaticamente eram capazes de compensar de 65 a 75\% dos erros. Os autores dizem que a compensação dos erros térmicos nas MM3Cs através de métodos computacionais faz sentido quando é requerida alta precisão e estabeleceram as condições ambientais razoáveis que minimizam os efeitos térmicos presentes nas medições.

\footnotetext{
$>\quad$ temperatura média $20^{\circ} \mathrm{C}$.

$>\quad$ variação da temperatura menor que $\pm 2{ }^{\circ} \mathrm{C}$.

$>$ gradiente de temperatura ao longo de qualquer direção menor que $2{ }^{\circ} \mathrm{C} / \mathrm{m}$.
} 
$>$ variações de temperatura no tempo que proporcionem condições quase-estacionárias.

BALSAMO et al. (1990) apresentaram um modelo para avaliação e correção das deformações térmicas em MMCs. O primeiro conjunto de equações, que relaciona as deformações com a distribuição de temperaturas, foi denominado de modelo de deformação. Enquanto que o segundo, chamado de modelo térmico, expressa a temperatura em função das coordenadas dos pontos medidos.

Para determinação dos parâmetros do modelo de deformação foram coletadas as coordenadas dos pontos e as temperaturas sob condições térmicas de referência, ou seja, num estado inicial não perturbado e para diferentes estados perturbados. Segundo o autor, o número de estados térmicos depende do modelo de deformação selecionado, isto é, do número de parâmetros desconhecidos e do número de pontos cujas coordenadas são coletadas em cada medição. Este modelo, caracterizado como extenso e complexo, quando aplicado a uma máquina instalada em um laboratório (SIP mod. $560 \mathrm{M}(420 \mathrm{~mm}$ x $230 \mathrm{~mm}$ x $330 \mathrm{~mm}$ )) permitiu descrever 80\% a $85 \%$ das deformações e corrigir de $65 \%$ a $75 \%$ destas durante a usinagem. Já para uma máquina instalada no meio industrial (SIP mod. 560 M (620 mm x 420 mm x 350 mm)) o modelo não foi adequado.

O modelo térmico resultou um polinômio de grau dois, em três coordenadas, com dez coeficientes, que são os parâmetros do modelo. Durante a modelagem foram considerados os gradientes constantes e os que apresentavam uma variação linear. Porém, as correções quando estes últimos estavam presentes não foram adequadas. Além disso, o referido modelo não considerou o movimento entre a peça e a estrutura da máquina devido às variações de temperatura. O modelo térmico foi testado numa máquina SIP modelo 560M instalada num laboratório, permitindo descrever $70 \%$ das deformações térmicas.

LINGARD et al. (1991) introduziram gradientes verticais e horizontais numa CMM Leitz PMM - 866 de alta precisão, através do uso de um aquecedor. O trabalho visava determinar a susceptibilidade da 
MMC às mudanças de temperatura ambiente. Nos testes desenvolvidos usou-se uma barra de esferas de zerodur. O gradiente vertical provocou erros de medição significativos no plano $Y-Z$. O comprimento da barra de esferas teve variações em função do gradiente e do tempo, esta última variação quando a coluna da máquina da direita estava aquecida. A mesa com o carro $Y$ experimentou uma deflexão em forma de arco de aproximadamente $3,5 \mu \mathrm{m}$. Durante o teste horizontal não houve mudanças significativas no comprimento da barra de esferas.

JEDRZYEWSKI e MODRZYCKI (1992) propuseram um modelo para descrever o comportamento térmico de Máquinas Ferramentas em condições normais de trabalho. A técnica foi baseada na determinação da liberação de energia nos componentes cinemáticos do sistema. Utilizaram elementos finitos e modelaram a estrutura completa da máquina, assim como as relações entre condições operacionais, energia e temperatura. Os ensaios realizados comprovaram a boa exatidão nos valores calculados de temperatura e de deslocamentos térmicos ocorridos na máquina.

\section{Modelos que utilizam Técnicas estatísticas}

Um modelo de erros generalizado para máquinas multi-eixos de qualquer configuração é apresentado por SOONS et al. (1992). Este modelo leva em consideração os erros geométricos, os dinâmicos e as deformações térmicas. Técnicas estatísticas foram utilizadas para obter funções polinomiais que representassem os erros individuais. Estes polinômios, em conjunto com uma escolha de parâmetros utilizando mínimos quadrados, resultaram num modelo para cada erro individual. O modelo proposto foi aplicado em uma fresadora de cinco eixos e em uma Máquina de Medir a Três Coordenadas.

DONMEZ et al. 1982, utilizando análise estatística, estudaram o erro de posicionamento de uma fresadora com CNC. Na análise foram aplicados testes de normalidade, análise de variância e planejamento de experimentos. Os autores efetuaram a compensação do erro de posicionamento em diferentes peças, diminuindo-o em até $40 \%$. 
VALDÉS (1999), utilizando técnicas de regressão, desenvolveu um modelo para cálculo do erro volumétrico em uma MM3C do tipo Ponte Móvel. Foram obtidas três equações de regressão, uma para cada componente do erro, a partir de dados levantados através da calibração direta, utilizando-se do interferômetro laser. A partir do modelo proposto efetuou-se a compensação do erro volumétrico em duas diagonais do volume de trabalho da máquina. A compensação permitiu diminuir o erro volumétrico em, aproximadamente, 94 e 95\% para os sentido de ida e volta, respectivamente, constatando-se assim a excelente capacidade do modelo na previsão do erro volumétrico.

MOU et al (1995) desenvolveram uma pesquisa para melhorar a precisão de Máquinas Ferramentas CNC. O modelo proposto descreve os erros geométrico-térmicos da máquina a partir da suposição da cinemática do corpo rígido. Cada componente do erro foi descrita em função da posição e da temperatura. No desenvolvimento do modelo foram utilizadas técnicas estatísticas, especificamente, a regressão.

KRULEWICH (1998) partiu da suposição de que numa determinada região a distribuição da temperatura pode ser descrita utilizando um polinômio. Esta aproximação exige a utilização de muitos sensores para levantar a distribuição da temperatura, no caso foram usados 100 sensores. O método proposto para os erros que independem da posição pode ser estendido também para erros dependentes da posição.

Modelos baseados na análise de regressão multi-variáveis (DONMEZ et al., 1986; CHEN et al., 1993) foram também utilizados no desenvolvimento de modelos de erros térmicos.

\subsection{NOVAS TENDÊNCIAS}

O desenvolvimento das pesquisas com o objetivo de diminuir os efeitos térmicos em MM3Cs continua através das mais diferentes maneiras. Alguns autores falam da necessidade de melhorar o projeto das MMCs (KRUTH et al., 2001). Esta melhora pode ser feita através da utilização de materiais com baixo coeficiente de expansão térmica como o 
invar, zerodur, fibra de carbono, cerâmica, etc. Outros autores propõem diminuir o tempo de medição (LOTZE, 1996). E por fim se dão os primeiros passos para determinação da incerteza associada às variações de temperatura ambiente (WECKENMANN et al., 2001).

LOTZE (1996) descreve a primeira MM3C ScanMax de alta precisão, projetada especialmente para trabalhar no chão de fabrica. Esta máquina consiste de uma escala linear e duas escalas angulares. Na fabricação da mesma foram utilizados materiais como a fibra de carbono e a cerâmica, além do zerodur para fabricar as escalas. Segundo o autor, o sistema ScanMax está dotado de um programa computacional muito poderoso e simples permitindo fazer medições de forma rápida, além da avaliação e correção dos erros. Operada manualmente esta máquina supera uma das limitações das MMCs convencionais, que consiste na medição ponto a ponto. A partir dos pontos medidos o programa calcula automaticamente a característica medida, as variações de tamanho, forma e posição e corrige completamente os erros cinemáticos e a deformação elástica dos acoplamentos.

KRUTH et al. (2001) apresentaram uma nova formulação para descrever o comportamento térmico das componentes do erro volumétrico em MM3Cs, para estados térmicos estacionários e transientes. Cada componente foi descrita como sendo a soma de várias parcelas. Estas parcelas simples são o resultado da combinação dos coeficientes de dilatação dos diferentes materiais que compõem a máquina, dos comprimentos dos componentes e das variações de temperatura. A Metodologia foi aplicada a uma MM3C do tipo Ponte Móvel, de tamanho médio. Os valores de drift térmico foram coletados através da medição continua de várias esferas e as temperaturas dos diferentes componentes da máquina foram monitoradas usando termístores. A diferença entre os valores levantados durante o drift térmico e os calculados utilizando-se do modelo proposto foram, aproximadamente, de $6 \mu \mathrm{m}$ para cada um dos eixos coordenados.

Os valores do drift indicaram que a deformação experimentada pela máquina depende da posição e da variação temporal da temperatura. 
Comprovou-se a influência negativa de fabricar máquinas com diferentes materiais, isto é, os efeitos de memória térmica e de expansão diferencial.

WECKENMANN et al. (2001) desenvolveram uma pesquisa para avaliar as possiveis contribuições das variações de temperatura, na incerteza de medição. Para tanto foi utilizada uma Máquina de Medir de grande porte com controle numérico computadorizado (CNC). No trabalho desenvolvido foram considerados três casos:

a-) Compensação da temperatura nas escalas e na peça;

b-) Compensação da temperatura somente nas escalas;

c-) Sem compensação da temperatura.

Segundo os autores não é recomendável fazer uma compensação parcial das variações da temperatura, isto é, compensação nas escalas e não na peça, pois a contribuição na incerteza aumenta. Neste caso deve-se excluir a compensação. Este problema pode ser resolvido monitorando a temperatura da peça on-line e efetuando a correção depois, manualmente.

Como exposto, a maioria dos métodos propostos para minimizar os efeitos térmicos requer experimentos demorados, tediosos e conseqüentemente caros. Estes métodos consistem principalmente na aplicação do interferômetro laser para coletar as componentes do erro volumétrico ou a combinação de instrumentos para medição dos erros individuais. Na tentativa de diminuir o tempo de experimentação utilizamse os artefatos padrões, porém paga-se um preço elevado que é a perda de poder de diagnóstico. Os métodos que utilizam artefatos padrões coletam a influência conjunta de vários erros geométricos numa determinada posição, impossibilitando o entendimento das causas dos erros térmicos e, conseqüentemente, levando a conclusões às vezes não muito acertadas.

Acredita-se que a via para resolver o problema das influências térmicas em MM3Cs está, ainda, no entendimento das causas e dos efeitos das variações de temperatura. 


\section{Capítulo 3}

\section{FERRAMENTAS MATEMÁTICAS UTILIZADAS NA \\ MODELAGEM E NO CÁLCULO DA INCERTEZA DE \\ MEDIÇÃO}

Neste capítulo são apresentados os fundamentos teóricos das ferramentas matemáticas utilizadas para descrever o comportamento térmico da Máquina de Medir a Três Coordenadas, avaliada. Assim sendo, fala-se sobre transformações homogêneas, técnicas de regressão e método dos mínimos quadrados. As transformações homogêneas foram utilizadas para equacionar as componentes do erro volumétrico, em função dos erros geométricos e dos respectivos braços de Abbé. Enquanto as técnicas de regressão e o método dos mínimos quadrados foram utilizados para descrever as variações termicamente induzidas dos erros geométricos. Finalmente são apresentados os conceitos básicos referentes à incerteza de medição.

\subsection{Modelagem Matemática. Transformações Homogêneas.}

Para descrever matematicamente o comportamento dos erros em MM3Cs existem diferentes ferramentas. Dentre elas as transformações 
homogêneas ocupam um lugar de destaque, dada sua flexibilidade, permitindo que sejam adaptadas facilmente a qualquer tipo de Máquina Ferramenta, Máquina de Medir ou Robô.

Através desta técnica e mediante o uso de matrizes $4 \times 4$, é possivel representar movimentos de translação, de rotação ou a combinação desses dois, possibilitando estabelecer as relações entre as partes móveis de um mecanismo e um sistema de coordenadas de referência (fixo). Dessa forma as matrizes de transformação homogênea conseguem explicar matricialmente os deslocamentos relativos sofridos pelos sistemas de coordenadas colocados em cada componente de um mecanismo ou máquina.

A seguir estão apresentadas algumas considerações teóricas a respeito das propriedades das Transformações Homogêneas.

\subsubsection{Considerações Gerais}

Um ponto $q$ no espaço Euclidiano $\mathbb{R}^{n}$ pode ser representado por um vetor $\overrightarrow{\mathrm{v}}$ de $n$ coordenadas em relação a um sistema de coordenadas cartesianas de referência.

A representação em coordenadas homogêneas deste mesmo ponto $q$ é dada por um vetor com $(n+1)$ coordenadas, onde $(n+1)$-ésima coordenada é chamada de fator de escala.

Considere um ponto $q$ qualquer no espaço tridimensional representado pelo vetor, Eq. (3.1).

$$
\vec{v}=a \vec{i}+b \vec{j}+c \vec{k}
$$

onde $\vec{i}, \vec{j}, \vec{k}$ são os vetores unitários de direção nos eixos $X, Y, Z$, respectivamente, como ilustrado na Figura 3.1. Tal ponto pode ser representado em coordenadas homogêneas pelo vetor dado na Eq. (3.2), onde $a=\frac{x}{w}, b=\frac{y}{w}, c=\frac{z}{w}$ e w sendo o fator de escala. 
Segundo RESHETOV e PORTMAN (1988), a representação tridimensional através de vetores de quarta ordem pode ser dividida em duas classes distintas dependendo de sua natureza geométrica. A primeira classe está relacionada com os autovetores que representam um ponto no espaço e, portanto, sua quarta coordenada homogênea é não nula. Enquanto que a segunda classe contém os não-autovetores que representam direções ou ângulos e, portanto, seu fator de escala é nulo.

$$
\vec{v}=[x, y, z, w]^{T}
$$

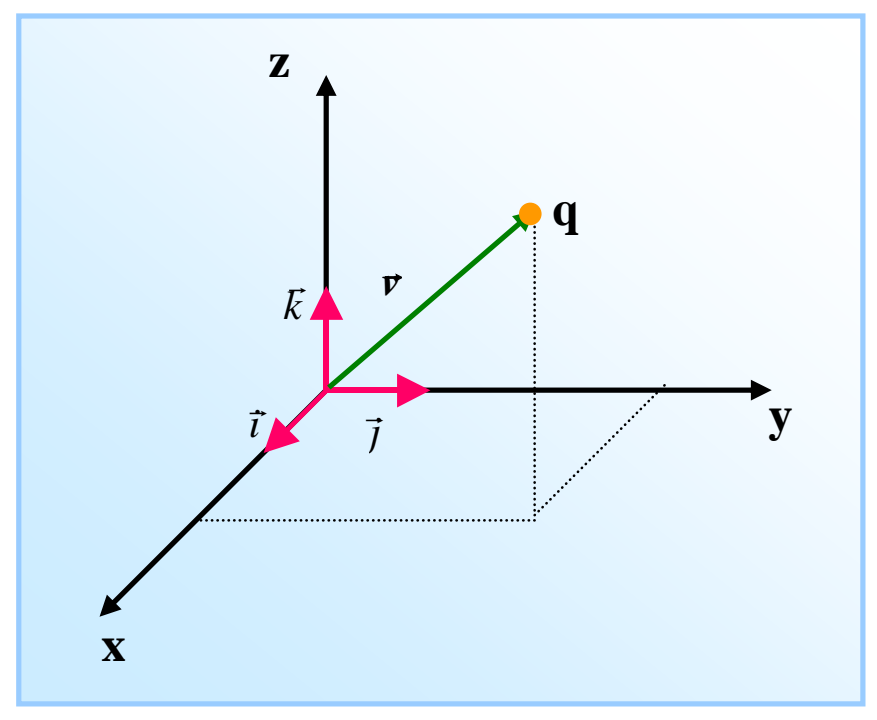

Figura 3.1 - Sistemas de coordenadas cartesianas.

Em um espaço tridimensional as transformações homogêneas são matrizes quadradas de ordem 4, e sua forma geral possui a seguinte estrutura, Eq. (3.3).

$$
M=\left[\begin{array}{llll}
O_{1 x} & O_{2 x} & O_{3 x} & P_{x} \\
O_{1 y} & O_{2 y} & O_{3 y} & P_{y} \\
O_{1 z} & O_{2 z} & O_{3 z} & P_{z} \\
O_{1 s} & O_{2 s} & O_{3 s} & P_{s}
\end{array}\right]
$$

onde $\vec{O}_{1}, \vec{O}_{2}, \vec{O}_{3}$ são não autovetores que descrevem a orientação de um sistema de coordenadas $S_{i}$ com relação a um outro sistema de 
coordenadas $S_{i-1}$. O autovetor $\vec{P}$ descreve a posição relativa da origem do sistema $S_{i}$ no sistema $\mathrm{S}_{\mathrm{i}-1}$. Assim, devidamente definidas, tais matrizes podem representar matematicamente deslocamentos espaciais de translação ou rotação ou, ainda, podem indicar uma mudança de sistemas de coordenadas. Como não se está interessado aqui em perspectiva, pode-se atribuir ao fator de escala do quarto vetor coluna o valor unitário, facilitando desta forma a compreensão dos valores $P_{x}, P_{y}, P_{z}$. A matriz dada na Eq. (3.3) pode ser reescrita na forma da Eq. (3.4).

$$
M=\left[\begin{array}{cccc}
O_{1 x} & O_{2 x} & O_{3 x} & p_{x} \\
O_{1 y} & O_{2 y} & O_{3 y} & p_{y} \\
O_{1 z} & O_{2 z} & O_{3 z} & p_{z} \\
0 & 0 & 0 & 1
\end{array}\right]
$$

Considere dois sistemas de coordenadas $S_{i}$ e $S_{i-1}$ distintos. Um ponto $q$ no espaço tem diferentes coordenadas nestes dois sistemas. Sejam $\vec{v}_{i}$ e $\vec{v}_{i-1}$ os vetores que descrevem $q$ nos sistemas $S_{i}$ e $S_{i-1}$, respectivamente. A relação matricial existente entre os dois vetores é dada pela Eq. (3.5).

$$
\vec{v}_{i-1}=\left[{ }^{(i-1)} M_{i}\right] \cdot \vec{v}_{i}
$$

onde $\left[{ }^{(i-1)} M_{i}\right]$ é uma matriz do tipo, Eq. (3.4), que indica a posição e orientação do $i$-ésimo sistema em relação ao (i-1)-ésimo sistema.

\section{Matrizes de Transformações Homogêneas Representando Movimentos de Translação Simples}

Considere dois sistemas de coordenadas $S_{i}$ e $S_{i-1}$. Suponha que o sistema $S_{i}$ tenha executado um movimento de translação em $X$ com relação ao sistema $S_{i-1}$ (Figura 3.2). Observe que as bases de $S_{i}$ e $S_{i-1}$ são iguais, havendo apenas uma alteração quanto à origem. 
A matriz de transformação homogênea que descreve o movimento de translação em $X$ é dada pela Eq. (3.6).

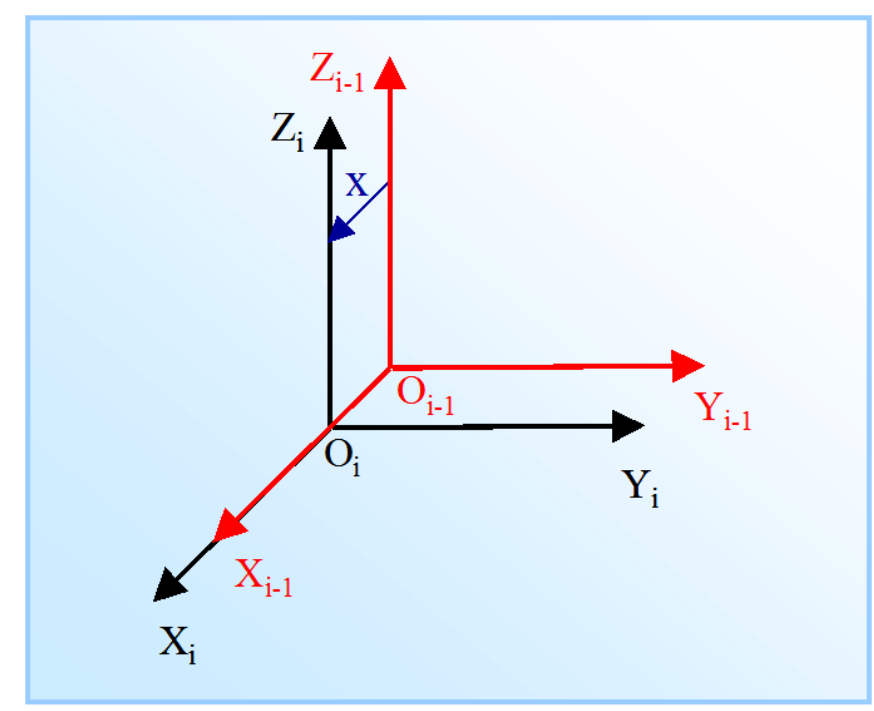

$$
\left[{ }^{(i-1)} M_{i}\right]_{\operatorname{Mov}(x)}=\left[\begin{array}{cccc}
1 & 0 & 0 & X \\
0 & 1 & 0 & 0 \\
0 & 0 & 1 & 0 \\
0 & 0 & 0 & 1
\end{array}\right]
$$

Figura 3.2 - Translação em $X$.

De forma análoga tem-se a Eq. (3.7) que descreve o movimento de translação em $Y$ do sistema $S_{i}$ com relação ao $S_{i-1}$, mostrado na Figura 3.3, e a Eq. (3.8) que descreve o movimento de translação em $Z$, Figura 3.4.

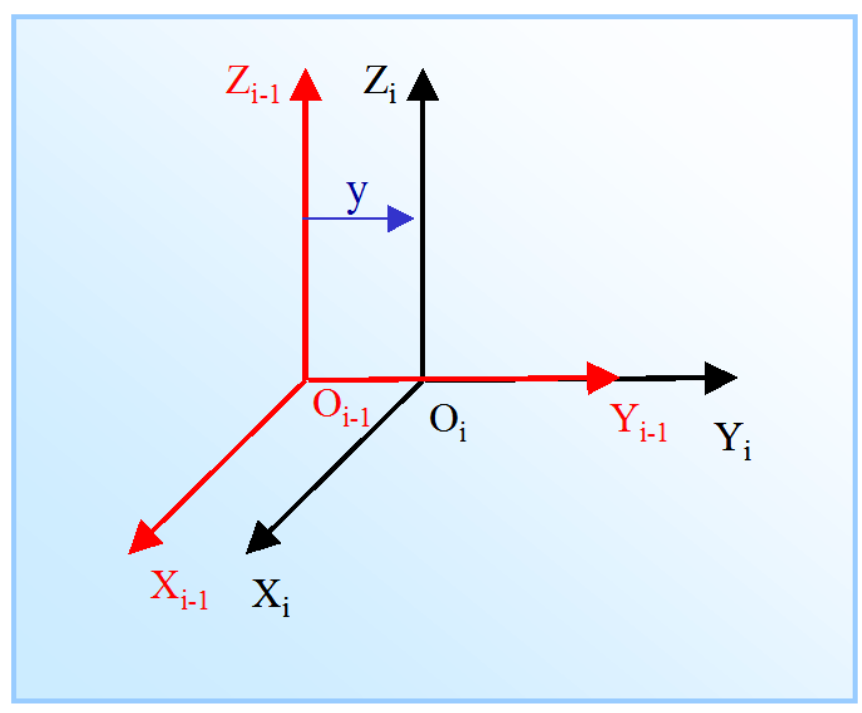

$$
\left[{ }^{(i-1)} M_{i}\right]_{M o v(y)}=\left[\begin{array}{cccc}
1 & 0 & 0 & 0 \\
0 & 1 & 0 & Y \\
0 & 0 & 1 & 0 \\
0 & 0 & 0 & 1
\end{array}\right]
$$

Figura 3.3 - Translação em Y. 


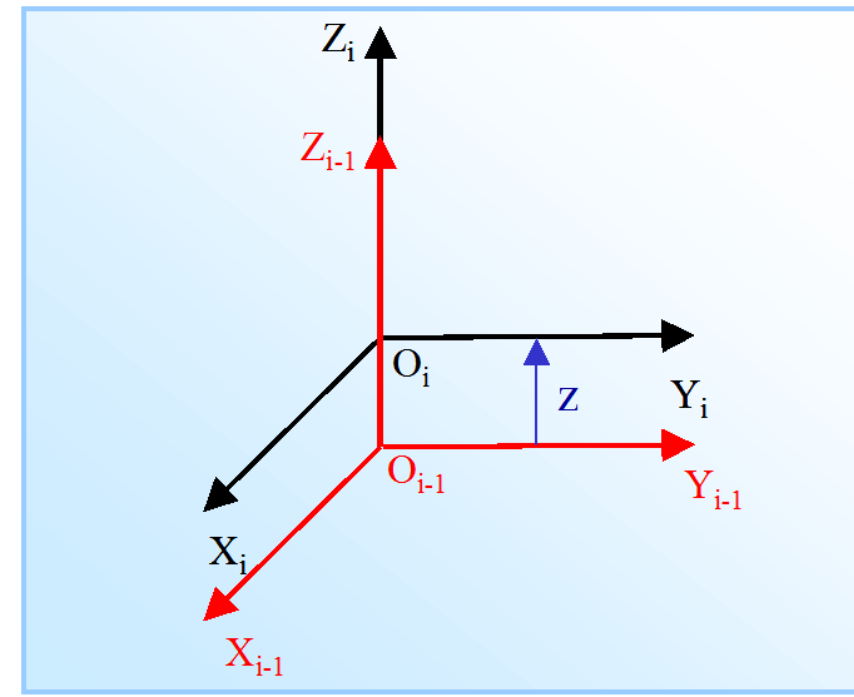

$$
\left[{ }^{(i-1)} M_{i}\right]_{\operatorname{Mov}(z)}=\left[\begin{array}{cccc}
1 & 0 & 0 & 0 \\
0 & 1 & 0 & 0 \\
0 & 0 & 1 & Z \\
0 & 0 & 0 & 1
\end{array}\right]
$$

Figura 3.4 - Translação em Z.

\section{Matrizes de Transformações Homogêneas Representando Movimentos de Rotação}

Considere $S_{i}$ e $S_{i-1}$ dois sistemas de coordenadas. Sejam $\vec{i}, \vec{j}, \vec{k}$ os vetores unitários de direção no sistema $S_{i}$ e $\overrightarrow{\mathrm{I}}, \overrightarrow{\mathrm{J}}, \overrightarrow{\mathrm{K}}$ os vetores unitários de direção no sistema $S_{i-1}$.

Seja $\alpha$ o ângulo de rotação em torno de $X$, que transforma o sistema $S_{i-1}$ no sistema $S_{i}$. Por hipótese, pode-se admitir que a origem do sistema $S_{i-1}$ seja coincidente com a origem do sistema $S_{i}$, como mostrado na Figura 3.5.

Os elementos de $S_{i}$ em termos de $S_{i-1}$ são dados pelas expressões abaixo.

$$
\begin{aligned}
& \overrightarrow{\mathrm{i}}=1 \cdot \overrightarrow{\mathrm{I}}+0 \cdot \overrightarrow{\mathrm{J}}+0 \cdot \overrightarrow{\mathrm{K}} \\
& \overrightarrow{\mathrm{j}}=0 \cdot \overrightarrow{\mathrm{I}}+\cos (\alpha) \cdot \overrightarrow{\mathrm{J}}+\operatorname{sen}(\alpha) \cdot \overrightarrow{\mathrm{K}} \\
& \overrightarrow{\mathrm{k}}=0 \cdot \overrightarrow{\mathrm{I}}-\operatorname{sen}(\alpha) \cdot \overrightarrow{\mathrm{J}}+\cos (\alpha) \cdot \overrightarrow{\mathrm{K}}
\end{aligned}
$$


Assim, agrupando convenientemente as expressões descritas anteriormente, obtém-se a matriz de transformação homogênea de rotação em torno do eixo $X$ que é dada pela Eq. (3.9).

$$
\left[{ }^{i-1} M_{i}\right]_{\operatorname{Rot}(x)}=\left[\begin{array}{cccc}
1 & 0 & 0 & 0 \\
0 & \cos (\alpha) & -\operatorname{sen}(\alpha) & 0 \\
0 & \operatorname{sen}(\alpha) & \cos (\alpha) & 0 \\
0 & 0 & 0 & 1
\end{array}\right]
$$

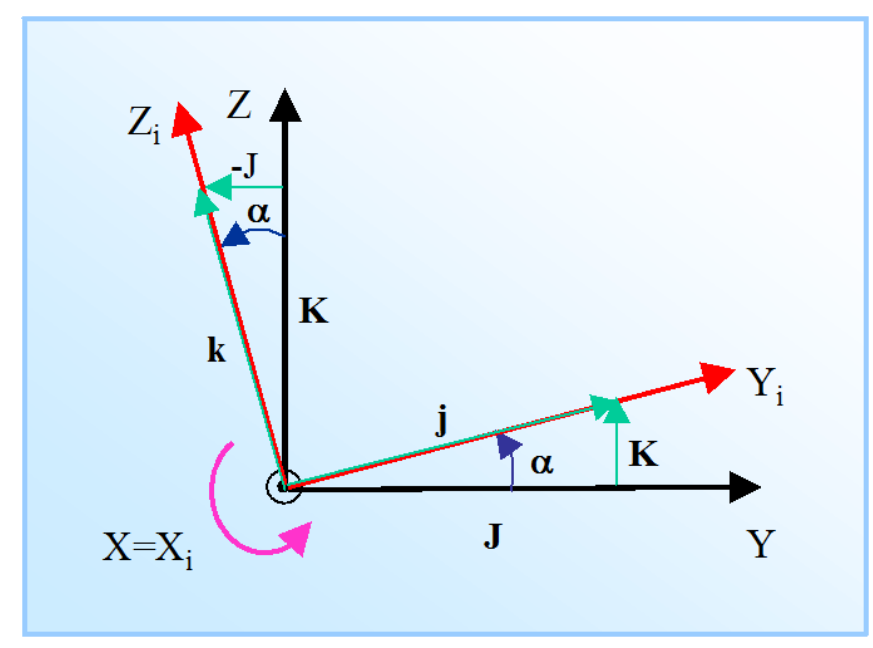

Figura 3.5 - Rotação $\alpha$ do sistema $\left(X_{i}, Y_{i}, Z_{i}\right)$ em torno do eixo $X$.

Suponha que o sistema $S_{i}=\left(X_{i}, Y_{i}, Z_{i}\right)$ tenha sofrido uma rotação em torno do eixo $Y$. Analogamente, admita que a origem do sistema $S_{i-1}$ seja coincidente com a origem do sistema $S_{i}$, representada na Figura 3.6.

As expressões que representam as direções dos eixos $\left(X_{i}, Y_{i}, Z_{i}\right)$ com relação ao sistema $S_{i-1}$ são dadas por:

$$
\begin{aligned}
& \overrightarrow{\mathrm{i}}=\cos (\beta) \cdot \overrightarrow{\mathrm{I}}+0 \cdot \overrightarrow{\mathrm{J}}-\operatorname{sen}(\beta) \cdot \overrightarrow{\mathrm{K}} \\
& \overrightarrow{\mathrm{j}}=0 \cdot \overrightarrow{\mathrm{I}}+1 \cdot \overrightarrow{\mathrm{J}}+0 \cdot \overrightarrow{\mathrm{K}} \\
& \overrightarrow{\mathrm{k}}=\operatorname{sen}(\beta) \cdot \overrightarrow{\mathrm{I}}+0 \cdot \overrightarrow{\mathrm{J}}+\cos (\beta) \cdot \overrightarrow{\mathrm{K}}
\end{aligned}
$$


Assim, a matriz de transformação homogênea de rotação em torno do eixo $Y$ é dada pela Eq. (3.10).

$$
\left[{ }^{i-1} M_{i}\right]_{\operatorname{Rot}(y)}=\left[\begin{array}{cccc}
\cos (\beta) & 0 & \operatorname{sen}(\beta) & 0 \\
0 & 1 & 0 & 0 \\
-\operatorname{sen}(\beta) & 0 & \cos (\beta) & 0 \\
0 & 0 & 0 & 1
\end{array}\right]
$$

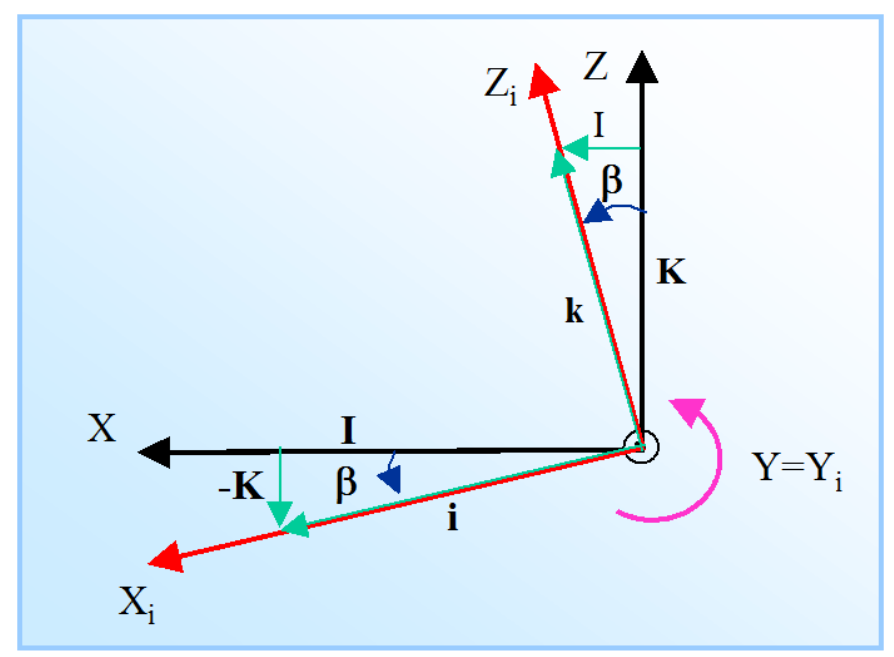

Figura 3.6 - Rotação $\beta$ do sistema (Xi, Yi, Zi) em torno do eixo $Y$.

O efeito de rotação em torno do eixo $Z$ é semelhante ao do eixo $X$ e ao do eixo $Y$ (Figura 3.7).

De forma análoga, têm-se as expressões:

$$
\begin{aligned}
& \vec{i}=\cos (\gamma) \cdot \vec{I}+\operatorname{sen}(\gamma) \cdot \vec{J}+0 \cdot \vec{K} \\
& \vec{j}=-\operatorname{sen}(\gamma) \cdot \vec{I}+\cos (\gamma) \cdot \vec{J}+0 \cdot \vec{K} \\
& \vec{k}=0 \cdot \vec{I}+0 \cdot \vec{J}+1 \cdot \vec{K}
\end{aligned}
$$

A matriz de transformação homogênea para rotação em torno de $Z$ é dada pela Eq. (3.11).

$$
\left[{ }^{i-1} M_{i}\right]_{\operatorname{Ror}(z)}=\left[\begin{array}{cccc}
\cos (\gamma) & -\operatorname{sen}(\gamma) & 0 & 0 \\
\operatorname{sen}(\gamma) & \cos (\gamma) & 0 & 0 \\
0 & 0 & 1 & 0 \\
0 & 0 & 0 & 1
\end{array}\right]
$$


Com as matrizes descritas nas Eqs (3.6) a (3.11), pode-se representar os 6 graus de liberdade, característicos na determinação da posição espacial de um corpo rígido. Portanto, se a cada elemento de uma máquina for associado um sistema de coordenadas, pode-se, através da combinação adequada destas matrizes, descrever os movimentos destes elementos, ou sistemas, e modelar o desempenho total da máquina.

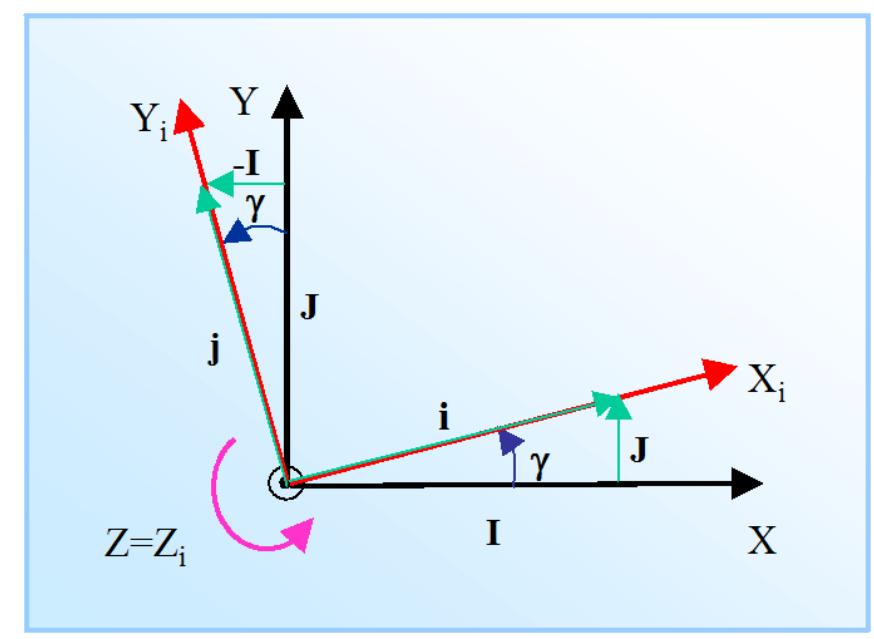

Figura 3.7 - Rotação $\gamma$ do sistema $(X i, Y i, Z i)$ em torno do eixo $Z$.

Quando feita a modelagem deve-se observar a ordem em que são multiplicadas as matrizes. A transformação correspondente ao primeiro movimento deve multiplicar primeiro as coordenadas e, assim, sucessivamente. O posicionamento das matrizes para a realização do produto deve ser cuidadosamente observado, pois o produto de matrizes não é comutativo (CARDOZA, 1995; VIEIRA SATO, 1998).

\subsection{Tratamento Estatístico de Dados. Conceitos Básicos}

A estatística é a ciência interessada nos métodos científicos para coleta, organização, resumo, apresentação, análise e interpretação de dados experimentais. Por isso desempenha um papel muito importante e crescente nas pesquisas de todo gênero. $\mathrm{Na}$ metrologia têm sido historicamente usada em gráficos de controle de qualidade, técnicas de amostragem e técnicas de planejamento de experimentos. 


\subsubsection{Conceitos Básicos}

Os dados experimentais representam o resultado quantitativo das observações reiteradas de um determinado evento ou fenômeno. O conjunto que agrupa a totalidade dos dados denomina-se população. Cada elemento da população recebe o nome de variável. Mas, às vezes, essas populações resultam muito grandes ou até infinitas, dificultando a análise. Neste caso, examinam-se quantidades limitadas de observações denominadas amostras.

A medida mais comum da tendência central de um conjunto de dados ou amostra é a média aritmética. Para uma amostra, esta média pode ser determinada pela Eq. (3.12), onde $x_{i}$ são os valores observados e n o número de observações.

$$
\bar{x}=\sum_{i=1}^{n} \frac{x_{i}}{n}
$$

O valor da média pode expressar a parcela sistemática dos erros obtidos em uma calibração. Estes dados numéricos encontram-se dispersos em torno de seu valor médio e, como medida dessa dispersão, são utilizados diferentes parâmetros estatísticos, sendo que o mais comum é o desvio padrão.

Para uma amostra, $\left(x_{1}, x_{2}, \ldots, x_{n}\right)$, onde $\bar{x}$ representa a média dos valores observados, o desvio padrão define-se como a Eq. (3.13):

$$
s=\sqrt{\frac{\sum_{i=1}^{n}\left(x_{i}-\bar{x}\right)^{2}}{n-1}}
$$

Para caracterizar uma distribuição de probabilidade, além do cálculo da média e do desvio padrão, eventualmente torna-se útil calcular os coeficientes relacionados à assimetria e achatamento da curva 
estudada. Para isto, devem ser determinados os momentos centrados em relação à média da distribuição, Eq. (3.14).

$$
m_{t}=\frac{\sum_{i=1}^{n}\left(x_{i}-\bar{x}\right)^{t}}{n-1}
$$

O momento de ordem $3\left(a_{3}\right)$ é denominado coeficiente de Skewness, Eq. (3.15). O valor deste momento é adimensional e indica se a distribuição é assimétrica ou não e o sentido da assimetria. Desta forma para $\left(a_{3}<0\right)$ as distribuições são assimétricas negativas, alongadas à esquerda e para $\left(a_{3}>0\right)$ as distribuições são assimétricas positivas, alongadas à direita.

$$
a_{3}=\frac{m_{3}}{s^{3}}
$$

O achatamento da distribuição pode ser avaliado através do coeficiente de Kurtosis $a_{4}$, Eq. (3.16). Se ( $a_{4}>3$ ) então a distribuição é considerada como sendo achatada ou platicúrtica; caso $\left(a_{4}=3\right)$, a distribuição é considerada normal ou mesocúrtica; caso (a < $<$ ) a distribuição é menos achatada que a normal ou leptocúrtica (MONTGOMERY et al., 1994).

$$
a_{4}=\frac{m_{4}}{s^{4}}
$$

A análise do comportamento dos resultados através de histogramas é sempre recomendada antes de aplicar qualquer técnica estatística. Para isto, são utilizados os testes de aderência. Dentre eles, o gráfico de probabilidade normal resulta de fácil aplicação. Nestes gráficos os valores medidos são colocados no eixo das abscissas e as probabilidades acumuladas no eixo das ordenadas. Se os resultados estão distribuídos 
normalmente então a distribuição de probabilidade acumulada se aproxima de uma linha reta.

Como visto, existem diferentes parâmetros estatísticos que podem ser utilizados para caracterizar um conjunto de dados ou amostra, ainda, é possível descrever o comportamento deste conjunto de dados e a relação entre as variáveis utilizando outras ferramentas, tais como as técnicas de regressão.

\subsection{2 - Regressão Linear}

A regressão linear expressa a relação entre uma variável dependente ou variável resposta y e uma ou mais variáveis independentes ou variáveis de entrada $x_{i}$. Utiliza-se quando, a partir de dados amostrais, deseja-se estimar o valor de uma variável, neste caso $y$, em função dos valores de outras variáveis $x_{i}$. A estimação pode ser efetuada através de uma curva que se ajuste aos dados amostrais, denominada curva de regressão de $y$ para $x_{i}$, já que $y$ é estimada a partir de $x_{i}$.

A relação entre $y$ e $x_{i}(\mathrm{i}=1, \ldots, \mathrm{n})$, expressa através de uma regressão linear, é dada através de uma Eq. (3.17). Onde os $\beta_{j},(j=0, \ldots, p)$ são os coeficientes da regressão; $\varepsilon_{i}$ são resíduos da regressão e $x_{j i}$, são variáveis independentes (variáveis de entrada).

$$
y_{i}=\beta_{0}+\beta_{1} x_{1 i}+\beta_{2} x_{2 i}, \ldots, \beta_{p} x_{p i}+\varepsilon_{i,} \quad \mathrm{i}=1,2, \ldots, \mathrm{n}
$$

Adotando-se a notação de função pode-se escrever a Eq. (3.17) de maneira abreviada como, $y_{i}=F\left(x_{1 i}, x_{2 i}, \ldots, x_{p i}\right)$, que se lê "yi é uma função de $\mathrm{x}_{1 \mathrm{i}}, \mathrm{x}_{2 \mathrm{i}}, \ldots, \mathrm{x}_{\mathrm{pi}}$ ".

A Equação (3.17) decompõe a variável $\mathrm{y}_{\mathrm{i}}$ em $p$ partes $\beta_{i} x_{p i}$ dependentes de $x_{p i}$, e uma parte $\varepsilon_{i}$ independente de $x_{p i}, i=1,2, \ldots, n$. 
Os estimadores de mínimos quadrados de $\beta_{0}, \beta_{1}, \beta_{2}, \ldots, \beta_{p}$ são determinados de maneira tal que minimizem a expressão dada na Eq. (3.18).

$$
S\left(\beta_{0}, \beta_{1}, \ldots, \beta_{p}\right)=\sum_{i=1}^{n} \varepsilon_{i}^{2}=\sum_{i=1}^{n}\left(y_{i}-\beta_{0}-\beta_{1} x_{1 i}-\ldots-\beta_{p} x_{p i}\right)^{2}
$$

Derivando $S\left(\beta_{0}, \beta_{1}, \ldots, \beta_{p}\right)$ com relação à $\beta_{1}, \beta_{2}, \ldots, \beta_{p}$ e igualando a zero, obtêm-se equações normais, isto é,

$$
\left\{\begin{array}{l}
S_{11} \hat{\beta}_{1}+S_{12} \hat{\beta}_{2}+\ldots+S_{1 p} \hat{\beta}_{p}=S_{y 1} \\
S_{12} \hat{\beta}_{1}+S_{22} \hat{\beta}_{2}+\ldots+S_{2 p} \hat{\beta}_{p}=S_{y 2} \\
\vdots \\
S_{1 p} \hat{\beta}_{1}+S_{2 p} \hat{\beta}_{2}+\ldots+S_{p p} \hat{\beta}_{p}=S_{y p}
\end{array}\right.
$$

onde

$$
\begin{aligned}
& S_{i j}=\sum_{k=1}^{n}\left(x_{i k}-\bar{x}_{i}\right)\left(x_{j k}-\bar{x}_{j}\right) ; \mathrm{i}, \mathrm{j}=1,2, \ldots, \mathrm{p} \\
& S_{y i}=\sum_{k=1}^{n}\left(y_{k}-\bar{y}\right)\left(x_{i k}-\bar{x}_{i}\right) ; \mathrm{i}=1,2, \ldots, \mathrm{p} \\
& \bar{x}_{i}=\sum_{k=1}^{n} \frac{x_{i k}}{n} \text { e } \quad \bar{y}=\sum_{k=1}^{n} \frac{y_{k}}{n}
\end{aligned}
$$

Resolvendo o sistema dado na Eq. (3.19), os estimadores de mínimos quadrados $\beta_{0}, \hat{\beta}_{1}, \ldots, \hat{\beta}_{p}$ são encontrados e os valores $\hat{y}_{i}$ calculados pela Eq. (3.20).

$$
\hat{y}_{i}=\hat{\beta}_{0}+\hat{\beta}_{1} x_{1 i}+\hat{\beta}_{2} x_{2 i}+\ldots+\hat{\beta}_{p} x_{p i}
$$


Uma notação matricial pode ser usada para utilizar as vantagens da teoria de matrizes. Desta forma o modelo dado na Eq. (3.17), matricialmente, é dado pela Eq. (3.21).

$$
Y=X \beta+\varepsilon
$$

onde $Y=\left[\begin{array}{l}y_{1} \\ y_{2} \\ \vdots \\ y_{n}\end{array}\right] ; \quad X=\left[\begin{array}{llll}1 & x_{11} & \ldots & x_{p 1} \\ 1 & x_{12} & \ldots & x_{p 2} \\ \vdots & \vdots & \ddots & \vdots \\ 1 & x_{1 n} & \cdots & x_{p n}\end{array}\right] ; \quad \beta=\left[\begin{array}{l}\beta_{0} \\ \beta_{1} \\ \beta_{2} \\ \vdots \\ \beta_{p}\end{array}\right] ; \quad \varepsilon=\left[\begin{array}{l}\varepsilon_{1} \\ \varepsilon_{2} \\ \vdots \\ \varepsilon_{n}\end{array}\right]$

Para o modelo dado na Eq. (3.21) as estimativas dos parâmetros de acordo com o método de mínimos quadrados, os valores previstos e os resíduos podem ser determinadas pelas Eqs (3.22), (3.23) e (3.24), respectivamente.

$$
\begin{aligned}
& \hat{\beta}=\left(X^{T} X\right)^{-1} X^{T} Y \\
& \hat{Y}=X \hat{\beta} \\
& \hat{\varepsilon}=Y-\hat{Y}=Y-X \hat{\beta}
\end{aligned}
$$

onde $X^{T}$ é a matriz transposta de $X$ e $\left(X^{T} X\right)^{-1}$ indica a inversa do produto das matrizes $X^{T} X$. É requisito indispensável que a matriz $X^{T} X$ seja invertivel.

O coeficiente de correlação múltiplo é dado por:

$$
r^{2}=1-\frac{\sum\left(y_{i}-\hat{y}_{i}\right)^{2}}{\sum\left(y_{i}-\bar{y}\right)^{2}}
$$

Este coeficiente mede o grau de dependência entre as variáveis, Eq. (3.17), e assume algum valor entre zero e um. Se $r^{2} \approx 1$ pode-se dizer que o 
ajuste é bom, caso contrário, a adequabilidade do modelo pode estar comprometida.

\subsection{ERRO E INCERTEZA DE MEDIÇÃo}

Todo resultado de medição é apenas uma estimativa do valor verdadeiro. Isto devido à influência de diversos fatores que interferem no processo de medição, tais como: variações associadas ao instrumento de medição, ao operador, às condições ambientes, e outros.

A diferença entre o valor verdadeiro e o valor encontrado em uma medição é denominada erro de medição. Em muitos processos de medição o valor verdadeiro é desconhecido, assim sendo, o erro de medição é dado pela diferença entre o resultado da medição e o valor obtido através da calibração.

De acordo com seu comportamento os erros de medição podem ser classificados em sistemáticos e aleatórios. Quando nenhuma das causas que provocam os erros aleatórios é predominante, pode-se dizer que sua ocorrência e comportamento coincidem com a curva de probabilidade normal ou curva de distribuição de Gauss. Portanto, pode-se assumir que os erros aleatórios seguem a lei de distribuição normal.

Porém, nem todas as fontes de erros num processo de medição apresentam distribuições normais de probabilidade. São freqüentes, por exemplo, distribuições quadradas, trapezoidais e triangulares (Figura 3.8).

Os efeitos sistemáticos, por sua vez, podem ser corrigidos sem grandes dificuldades, no entanto, após a correção permanecerá, ainda, uma dúvida sobre o quão correto é o valor obtido em uma medição. Somando a esta dúvida aquela proveniente dos efeitos aleatórios, obtémse o que convencionou-se chamar de incerteza de medição (ISO, 1993; INMETRO, 1998).

$\mathrm{Na}$ atualidade não é suficiente expressar o valor numérico dos erros medidos, surgindo assim, a necessidade de indicar quantitativamente a qualidade do resultado de uma medição, ou seja, 
acrescentar ao resultado da medição uma declaração sobre a confiança associada a ele. Isto é a incerteza de medição.

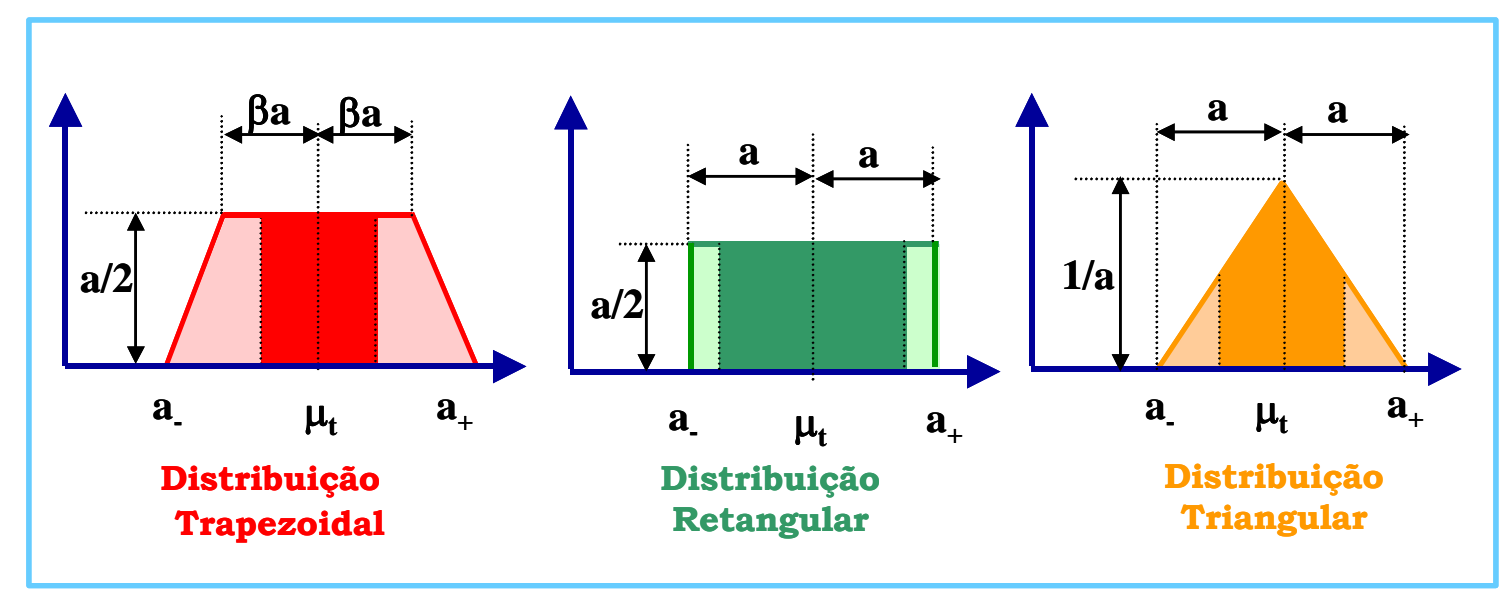

Figura 3.8 - Distribuições de Probabilidade (ISO, 1993).

Segundo o documento ISO (Guide to the expression of uncertainty in measurement), cuja versão brasileira "Guia para expressão da incerteza de medição" publicada em 1997, a incerteza de medição pode ser definida como sendo o parâmetro, associado ao resultado de uma medição, que caracteriza a dispersão dos valores que poderiam ser razoavelmente atribuídos à grandeza. Tal parâmetro pode ser o desvio padrão ou múltiplo dele ou a metade de um intervalo correspondente a um dado nível de abrangência.

A incerteza de medição é expressa, geralmente, como uma faixa de valores distribuídos simetricamente em torno do valor obtido como resultado de uma medição (PHILLIPS, 1995). Na incerteza de medição estão contidos os efeitos de todos os fatores que influenciam o resultado da medição. A incerteza associada a um resultado pode ser classificada em incerteza padrão, incerteza padrão combinada e incerteza expandida. 


\subsubsection{Incerteza Padrão}

Toda medição é um conjunto de operações que têm por objetivo determinar o valor de uma grandeza. Esta grandeza, geralmente, pode ser medida diretamente ou, ainda, determinada a partir de $N$ outras grandezas $\left(X_{1}, X_{2}, \ldots, X_{N}\right)$, denominadas grandezas de entrada, através de uma relação funcional $f$, como mostra a Eq. (3.26).

$$
Y=f\left(X_{1}, X_{2}, \cdots, X_{N}\right)
$$

As grandezas de entrada, por sua vez, podem também ser consideradas mensurandos que dependem de outras grandezas. Seus valores e respectivas incertezas podem ser obtidos a partir de uma única observação ou de repetidas observações, de dados fornecidos pelos fabricantes dos instrumentos, da experiência do observador, da literatura, de medições realizadas anteriormente, de padrões de calibração, de materiais de referência ou de certificados de calibração, etc.

Assim sendo, a incerteza associada ao resultado da medição deve levar em consideração as incertezas individuais das variáveis que afetam o processo de medição.

De acordo com o método usado para avaliação do valor numérico das incertezas, estas podem ser classificadas em: avaliação tipo A e avaliação tipo B.

A avaliação tipo A é obtida estatisticamente a partir de medições ou observações repetidas de uma dada grandeza, assumindo uma distribuição normal ou outra qualquer. Neste caso, a média dos valores obtidos em um dado experimento é a estimativa do mensurando, enquanto que a raiz quadrada da variância é a incerteza padrão associada ao estimador. A incerteza padrão considera as flutuações aleatórias dos resultados do experimento e outras influências que são consideradas constantes para este experimento (BS 6808: Code of Practice, 1989). A representação das componentes de incertezas, segundo a proposta do Comitê Internacional de Pesos e Medidas (CIPM), é feita pela estimativa de 
um desvio padrão, denotada por $u$, chamada incerteza padrão. No caso de incertezas tipo A, quando o conjunto de $N$ medições $x_{i}(i=1, \ldots, N)$ representa uma amostra, a incerteza padrão é calculada pela expressão (3.13), onde a estimativa do mensurando é $\bar{x}=\frac{x_{1}+x_{2}+\cdots x_{n}}{n}$.

A incerteza do tipo B é estimada a partir de um julgamento científico baseado em todas as informações relevantes disponiveis sobre o instrumento e o processo de medição. (ISO, 1993; DECKER e PEKELSKY, 1999).

Quando a estimativa de uma grandeza for obtida de uma especificação do fabricante, certificado de calibração, manual técnico ou de outra fonte e a incerteza dada como um múltiplo do desvio padrão, então, a incerteza padrão é a incerteza citada dividida pelo multiplicador (ISO, 1993; NIST Technical Note 1297, 1994). Por outro lado, se a incerteza declarada é um parâmetro ao qual está associado um dado nível de confiança, o cálculo da incerteza padrão só será efetuado se a distribuição de probabilidade caracterizada pela estimativa do mensurando e sua incerteza forem conhecidas. Neste caso, a incerteza padrão é a incerteza citada dividida pelo fator de abrangência apropriado para a distribuição adotada. Tal fator é encontrado nas tabelas de distribuições de probabilidades (DRAPER e SMITH, 1966).

Em geral, de posse de todas as informações disponíveis sobre o instrumento e a medição, é possivel determinar o intervalo que contém o valor verdadeiro da grandeza analisada e fazer alguma hipótese sobre a distribuição de erros. Quando, porém, o intervalo é bem definido, mas a distribuição de erros não é bem conhecida, devem-se admitir outras distribuições tais como a retangular, a trapezoidal ou a triangular (ISO, 1993).

A distribuição retangular é utilizada quando é possivel estimar apenas os limites superior e inferior para $X_{i}$ e estabelecer que a probabilidade de que o valor $X_{i}$ pertença ao intervalo $\left(a_{-}, a_{+}\right)$é um e a probabilidade para que o valor de $X_{i}$ esteja fora desse intervalo é zero. Se 
não houver conhecimento específico de possiveis valores de $X_{i}$ dentro do intervalo, pode-se assumir que é igualmente provável que $X_{i}$ esteja em qualquer ponto do intervalo, e conseqüentemente o seu grau de liberdade é infinito (LINK, 1997).

A variância para uma distribuição quadrada é dada pela Eq. (3.27).

$$
s^{2}\left(X_{i}\right)=\left(a_{+}-a_{-}\right)^{2} / 12
$$

Se a diferença entre os limites, $a_{+}-a_{-}$é designada por $2 \mathrm{a}$, então a Eq. Eq. (3.27) anterior torna-se a Eq. (3.28).

$$
s^{2}\left(X_{i}\right)=a^{2} / 3
$$

Distribuição trapezoidal: Em muitos casos é mais razoável considerar que os valores junto aos limites do intervalo são menos prováveis de ocorrerem que os valores próximos do centro. Nestes casos assume-se uma distribuição trapezoidal simétrica.

A base maior do trapézio é igual a $2 a$ e a base menor $2 \beta a$ com $0 \leq \beta \leq 1$. Se $\beta \rightarrow 1$, a distribuição trapezoidal se aproxima da distribuição retangular, enquanto que para $\beta=0$ tem-se a distribuição triangular.

Assumindo que $X_{i}$ apresenta uma distribuição trapezoidal a variância associada é dada pela Eq. (3.29).

$$
s^{2}\left(X_{i}\right)=a^{2}\left(1+\beta^{2}\right) / 6
$$

Distribuição triangular: quando $\beta=0$, a partir da Eq. (3.29) tem-se que a variância associada à $X_{i}$ é dada pela Eq. (3.30).

$$
s^{2}\left(X_{i}\right)=a^{2} / 6
$$




\subsubsection{Incerteza Padrão Combinada}

A incerteza padrão combinada pode ser calculada a partir das incertezas padrão individuais das variáveis que interferem no processo de medição, através de uma lei conhecida como "lei de propagação de incertezas". A incerteza, assim determinada, é definida pelo Comitê Internacional de Pesos e Medidas (CIPM) como incerteza padrão combinada e é designada por $u_{c}$. A lei de propagação de incertezas, porém, somente pode ser aplicada quando o modelo matemático que relaciona a variável resposta da medição com as variáveis que afetam o seu comportamento for conhecido. Isto é, quando a função $f$ da equação (3.26) for conhecida. Neste caso, a incerteza padronizada combinada, $u_{c}(y)$, é dada pela raiz quadrada positiva da Eq. (3.31).

$$
u_{c}^{2}(y)=\sum_{i=l}^{N}\left(\frac{\partial f}{\partial x_{i}}\right)^{2} u^{2}\left(x_{i}\right)+2 \sum_{i=l}^{N-1} \sum_{j=i+l}^{N} \frac{\partial f}{\partial x_{i}} \frac{\partial f}{\partial x_{j}} u\left(x_{i}\right) \cdot u\left(x_{j}\right) \cdot r\left(x_{i}, x_{j}\right)
$$

onde $y$ a estimativa da grandeza $Y, x_{i}$ a estimativa da variável $X_{i}, u^{2}\left(x_{i}\right)$ a variância associada a $x_{i}$, para todo $i$ variando de 1 até $N$, onde $N$ é o número de variáveis que afetam a variável resposta $Y, u\left(x_{i}\right)$ é a incerteza associada à fonte de erro representada pela estimativa $x_{i}$ e $r\left(x_{i}, x_{j}\right)$ é o coeficiente de correlação entre as estimativas $x_{i}$ e $x_{j}$,

A Equação (3.31), referenciada como a lei de propagação de incerteza, é baseada numa aproximação da série de Taylor de primeira ordem de $Y=f\left(x_{1}, x_{2}, \cdots x_{N}\right)$.

As derivadas parciais em função de cada variável $x_{i}(i=1, \ldots, n)$ que aparecem na Eq. (3.31) são denominadas coeficientes de sensibilidade. A grandeza desses coeficientes descreve a contribuição de cada fonte de incerteza no valor final da incerteza de medição. 
O segundo termo da Eq. (3.31) expressa a correlação existente entre duas fontes de incertezas $x_{i}, x_{j}(i \neq j)$. O coeficiente $r$ fornece uma medida do grau de correlação entre as variáveis.

A Equação (3.32) apresenta o coeficiente de correlação entre duas variáveis $x_{i}$ e $x_{j}$.

$$
r\left(x_{i}, x_{j}\right)=\frac{\sum_{k=1}^{M}\left(x_{i k}-\bar{x}_{i}\right) \cdot\left(x_{j k}-\bar{x}_{j}\right)}{\sqrt{\sum_{k=1}^{M}\left(x_{i k}-\bar{x}_{i}\right)^{2} \cdot \sum_{k=1}^{M}\left(x_{j k}-\bar{x}_{j}\right)^{2}}}
$$

onde $M$ é o número de valores atribuídos às variáveis $x_{i}$ e $x_{j}$ e $\bar{x}_{i}$ e $\bar{x}_{j}$ são respectivamente as médias aritméticas dos $M$ valores atribuídos à $x_{i}$ e $x_{j}$.

O coeficiente de correlação varia de -1 a 1 . Quando esse valor se aproxima dos extremos significa que as variáveis $x_{i}$ e $x_{j}$ são altamente correlacionadas. Por outro lado, se o coeficiente de correlação é zero significa que não há correlação entre as variáveis. Portanto, se as estimativas $x_{i}, x_{j}$ são independentes entre si, o coeficiente de correlação é igual a zero e o segundo termo da Eq. (3.31) desaparece, diminuindo, assim, o número de cálculos necessários para determinar a incerteza padrão combinada.

\subsubsection{Incerteza Expandida}

Além da incerteza padrão combinada, o Comitê Internacional de Pesos e Medidas propõe descrever a incerteza de medição através de intervalos que representam os valores esperados para os erros de medição, com uma probabilidade conhecida. O CIPM usa o termo incerteza expandida $\left(U_{p}\right)$ para descrever tal intervalo. Seu valor é obtido pela Eq. (3.33), onde $u_{c}$ é a incerteza padrão combinada e $k>0$ é o fator de abrangência.

$$
U_{p}=k \cdot u_{c}
$$


O fator $k$ está associado à distribuição de probabilidades dos valores obtidos na medição, que geralmente apresentam uma distribuição Normal. Para esta distribuição, assume-se $k$ igual a 2,00 para um intervalo de confiança de $95,5 \%$ (ou $95 \%$ ) e 3 para um intervalo com 99,7\% de probabilidade.

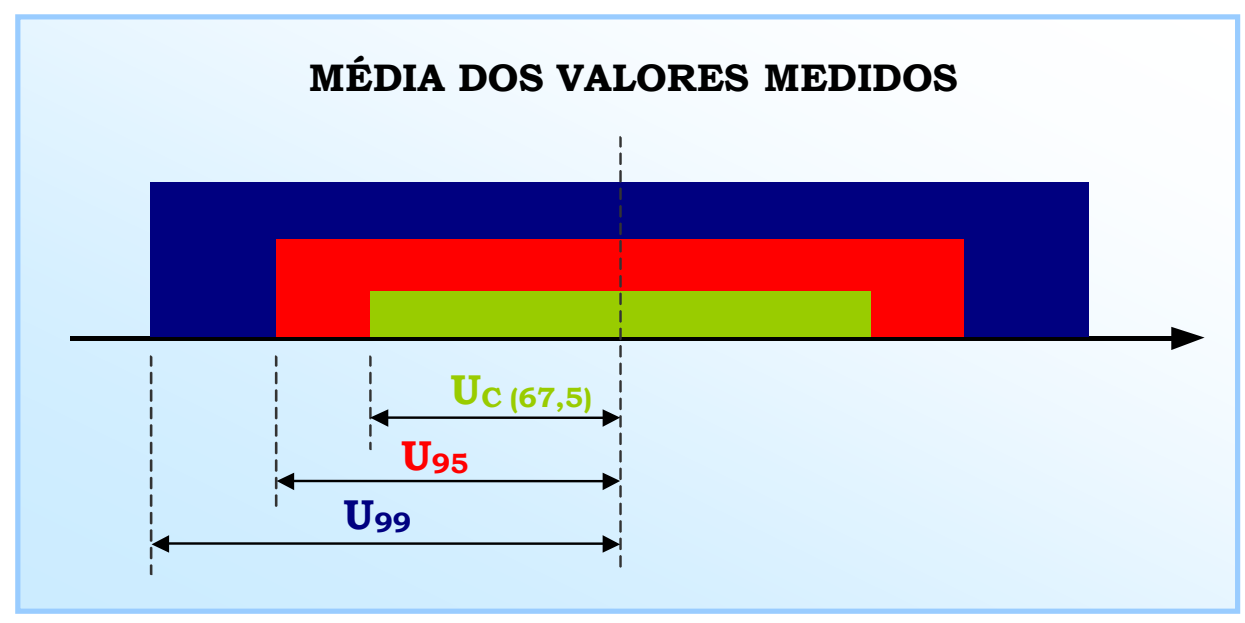

Figura 3.9 - Representação da Incerteza padronizada combinada $\left(u_{c}\right)$ e da incerteza expandida com 95\% (U $\left.\mathrm{U}_{95}\right)$ e 99\% (U $\left.\mathrm{U}_{99}\right)$ de confiança.

A incerteza expandida é uma maneira de apresentar a informação para satisfazer requisitos de algumas aplicações comerciais e industriais, que necessitam de um intervalo de valores em torno do resultado de medição (ISO, 1993; INMETRO, 1997). Ela pode ser apresentada junto com o valor médio das medidas, $\bar{y}$, pela Eq. (3.34).

$$
\bar{y} \pm U_{p}
$$

\subsubsection{Incerteza Tridimensional}

A avaliação do desempenho de instrumentos de medição tais como Máquinas de Medir a Três Coordenadas através da incerteza de medição é uma tarefa um tanto dificil. Dentre as fontes de incerteza presentes nestas máquinas podem-se citar (MARTINEZ ORREGO, 1997): 
> imperfeições geométricas resultantes da manufatura dos componentes mecânicos, deformações elásticas, efeitos dinâmicos nos elementos da máquina que definem sua estrutura;

$>$ imperfeições do sistema de medição (sonda) encarregado de tomar os pontos coordenados sobre a superfície da peça medida, velocidade e força com que se faz a medição;

$>$ distorções mecânicas da estrutura da máquina produto de mudanças e gradientes de temperatura;

$>$ incertezas associadas com a quantidade e a dispersão dos pontos coordenados escolhidos para determinar a geometria da peça;

> incertezas associadas ao algoritmo matemático que determina a superficie de ajuste e com a sua implementação computacional;

$>$ acabamento da peça a ser medida (erros de forma, rugosidade, etc).

Durante um processo de medição a três coordenadas as características geométricas e dimensionais são determinadas a partir das coordenadas $\left(X_{i}, Y_{i}, Z_{i}\right)$ dos pontos dispersos sobre a superficie da peça. Para tanto são utilizados os programas computacionais incorporados à máquina. Assim sendo, a incerteza de medição a três coordenadas é estabelecida a partir das incertezas associadas aos pontos espaciais que definem a característica dimensional inspecionada. Tal incerteza é denominada tridimensional ou volumétrica.

A incerteza de cada um desses pontos espaciais, por sua vez, está relacionada com uma região no espaço cuja forma e tamanho são definidos pela combinação das incertezas unidimensionais de cada coordenada.

A incerteza tridimensional somente pode ser determinada se todos os detalhes de medição forem especificados, tais como: posição e orientação da peça inspecionada dentro do volume de trabalho da máquina, a quantidade de pontos levantados sobre a superfície da peça, o método de ajuste para definir a geometria medida, o programa computacional utilizado, etc. Não existe, ainda, uma expressão geral que 
descreva a incerteza tridimensional associada a todos os tipos de medições que uma MM3C pode realizar.

Várias metodologias foram desenvolvidas para quantificar a incerteza tridimensional. Mas, nenhuma delas mostra, de forma explícita, o cálculo da incerteza de medição das diferentes inspeções realizadas em uma MM3C. Os métodos para estimar a incerteza podem ser classificados em: Método de Avaliação de Desempenho, Método da Comparação, Método da Modelagem Matemática.

\section{Método de Avaliação de Desempenho}

Os testes de avaliação de desempenho são realizados para avaliar o comportamento metrológico do instrumento de medição durante o seu funcionamento. Existem algumas normas técnicas que descrevem procedimentos para avaliar o desempenho de MM3Cs e oferecem informações para estimar a incerteza de medição, dentre elas: ASME B89, VDI/VDE 2617, CMMA, BS 6808, JIS B7440 e a ISO 10360.

Os testes especificados nas normas propõem a medição de diferentes artefatos para avaliar a capacidade das máquinas (KUNZMANN, et al., 1993). Normalmente, tais artefatos são medidos pela máquina em diferentes posições e orientações dentro do seu volume de trabalho. Os resultados dessas medições são analisados estatisticamente.

Segundo ABACKERLI e MIGUEL (1997), dentre as normas existentes sobre testes de desempenho as normas ISO 10360 são as únicas aceitas como estado da arte em avaliação de MM3Cs estabelecendo bases para a rastreabilidade das medições testadas. Entretanto tais normas apresentam limitações na análise do volume de trabalho em função das condições experimentais sugeridas para os testes. Segundo os autores os testes propostos são necessários, mas não suficientes para a rastreabilidade completa das MM3Cs.

\section{Método da Comparação}

O método da comparação envolve a utilização de um artefato padrão calibrado idêntico quanto a forma, material e dimensão à peça a 
ser inspecionada pelo instrumento de medição (MM3C). O procedimento de medição de ambos, padrão e peça, deve ser o mesmo, ou seja: mesma localização no volume de trabalho, mesma sonda de medição, mesma estratégia de medição (mesmo número de pontos, mesma dispersão dos pontos sobre a superficie da peça), mesmos programas computacionais para calcular e definir a característica inspecionada. É aconselhável efetuar repetidas medições, variando-se todos os fatores que podem acarretar variações na peça. A máquina, então, compara os resultados obtidos durante a medição da peça e do artefato padrão, usado como referência.

Neste método, a incerteza de medição é determinada pelo desvio padrão dos resultados.

Apesar do método da comparação ser uma técnica poderosa para obter a incerteza de medição, ela restringe uma característica fundamental das MM3Cs que é sua flexibilidade, na medida em que ela avalia os resultados de uma tarefa específica. É impossível, na prática, dispor de artefatos padrões idênticos à grande diversidade de peças que podem ser inspecionadas por uma MM3C. Além disso, é difícil efetuar as medições do padrão e peça na mesma posição e orientação espacial e nem sempre se dispõe de recursos financeiros para realizar o número de medições necessárias a fim de se obter uma boa estimativa para o desvio padrão.

\section{Método da modelagem matemática}

Esta abordagem visa determinar a incerteza através de um equacionamento que descreva a relação entre a variável resposta do instrumento de inspeção e as variáveis envolvidas na medição que afetam o valor do mensurando. Um método descrito na literatura, que emprega a modelagem matemática, é o da Máquina Virtual de Medir a Três Coordenadas (MVM3Cs). Esse método simula o comportamento metrológico da MM3C em diferentes operações de medição, a partir do conhecimento dos seus erros volumétricos (KUNZMANN, 1993; CARDOZA, 
1995; MARTINEZ ORREGO, 1999). A incerteza de medição é determinada através da simulação computacional (PHILLIPS, 1995).

A maior vantagem das MVM3Cs frente ao método do comparador é preservar a flexibilidade na utilização da MM3C, entretanto a sua utilização está restrita a laboratórios sendo pouco utilizada para aplicações no meio produtivo.

Segundo CARDOZA (1995), uma Máquina Virtual de Medir a Três Coordenadas é um sistema numérico que simula através de um modelo matemático as operações de medição de uma MM3C. Através desse modelo as diferentes fontes de incerteza são combinadas e seus efeitos propagados. A partir do conhecimento do erro é possível simular uma geometria ideal (sem erro) da característica medida da peça. A geometria simulada funciona como um artefato padrão e o erro de medição seria dado pela diferença entre a geometria calculada pela MM3C e a geometria simulada pela MVM3C.

Para se chegar à declaração da incerteza de uma medição, utilizando a modelagem matemática, é necessário conhecer detalhes relativos à inspeção, ou seja, (VIEIRA SATO, 2001):

$>$ identificar todas as fontes de incerteza, isto é, todas as variáveis envolvidas na medição que afetam o valor do mensurando.

$>$ construir um modelo matemático que gera o mapa de erros da máquina, ou seja, determinar a relação entrada-saída do sistema. Normalmente, as coordenadas dos pontos pertencentes ao volume de trabalho da máquina são consideradas variáveis de entrada e as componentes do erro volumétrico as saídas;

$>$ determinar a incerteza de cada ponto coordenado medido sobre a superficie analisada. A incerteza de cada um desses pontos é o resultado da combinação das incertezas dos pontos observados na calibração e das incertezas associadas a outras variáveis de entrada, propagadas através das equações que descrevem o erro volumétrico. Desta forma, tem-se a nuvem de 
incerteza de cada ponto medido pela máquina sobre a superficie da peça inspecionada;

$>$ utilizar um método matemático (mínimos quadrados, mínima zona, ou outro) para ajustar a geometria ao conjunto de pontos medidos sobre a superficie da peça;

$>$ determinar as incertezas associadas aos estimadores do método de ajuste. Tais incertezas são a combinação das incertezas dos pontos utilizados pelo método de ajuste, propagadas através das expressões dos estimadores;

$>$ determinar a incerteza padrão combinada da característica requerida.

Uma das desvantagens das MVM3Cs é a necessidade da reavaliação dos erros periodicamente, pois estes mudam com as condições e a idade da máquina. Entretanto, pode-se dizer que as Máquinas Virtuais de Medir a Três Coordenadas é o único método que satisfaz os requisitos necessários para a rastreabilidade (KUNZMANN et al., 1994). 


\section{CAPÍtULO 4}

\section{EQUACIONAMENTO DOS \\ ERROS TERMICAMENTE INDUZIDOS EM MM3CS}

Neste trabalho é apresentada uma formulação matemática para o equacionamento das componentes do erro volumétrico em Máquinas de Medir a Três Coordenadas, considerando as influências térmicas. Esta nova formulação considera a superposição dos efeitos que acontecem durante o aquecimento e esfriamento da máquina e permite prever o comportamento da MM3C para qualquer estado de temperatura.

Utilizando um modelo de sintetização de erros, obtido através da aplicação das transformações homogêneas, cada componente do erro volumétrico pode ser descrita como sendo a somatória de diferentes parcelas que estão estreitamente relacionadas aos erros geométricos da máquina e aos braços de Abbé correspondentes. Os erros geométricos foram descritos em função da posição e da temperatura, enquanto, os não paramétricos foram descritos em função apenas da temperatura. $O$ modelo proposto está baseado na facilidade de aplicação e adaptação das transformações homogêneas a qualquer tipo de Máquina de Medir e 
também na elevada capacidade de diagnóstico do método de sintetização de erros.

A formulação proposta requer a medição de cada erro geométrico de forma individual, considerando-se as influências térmicas, uma vez que as variações de temperatura podem provocar mudanças na geometria da máquina e de seus elementos. Assim sendo, a coleta dos dados deve ser feita para estados térmicos similares àqueles que acontecem no chão de fábrica. Isto é, para estados térmicos transientes e estacionários, de forma que seja possivel determinar o erro volumétrico para qualquer posição e para qualquer estado de temperatura.

O método foi aplicado a uma Máquina de Medir a Três Coordenadas do tipo Ponte Móvel. Para verificar a adequabilidade do mesmo foi realizada uma comparação entre os valores dos erros obtidos através das equações de sintetização e aqueles obtidos na medição de um anel padrão. Também foram determinadas as incertezas associadas às componentes do erro volumétrico.

Para um melhor entendimento do desenvolvimento desta tese, a mesma foi dividida em cinco etapas, descritas a seguir. Estudo do sistema de medição; desenvolvimento do modelo da máquina; calibração da máquina; obtenção e avaliação do modelo proposto e determinação da incerteza de medição.

\subsection{Estudo do Sistema de Medição.}

Foi efetuado um estudo minucioso da Máquina de Medir a fim de identificar os componentes do sistema de medição; identificar os materiais que compõem a máquina e estudar suas características; determinar os pontos quentes da estrutura da máquina para detectar possiveis fontes localizadas de calor e otimizar a localização física dos termopares que estão encarregados de monitorar as temperaturas; levantar a distribuição da temperatura na estrutura da máquina e a existência de gradientes térmicos espaciais. 


\subsection{Desenvolvimento do Modelo da Máquina.}

A descrição do par geometria e deformação termicamente induzida pode ser entendida como variáveis independentes e, portanto, pode ser realizada através de um modelo matemático que leva em consideração a superposição dos efeitos. Para um melhor entendimento da estratégia de modelagem os efeitos do par foram separados em efeitos dos erros geométricos e das variações termicamente induzidas destes erros.

\section{Efeito geométrico sobre as componentes do erro volumétrico}

Utilizando a técnica das transformações homogêneas e considerando a suposição do corpo rígido foi desenvolvido um modelo matemático. Este modelo combina de forma complexa a contribuição dos erros individuais em cada uma das direções preferenciais da máquina, fornecendo uma expressão para cálculo do erro volumétrico.

Para obter as expressões das componentes do erro volumétrico foi necessário efetuar uma análise preliminar da estrutura da máquina. Esta análise deve ser realizada para determinar os pontos onde os sistemas de coordenadas de referência e intermediários devem ser colocados.

Definida a localização dos sistemas de coordenadas, determinouse, a partir de um sistema de referência, dois caminhos de modelagem: caminho da peça e caminho da sonda. Matrizes de transformação homogênea foram então escritas para descrever os erros e os movimentos de um sistema com relação a outro. Através da multiplicação adequada destas matrizes, foi possivel determinar as matrizes de erros para os dois caminhos de modelagem descritos.

Considerando o contato sonda-peça puntiforme e realizando as operações matemáticas pertinentes, obtiveram-se dois vetores, um representando o caminho da peça e o outro o caminho da sonda. As componentes do erro volumétrico foram então calculadas através da diferença entre estes dois vetores. 


\section{Efeito térmico sobre as componentes do erro volumétrico}

O maior desafio encontrado no estudo e modelagem do comportamento térmico das Máquinas de Medir é a previsão dos erros geométricos durante os transientes de temperatura. Isto é, o equacionamento da variação dos erros geométricos para estados térmicos transientes.

Se durante a realização de um determinado processo (medição ou calibração) acontecerem variações de temperatura ambiente, então, o efeito das influências térmicas se torna mais complexo. A modelagem do comportamento térmico das Máquinas de Medir nestas condições constitui um grande desafio.

Neste trabalho, o equacionamento da variação do erro geométrico devido às mudanças de temperatura $\left(\operatorname{Verro}_{i}(T)\right)$, foi efetuado utilizando-se de técnicas de regressão linear múltipla, Eq. (4.1).

$$
\operatorname{Verro}_{i}(T) \cong \alpha_{0}+\alpha_{1} T_{1}+\alpha_{2} T_{2}+\ldots+\alpha_{j} T_{j}
$$

Assim sendo, para cada erro foram obtidas quatro equações, uma para cada conjunto de dados levantado nos quatro pontos de observação do drift térmico. Em seguida superpõem-se os efeitos das variáveis $p$ e $T$ para determinação da variação do erro em qualquer posição e qualquer estado de temperatura ( $\left.\operatorname{verro}_{i}(p, T)\right)$, Eq. (4.2).

$$
\operatorname{verro}_{i}(p, T)=\beta_{O}(T)+\beta_{1}(T) \cdot p_{i}+\beta_{2}(T) \cdot p_{i}^{2}+\ldots+\beta_{n}(T) \cdot p_{i}^{n}
$$

Estabelecendo uma igualdade entre as equações dadas na Eq. (4.2) e os vetores erro da Eq. (4.1) e aplicando o método dos mínimos quadrados é possivel estimar os coeficientes $\beta_{n}$.

\section{Superposição dos efeitos}

A superposição dos efeitos foi feita a partir dos erros geométricos. Cada erro foi escrito como sendo a soma de duas parcelas. A primeira 
parcela representa o erro geométrico para $20{ }^{\circ} \mathrm{C}$ e depende apenas da posição do carro de movimentação correspondente. A segunda parcela representa a variação termicamente induzida destes erros e foi descrita em função da posição e da temperatura. Desta forma, matematicamente o erro geométrico foi expresso por meio da Eq. (4.3).

$$
\operatorname{Erro}_{i}=\operatorname{Erro}_{i}(p)+\operatorname{verro}_{i}(p, T)
$$

onde $\operatorname{Erro}_{i}$ é o erro geométrico-térmico, $\operatorname{Erro}_{i}(p)$ é o erro geométrico (20 ${ }^{\circ} \mathrm{C}$ ) e $\operatorname{verro}_{i}(p, T)$ é a variação do erro geométrico em função de $p$ (posição de medição) e $T$ (vetor variação de temperatura).

A medição do erro geométrico é feita em posições discretas, assim sendo, para as infinitas posições existentes entre duas posições de medição o erro geométrico é desconhecido. Nesses casos, assume-se que a variação do erro se dá de forma lenta e progressiva ou regressiva sendo possivel atribuir um caráter linear à mesma. Desta forma, entre duas posições de medição, muito próximas, a melhor interpolação é a linear. A variação do erro, por sua vez, foi equacionada utilizando-se de técnicas de regressão e do método dos mínimos quadrados. A escolha de tal formulação está justificada pela facilidade de aplicação do método dos mínimos quadrados.

\subsection{Calibração da máquina.}

Uma vez proposto o modelo foi selecionado o procedimento experimental para obtenção dos dados. O modelo de sintetização requer o levantamento de todos os erros geométricos presentes nas equações das componentes do erro volumétrico. Este levantamento deve fornecer também informações sobre o comportamento térmico da máquina. Para tanto foi necessário o desenvolvimento de um sistema de aquisição de dados automatizado, possibilitando experimentos de longa duração e o mais independente possivel da influência do elemento humano. Para esta 
automatização, utilizou-se um microcomputador e programas computacionais especificamente desenvolvidos para controlar e sequenciar as tarefas a serem executadas pelos sistemas de medição de temperatura e do erro geométrico.

Os dados referentes aos erros geométricos de posição, de retitude e dos erros angulares pitch e yaw de todos os eixos foram obtidos através do uso do interferômetro laser Hewlett Packard, modelo HP5528A. Na determinação dos erros de perpendicularidade foi utilizado um esquadro mecânico e um apalpador LVDT. Enquanto que na determinação do erro roll em $X$ e $Y$ foi utilizado o nível eletrônico da Rank Taylor-Hobson, modelo Talyvel 3.

Dois conjuntos de dados foram obtidos para cada erro geométrico. Um contendo informações do erro a $20^{\circ} \mathrm{C}$ e outro contendo informações sobre a variação do erro e a variação das temperaturas em quatro pontos.

\subsection{Avaliação do Modelo Proposto.}

Os dados resultantes da calibração foram utilizados para gerar as expressões dos erros individuais e, posteriormente, as equações de sintetização.

A eficiência do modelo na previsão do erro volumétrico foi verificada através da comparação entre os valores obtidos utilizando-se da formulação proposta e aqueles encontrados durante a medição de um artefato padrão, especificamente, um círculo. Este artefato foi medido em diferentes posições no volume de trabalho da máquina e para diferentes temperaturas.

\subsection{DeterminaçÃo da InCERTEZA ASSOCIAda Às Componentes do ERRO VOLUMÉTRICO}

Após a validação do modelo proposto, procedeu-se, finalmente, à determinação das incertezas associadas às componentes do erro 
volumétrico para cada ponto coordenado. Para tanto, utilizou-se o procedimento proposto pelo Guia para Expressão das Incertezas de Medição (ISO, 1993), que recomenda a aplicação da lei de propagação de incertezas.

Tal procedimento exigiu a identificação e observação de todas as grandezas que interferiram nos resultados obtidos, tais como resolução da MM3C e dos instrumentos utilizados durante a calibração, variação da temperatura, coeficiente de expansão térmica da escala da máquina, entre outros. A seguir procede-se à determinação da incerteza padrão de todas as grandezas e a avaliação segundo seus tipos A ou B. Por fim, aplicação da lei de propagação de incertezas para calcular a incerteza associada às componentes do erro volumétrico, a partir das incertezas individuais. 


\section{Capítulo 5}

\section{Desenvolvimento da Metodologia Proposta PARA EQUaCIONAMENTO dOS ERROS TERMICAMENTE INDUZIDOS NA MM3C}

Neste capítulo é apresentada, de forma detalhada, a metodologia proposta para o equacionamento matemático das componentes do erro volumétrico, considerando as variações de temperatura.

$\mathrm{Na}$ procura de uma melhor compreensão, o conteúdo do mesmo foi dividido em cinco itens, conforme proposto no capítulo quatro. Cada um destes itens está descrito de forma detalhada a seguir.

\subsection{Estudo do Sistema de Medição e Identificação dos Pontos QUENTES DA ESTRUTURA}

Todos os experimentos necessários para o levantamento dos erros e das temperaturas foram conduzidos em uma Máquina de Medir a Três Coordenadas do tipo Ponte Móvel, fabricada pela Brown \& Sharpe Mfg. Co. modelo Micro Validator.

A estrutura desta máquina é feita em alumínio fundido, em forma de ponte que se movimenta relativamente a um desempeno de granito, 
sobre o qual são posicionadas e fixadas as peças objeto de medição, através de dispositivos e parafusos. O desempeno está montado sobre esferas em blocos em $V$ na estrutura fixa da máquina. São partes integrantes, ainda, três conjuntos de mancais aerostáticos que permitem o movimento dos eixos $X, Y$ e $Z$ sobre as guias. Estes mancais necessitam de ar comprimido, seco e limpo para criar o colchão de ar que sustenta a parte móvel da estrutura.

As guias e as colunas da máquina são de alumínio e ocas, com paredes finas. Este material absorve e/ou libera calor muito rapidamente, precisando de um intervalo de tempo pequeno para atingir o equilíbrio térmico. Cada eixo coordenado consta de duas escalas de vidro, uma fixa e outra móvel. A escala fixa está colada à guia.

A máquina avaliada é fabricada dos mais diversos materiais, com as mais diversas características. Dentre eles o alumínio e o aço que apresentam coeficientes de dilatação térmica elevados e o vidro e o granito cujos coeficientes de dilatação térmica são relativamente baixos. Desta forma, quando a máquina é submetida a variações de temperatura seus componentes dilatam-se ou contraem-se diferentemente provocando estados complexos de deformação. Assim sendo, a posição da sonda fica comprometida introduzindo erros térmicos nas medições.

\subsubsection{Identificação dos pontos quentes da estrutura da máquina}

Para a identificação dos pontos quentes da estrutura da máquina foi utilizada uma câmera de visão infravermelha do tipo AGA Thermovisión 720. O princípio de funcionamento desta câmera é similar à visão humana. Através da mesma é possivel decodificar informações de radiação do mundo exterior, permitindo entre outras coisas identificar objetos e perceber diferença de temperaturas. Desta forma, é objetivo do sistema interpretar uma imagem, isto é, descrever o mundo real de forma simbólica e posteriormente interpretá-lo.

A Figura 5.1 mostra o arranjo experimental utilizado para identificação dos pontos quentes da estrutura da Máquina de Medir. 
Foram desenvolvidos dois grupos de testes, o primeiro, em uma cena com temperatura próxima de $25^{\circ} \mathrm{C}$ e o segundo a $20{ }^{\circ} \mathrm{C}$. Para ambos os testes foram observadas e analisadas as seguintes fontes: estrutura da máquina, computador, operador, cabos de alimentação do processador de sinais da máquina, peças e mangueiras de alimentação de ar. Os resultados obtidos, nesta etapa, são apresentados no Capítulo 6.

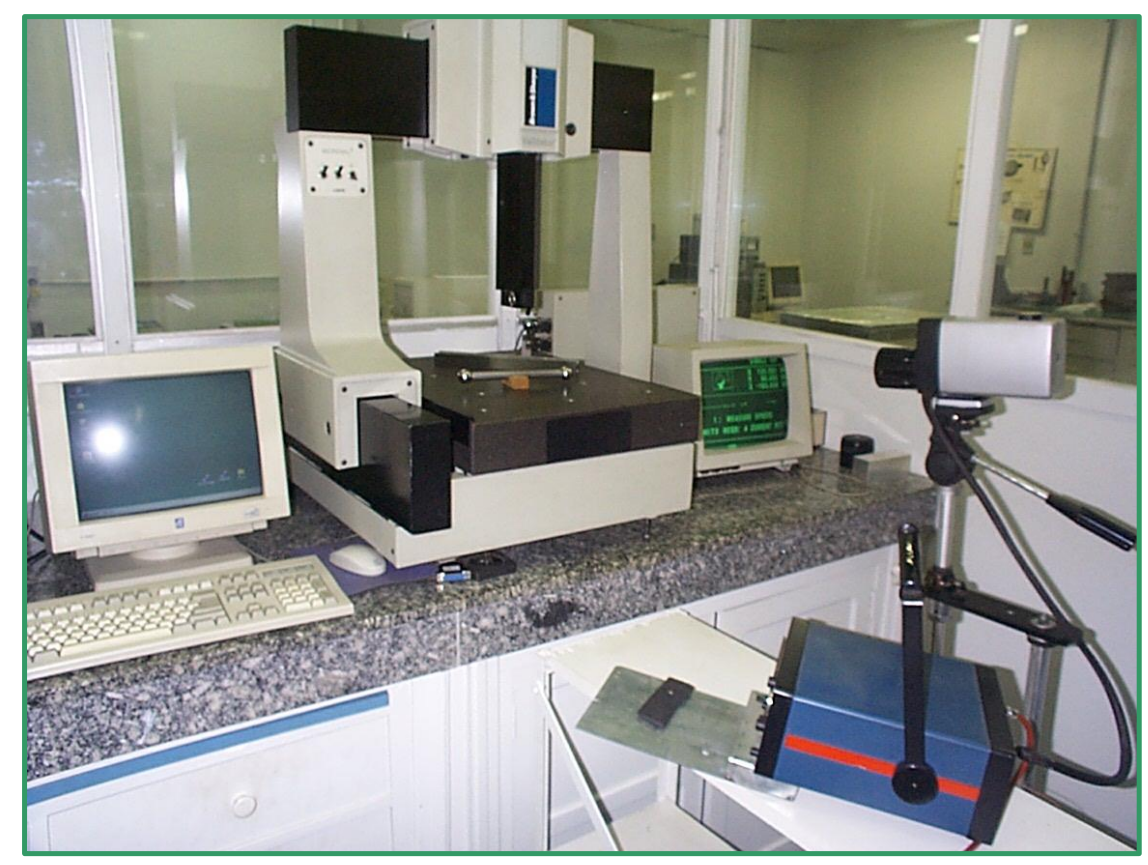

Figura 5.1 - Arranjo experimental para identificação dos pontos quentes.

\subsection{Desenvolvimento do Modelo Geométrico-Térmico dA MM3C}

Tendo um conhecimento preliminar do sistema de medição procedeu-se o equacionamento do comportamento térmico das componentes do erro volumétrico. Na escolha da ferramenta matemática e do modelo procurou-se elevado poder de diagnóstico. A modelagem foi efetuada em duas etapas. Inicialmente, foram equacionadas as componentes do erro volumétrico para a temperatura de referência, $20{ }^{\circ} \mathrm{C}$ utilizando-se de matrizes de transformações homogêneas. Na segunda etapa foram equacionadas as variações termicamente induzidas dos erros 
geométricos. Este equacionamento foi efetuado utilizando-se técnicas de regressão e o método dos mínimos quadrados.

\subsubsection{Equacionamento do Comportamento Geométrico da Máquina}

Tendo-se como base a teoria exposta no Capítulo 3 foi desenvolvido um modelo matemático para representar as relações entre as partes móveis da MM3C, visando a descrição das componentes do erro volumétrico em um ponto qualquer dentro do volume de trabalho. A partir de uma análise detalhada da máquina, foram identificados os pontos onde seriam colocados os diferentes sistemas de coordenadas, Figura 5.2.

Na Figura 5.2 podem ser observados, também, os diferentes braços de Abbé, aqui chamados de braços fixos.

Inicialmente foi escolhida a posição no volume de trabalho da máquina onde seria colocado o sistema de referência absoluto para o modelamento. Este ponto, denominado de ponto "O" (zero) ou ponto de referência, foi colocado nas coordenadas $X=25 \mathrm{~mm}, Y=25 \mathrm{~mm}$ e $Z=-300 \mathrm{~mm}$, com relação ao zero da máquina. Este ponto foi escolhido para facilitar a calibração da máquina. Em seguida procedeu-se à escolha do local para colocação dos sistemas de coordenadas intermediários.

O sistema de coordenadas " 1 " foi colocado na geratriz $Y=25 \mathrm{~mm}$, exatamente, no ponto de interseção entre esta geratriz e a projeção da escala do eixo $X$. O sistema de coordenadas "1" pode assumir infinitas posições ao longo do eixo $Y$ devido à movimentação da ponte, esta distância é diferente em cada posição e corresponde ao valor da coordenada $Y$. O sistema de coordenadas "2" representa o sistema de coordenadas "1" transladado um braço fixo $Z_{12}$ chamada de translação pura, pois não existem movimentos entre os dois referenciais. O braço $Z_{12}$ representa a distância entre a escala do eixo $Y$ e a linha da escala do eixo $X$.

O sistema de coordenadas " 3 " foi colocado sobre o carro que se movimenta na direção do eixo $X$. A distância entre os sistemas "2" e "3" é a soma de duas parcelas, a primeira corresponde ao braço fixo que existe 
entre o sistema de coordenadas " 2 " e o início da escala do eixo $X$, denominada de $X^{\prime}{ }_{23}$.

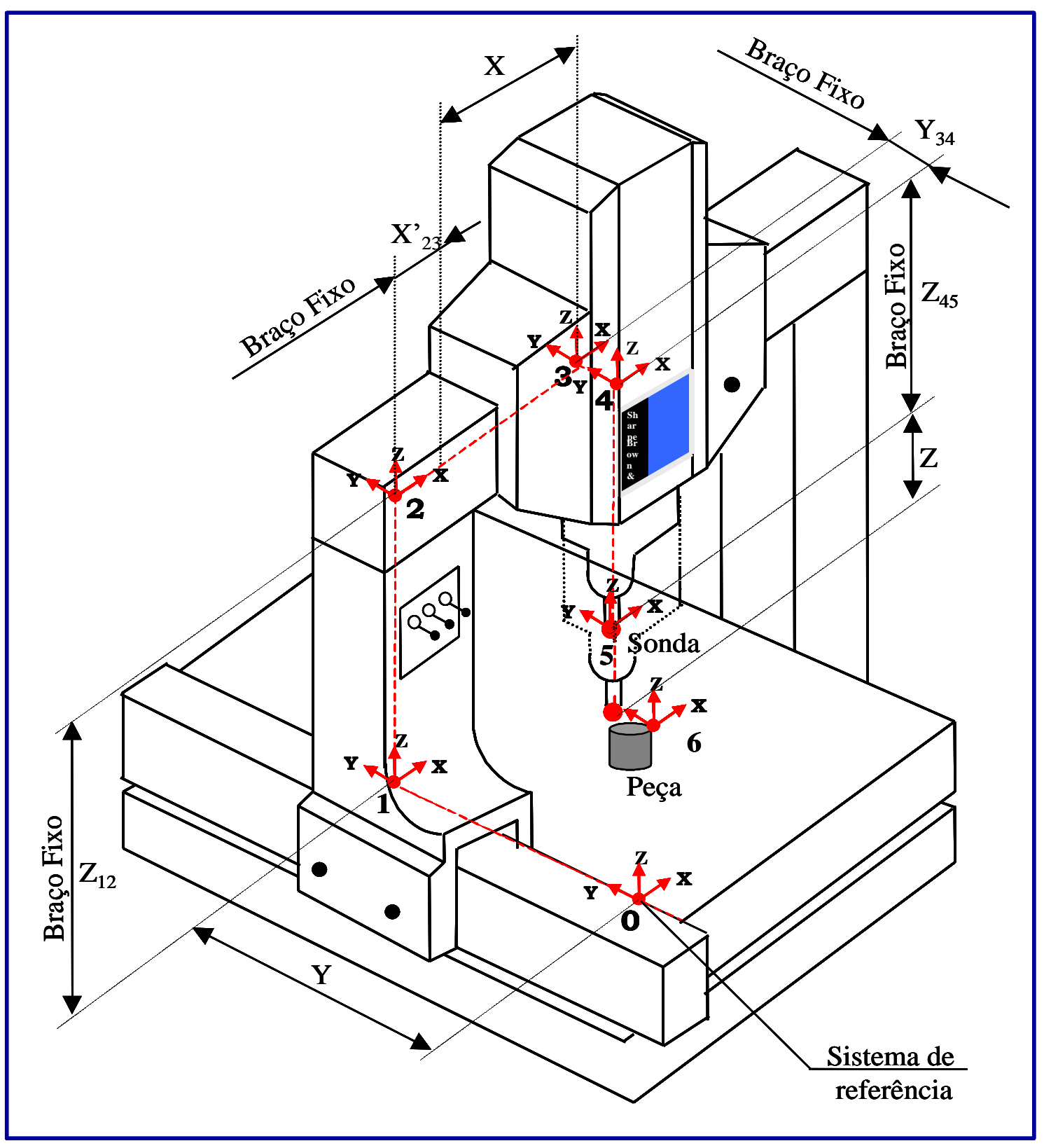

Figura 5.2 - Representação da MM3C com os sistemas de coordenadas.

A segunda parcela representa as infinitas posições que o carro de movimentação $X$ pode assumir ao longo do eixo, e denota-se por $X$. O referido carro transporta o eixo $Z$ e vincula o sistema de coordenadas "4" que foi colocado no eixo $Z$, mais especificamente no centro desse eixo. O braço que vincula o sistema "3" e “4” representa uma distância fixa aqui 
chamada de $Y_{34}$. O sistema de coordenadas "5" foi colocado na ponta da sonda, no centro do apalpador, quando o eixo $Z$ está completamente recolhido, este braço fixo é denotado por $Z_{45}$. O centro do apalpador pode assumir diferentes posições ao longo do eixo $Z$, as quais estão definidas pelo valor da coordenada $Z$.

Depois de colocados os sistemas de coordenadas nos devidos componentes da MM3C foi possivel representar através de matrizes de transformação homogênea as translações desses sistemas em relação ao sistema de coordenadas de referência (0). Posteriormente, foi estudada a relação entre os sistemas de coordenadas que definem a contribuição dos erros de translação, os angulares e os de perpendicularidade no caminho entre o ponto de referência e a ponta da sonda.

Empregando corretamente a técnica de transformações homogêneas e considerando que, se subtrairmos o caminho da sonda (caminho com erro) denominado por $(V)_{\text {sonda }}$ do caminho da peça (caminho sem erro), (V) peça, teremos o erro volumétrico através da Eq. (5.1), Figura 5.3.

$(E)=(V)_{\text {sond } a}-(V)_{\text {peça }}$

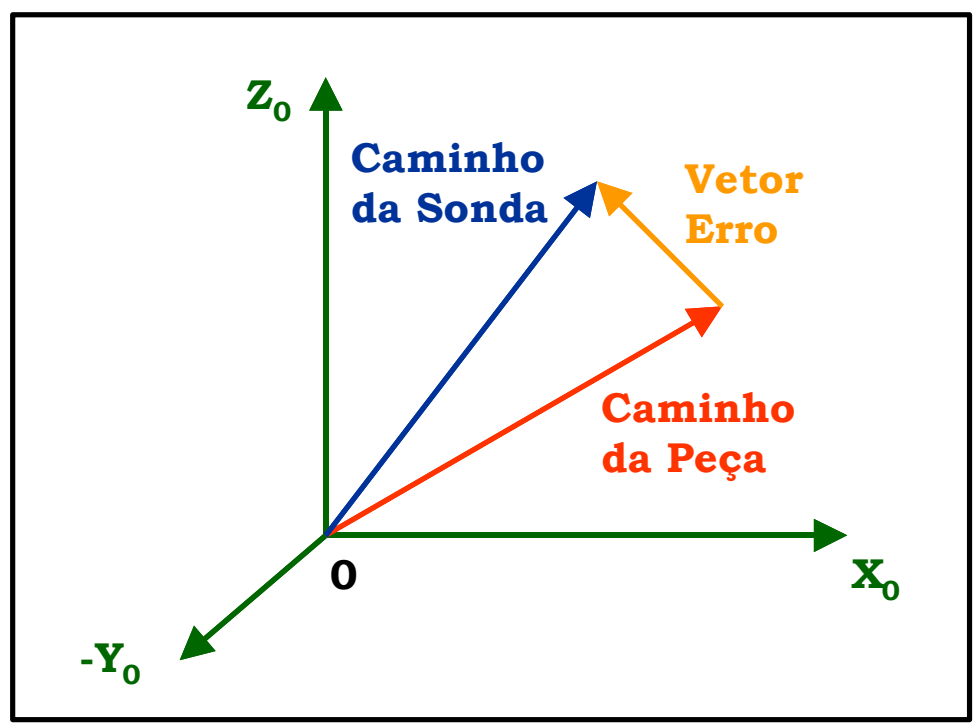

Figura 5.3 - Representação vetorial dos caminhos real e ideal. 
$\mathrm{Na}$ Tabela 5.1 estão indicados os diferentes movimentos entre sistemas de coordenadas e as matrizes correspondentes.

\begin{tabular}{|c|c|c|}
\hline $\begin{array}{l}\text { Sistemas de } \\
\text { Coordenadas }\end{array}$ & $\begin{array}{c}\text { Movimentos entre } \\
\text { Sistemas }\end{array}$ & $\begin{array}{l}\text { Mov. verdadeiros } \\
\text { ocorridos }\end{array}$ \\
\hline Sistema 0 - Sistema 1 & Translação em $Y$ & $\begin{array}{c}\left({ }^{0} \mathrm{M}_{1}\right)_{\mathrm{Mov}(\mathrm{Y})} \\
\left({ }^{0} \mathrm{M}_{1}\right)_{\text {Tranlaçãao Infinitesimal }} \\
\left({ }^{0} \mathrm{M}_{1}\right)_{\text {Rotação Infinitesimal }}\end{array}$ \\
\hline Sistema 1 - Sistema 2 & $\begin{array}{c}\text { Translação em } Z_{\text {(braço }} \\
\text { Fixo) }\end{array}$ & $\begin{array}{l}\left({ }^{1} \mathrm{M}_{2}\right) \text { Translacão Pura(Z) } \\
\left({ }^{1} \mathrm{M}_{2}\right) \operatorname{Ort}(\mathrm{YX})\end{array}$ \\
\hline Sistema 2 - Sistema 3 & Translação em $X$ & $\begin{array}{c}\left({ }^{2} \mathrm{M}_{3}\right)_{\operatorname{Mov}}(\mathrm{X}) \\
\left({ }^{2} \mathrm{M}_{3}\right) \text { Tranlação Infinitesimal } \\
\left({ }^{2} \mathrm{M}_{3}\right)_{\text {Rotação Infinitesimal }}\end{array}$ \\
\hline Sistema 3 - Sistema 4 & $\begin{array}{l}\text { Translação em } Y_{\text {(braço }} \\
\text { Fixo) }\end{array}$ & $\begin{array}{c}\left.\left({ }^{3} \mathrm{M}_{4}\right) \text { Translação Pura( } \mathrm{Y}\right) \\
\left({ }^{3} \mathrm{M}_{4}\right) \text { Ort(ZX,ZY) } \\
\left({ }^{3} \mathrm{M}_{4}\right)_{\text {Rotação Infinitesimal }} \\
\left({ }^{3} \mathrm{M}_{4}\right) \text { Tranlação Infinitesimal }\end{array}$ \\
\hline Sistema 4 - Sistema 5 & Translação em $Z$ & $\left({ }^{4} M_{5}\right)_{\operatorname{Mov}(Z)}$ \\
\hline Sistema 0 - Sistema 6 & Translação em $X Y Z$ & $\left({ }^{0} \mathrm{M}_{6}\right)_{\operatorname{Mov}(\mathrm{XYZ})}$ \\
\hline
\end{tabular}

\section{Caminho da peça}

$O$ vetor que representa o caminho da peça, sem erros tem como componentes as translações ideais e são observadas na matriz de transformação, Eq. (5.2). Observe que nesta matriz não estão incluídos os erros de rotação e também os erros de translação.

$$
[M]_{\text {Pesa }}=[M]_{\text {Mov XYZ }}=\left[{ }^{0} M_{6}\right]=\left[\begin{array}{cccc}
1 & 0 & 0 & \left(X_{23}^{\prime}+X\right) \\
0 & 1 & 0 & \left(Y-Y_{34}\right) \\
0 & 0 & 1 & \left(Z_{12}-Z_{45}-Z\right) \\
0 & 0 & 0 & 1
\end{array}\right]
$$

onde $X, Y$ e $Z$ são as leituras mostradas na máquina; $X_{23}^{\prime}, Y_{34}, Z_{12}$ e $Z_{45}$ são os braços fixos. 


\section{Caminho da Sonda}

Do sistema de coordenadas "0" até o sistema "1" ocorre uma translação na direção do eixo $Y$ aqui chamado de $\left[{ }^{0} M_{1}\right\rfloor_{\operatorname{Mov}(Y)}$, Eq. (5.3). Como essa translação depende do posicionamento da ponte da máquina sobre esse eixo torna-se necessário definir outra matriz, Eq. (5.4), a qual carrega os erros de translação e rotação na direção preferencial do eixo $Y$ a qual chamamos de $\left[{ }^{0} M_{1}\right]_{\text {ErroGeom }}$. Assim:

$$
\begin{aligned}
{\left[{ }^{0} M_{1}\right]_{\operatorname{Mov}(Y)} } & =\left[\begin{array}{llll}
1 & 0 & 0 & 0 \\
0 & 1 & 0 & Y \\
0 & 0 & 1 & 0 \\
0 & 0 & 0 & 1
\end{array}\right] \\
{\left[{ }^{0} M_{1}\right]_{\text {ErroGeom }} } & =\left[\begin{array}{cccc}
1 & -\operatorname{Yaw}(y) & \operatorname{Roll}(y) & \operatorname{Rx}(y) \\
\operatorname{Yaw}(y) & 1 & -\operatorname{Pitch}(y) & \operatorname{Pos}(y) \\
-\operatorname{Roll}(y) & \operatorname{Pitch}(y) & 1 & \operatorname{Rz}(y) \\
0 & 0 & 0 & 1
\end{array}\right]
\end{aligned}
$$

Entre os sistemas "1" e "2" observa-se que não há nenhum movimento, apenas uma translação pura do sistema de coordenadas. Essa translação já foi definida anteriormente pela distância fixa $\left(Z_{12}\right)$. Porém ocorreu uma mudança do eixo $Y$ para o eixo $X$, o sistema "2" esta na parte fixa do eixo $X$. Como se trata de um instrumento mecânico e que depende de ajustes, isso implica na introdução de possiveis erros de perpendicularidade entre os sistemas "1" e "2", Eq. (5.5).

$$
\left[{ }^{1} M_{2}\right]_{\text {Translaçã } \operatorname{pura}(Z)}=\left[\begin{array}{cccc}
1 & 0 & 0 & 0 \\
0 & 1 & 0 & 0 \\
0 & 0 & 1 & Z_{12} \\
0 & 0 & 0 & 1
\end{array}\right]
$$


A matriz de transformação que rege o erro de perpendicularidade entre os eixos $Y$ e $X$ é definida como $\left[{ }^{1} M_{2}\right]_{\text {ort }(Y X)}$, Eq. (5.6).

$$
\left[{ }^{1} M_{2}\right]_{\operatorname{Ort}(Y X)}=\left[\begin{array}{cccc}
1 & -\operatorname{Ort}(x y) & 0 & 0 \\
\operatorname{Ort}(x y) & 1 & 0 & 0 \\
0 & 0 & 1 & 0 \\
0 & 0 & 0 & 1
\end{array}\right]
$$

Há duas matrizes de transformação que modelam o vínculo entre os sistemas “2" e "3". Uma matriz $\left[{ }^{2} M_{3}\right]_{\operatorname{Mov}(X)}$, Eq. (5.7), que representa a translação entre estes sistemas e que depende do posicionamento do carro que se movimenta sobre o eixo $X$. A outra matriz, Eq. (5.8), considera os erros de translação e rotação que ocorrem durante o deslocamento do carro, ela foi chamada de $\left[{ }^{2} M_{3}\right]_{E r r o}$.

$$
\begin{aligned}
& {\left[{ }^{2} M_{3}\right]_{\text {Mor } X)}=\left[\begin{array}{llll}
1 & 0 & 0 & X_{23}^{\prime}+X \\
0 & 1 & 0 & 0 \\
0 & 0 & 1 & 0 \\
0 & 0 & 0 & 1
\end{array}\right]} \\
& {\left[{ }^{2} M_{3}\right]_{\text {ErroGoem }}=\left[\begin{array}{cccc}
1 & -\operatorname{Yaw}(x) & \operatorname{Pitch}(x) & \operatorname{Pos}(x) \\
\operatorname{Yaw}(x) & 1 & -\operatorname{Roll}(x) & \operatorname{Ry}(x) \\
-\operatorname{Pitch}(x) & \operatorname{Roll}(x) & 1 & \operatorname{Rz}(x) \\
0 & 0 & 0 & 1
\end{array}\right]}
\end{aligned}
$$

Entre os sistemas "3" e "4" observa-se uma translação pura e possiveis erros de perpendicularidade, isto deve-se ao fato do sistema de coordenada 4 estar sobre o eixo $Z$ o qual desliza sobre os mancais fixos presos no carro $X$. Portanto, torna-se necessário modelar os erros de perpendicularidade $Z X$ e $Z Y$ e ainda modelar os erros de translação e rotação que ocorrem no sistema de coordenadas "4" quando o eixo $Z$ se movimenta. 
As matrizes dadas nas Eqs (5.9), (5.10) e (5.11) descrevem os movimentos entre os sistemas 3 e 4 .

$$
\begin{aligned}
{\left[{ }^{3} M_{4}\right]_{\text {Translaçãäura }} } & =\left[\begin{array}{cccc}
1 & 0 & 0 & 0 \\
0 & 1 & 0 & -Y_{34} \\
0 & 0 & 1 & 0 \\
0 & 0 & 0 & 1
\end{array}\right] \\
{\left[{ }^{3} M_{4}\right]_{\text {Ort (ZX,ZY) }} } & =\left[\begin{array}{cccc}
1 & 0 & \operatorname{Ort}(z x) & 0 \\
0 & 1 & -\operatorname{Ort}(z y) & 0 \\
-\operatorname{Ort}(z x) & \operatorname{Ort}(z y) & 1 & 0 \\
0 & 0 & 0 & 1
\end{array}\right] \\
{\left[{ }^{3} M_{4}\right]_{\text {ErroGeom }} } & =\left[\begin{array}{cccc}
1 & -\operatorname{Roll}(z) & \operatorname{Yaw}(z) & \operatorname{Rx}(z) \\
\operatorname{Roll}(z) & 1 & -\operatorname{Pitch}(z) & \operatorname{Ry}(z) \\
-\operatorname{Yaw}(z) & \operatorname{Pitch}(z) & 1 & \operatorname{Pos}(z) \\
0 & 0 & 0 & 1
\end{array}\right]
\end{aligned}
$$

Para modelar as translações entre os sistemas "4" e " 5 " foram utilizadas duas matrizes de transformação. A Eq. (5.12) modela a translação do eixo $Z$.

$$
\left[{ }^{4} M_{5}\right]_{M o v(Z)}=\left[\begin{array}{cccc}
1 & 0 & 0 & 0 \\
0 & 1 & 0 & 0 \\
0 & 0 & 1 & -Z \\
0 & 0 & 0 & 1
\end{array}\right]
$$

A outra matriz designada por $(M)_{\text {sonda, }}$ Eq. (5.13), modela o comprimento fixo do término do eixo $Z$ até o centro da esfera da sonda.

$$
(\mathrm{M})_{\text {sonda }}=\left[\begin{array}{cccc}
1 & 0 & 0 & 0 \\
0 & 1 & 0 & 0 \\
0 & 0 & 1 & -Z_{45} \\
0 & 0 & 0 & 1
\end{array}\right]
$$


Para se obter a $(V)_{\text {sonda }}$ que relaciona os movimentos da ponta da sonda com o sistema de coordenadas de referência, deve-se executar a soma dos vetores entre os referenciais intermediários. Isso se da através da multiplicação entre as matrizes definidas acima, respeitando sua ordem de ocorrência, Eq. (5.14).

$$
\begin{aligned}
{[\text { Vet }]_{\text {Sonda }} } & =\left[{ }^{0} M_{1}\right]_{\text {Mov }(Y)} *\left[{ }^{0} M_{1}\right]_{\text {ErroGeom }} *\left[{ }^{1} M_{2}\right]_{\operatorname{Translaçãarura}(Z)} *\left[{ }^{1} M_{2}\right]_{\operatorname{Ort}(Y X)} *\left[{ }^{2} M_{3}\right]_{\text {Mov }(X)} * \\
& *\left[{ }^{2} M_{3}\right]_{\text {ErroGeom }} *\left[{ }^{3} M_{4}\right]_{\text {TranslaçãäPura }} *\left[{ }^{3} M_{4}\right]_{\operatorname{Ort}(Z X, Z Y)} *\left[{ }^{3} M_{4}\right]_{\text {ErroGeom }} *\left[{ }^{4} M_{5}\right]_{\text {Mov }(Z)} * \\
& *\left[M_{\text {Sonda }}\right]
\end{aligned}
$$

Realizando as operações indicadas na Eq. (5.14) e desconsiderando os termos de segunda ou maior ordem (DI GIACOMO et al., 1997), obtémse duas matrizes $4 \times 4$, com parcelas de rotações e translações. Se além desta simplificação, for considerado que o ponto de contato entre a sonda e a peça é puntiforme, então as rotações perdem sua importância podendo ser eliminadas do equacionamento, basta para isso multiplicar cada uma das matrizes $(V)_{\text {sonda }}$ e $(V)_{\text {peça }}$ pelo vetor dado na Eq. (5.15):

$$
(e)=\left(\begin{array}{llll}
0 & 0 & 0 & 1
\end{array}\right)^{T}
$$

Subtraindo os caminhos de medição $V_{\text {sonda }}$ e $V_{\text {peça }}$ conforme a Eq. (5.1) definida previamente, pode-se com algumas simplificações chegar às Eqs (5.16), (5.17) e (5.18) para determinação das componentes do erro volumétrico

$$
\begin{aligned}
E x & =\operatorname{Pos}(x)+\operatorname{Ry}(x)+\operatorname{Rz}(x)+[\operatorname{Ort}(x y)+\operatorname{Yaw}(x)] \cdot Y_{34}+ \\
& +[\operatorname{Ort}(x z)+\operatorname{Pitch}(x)+\operatorname{Yaw}(z)+\operatorname{Roll}(y)]-Z-Z 45)+\operatorname{Roll}(y) \cdot Z_{12} \\
E y & =\operatorname{Pos}(y)+\operatorname{Ry}(x)+\operatorname{Ry}(z)+[\operatorname{Ort}(\mathrm{xy})+\operatorname{Yaw}(\mathrm{y})] \cdot\left(X_{23}+X\right)-\operatorname{Pitch}(y) \cdot Z_{12}+ \\
& -[\operatorname{Ort}(y z)+\operatorname{Roll}(x)+\operatorname{Pitch}(y)+\operatorname{Pitch}(z)]\left(-Z-Z_{45}\right) \\
E z & =\operatorname{Pos}(z)+\operatorname{Rx}(z)+\operatorname{Ry}(z)-\operatorname{Roll}(y) \cdot\left(X_{23}+X\right)-[\operatorname{Roll}(x)+\operatorname{Pitch}(y)] \cdot Y_{34}
\end{aligned}
$$


Uma análise das equações anteriores revela que a componente $E z$ do erro volumétrico é afetada por um número menor de erros que as outras componentes. Se nas Eqs (5.16) - (5.18) forem introduzidos os valores dos erros e dos braços medidos para $20{ }^{\circ} \mathrm{C}$, obtém-se o comportamento geométrico da máquina avaliada.

Para obtenção do comportamento geométrico-térmico, além dos valores a $20^{\circ} \mathrm{C}$ é necessário, também, conhecer a grandeza dos erros termicamente induzidos e a variação experimentada pelos braços fixos devido às variações de temperatura. Portanto, os erros geométricos devem ser levantados para diferentes estados de temperatura. Os dados resultantes devem ser equacionados em função da posição e da temperatura e por fim devem ser introduzidos adequadamente nas equações de sintetização.

Desta forma, cada erro geométrico foi escrito como sendo a soma de duas parcelas. A primeira parcela representa o erro geométrico para 20 ${ }^{\circ} \mathrm{C}$ e depende apenas da posição do carro de movimentação correspondente. A segunda parcela representa a variação termicamente induzida deste erro e pode ser descrita em função da temperatura e, também da posição, pois as mudanças de temperatura podem provocar variações do erro de forma diferenciada ao longo dos eixos. Desta forma, matematicamente o erro geométrico pode ser dado pela Eq. (5.19).

$$
\operatorname{erro}_{i}=\operatorname{erro}_{i}(p)+\operatorname{verro}_{i}(p, T)
$$

onde $e^{2 r o} o_{i}$ é o erro em qualquer posição $i$ e para qualquer estado de temperatura, $\operatorname{erro}_{i}(p)$ é o erro geométrico na posição $i$ e $\operatorname{verro}_{i}(p, T)$ é a variação termicamente induzida do erro geométrico na posição $i$.

$\mathrm{O}$ erro geométrico é aquele levantado para a temperatura de referência $\left(20^{\circ} \mathrm{C}\right)$.

O equacionamento da variação do erro geométrico devido às mudanças de temperatura é relativamente complexo. Para tanto foram 
usados os dados coletados a partir do drift térmico, em quatro pontos espalhados ao longo de cada eixo avaliado.

Em cada ponto de observação foi levantado um conjunto de dados. Estes conjuntos representam a variação termicamente induzida do erro numa determinada posição até a estabilização. Assim sendo, utilizando-se de técnicas de regressão foram obtidas as expressões que descrevem a variação do erro, em função da temperatura, em cada ponto de observação do drift térmico. Esta variação é descrita pela Eq. (5.20).

$$
\operatorname{Verro}_{i}(T) \cong \alpha_{0}+\alpha_{1} T_{1}+\alpha_{2} T_{2}+\ldots+\alpha_{j} T_{j}
$$

onde $\operatorname{Verro}_{i}(T)$ é a variação do erro em cada ponto $i$ para $i=1 . .4 ; T$ contém as componentes do vetor variação de temperatura dos diferentes termopares $j$ para todo $j=1, \ldots 18$.

No vetor temperatura foram incluídos somente aqueles termopares cujas temperaturas influenciam significativamente o comportamento do erro. A escolha dos termopares que integram o vetor temperatura, em cada ponto $i$, foi feita através da aplicação do procedimento Stepwise (Apêndice A). Assim sendo, foram agrupados aqueles termopares cujas temperaturas apresentaram uma correlação maior ou igual a 99,9\%.

Na seqüência, superpõem-se os efeitos das variáveis $p$ e $T$ para determinação da variação do erro em qualquer posição e para qualquer estado de temperatura. Neste trabalho, este equacionamento foi efetuado aplicando técnicas de regressão e o método dos mínimos quadrados, Eq. (5.21), onde $\beta_{i},(i=0, \ldots, n)$ são os coeficientes da regressão; $p_{i}$, $(i=1, \ldots, 4)$ são as posições de observação do drift térmico.

$$
\operatorname{verro}_{i}(p, T)=\beta_{O}(T)+\beta_{1}(T) \cdot p_{i}+\beta_{2}(T) \cdot p_{i}^{2}+\ldots+\beta_{n}(T) \cdot p_{i}^{n}
$$

Estabelecendo uma igualdade entre as equações dadas na Eq. (5.21) e o vetor erro da Eq. (5.20) e aplicando o método dos mínimos quadrados foi possivel estimar os coeficientes $\beta_{n}$. O sistema resultante é 
dado na Eq. (5.22). Enquanto os estimadores de mínimos quadrados de $\beta_{0}, \beta_{1}, \beta_{2}, \ldots, \beta_{n}$ são determinados de maneira tal que minimizem a expressão dada na Eq. (5.23).

$$
\begin{aligned}
& \left\{\begin{array}{l}
\beta_{0}(T)+\beta_{1}(T) \cdot p_{1}+\beta_{2}(T) \cdot p_{1}^{2}+\ldots+\beta_{n}(T) \cdot p_{1}^{n}=\operatorname{Verro}_{1}(T) \\
\beta_{0}(T)+\beta_{1}(T) \cdot p_{2}+\beta_{2}(T) \cdot p_{2}^{2}+\ldots+\beta_{n}(T) \cdot p_{2}^{n}=\operatorname{Verro}_{2}(T) \\
\beta_{O}(T)+\beta_{1}(T) \cdot p_{3}+\beta_{2}(T) \cdot p_{3}^{2}+\ldots+\beta_{n}(T) \cdot p_{3}^{n}=\operatorname{Verro}_{3}(T) \\
\beta_{0}(T)+\beta_{1}(T) \cdot p_{4}+\beta_{2}(T) \cdot p_{4}^{2}+\ldots+\beta_{n}(T) \cdot p_{4}^{n}=\operatorname{Verro}_{4}(T)
\end{array}\right. \\
& S\left(\beta_{0}, \beta_{1}, \ldots, \beta_{n}\right)=\sum_{i=1}^{m} \varepsilon_{i}^{2}=\sum_{i=1}^{m}\left(\operatorname{Verro}_{i}-\beta_{0}-\beta_{1} x_{1 i}-\ldots-\beta_{n} x_{n i}\right)^{2}
\end{aligned}
$$

Os estimadores da Eq. (5.23) foram obtidos utilizando-se o aplicativo "Matemática v.2.2, Wolfram Research inc - 1993". O modelo adotado para superposição dos efeitos de posição e temperatura não é linear e devido à complexidade dos termos eles não estão impressos. Para ter-se uma idéia do equacionamento são apresentadas as equações que permitem estimar os coeficientes $\beta_{0}$ e $\beta_{1}$ de um modelo linear, Eqs (5.24) e (5.25), respectivamente.

$$
\begin{aligned}
\beta_{0}= & {\left[\frac{\left(p_{1}^{2}+p_{2}^{2}+p_{3}^{2}+p_{4}^{2}\right) \cdot\left(V e_{1}(T)+V e_{2}(T)+V e_{3}(T)+V e_{4}(T)\right)}{-\left(p_{1}+p_{2}+p_{3}+p_{4}\right)^{2}+4\left(p_{1}^{2}+p_{2}^{2}+p_{3}^{2}+p_{4}^{2}\right)}\right]+} \\
& +\frac{\left(-p_{1}-p_{2}-p_{3}-p_{4}\right) \cdot\left(p_{1} \cdot V e_{1}(T)+p_{2} \cdot V e_{2}(T)+p_{3} \cdot V e_{3}(T)+p_{4} \cdot V e_{4}(T)\right)}{-\left(p_{1}^{2}+p_{2}^{2}+p_{3}^{2}+p_{4}^{2}\right)^{2}+4\left(p_{1}^{2}+p_{2}^{2}+p_{3}^{2}+p_{4}^{2}\right)} \\
\beta_{1}= & {\left[\frac{\left(-p_{1}-p_{2}-p_{3}-p_{4}\right) \cdot\left(V e_{1}(T)+V e_{2}(T)+V e_{3}(T)+V e_{4}(T)\right)}{-\left(p_{1}+p_{2}+p_{3}+p_{4}\right)^{2}+4\left(p_{1}^{2}+p_{2}^{2}+p_{3}^{2}+p_{4}^{2}\right)}\right]+} \\
& +\frac{4\left(p_{1} \cdot V e_{1}(T)+p_{2} \cdot V e_{2}(T)+p_{3} \cdot V e_{3}(T)+p_{4} \cdot V e_{4}(T)\right)}{-\left(p_{1}^{2}+p_{2}^{2}+p_{3}^{2}+p_{4}^{2}\right)^{2}+4\left(p_{1}^{2}+p_{2}^{2}+p_{3}^{2}+p_{4}^{2}\right)}
\end{aligned}
$$

\subsection{Calibração da máquina}

Definida a estratégia de modelagem foram planejados e executados de forma adequada os experimentos necessários para coleta dos dados. 
Estes experimentos constam do levantamento dos erros geométricos, da coleta dos valores de drift e do monitoramento das temperaturas.

\subsubsection{Levantamento dos Erros Geométricos}

Como comentado no Capítulo 4, os erros geométricos foram levantados para a temperatura de $20{ }^{\circ} \mathrm{C}$ utilizando-se de instrumentos, tais como, interferômetro laser da Hewlett Packard modelo HP5528A, nível eletrônico da Rank Taylor-Hobson modelo Talyvel 3, esquadro mecânico e apalpador LVDT. A montagem utilizada para determinação de cada erro geométrico é descrita de forma detalhada no Apêndice $B$, enquanto que no Apêndice C são apresentadas as características metrológicas dos instrumentos utilizados.

\subsubsection{Desenvolvimento do Sistema de Monitoramento das Temperaturas}

Para monitorar as temperaturas foram utilizados 28 termopares do tipo “T" cobre-constantan $(\mathrm{Cu}-\mathrm{C}), 16$ deles distribuidos em pontos distintos na estrutura da máquina, 3 utilizados para monitoramento da temperatura de fontes localizadas de calor e 8 para verificação dos gradientes térmicos espaciais. Ainda, foi colocado um termopar num banho de gelo, servindo como referência.

Todos os termopares foram colocados em locais devidamente escolhidos. Na Figura 5.4 estão apresentados estes locais, onde as estrelinhas vermelhas representam cada um dos termopares. Para melhor visualização dos mesmos são mostradas duas perspectivas da máquina uma de frente e outra detrás.

Os termopares 1, 2 e 4 monitoram a temperatura da base da máquina; os termopares 5 e 15 da guia do eixo $Y$. Os termopares 8 e 11 foram destinados a monitorar a temperatura das colunas da ponte. Os termopares 12 e 16 foram colocados nos extremos inferior e superior do eixo $Z$, respectivamente, e os termopares 6,13 e 14 no carro do eixo $X$. O 
termopar 9 foi colocado no desempeno. Os termopares 3 e 10 monitoram a temperatura da guia do eixo $X$, enquanto que os termopares 7,18 e 19 monitoram a temperatura do ar comprimido alimentado à máquina, do processador de sinais e do computador, respectivamente. Por sua vez o termopar 20 foi colocado em um banho de gelo e o termopar 17 monitorou a temperatura ambiente.

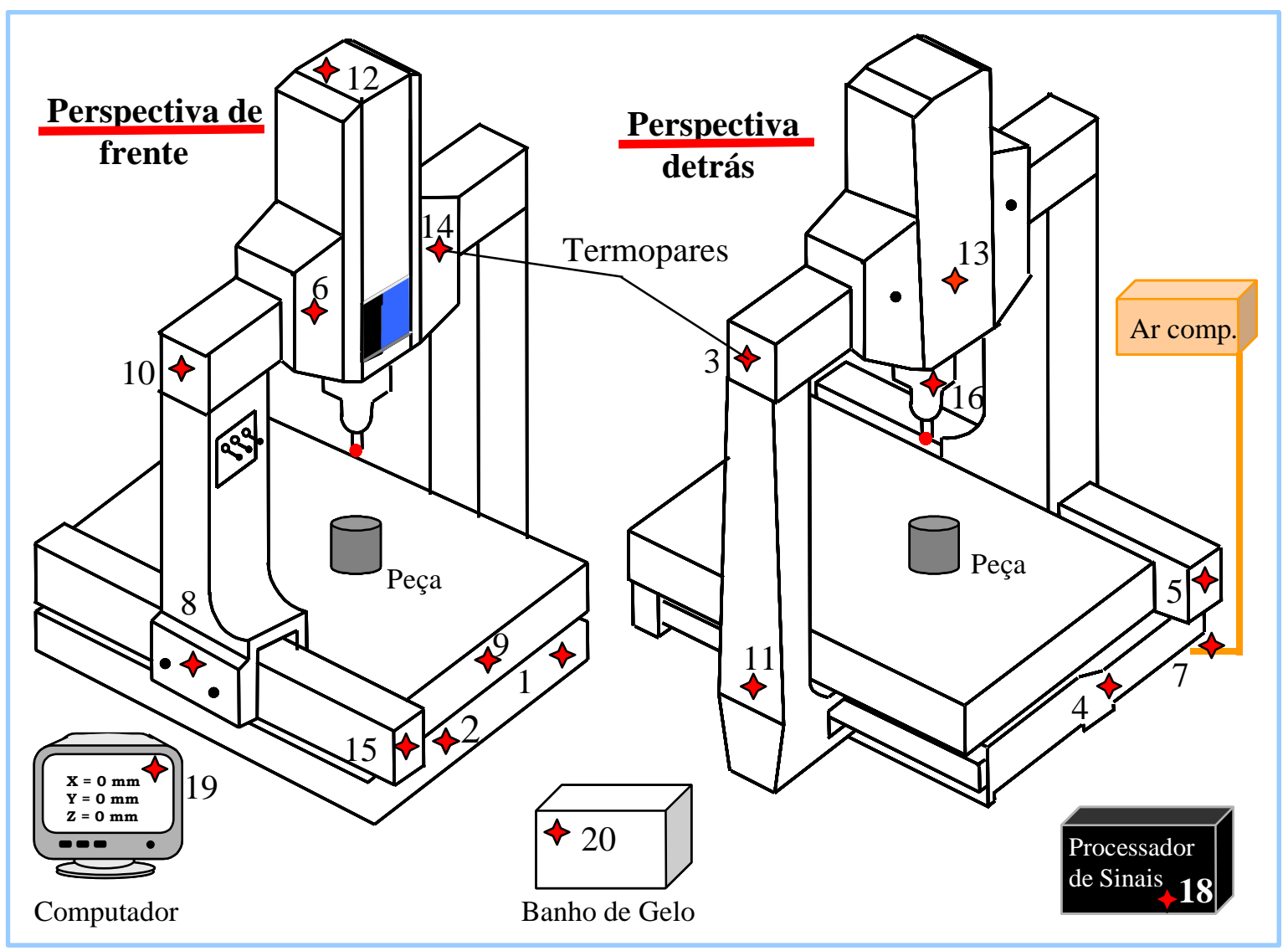

Figura 5.4 - Localização física dos termopares.

Ainda foram colocados 8 termopares, em uma base de madeira, para monitorar os gradientes espaciais de temperatura (21-28), Figura 5.5 .

A construção e fixação dos termopares podem ser visualizadas na Figura 5.6. Com o propósito de evitar o contato elétrico entre o termopar e a máquina foi colocada entre ambos uma fina lâmina de mica. Todo este conjunto foi então colado na estrutura da máquina. Para garantir que a pintura da superfície da máquina não atuasse como um isolante térmico 
entre o sensor e a máquina, foi providenciada a retirada da pintura nos locais de colagem dos termopares. Cobrindo esta montagem, uma meia esfera de isopor foi colocada e fixada à superficie da máquina por uma camada de cola de silicone, evitando que correntes de ar pudessem influenciar as leituras dos termopares. Montagens similares foram utilizadas por PEREIRA (1995); VIEIRA SATO (1998) e KRUTH et al. (2001).

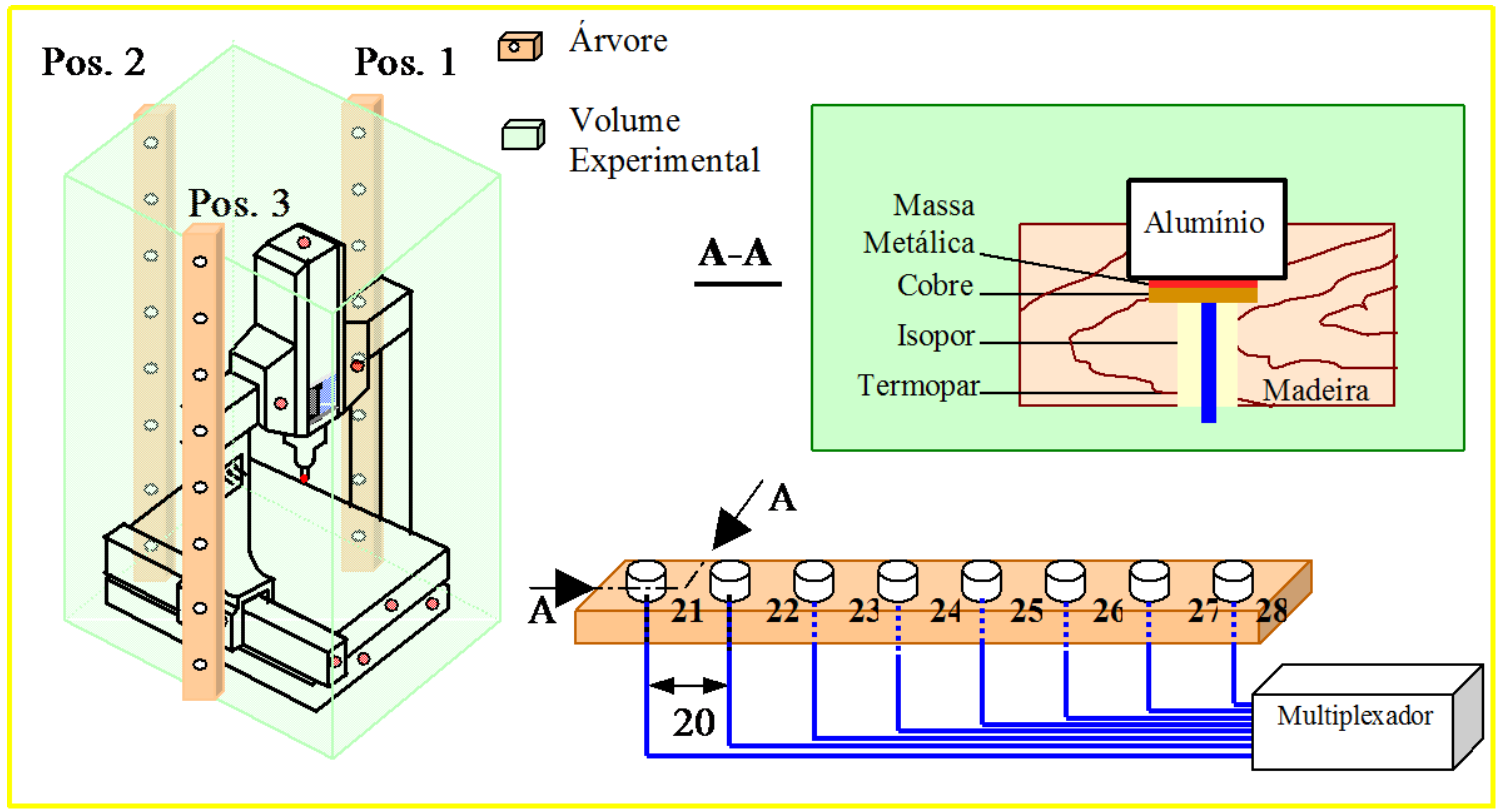

Figura 5.5 - Termopares destinados para monitoramento dos gradientes térmicos espaciais.

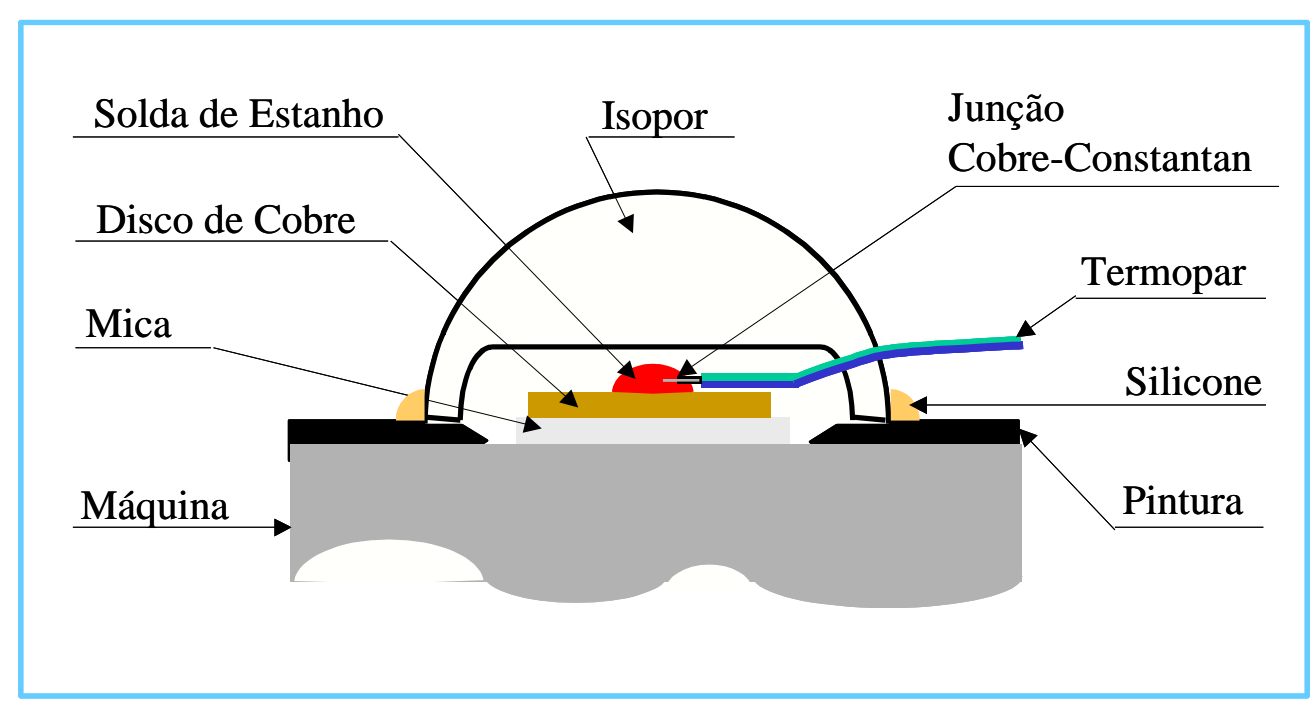

Figura 5.6 - Esquema de montagem do termopar. 
A montagem dos termopares para coletar a temperatura ambiente difere um pouco da utilizada para monitorar a temperatura da máquina, como mostrado na Figura 5.6. Observe que estes termopares não precisam da mica, pois eles são colocados numa base de madeira, que é um bom isolante elétrico. Enquanto que a chapa de cobre foi colocada numa peça de alumínio de $31 \mathrm{~mm}$ de diâmetro e $8 \mathrm{~mm}$ de espessura, que serve de inércia térmica.

Termopar tipo "T": Os termopares tipo "T" (Cobre-Constantan) são sensores de temperatura que funcionam segundo o princípio de Seebeck, assim sendo, quando o circuito é aberto na junção fria, Figura 5.7, se produz uma diferença de potencial entre as junções ou extremidades (tensão de Seebeck). A tensão produzida varia proporcionalmente à variação de temperatura sofrida pela extremidade oposta. Esta relação pode ser equacionada e medindo-se a tensão com um voltímetro, pode ser calculada a variação de temperatura que a outra extremidade sofre.

Quando o voltímetro é conectado na extremidade aberta criam-se outros pares bimetálicos na ligação entre os fios do termopar com os conectores do voltímetro. Conforme os materiais do termopar utilizado, serão dois outros pares criados. Estes novos pares também geram correntes em função de sua própria temperatura, o que pode comprometer a medição da temperatura de interesse e, portanto, devem ser evitados.

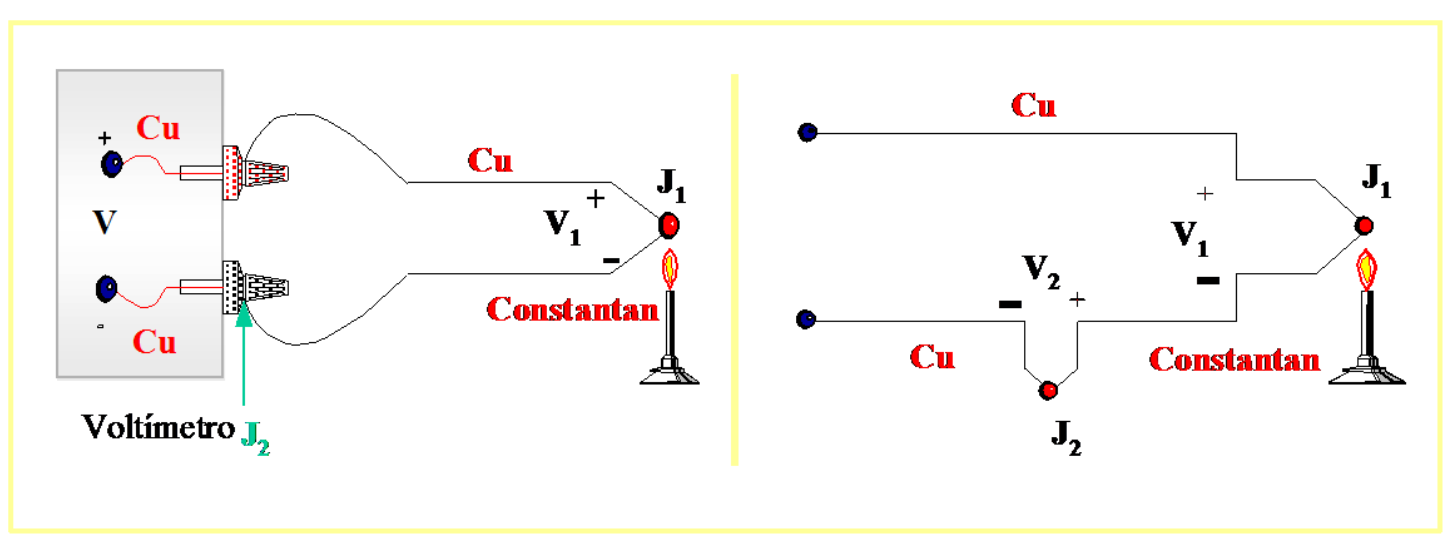

Figura 5.7 - Termopar conectado ao voltímetro e o circuito equivalente (OMEGA ENGINEERING, 1995). 
Considerando-se um termopar de cobre-constantan conectado a um voltímetro, Figura 5.7 à esquerda, e tendo como circuito equivalente o mostrado na Figura 5.7 à direita, pode-se observar que o ponto de união $\left(\mathrm{J}_{2}\right)$ entre o fio de constantan do sensor e o conector de cobre do voltímetro forma um novo termopar no circuito.

Este problema deixaria de existir se a temperatura na junção do fio de constantan do termopar com o conector de cobre do voltímetro fosse conhecida de alguma maneira, pois durante a calibração dos termopares este efeito seria considerado. A solução é manter esta junção a uma temperatura estável conhecida e mesmo assim, a tensão $V_{2}$ gerada no ponto $J_{2}$ não é zero, porém, é constante. Desta forma, se a calibração dos termopares for feita usando-se esta configuração, a equação gerada levará em consideração a diferença entre $V_{1}$ e $V_{2}$. Sendo conhecida a temperatura em $J_{2}$, torna-se simples calcular a temperatura que o termopar de interesse está medindo.

A maneira mais prática de materializar uma temperatura conhecida é imergindo o termopar de referência numa mistura de água e gelo, garantindo a temperatura de $0{ }^{\circ} \mathrm{C}$, Figura 5.8. A montagem anterior garante que os fios que chegam ao voltimetro sejam ambos de cobre, não inserindo novos pares térmicos.

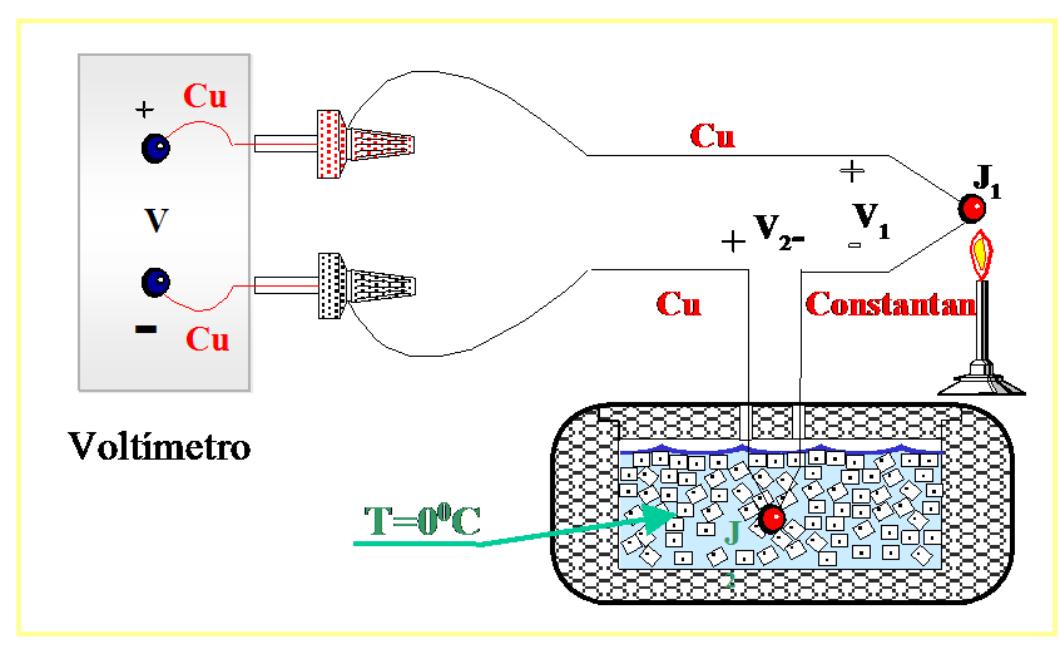

Figura 5.8 - Montagem do termopar de referência (OMEGA ENGINEERING, 1995). 
Para a leitura destes termopares foi construída uma caixa multiplexadora, na qual estes sensores são conectados. Para isto, o multiplexador consta com 32 canais. Ainda é utilizada uma placa de aquisição de dados que contem um conversor A/D de 12 bits de resolução. Esta placa é responsável pela seleção do canal a ser lido e pela conversão do sinal em tensão analógica do termopar em valores digitais. Ainda, foi desenvolvido um programa computacional em linguagem Delphi para executar a leitura dos termopares.

A seleção do termopar a ser lido é efetuada através de comandos binários enviados à caixa multiplexadora pelo programa computacional. Estas informações são enviadas através de uma porta paralela da placa de aquisição. Recebido o sinal pelo multiplexador, ele seleciona o canal escolhido e faz a ligação entre ele e o amplificador.

A variação de temperatura entre as junções do termopar provoca uma variação de tensão, este sinal analógico é detectado pela caixa multiplexadora, onde é amplificado 1000 vezes. Em seguida, o multiplexador envia o sinal amplificado para o conversor $A D$, onde é convertido em um sinal digital. Através do programa computacional desenvolvido estabelece-se uma conexão com o conversor, permitindo a leitura dos níveis digitais.

Como a variável de interesse é a temperatura e não os níveis digitais foi necessário fazer uma calibração a fim de determinar a equação que relaciona ambas as variáveis. Este equacionamento foi efetuado aplicando-se regressão linear. Para tanto, foram coletados os valores de saída (níveis digitais) para diferentes valores de entrada (temperatura). Estas entradas foram materializadas utilizando um banho térmico controlado. Obtida a curva de calibração o sistema está pronto para monitoramento das temperaturas.

Através do programa são definidos, ainda, o número de pontos a coletar e o intervalo de aquisição (tempo). Se desejado podem ser lidos todos os termopares em um intervalo de tempo de $12 \mathrm{~s}$, evitando-se assim a influência do drift térmico dentro de um mesmo ciclo de leitura e 
permitindo coletar os dados necessários para descrever o comportamento da máquina durante os transientes térmicos.

\subsubsection{Levantamento dos Dados de Drift}

O teste de drift desenvolvido consiste na observação da variação dos erros geométricos em uma determinada posição até a estabilização, utilizando-se a montagem experimental mostrada na Figura 5.9. O levantamento destes dados se fez necessário para que a correlação entre a variação do erro e a variação de temperatura fosse definida.

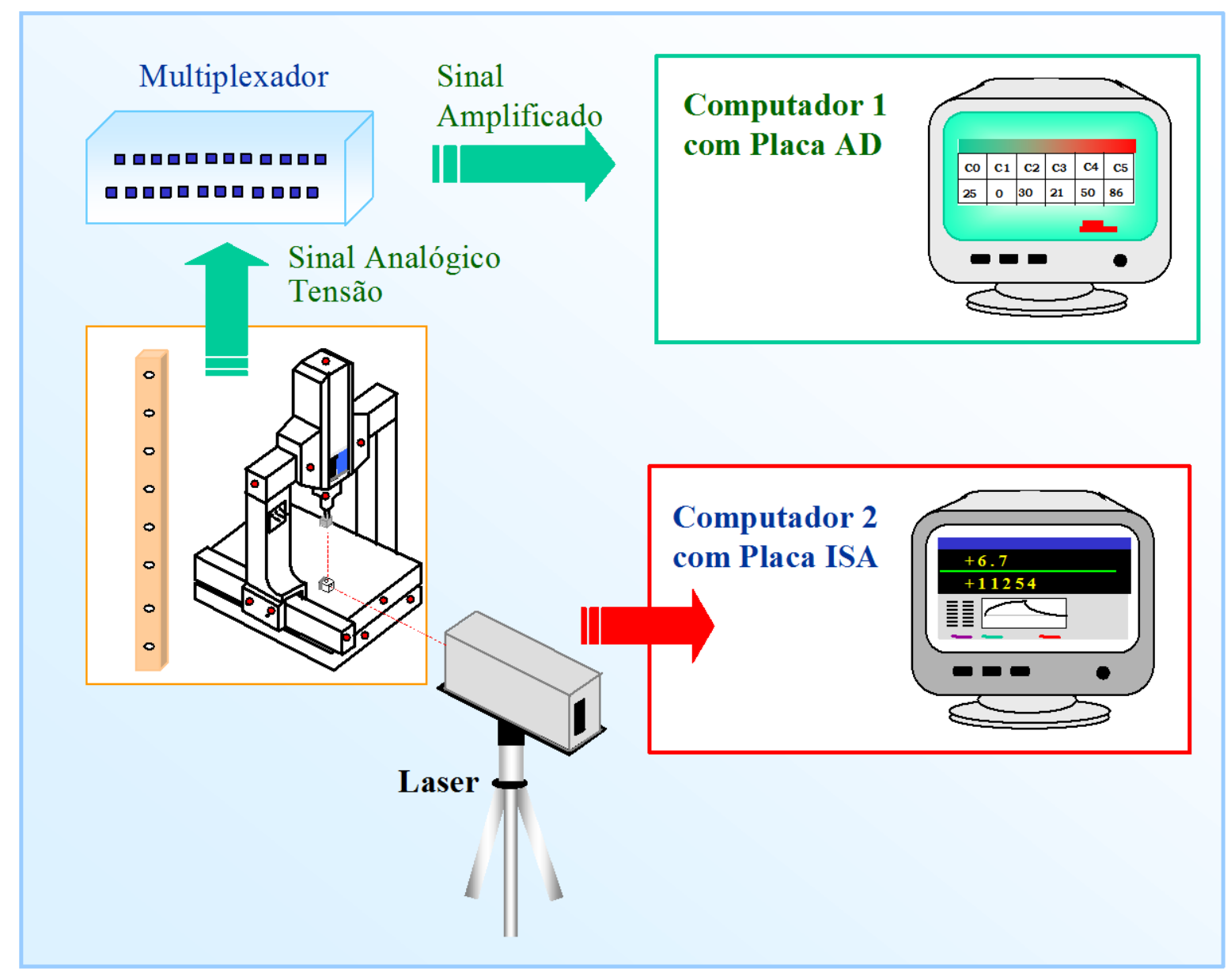

Figura 5.9 - Diagrama da montagem experimental.

Tomando como referência o trabalho desenvolvido por VIEIRA SATO (1998) foram coletados os dados referentes à variação dos erros em quatro pontos, distribuídos ao longo do eixo avaliado. 
Inicialmente foi desenvolvido um teste para determinar o tempo que a máquina precisa para atingir o equilíbrio térmico. Assim sendo, foi observada e coletada a variação do erro de posição do eixo $\mathrm{Y}$, no ponto zero, durante $5 \mathrm{~h} 30 \mathrm{~min}$. O estado inicial de temperatura foi de $20^{\circ} \mathrm{C}$ e o final de $26^{\circ} \mathrm{C}$. Os resultados deste teste estão mostrados no Capítulo 6 .

A partir dos valores coletados determinou-se a constante de tempo $\tau$ e o tempo que deve transcorrer para a estabilização do erro. Também foi estudada a capacidade de resposta da máquina.

A seguir foram coletados os valores de drift em quatro pontos. Considerando os resultados obtidos a partir do teste preliminar realizado, foi desenvolvida uma estratégia de medição, descrita na Tabela 5.2.

Tabela 5.2 - Procedimento experimental para coleta do drift.

\begin{tabular}{l|l|c}
\hline TEMPO (HORAS) & \multicolumn{2}{c}{ ETAPAS } \\
\hline & \multicolumn{1}{c}{ Montagem experimental } \\
\hline $0: 00$ & \multicolumn{2}{|c}{ Ligar o sistema de controle de temperatura a $20^{\circ} \mathrm{C}$} \\
\hline $0: 00-3: 10$ & \multicolumn{2}{|c}{ Estabilização da temperatura a $20^{\circ} \mathrm{C}$} \\
\hline $3: 10$ & $\begin{array}{l}\text { Trocar a temperatura para } 26{ }^{\circ} \mathrm{C} \text { e } \\
\text { começar a leitura do erro a cada } 10 \\
\text { segundos, no ponto escolhido. }\end{array}$ & $\begin{array}{c}\text { Inicia-se o monitora- } \\
\text { mento das tempera- } \\
\text { turas }\end{array}$ \\
\hline $3: 10-6: 20$ & Coleta do erro até a estab. a $20^{\circ} \mathrm{C}$ & \multirow{2}{*}{$\begin{array}{c}\text { Coleta da } \\
\text { temperatura }\end{array}$} \\
\hline $6: 20$ & Trocar a temperatura para $20^{\circ} \mathrm{C}$ & \\
\hline $6: 20-9: 30$ & Coleta do erro até a estab. a $26^{\circ} \mathrm{C}$ & \\
\hline $9: 30$ & Fim do experimento & \\
\hline $9: 30$ & Desligar o sistema & \\
\hline
\end{tabular}

Como resultado foram obtidos quatro conjuntos de dados para cada erro, Tabela 5.3.

\begin{tabular}{|c|c|c|c|c|c|c|c|c|c|}
\hline & & \multicolumn{4}{|c|}{ PosiçÃo } & \multicolumn{4}{|c|}{ TEMPERATURA } \\
\hline $\begin{array}{c}\text { Tempo } \\
(\mathrm{h})\end{array}$ & $\begin{array}{c}\text { Estado } \\
\text { Térmico }\end{array}$ & $P_{1}$ & $P_{2}$ & $P_{3}$ & $P_{4}$ & $T_{1}$ & $T_{2}$ & ... & $T_{18}$ \\
\hline 0 & 1 & Verrol ${ }_{1}^{l}$ & Verro $_{2}^{l}$ & Verro $_{3}^{l}$ & Verro $_{4}^{l}$ & $T_{1}^{l}$ & $T_{2}^{l}$ & $\ldots$ & $T_{18}^{l}$ \\
\hline $0: 00: 27$ & 2 & Verro $_{1}^{2}$ & Verro $_{2}^{2}$ & Verro $_{3}^{3}$ & Verro $_{4}^{4}$ & $T_{1}^{2}$ & $T_{2}^{2}$ & ... & $T_{18}^{2}$ \\
\hline ... & $\ldots$ & $\ldots$ & ... & ... & ... & ... & ... & ... & ... \\
\hline $3: 10: 00$ & $\mathrm{~m}$ & Verro $_{1}^{m}$ & Verro $_{2}^{m}$ & Verro $_{3}^{m}$ & Verro $_{4}^{m}$ & $\overline{T_{1}^{m}}$ & $T_{2}^{m}$ & ... & $T_{18}^{m}$ \\
\hline
\end{tabular}


Concluídos os experimentos e de posse dos conjuntos de dados necessários procedeu-se à obtenção e avaliação do modelo proposto.

\subsection{Avaliação do Modelo Proposto}

Para obtenção do modelo proposto foram substituídos, adequadamente, os dados coletados nas equações matemáticas e efetuada a manipulação conveniente dos mesmos. Numa primeira fase foram obtidas as equações que descrevem o comportamento geométrico-térmico dos erros individuais. Posteriormente, obtiveram-se as equações das componentes do erro volumétrico considerando as influências térmicas para que o mapa de erros da máquina possa ser gerado. Os resultados concernentes a esta etapa estão apresentados no Capítulo 6.

A validação do modelo obtido foi efetuada através da medição de um anel padrão. Desta forma, foram comparados os valores dos diâmetros medidos com a máquina e aqueles obtidos através do modelo de sintetização. Este anel foi medido em diferentes posições do volume de trabalho da máquina e para diferentes temperaturas.

$\mathrm{O}$ anel padrão foi medido em distintas posições e para diferentes valores de temperatura, para tanto, foram coletadas as coordenadas de 11 pontos distribuídos, aleatoriamente, na superficie que define o diâmetro padrão do referido anel. Para as coordenadas dos pontos coletados durante a medição foram sintetizados os valores das componentes do erro volumétrico, através do modelo proposto. Em seguida foi efetuada a correção dos erros nestes pontos, obtendo-se os valores reais das coordenadas, então calculado o diâmetro do círculo.

A equação de um círculo de centro $\mathrm{C}=\left(\mathrm{X}_{0}, \mathrm{Y}_{0}\right)$ e raio $\mathrm{r}>0$ é dada pela Eq. (5.26).

$$
\left(x-x_{c}\right)^{2}+\left(y-y_{c}\right)^{2}=r^{2}
$$


Aplicando-se o Método dos Mínimos Quadrados foi possível estimar as coordenadas do centro e o raio do círculo, tais expressões estão apresentadas na Eq. (5.27).

$$
\mathrm{x}_{\mathrm{c}}=\frac{-\mathrm{a}}{2}, \quad \mathrm{y}_{\mathrm{c}}=\frac{-\mathrm{b}}{2}, \quad \mathrm{r}=\sqrt{\mathrm{x}_{\mathrm{c}}^{2}+\mathrm{y}_{\mathrm{c}}^{2}-\mathrm{c}}
$$

No Apêndice E está descrita de forma detalhada a metodologia de cálculo das características do círculo.

Para se conhecer a eficiência do modelo proposto na previsão do erro volumétrico é preciso determinar a diferença entre os valores dos diâmetros calculados e o padrão. O diâmetro padrão foi determinado através da calibração. Para tanto, foi utilizada uma máquina universal de medir, fabricada pela Societe Geneovoise D'Instruments de Physique (SIP), tipo 302M, cuja resolução e incerteza são $0,1 \mu \mathrm{m}$ e $\pm 0,1 \mu \mathrm{m}$, respectivamente. Na Tabela 5.4 estão os resultados da calibração do anel padrão.

\begin{tabular}{c|c}
\hline Tabela $5.4-$ Resultados da calibração do anel padrão \\
\hline Temperatura ${ }^{\circ} \mathrm{C}$ & Diâmetro \\
\hline 20 & $140,0124 \mathrm{~mm} \pm 1,0 \mu \mathrm{m}$ \\
\hline 26 & $140,0137 \mathrm{~mm} \pm 0,7 \mu \mathrm{m}$ \\
\hline
\end{tabular}

Conhecidos o diâmetro real e o padrão é determinada a diferença entre estes valores, Eq. (5.28). Esta diferença é denominada "erro residual".

$$
\text { Erro Re sidual }=D_{R}-D_{P}
$$

A partir dos valores dos erros residuais foi efetuada uma análise para decidir se o modelo é adequado ou não. A adequabilidade do modelo está condicionada a valores de "erro residual" muito próximos de zero e distribuídos normalmente. 


\subsection{DeterminaÇÃo da INCERTEZA}

O cálculo da incerteza de medição foi efetuado a partir das equações matemáticas que descrevem as componentes $E x, E y$ e $E z$ do erro volumétrico, através da aplicação da Lei de Propagação de Incertezas. Nos cálculos foram considerados os fatores que influenciam as grandezas medidas, dentre eles: temperatura e resolução dos instrumentos de medição.

\subsubsection{Determinação da incerteza de medição associada às} componentes do erro volumétrico Ex, Ey e Ez

De posse das equações de sintetização, Eqs (5.16), (5.17) e (5.18), procedeu-se ao cálculo da incerteza de medição. Através da aplicação da lei de propagação das incertezas foram obtidas as Eqs (5.30), (5.31) e (5.32), utilizadas para estimar a incerteza das componentes $E x, E y$ e $E z$ do erro volumétrico, respectivamente.

$$
\begin{aligned}
& u^{2} E x=\left(\frac{\partial E x}{\partial P O S(x)}\right)^{2} u_{P o s(x)}^{2}+\left(\frac{\partial E x}{\partial R y(x)}\right)^{2} u_{R y(x)}^{2}+\left(\frac{\partial E x}{\partial R z(x)}\right)^{2} u_{R z(x)}^{2}+ \\
& +\left(\frac{\partial E x}{\partial[\operatorname{Ort}(x y)]}\right)^{2} u_{[\text {Ort }(x y)]}^{2} \cdot\left(\frac{\partial E x}{\partial\left[Y_{34}\right]}\right)^{2} u_{\left[Y_{34}\right]}^{2}+\left(\frac{\partial E x}{\partial[\operatorname{Yaw}(y)]}\right)^{2} u_{[\text {Yaw } y)]}^{2} . \\
& \cdot\left(\frac{\partial E x}{\partial\left[Y_{34}\right]}\right)^{2} u_{\left[Y_{34}\right]}^{2}+\left(\frac{\partial E x}{\partial[\operatorname{Ort}(x z)]}\right)^{2} u_{[\operatorname{Ort}(x z)]}^{2} \cdot\left(\frac{\partial E x}{\partial\left[-Z-Z_{45}\right]}\right)^{2} u_{\left[-Z-Z_{45}\right]}^{2}+ \\
& +\left(\frac{\partial E x}{\partial[\operatorname{Pitch}(x)}\right)^{2} u_{[\text {Pitch }(x)]}^{2} \cdot\left(\frac{\partial E x}{\partial\left[-Z-Z_{45}\right]}\right)^{2} u_{\left[-Z-Z_{45}\right]}^{2}+\left(\frac{\partial E x}{\partial[\operatorname{Yaw}(z)]}\right)^{2} u_{[\operatorname{Yaw}(z)]}^{2} \cdot \\
& \cdot\left(\frac{\partial E x}{\partial\left[-Z-Z_{45}\right]}\right)^{2} u_{\left[-Z-Z_{45}\right]}^{2}+\left(\frac{\partial E x}{\partial[\operatorname{Ort}(x z)]}\right)^{2} u_{[\operatorname{lort}(x z)]}^{2} \cdot\left(\frac{\partial E x}{\partial\left[-Z-Z_{45}\right]}\right)^{2} u_{\left[-Z-Z_{45}\right]}^{2}+ \\
& +\left(\frac{\partial E x}{\partial[\operatorname{Roll}(y)]}\right)^{2} u_{[\operatorname{Roll}(y)]}^{2} \cdot\left(\frac{\partial E x}{\partial\left[Z_{12}-Z-Z_{45}\right]}\right)^{2} u_{\left[\left(Z_{12}-Z-Z_{45}\right)\right]}^{2}
\end{aligned}
$$




$$
\begin{aligned}
u^{2} E y & =\left(\frac{\partial E y}{\partial \operatorname{Pos}(y)}\right)^{2} u_{P o s(y)}^{2}+\left(\frac{\partial E y}{\partial R x(y)}\right)^{2} u_{R x(y)}^{2}+\left(\frac{\partial E y}{\partial R z(y)}\right)^{2} u_{R z(y)}^{2}+ \\
& +\left(\frac{\partial E y}{\partial[\operatorname{Ort}(x y)]}\right)^{2} u_{[\operatorname{Ort}(x y)]}^{2}+\left(\frac{\partial E y}{\partial\left[X_{23}\right]}\right)^{2} u_{\left[X_{23}\right]}^{2}+\left(\frac{\partial E y}{\partial[X]}\right)^{2} u_{[X]}^{2} \\
& +\left(\frac{\partial E y}{\partial[\operatorname{Yaw}(y)]}\right)^{2} u_{[\operatorname{Yaw}(y)]}^{2} \cdot\left(\frac{\partial E y}{\partial\left[X_{23}+X\right]}\right)^{2} u_{\left[X_{23}+X\right]}^{2}- \\
& -\left(\frac{\partial E y}{\partial[\operatorname{Pitch}(y))}\right)^{2} u_{[\operatorname{Pitch}(y)]}^{2} \cdot\left(\frac{\partial E y}{\partial\left[\left(Z_{12}-Z-Z_{45}\right)\right]}\right)^{2} u_{\left[\left(Z_{I 2}-Z-Z_{45}\right)\right]}^{2}- \\
& -\left(\frac{\partial E y}{\partial[\operatorname{Ort}(y z)]}\right)^{2} u_{[\operatorname{Ort}(y z)]}^{2} \cdot\left(\frac{\partial E y}{\partial\left[\left(-Z-Z_{45}\right)\right]}\right)^{2} u_{\left[\left(-Z-Z_{45}\right)\right]}^{2}-\left(\frac{\partial E y}{\partial[\operatorname{Roll}(x)]}\right)^{2} u_{[\operatorname{Roll}(x)]}^{2} \\
& \cdot\left(\frac{\partial E y}{\partial\left[\left(-Z-Z_{45}\right)\right]}\right)^{2} u_{\left[\left(-Z-Z_{45}\right)\right]}^{2}-\left(\frac{\partial E y}{\partial[\operatorname{Pitch}(z)]}\right)^{2} u_{[P i t c h(z)]}^{2} \cdot\left(\frac{\partial E y}{\partial\left[\left(-Z-Z_{45}\right)\right]}\right)^{2} u_{\left[\left(-Z-Z_{45}\right)\right]}^{2}
\end{aligned}
$$

$$
\begin{aligned}
u^{2} E z & =\left(\frac{\partial E z}{\partial \operatorname{Pos}(z)}\right)^{2} u_{P o s(z)}^{2}+\left(\frac{\partial E z}{\partial R x(z)}\right)^{2} u_{R x(z)}^{2}+\left(\frac{\partial E z}{\partial R y(z)}\right)^{2} u_{R y(z)}^{2}- \\
& -\left(\frac{\partial E z}{\partial[\operatorname{Roll}(y)]}\right)^{2} u_{[\operatorname{Roll}(y)]}^{2} \cdot\left(\frac{\partial E z}{\partial\left[\left(X_{23}+X\right)\right]}\right)^{2} u_{\left[\left(X_{23}+X\right)\right]}^{2}-\left(\frac{\partial E z}{\partial[\operatorname{Roll}(x)]}\right)^{2} u_{[\operatorname{Roll}(x)]}^{2} . \\
& -\left(\frac{\partial E z}{\partial\left[Y_{34}\right]}\right)^{2} u_{\left[Y_{34}\right]}^{2}-\left(\frac{\partial E z}{\partial[\operatorname{Pitch}(x)}\right)^{2} u_{[\operatorname{Pitch}(x)]}^{2} \cdot\left(\frac{\partial E z}{\partial\left[Y_{34}\right.}\right)^{2} u_{\left[Y_{34}\right]}^{2}
\end{aligned}
$$

Como cada uma das parcelas que representam os erros geométricos nas Eqs (5.30) - ( 5.32) foram determinadas a partir do somatório de outras parcelas o cálculo da incerteza foi efetuado neste nível procedendo-se posteriormente à somatória das contribuições individuais de cada erro na incerteza total. 


\subsubsection{Estimativa da incerteza associada à medição de erros utilizando o esquadro mecânico.}

A Equação (5.33) permite estimar a incerteza associada aos erros de perpendicularidade medidos utilizando o esquadro mecânico como padrão de referência.

$$
D=L_{L V D T}+C_{E s q}+R_{L V D T}
$$

onde

$$
\begin{array}{ll}
> & D: \text { deslocamento medido } \\
> & L_{L V D T}: \text { leitura feita no LVDT } \\
> & C_{E s q}: \text { correção devido ao erro do esquadro } \\
> & R_{L V D T}: \text { resolução do LVDT }
\end{array}
$$

Aplicando a lei de propagação de incertezas na Eq. (5.33) tem-se:

\begin{tabular}{|c|c|}
\hline $\begin{array}{l}\text { COEFICIENTE DE } \\
\text { SENSIBILIDADE }\end{array}$ & INCERTEZA PADRÃO COMBINADA \\
\hline$\frac{\partial D}{\partial L_{L V D T}}=1$ & $\begin{array}{l}\text { Avaliação Tipo A : Tamanho da Amostra: } 5 \\
\text { G.L.: } 4 \text { Distribuição de Prob: Normal } \\
\text { Coeficiente t-Student }(95 \%)=2,78 \quad u_{L V D T}=\sqrt{\frac{s^{2}}{N}}\end{array}$ \\
\hline$\frac{\partial D}{\partial C_{\text {Esquadro }}}=1$ & $\begin{array}{l}\text { Avaliação Tipo B : G.L.: } \infty \\
\text { Distrib. de Prob: Retangular } \quad u_{\text {Esquadro }}=\frac{C_{\text {Esquadro }}}{\sqrt{3}}\end{array}$ \\
\hline$\frac{\partial D}{\partial R_{L V D T}}=1$ & $\begin{array}{l}\text { Avaliação Tipo B : G.L.: } \infty \\
\text { Distrib. de Prob: Triangular }\end{array}$ \\
\hline
\end{tabular}

$$
u(D)^{2}=\left(\frac{\partial D}{\partial L_{L V D T}}\right)^{2}\left(u_{L_{L V D T}}\right)^{2}+\left(\frac{\partial D}{\partial C_{E s q}}\right)^{2}\left(u_{C_{E q q}}\right)^{2}+\left(\frac{\partial D}{\partial R_{L V D T}}\right)^{2}\left(u_{R_{L V D T}}\right)^{2}
$$

Tabela 5.5. Parâmetros para determinar a incerteza da medição dos erros de Perpendicularidade. 


\subsubsection{Estimativa da incerteza associada aos erros de posição medidos com o interferômetro laser.}

A Equação (5.35) permite determinar a incerteza associada à medição dos erros de posição.

$$
E_{P o s}=M-P+P \alpha_{P} \Delta T_{P}+P \alpha_{E} \Delta T_{E}+R_{\text {Laser }}+R_{M M 3 C}
$$

Agrupando convenientemente os termos e considerando que $\delta T=\Delta T_{E}-\Delta T_{P} \Rightarrow \Delta T_{E}=\delta T+\Delta T_{P}$ obtêm-se a Eq. (5.36).

$$
E_{P o s}=M-P\left[1+\alpha_{P} \Delta T_{P}+\alpha_{E}\left(\delta T+\Delta T_{P}\right)\right]+R_{\text {Laser }}+R_{M M 3 C}
$$

onde

$E_{P o s}:$ erro de posição;

$M$ : valor indicado pela máquina;

P: valor utilizado como referência / Laser;

$\alpha_{E}:$ coeficiente de dilatação térmica da escala;

$\alpha_{P}$ : coeficiente de dilatação térmica do feixe laser;

$\Delta T_{P}$ : diferença entre a temperatura ambiente e a temperatura de referência;

$\Delta T_{E}:$ diferença entre a temperatura da régua e a temperatura de referência;

$R_{\text {Laser }}:$ Resolução do laser;

$R_{M M 3 C}:$ Resolução da máquina.

A incerteza associada ao erro de posição é calculada através da Eq. (5.37).

$$
\begin{aligned}
u\left(E_{P o s}\right)^{2} & =\left(\frac{\partial E_{P o s}}{\partial M}\right)^{2}\left(u_{M}\right)^{2}+\left(\frac{\partial E_{P o s}}{\partial P}\right)^{2}\left(u_{P}\right)^{2}+\left(\frac{\partial E_{P o s}}{\partial \Delta T_{P}}\right)^{2}\left(u_{\Delta T_{P}}\right)^{2}+ \\
& \left(\frac{\partial E_{P o s}}{\partial \alpha_{E}}\right)^{2}\left(u_{\alpha_{E}}\right)^{2}+\left(\frac{\partial E_{P o s}}{\partial \alpha_{P}}\right)^{2}\left(u_{\alpha_{P}}\right)^{2}+\left(\frac{\partial E_{P o s}}{\partial \Delta T_{E}}\right)^{2}\left(u_{\Delta T_{E}}\right)^{2}+\left(\frac{\partial E_{P o s}}{\partial T}\right)^{2}\left(u_{\partial T}\right)^{2}
\end{aligned}
$$




\begin{tabular}{|c|c|}
\hline $\begin{array}{l}\text { Coeficiente de } \\
\text { Sensibilidade }\end{array}$ & Incerteza Padrão Combinada \\
\hline$\frac{\partial E_{P o s}}{\partial M}=1$ & $\begin{array}{l}\text { Avaliação Tipo A : Dist. Normal : N=5 : G.L. } 4 \\
\text { Coeficiente t-Student }(95 \%)=2,78 \quad u\left(\operatorname{Re} p_{M M 3 C}\right)=\sqrt{\frac{s^{2}}{N}}\end{array}$ \\
\hline$\frac{\partial E_{P o s}}{\partial R_{M M 3 C}}=1$ & $\begin{array}{l}\text { Avaliação Tipo B : Dist. Retangular : G.L. } \infty \\
\text { Resolução da } \mathrm{MM} 3 \mathrm{C}=0,002 \mathrm{~mm} \quad u\left(\operatorname{Re} s_{M M 3 C}\right)=\frac{0,002}{\sqrt{3}}\end{array}$ \\
\hline$\frac{\partial E_{P o s}}{\partial P}=1$ & $\begin{array}{l}\text { Avaliação Tipo B : Dist. Retangular : G.L. } \infty \\
\text { Resolução do } \operatorname{Laser}_{(\text {Posição) }}=0,01 \mu \mathrm{m} \quad u\left(\operatorname{Res}_{\text {Laser }}\right)=\frac{0,01}{\sqrt{3}}\end{array}$ \\
\hline$\frac{\partial E_{P o s}}{\partial \alpha_{P}}=-\Delta T_{P} \cdot P$ & $\begin{array}{l}\text { Avaliação Tipo B : Dist. Retangular : G.L. } \infty \\
\text { Incerteza conservativa } 10 \% \\
\qquad u\left(\alpha_{P}\right)=\frac{0,01 \cdot \alpha_{P}}{\sqrt{3}}\end{array}$ \\
\hline \multirow{3}{*}{$\frac{\partial E_{P o s}}{\partial \Delta T_{P}}=\left(\alpha_{E}-\alpha_{P}\right) \cdot P$} & $\begin{array}{l}\text { Incerteza associada à calibração do sensor de temp. } \\
\text { Avaliação Tipo B : Dist. Retangular : G.L. } \infty \\
\mathrm{u}\left(\text { Term) - Incerteza dada fabricante } u(\text { sen sor })=\frac{u(\text { Term })}{\sqrt{3}}\right.\end{array}$ \\
\hline & $\begin{array}{l}\text { Var. da temp. ambiente com relação à referência } \\
\text { Avaliação Tipo B : Dist. Retangular: G.L. } \infty \\
\text { varT - Variação de Temperatura } u(v a r T e m p)=\frac{v a r T}{\sqrt{3}}\end{array}$ \\
\hline & $u\left(\Delta T_{P}\right)=\sqrt{[u(\text { Term })]^{2}+[u(\text { varTemp })]^{2}}$ \\
\hline \multirow{4}{*}{$\frac{\partial E_{P o s}}{\partial \delta T}=-\alpha_{E} \cdot P$} & $\begin{array}{l}\text { Incerteza associada à calibração do sensor de temp. } \\
\text { Avaliação Tipo B : Dist. Retangular : G.L. } \infty \\
\mathrm{u}\left(\text { Term) - Incerteza dada fabric. } \quad u(\text { sen sor })=\frac{u(\text { Term })}{\sqrt{3}}\right.\end{array}$ \\
\hline & $\begin{array}{l}\text { Incerteza associada à calibração do sensor da régua } \\
\text { Avaliação Tipo B : Dist. Retangular : G.L. } \infty \\
\mathrm{u}\left(\text { TerR) - Incert. dada fabric. } u(\text { sen sorRégua })=\frac{u(\text { TerR })}{\sqrt{3}}\right.\end{array}$ \\
\hline & $\begin{array}{l}\text { Var. da temp. ambiente com relação à referência } \\
\text { Avaliação Tipo B : Dist. Retangular : G.L. } \infty \\
\Delta \mathrm{T} \text { - Diferença de Temperatura } u(d T)=\frac{\Delta T}{\sqrt{3}}\end{array}$ \\
\hline & $u(\delta T)=\sqrt{[u(\text { sen sor })]^{2}+[u(\text { sen sorRégua })]^{2}+[u(d T)]^{2}}$ \\
\hline$\frac{\partial E_{P o s}}{\partial \alpha_{E}}=-P \cdot\left(\delta T+\Delta T_{P}\right)$ & $\begin{array}{l}\text { Avaliação Tipo B : Dist. Retangular : G.L. } \infty \\
\text { Incerteza de } 10 \% \\
u\left(\alpha_{E}\right)=\frac{0,01 \cdot \alpha_{E}}{\sqrt{3}}\end{array}$ \\
\hline
\end{tabular}




\subsubsection{Incerteza associada aos erros de retitude e angulares pitch e yaw medidos com o interferômetro laser.}

O modelo matemático que representa os erros de retitude $\mathrm{e}$ angulares pitch e yaw de todos os eixos é dado na Eq. (5.38).

$$
E=e+R_{L A S E R}+\Delta T_{P / M}
$$

onde

$$
\begin{array}{ll}
> & E: \text { erro em questão } \\
> & e: \text { valor indicado pelo laser } \\
> & R_{L A S E R}: \text { resolução do laser } \\
>\quad & \Delta T_{P / M}: \text { variação da temperatura ambiente com relação à de } \\
& \text { referência. }
\end{array}
$$

Aplicando a lei de propagação de incertezas na Eq. (5.38) tem-se a

\begin{tabular}{|c|c|}
\hline $\begin{array}{l}\text { Coeficiente de } \\
\text { Sensibilidade }\end{array}$ & Incerteza Padrão Combinada \\
\hline$\frac{\partial E}{\partial e}=1$ & $\begin{array}{l}\text { Avaliação Tipo A : Dist. Normal : N=5 : G.L. } \infty \\
\text { Coeficiente t-Student }(95 \%)=2,78 \quad u(e)=\sqrt{\frac{s^{2}}{N}}\end{array}$ \\
\hline$\partial E$ & $\begin{array}{l}\text { Erros de Retitude } \\
\text { Avaliação Tipo B : Dist. Retangular : G.L. } \infty \\
\begin{array}{l}\text { Resolução do } \operatorname{Laser}_{(\text {Ret. }}=0,01 \mu \mathrm{m} \quad u\left(\operatorname{Res}_{\text {Laser }}\right)=\frac{0,01}{\sqrt{3}}\end{array}\end{array}$ \\
\hline$\partial R_{\text {Laser }}$ & 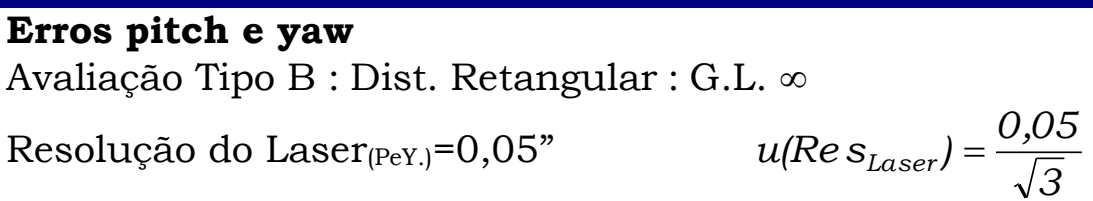 \\
\hline
\end{tabular}
Eq. (5.39).

$$
u(E)^{2}=\left(\frac{\partial E}{\partial e}\right)^{2}\left(u_{e}\right)^{2}+\left(\frac{\partial E}{\partial R_{L A S E R}}\right)^{2}\left(u_{R_{L S E R R}}\right)^{2}+\left(\frac{\partial E}{\partial \Delta T_{P / M}}\right)^{2}\left(u_{\Delta T_{P / M}}\right)^{2}
$$

$$
\text { Tabela } 5.7 \text { - Parâmetros para determinar a incerteza da medição dos }
$$
erros de Retitude e Angulares pitch e yaw. 
Tabela 5.7 - Parâmetros para determinar a incerteza da medição dos erros de Retitude e Angulares pitch e yaw.

\begin{tabular}{|c|c|}
\hline $\begin{array}{l}\text { COEFICIENTE DE } \\
\text { SENSIBILIDADE }\end{array}$ & INCERTEZA PADRÃO COMBINADA \\
\hline \multirow{3}{*}{$\frac{\partial E}{\partial \Delta T_{P / M}}=1$} & $\begin{array}{l}\text { Incerteza associada à calibração do sensor de temp. } \\
\text { Avaliação Tipo B : Dist. Retangular : G.L. } \infty \\
\mathrm{u}\left(\text { Term) - Incerteza dada fabricante } u(\text { sen sor })=\frac{u(\text { Term })}{\sqrt{3}}\right.\end{array}$ \\
\hline & $\begin{array}{l}\text { Variação da temp. ambiente com relação à referência } \\
\text { Avaliação Tipo B : Dist. Retangular : G.L. } \infty \\
\text { varT - Variação de Temperatura } \quad u(\text { varTemp })=\frac{\text { varT }}{\sqrt{3}}\end{array}$ \\
\hline & $u\left(\Delta T_{P}\right)=\sqrt{[u(\text { Term })]^{2}+[u(\text { varTemp })]^{2}}$ \\
\hline
\end{tabular}

\subsubsection{Incerteza associada à medição dos erros roll com o nivel eletrônico.}

O modelo matemático da medição dos erros angulares roll é dado na Eq. (5.40).

$$
E=e+R_{N}+\Delta T_{P / M}
$$

onde

$$
\begin{aligned}
& >E: \text { Erro } \\
& >\quad e: \text { valor indicado pelo nível } \\
& >\quad R_{N}: \text { resolução do nível } \\
& >\quad \Delta T_{P / M} \text { : variação da temperatura com relação à referência. }
\end{aligned}
$$

Aplicando a lei de propagação de incertezas na Eq. (5.40) obtém-se a Eq. (5.41).

$$
u(E)^{2}=\left(\frac{\partial E}{\partial e}\right)^{2}\left(u_{e}\right)^{2}+\left(\frac{\partial E}{\partial R_{N}}\right)^{2}\left(u_{R_{N}}\right)^{2}+\left(\frac{\partial M}{\partial \Delta T_{P / M}}\right)^{2}\left(u_{\Delta T_{P / M}}\right)^{2}
$$




\begin{tabular}{|c|c|}
\hline $\begin{array}{l}\text { Coeficiente de } \\
\text { Sensibilidade }\end{array}$ & Incerteza Padrão Combinada \\
\hline$\frac{\partial E}{\partial e}=1$ & $\begin{array}{l}\text { Avaliação Tipo A : Dist. Normal : N=5 : G.L. } 4 \\
\text { Coeficiente t-Student }(95 \%)=2,78 \quad u\left(\operatorname{Re} p_{M M 3 C}\right)=\sqrt{\frac{s^{2}}{N}}\end{array}$ \\
\hline \multirow{3}{*}{$\frac{\partial E}{\partial R_{N}}=1$} & $\begin{array}{l}\text { Nivel eletrônico } \\
\text { Avaliação Tipo B : Dist. Retangular : G.L. } \infty \\
\text { Resolução do Nivel eletrônico=0,1 s } \quad u\left(\operatorname{Re} s_{N e}\right)=\frac{0,1}{\sqrt{3}}\end{array}$ \\
\hline & $\begin{array}{l}\text { Nivel de bolha } \\
\text { Avaliação Tipo B : Dist. Retangular : G.L. } \infty \\
\text { Resolução do Nível de bolha=4 s } u\left(\operatorname{Re} s_{N b}\right)=\frac{4}{\sqrt{3}}\end{array}$ \\
\hline & $u\left(\Delta T_{P}\right)=\sqrt{\left[u\left(\operatorname{Re} s_{N b}\right)\right]^{2}+\left[u\left(\operatorname{Re} s_{N e}\right)\right]^{2}}$ \\
\hline \multirow{3}{*}{$\frac{\partial E}{\partial \Delta T_{P / M}}=1$} & $\begin{array}{l}\text { Incerteza associada à calibração do sensor de temp. } \\
\text { Avaliação Tipo B : Dist. Retangular : G.L. } \infty \\
u\left(\text { Term) - Incerteza dada fabricante } u(\text { sen sor })=\frac{u(\text { Term })}{\sqrt{3}}\right.\end{array}$ \\
\hline & $\begin{array}{l}\text { Variação da temp. ambiente com relação à referência } \\
\text { Avaliação Tipo B : Dist. Retangular : G.L. } \infty \\
\text { varT - Variação de Temperatura } \quad u(\text { varTemp })=\frac{\operatorname{varT}}{\sqrt{3}}\end{array}$ \\
\hline & $u\left(\Delta T_{P}\right)=\sqrt{[u(\text { Term })]^{2}+[u(\text { varTemp })]^{2}}$ \\
\hline
\end{tabular}

\subsubsection{Incerteza associada aos braços medidos com a régua mecânica.}

O modelo matemático para determinação da incerteza de medição associada aos braços medidos é dado pela Eq. (5.42).

$$
L=l+R_{R M}+\alpha_{R M} \cdot \Delta T_{P / M}
$$

onde

l: valor lido

$\alpha_{R M}$ : coeficiente de dilatação térmica da régua

$R_{R M}:$ resolução da régua 
$\Delta T_{P / M}$ : variação da temperatura ambiente com relação à de referência.

Aplicando a lei de propagação de incertezas na Eq. (5.42) obtém-se a Eq. (5.43).

$$
u(L)^{2}=\left(\frac{\partial L}{\partial l}\right)^{2}\left(u_{l}\right)^{2}+\left(\frac{\partial L}{\partial R_{R M}}\right)^{2}\left(u_{R_{R M}}\right)^{2}+\left(\frac{\partial L}{\partial \alpha_{R M}}\right)^{2}\left(u_{\alpha_{R M}}\right)^{2}+\left(\frac{\partial L}{\partial \Delta T_{P / M}}\right)^{2}\left(u_{\Delta T_{P / M}}\right)^{2}
$$

\begin{tabular}{|c|c|}
\hline $\begin{array}{l}\text { Coeficiente de } \\
\text { Sensibilidade }\end{array}$ & Incerteza Padrão Combinada \\
\hline$\frac{\partial L}{\partial l}=1$ & $\begin{array}{l}\text { Avaliação Tipo A : Dist. Normal : N=5 : G.L. } 4 \\
\text { Coeficiente t-Student }(95 \%)=2,78 \quad u(l)=\sqrt{\frac{s^{2}}{N}}\end{array}$ \\
\hline$\frac{\partial L}{\partial R_{R M}}=1$ & $\begin{array}{l}\text { Avaliação Tipo B : Dist. Retangular : G.L. } \infty \\
\text { Resolução de régua mecânica } 1 \mathrm{~mm} \quad u\left(R_{R M}\right)=\frac{1}{\sqrt{3}}\end{array}$ \\
\hline$\frac{\partial L}{\partial \alpha_{R M}}=\Delta T_{P / M}$ & $\begin{array}{l}\text { Avaliação Tipo B : Dist. Retangular : G.L. } \infty \\
\text { Incerteza de } 10 \% \\
\qquad u\left(\alpha_{P}\right)=\frac{0,01 \cdot \alpha_{R M}}{\sqrt{3}}\end{array}$ \\
\hline$\frac{\partial L}{\partial \Delta T_{P / M}}=\alpha_{R M}$ & $\begin{array}{l}\text { Avaliação Tipo B : Dist. Retangular : G.L. } \infty \\
\text { varT - Variação de Temperatura } \quad u(\text { varTemp })=\frac{\operatorname{varT}}{\sqrt{3}}\end{array}$ \\
\hline
\end{tabular}

A partir das indicações para o cálculo, dispostas nas Tabelas (5.5) - (5.9), podem ser encontrados os valores das derivadas parciais presentes nas Eq (5.30) - (5.32). 
Para ilustrar, apresenta-se a equação para o cálculo da incerteza associada à componente $Z$ do erro volumétrico, Eq. (5.44).

$$
\begin{aligned}
& u^{2} E z=\left[\begin{array}{l}
\left(\frac{\partial E_{\text {Pos } Z}}{\partial M}\right)^{2}\left(u_{M}\right)^{2}+\left(\frac{\partial E_{P o s Z}}{\partial P}\right)^{2}\left(u_{P}\right)^{2}+\left(\frac{\partial E_{P o s Z}}{\partial \Delta T_{P}}\right)^{2}\left(u_{\Delta T_{P}}\right)^{2}+\left(\frac{\partial E_{P o s Z}}{\partial \alpha_{E}}\right)^{2}\left(u_{\alpha_{E}}\right)^{2}+ \\
\left(\frac{\partial E_{\text {Pos } Z}}{\partial \alpha_{P}}\right)^{2}\left(u_{\alpha_{P}}\right)^{2}+\left(\frac{\partial E_{P o s Z}}{\partial \Delta T_{E}}\right)^{2}\left(u_{\Delta T_{E}}\right)^{2}+\left(\frac{\partial E_{P o s Z}}{\partial T}\right)^{2}\left(u_{\partial T}\right)^{2}
\end{array}\right]+ \\
& +\left[\left(\frac{\partial E_{R X z}}{\partial e}\right)^{2}\left(u_{e}\right)^{2}+\left(\frac{\partial E_{R X z}}{\partial R_{L A S E R}}\right)^{2}\left(u_{R_{L A S E R}}\right)^{2}+\left(\frac{\partial E_{R X z}}{\partial \Delta T_{P / M}}\right)^{2}\left(u_{\Delta T_{P / M}}\right)^{2}\right]+ \\
& +\left[\left(\frac{\partial E_{R Y z}}{\partial e}\right)^{2}\left(u_{e}\right)^{2}+\left(\frac{\partial E_{R Y Z}}{\partial R_{\text {LASER }}}\right)^{2}\left(u_{R_{\text {LASER }}}\right)^{2}+\left(\frac{\partial E_{R Y Z}}{\partial \Delta T_{P / M}}\right)^{2}\left(u_{\Delta T_{P / M}}\right)^{2}\right]- \\
& -\left[\left(\frac{\partial E_{\text {RollY }}}{\partial e}\right)^{2}\left(u_{e}\right)^{2}+\left(\frac{\partial E_{\text {RollY }}}{\partial R_{N}}\right)^{2}\left(u_{R_{N}}\right)^{2}+\left(\frac{\partial E_{R o l l Y}}{\partial \Delta T_{P / M}}\right)^{2}\left(u_{\Delta T_{P / M}}\right)^{2}\right] . \\
& {\left[\begin{array}{l}
\left(\frac{\partial\left(X_{23}+X\right)}{\partial l}\right)^{2}\left(u_{l}\right)^{2}+\left(\frac{\partial\left(X_{23}+X\right)}{\partial R_{R M}}\right)^{2}\left(u_{R_{R M}}\right)^{2}+ \\
+\left(\frac{\partial\left(X_{23}+X\right)}{\partial \alpha_{R M}}\right)^{2}\left(u_{\alpha_{R M}}\right)^{2}+\left(\frac{\partial\left(X_{23}+X\right)}{\partial \Delta T_{P / M}}\right)^{2}\left(u_{\Delta T_{P / M}}\right)
\end{array}\right]-} \\
& -\left[\left(\frac{\partial E_{\text {RollX }}}{\partial e}\right)^{2}\left(u_{e}\right)^{2}+\left(\frac{\partial E_{\text {RollX }}}{\partial R_{N}}\right)^{2}\left(u_{R_{N}}\right)^{2}+\left(\frac{\partial E_{\text {RollX }}}{\partial \Delta T_{P / M}}\right)^{2}\left(u_{\Delta T_{P / M}}\right)^{2}\right] . \\
& \cdot\left[\left(\frac{\partial Y_{34}}{\partial l}\right)^{2}\left(u_{l}\right)^{2}+\left(\frac{\partial Y_{34}}{\partial R_{R M}}\right)^{2}\left(u_{R_{R M}}\right)^{2}+\left(\frac{\partial Y_{34}}{\partial \alpha_{R M}}\right)^{2}\left(u_{\alpha_{R M}}\right)^{2}+\left(\frac{\partial Y_{34}}{\partial \Delta T_{P / M}}\right)^{2}\left(u_{\Delta T_{P / M}}\right)\right] \text { - } \\
& -\left[\left(\frac{\partial E_{\text {PitchX }}}{\partial e}\right)^{2}\left(u_{e}\right)^{2}+\left(\frac{\partial E_{\text {PitchX }}}{\partial R_{\text {LASER }}}\right)^{2}\left(u_{R_{\text {LASER }}}\right)^{2}+\left(\frac{\partial E_{P i t c h X}}{\partial \Delta T_{P / M}}\right)^{2}\left(u_{\Delta T_{P / M}}\right)^{2}\right] . \\
& \cdot\left[\left(\frac{\partial Y_{34}}{\partial l}\right)^{2}\left(u_{l}\right)^{2}+\left(\frac{\partial Y_{34}}{\partial R_{R M}}\right)^{2}\left(u_{R_{R M}}\right)^{2}+\left(\frac{\partial Y_{34}}{\partial \alpha_{R M}}\right)^{2}\left(u_{\alpha_{R M}}\right)^{2}+\left(\frac{\partial Y_{34}}{\partial \Delta T_{P / M}}\right)^{2}\left(u_{\Delta T_{P / M}}\right)\right]
\end{aligned}
$$

Pode-se observar que na Eq. (5.44) está presente um número grande de termos fazendo do cálculo da incerteza associada às componentes do erro volumétrico uma tarefa trabalhosa. 


\section{Capítulo 6}

\section{RESUlTADOS E DISCUSSÕES}

Depois de apresentados os aspectos teóricos e os procedimentos utilizados no desenvolvimento deste trabalho, cabe fazer a apresentação e discussão dos resultados. Para tanto, este capítulo está dividido em quatro itens. No primeiro item são apresentados os resultados da análise do sistema de medição. No segundo, as curvas que descrevem o comportamento dos erros geométricos para diferentes estados térmicos estacionários, assim como, as equações descrevendo a variação do erro em função das temperaturas durante o aquecimento. No terceiro item são apresentados os resultados da avaliação do modelo proposto. Por fim, no item quatro apresenta-se o cálculo da incerteza de medição.

\subsection{Resultados da ANálise do Sistema}

Neste item são apresentados os resultados obtidos durante a análise do sistema, isto é, onde estão as fontes de calor; os pontos quentes na estrutura da máquina e no ambiente, os resultados preliminares do monitoramento das temperaturas e os resultados do drift térmico. 


\subsubsection{Fontes de calor}

As fontes de calor que afetam o desempenho da máquina avaliada são:

a- Ar comprimido: A Máquina de Medir para seu funcionamento precisa de ar comprimido. Assim sendo, o ar do meio ambiente é comprimido, seco e filtrado e então direcionado à máquina a uma pressão constante através de mangueiras. Para tanto é utilizado um compressor de ar da marca PEG NAP 30/350, de alta pressão (AP) e um secador DPR DD15 com a finalidade de eliminar a umidade da rede de ar comprimido, evitando-se assim, erros de leitura da máquina, acúmulo de água nas vedações, entre outros. O sistema consta, ainda, de dois filtros de grau AO e AA utilizados para obter ar isento de água, óleo e partículas.

b- Memória térmica: A Máquina de Medir é constituída, basicamente, de alumínio, aço, granito e vidro. Estes materiais respondem de forma diferenciada às variações de temperatura e necessitam de intervalos de tempo diferentes para entrar em equilíbrio térmico com o ambiente.

c- Ambiente: $\mathrm{O}$ ambiente pode estar com temperatura controlada ou não. Para aqueles ambientes cuja temperatura é de $20 \pm 1{ }^{\circ} \mathrm{C}$ os efeitos térmicos presentes nas medições são mínimos. Para ambientes não controlados as variações da temperatura constituem uma grande preocupação.

d- Sistema de iluminação: O sistema de iluminação da sala consiste de quatro lâmpadas fluorescentes, sem proteção. As mesmas garantem luz adequada para o operador trabalhar, entretanto, o calor transmitido por radiação para a MM3C é muito grande. Estas lâmpadas ficaram ligadas durante todo o tempo de ensaio evitando-se, assim, efeitos térmicos cíclicos.

e- Pessoas: A máquina avaliada é manual, portanto requer da presença de um operador.

f- Outras Máquinas: Existem equipamentos nas proximidades da MM3C avaliada, eles são: computador, monitor, processador de sinais, 
etc. Estes equipamentos contribuem na geração de calor e modificam o comportamento térmico dos componentes da máquina durante o seu funcionamento.

$\mathrm{Na}$ máquina avaliada o número de fontes é reduzido, assim como, o calor gerado internamente. Isto, entretanto, não torna o problema das influências térmicas mais simples, pois esta máquina exige requisitos de precisão muito rigorosos.

\subsubsection{Pontos Quentes da Estrutura}

$\mathrm{Na}$ Figura 6.1 estão mostradas as imagens adquiridas com a câmera de visão infravermelha.

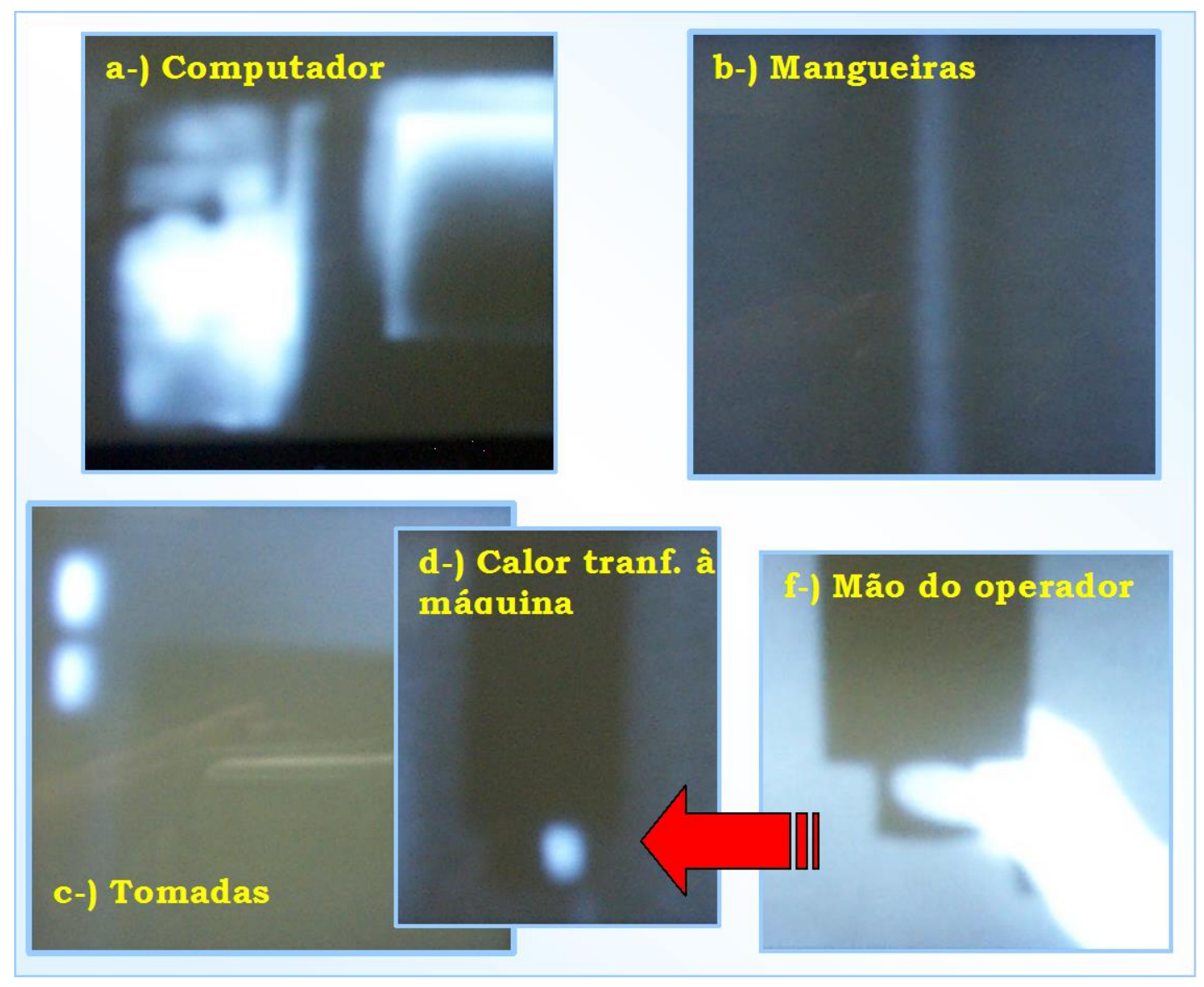

Figura 6.1 - Imagens de diferentes componentes. 
Na Figura 6.1 pode-se observar o computador, os cabos de alimentação, o ar fornecido à máquina e o operador representados por regiões claras indicando que a temperatura dos mesmos é maior que a da cena, isto é, maior que a temperatura ambiente. Estes componentes constituem fontes geradoras de calor. Com relação às três primeiras fontes deve-se ter um cuidado muito especial com sua localização, para assim diminuir seus efeitos. Destaca-se, também, a importância da manipulação correta da máquina e da peça a ser medida pelo operador durante as medições.

O operador constitui uma fonte de calor importante, dependendo da sua habilidade este efeito pode ser diminuído. A Figura 6.1 (e) mostra a mão do operador, segurando o eixo $Z$ como feito durante as medições e na Figura 6.1 (d) observa-se outra região clara no local do contato máquinaoperador, indicando que foi transferido calor à máquina por condução.

Entre os tons de cinza dos componentes da máquina não foram observadas diferenças significativas, muito provavelmente porque a diferença de temperatura entre eles é pequena. Porém, não pode ser descartada a existência de uma distribuição não homogênea das temperaturas, na estrutura da máquina.

A Figura 6.2 mostra os resultados dos testes envolvendo peças. A imagem a-) corresponde a uma peça de alumínio a temperatura ambiente, aproximadamente $30^{\circ} \mathrm{C}$ numa cena com temperatura de $20{ }^{\circ} \mathrm{C}$. Pode-se observar a peça em tons mais claros indicando temperatura maior que a ambiental.

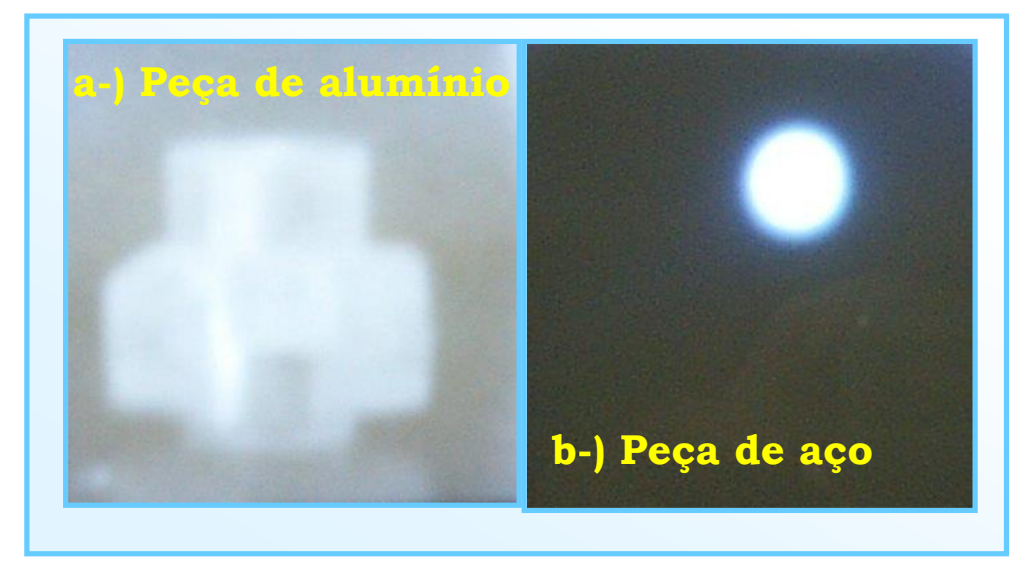

Figura 6.2 - Imagem das peças de aluminio e de aço inox. 
A imagem b-) mostra uma peça de aço inox com $14.4 \mathrm{~mm}$ e $11.5 \mathrm{~mm}$ de diâmetro e comprimento, respectivamente. Nesta peça foi praticado um rebaixo cônico, logo após a usinagem foi levada para o laboratório a temperatura ambiente, simulando procedimentos de medição efetuados nas linhas de produção. Na Figura pode-se observar uma região clara intensa no lugar da peça indicando que a mesma está aquecida.

Ambos os testes envolvendo peças mostraram que as temperaturas do sistema de medição e das peças são diferentes, assim sendo, se forem feitas medições nestas condições serão acrescentados erros ao resultado medido. Uma atenção especial deve ser prestada ao controle dimensional efetuado durante a usinagem, pois o calor transferido à peça durante esta fase é considerável.

\subsubsection{Gradientes térmicos espaciais}

Na Figura 6.3 estão mostradas as curvas que descrevem a variação da temperatura ambiente à direita da máquina, onde as curvas T21:T28 representam os diferentes termopares.

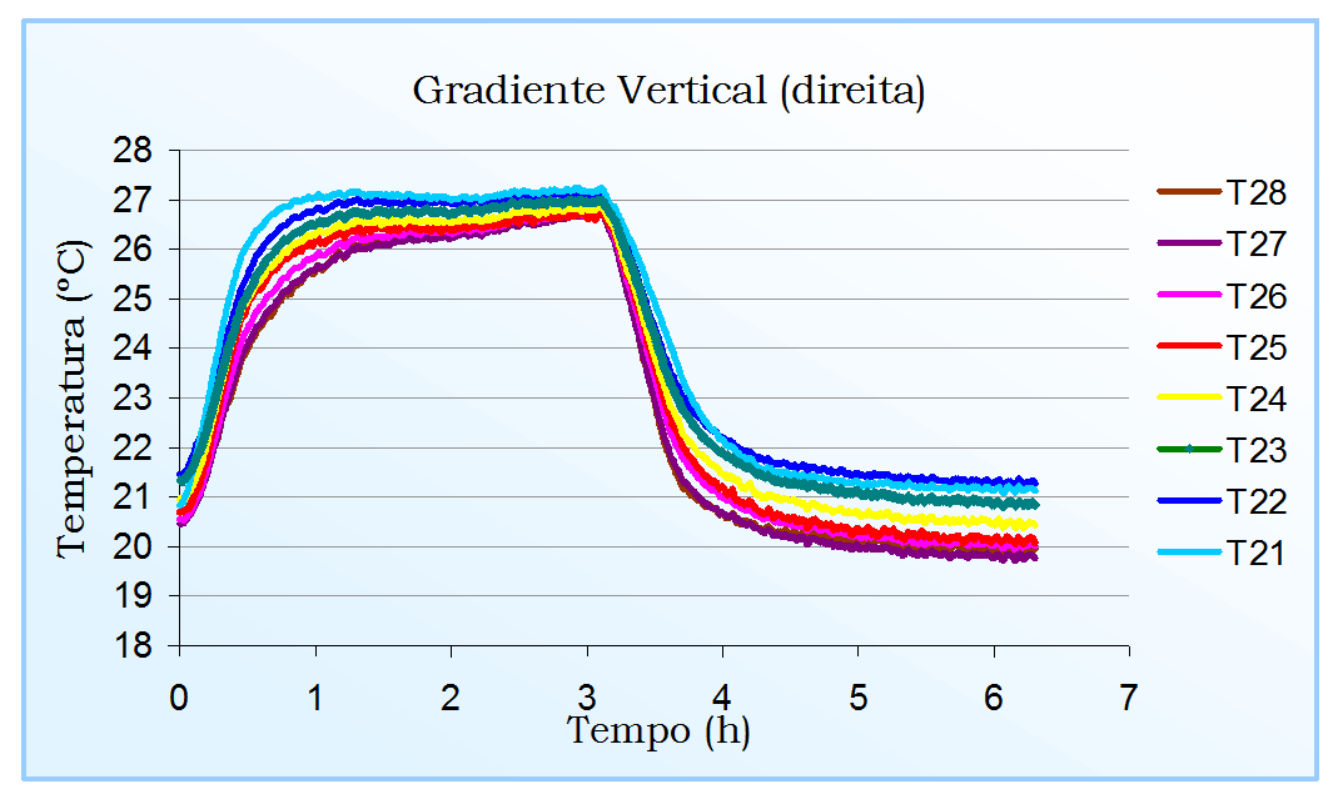

Figura 6.3 - Gradiente térmico vertical, à direita da máquina.

Verifica-se na Figura 6.3 a existência de um gradiente vertical que varia entre 0,4 e $1,0{ }^{\circ} \mathrm{C} / \mathrm{m}$, sendo que as temperaturas maiores foram 
registradas pelos termopares colocados na parte superior da árvore. Isto é, perto do teto da sala.

A Figura 6.4 corresponde ao monitoramento das temperaturas atrás da máquina. Verifica-se, nesta posição, que durante o aquecimento o gradiente vertical é, aproximadamente, de $0,7^{\circ} \mathrm{C} / \mathrm{m}$. Enquanto que para o esfriamento o gradiente atinge $1,7^{\circ} \mathrm{C} / \mathrm{m}$.

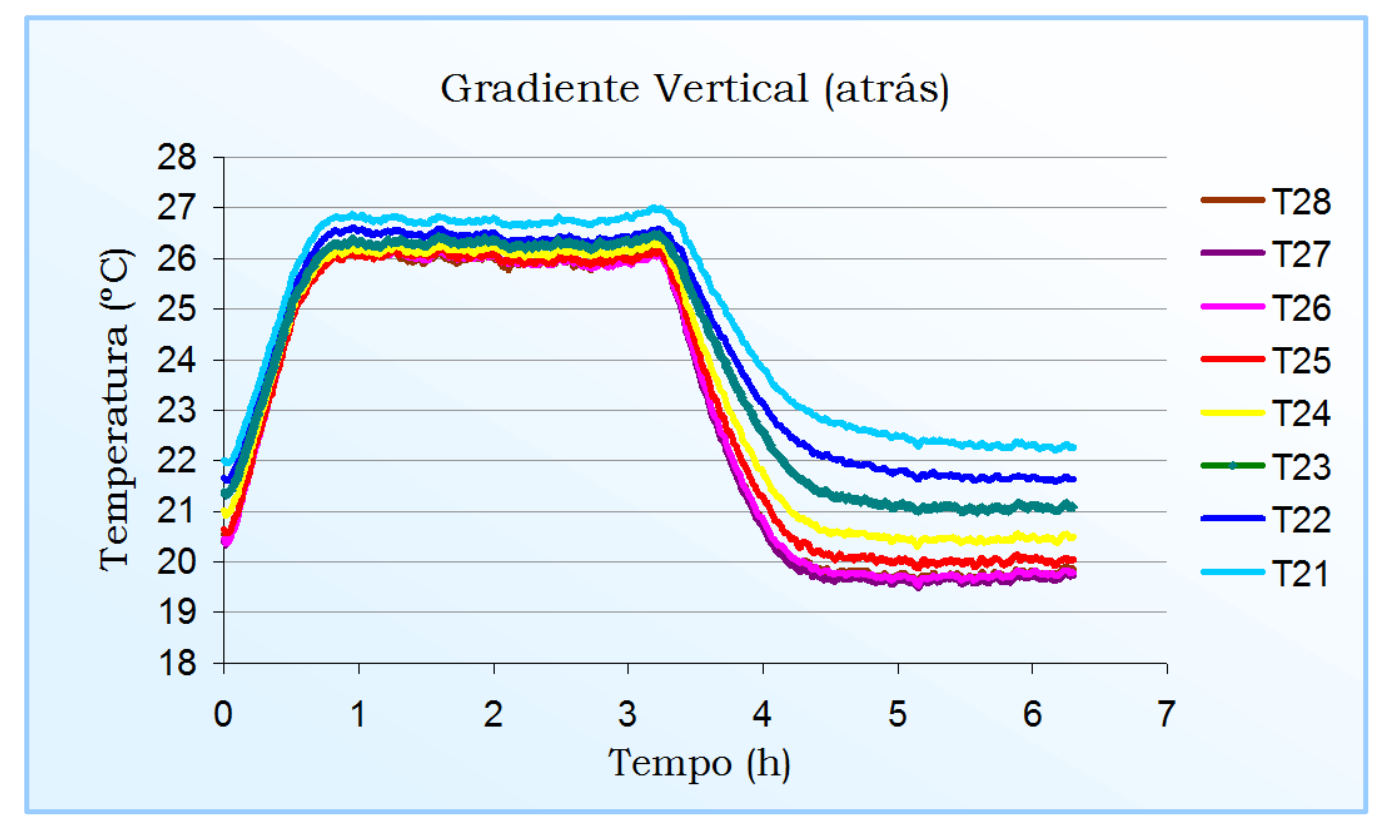

Figura 6.4 - Gradiente térmico vertical atrás da máquina.

A Figura 6.5 mostra as curvas que descrevem o gradiente vertical à esquerda da Máquina de Medir. Pode-se observar que nesta posição o gradiente tanto para aquecimento quanto para esfriamento são similares e de $1,7^{\circ} \mathrm{C} / \mathrm{m}$, aproximadamente. A posição das curvas de temperatura dos diferentes termopares no gráfico é diferente às anteriores. A temperatura do termopar 21 (T21) é a maior e a do termopar 28 (T28) é a menor. Isto porque nesta posição a árvore recebe um fluxo intenso de ar, proveniente do sistema de condicionamento de ar.

A temperatura do termopar 28 ultrapassa os $28{ }^{\circ} \mathrm{C}$ quando imposta uma temperatura ambiente de $26^{\circ} \mathrm{C}$. Observe também que para a temperatura imposta de $20{ }^{\circ} \mathrm{C}$ o termopar 28 apresenta $21,5{ }^{\circ} \mathrm{C}$, 
aproximadamente. Este fato é justificado pela presença de um

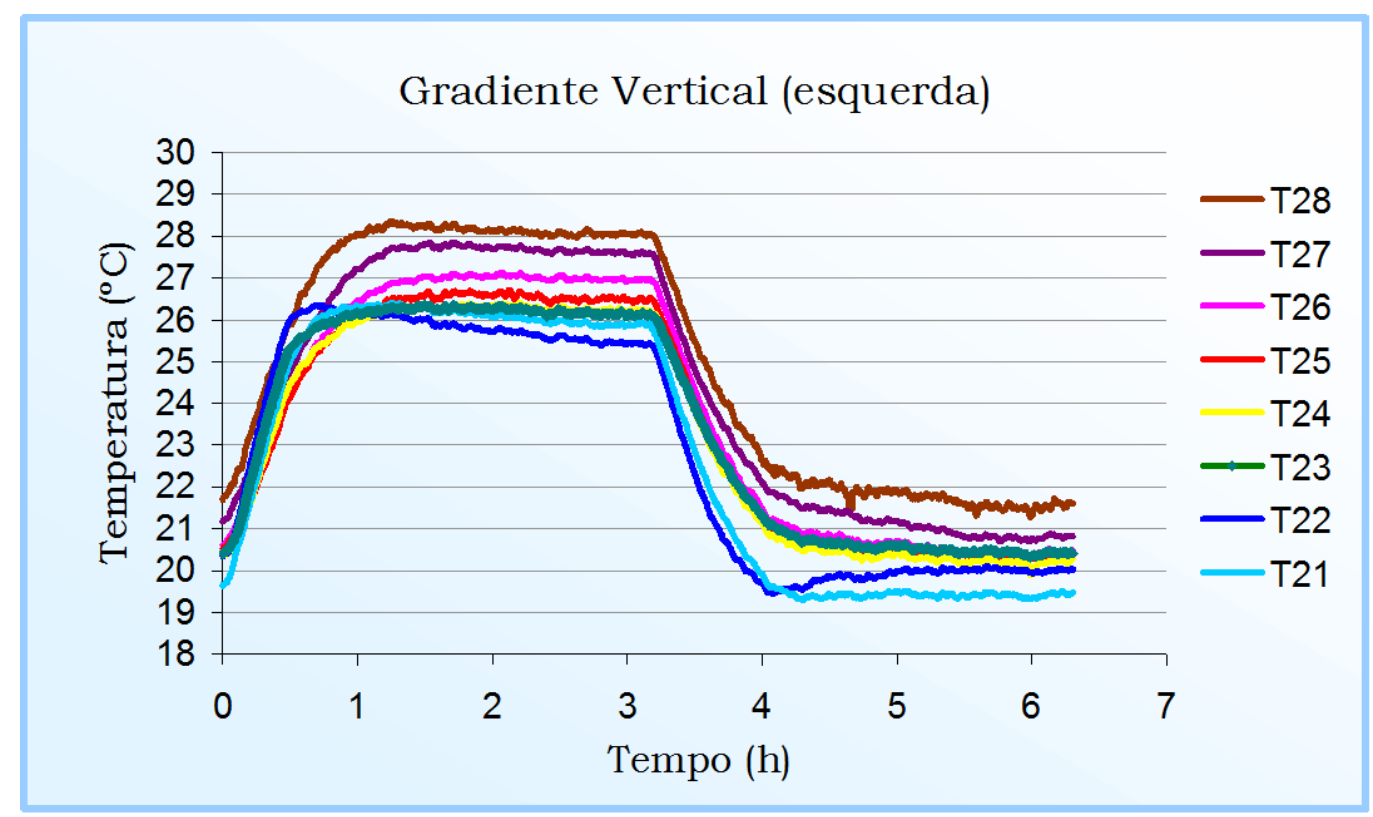

computador próximo da parte inferior da árvore.

Figura 6.5 - Gradiente térmico vertical à esquerda da máquina.

As diferenças encontradas entre as posições de observação estão dadas pela proximidade ou não de fontes localizadas de calor e pelo tipo de fonte.

\subsubsection{Distribuição da temperatura na estrutura da máquina}

Dos 16 termopares distribuídos na estrutura da máquina, 7 foram colados em componentes fixos, portanto as curvas que descrevem a temperatura dos mesmos são iguais para todos os ensaios de drift. Estes termopares são: $1,2,4,5,7,9$ e 15.

$\mathrm{Na}$ Figura 6.6 pode-se observar que a temperatura inicial dos componentes fixos é diferente, apesar de ter-se aguardado 3h 10min para iniciar a coleta dos dados, verifica-se que existe uma distribuição não homogênea de temperatura na estrutura da máquina. Este fato é melhor visualizado na Figura 6.7. Verifica-se que após $1 \mathrm{~h}$ 30min a temperatura 
da sala atingiu o equilíbrio térmico e que existe uma defasagem entre as curvas que descrevem a temperatura dos componentes da máquina e a do ambiente.

Os termopares 5 e 15 colocados nos extremos da guia esquerda do eixo $Y$ mostram valores de temperatura diferentes indicando a existência de um gradiente de temperatura horizontal. A parte dianteira da máquina tem a menor temperatura.

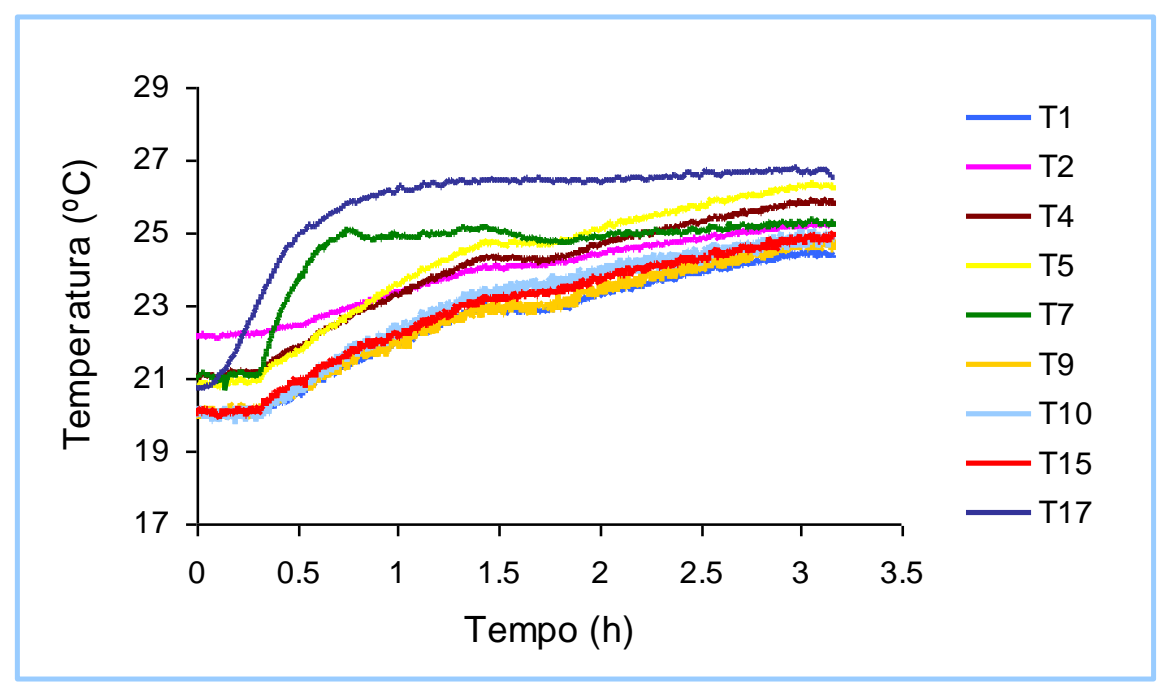

Figura 6.6 - Curvas da variação da temperatura dos elementos fixos da máquina e do ambiente.

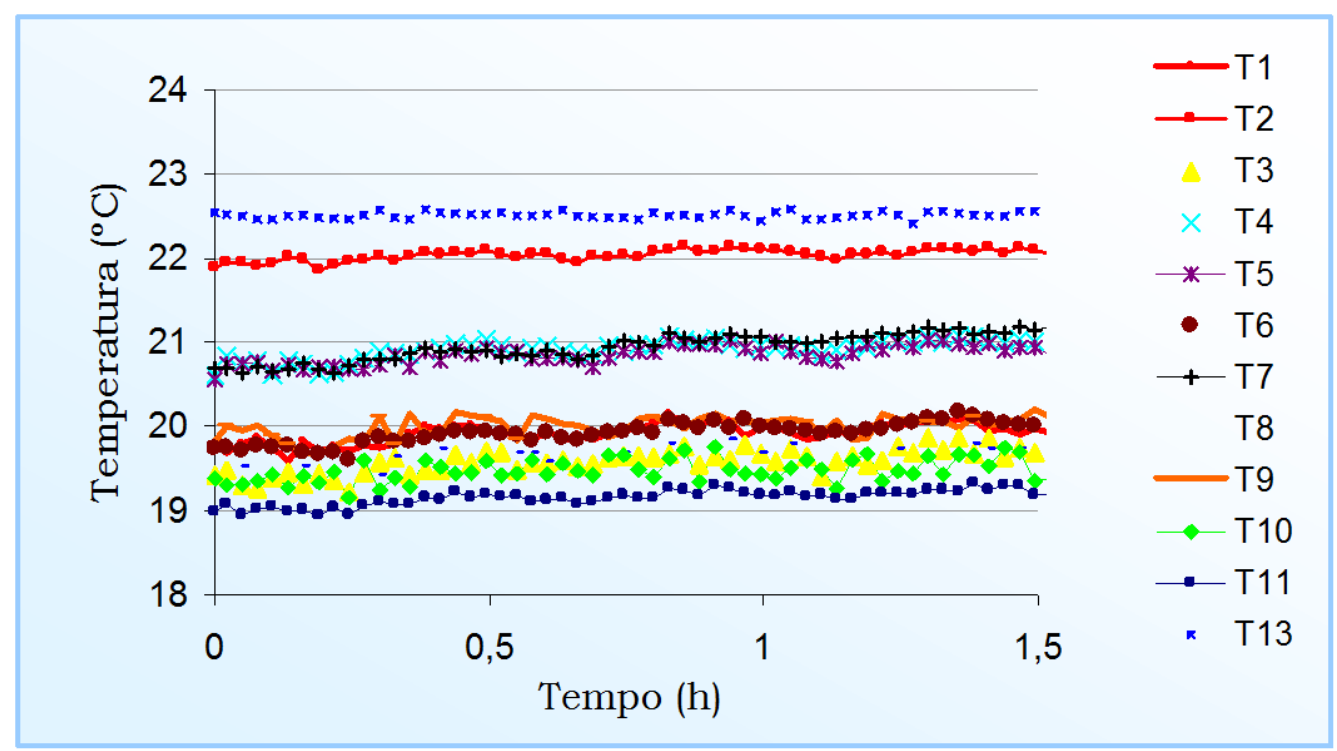

Figura 6.7 - Distribuição das temperaturas para $20^{\circ} \mathrm{C}$. 
O termopar 7 monitora a temperatura do sistema de alimentação de ar comprimido, especificamente a mangueira que alimenta os eixos $X, Y$ e $Z$. Observa-se na Figura 6.6 como T7 cresce rapidamente atingindo 24 ${ }^{\circ} \mathrm{C}$, em aproximadamente, 40min, após este tempo a temperatura permanece constante.

Na Figura 6.7 pode-se observar que a temperatura dos diferentes termopares encontra-se em regime estacionário, com uma variação de, aproximadamente, $3{ }^{\circ} \mathrm{C}$. Verifica-se a existência de uma distribuição não homogênea de temperaturas, de gradientes espaciais vertical e horizontal devido, principalmente, ao sistema de condicionamento de ar e a presença de fontes localizadas de calor. Recomenda-se a necessidade de projetar e instalar sistemas de condicionamento de ar que garantam uma distribuição mais homogênea de temperaturas.

\subsubsection{Resultados Preliminares de Levantamento dos Drifts}

O gráfico da Figura 6.8 mostra a variação termicamente induzida no erro de posição do eixo $Y$, no ponto zero, durante 5 h $30 \mathrm{~min}$, para um gradiente térmico de $6^{\circ} \mathrm{C}$. O estado inicial de temperatura foi de $20^{\circ} \mathrm{C}$ e o final de $26^{\circ} \mathrm{C}$.

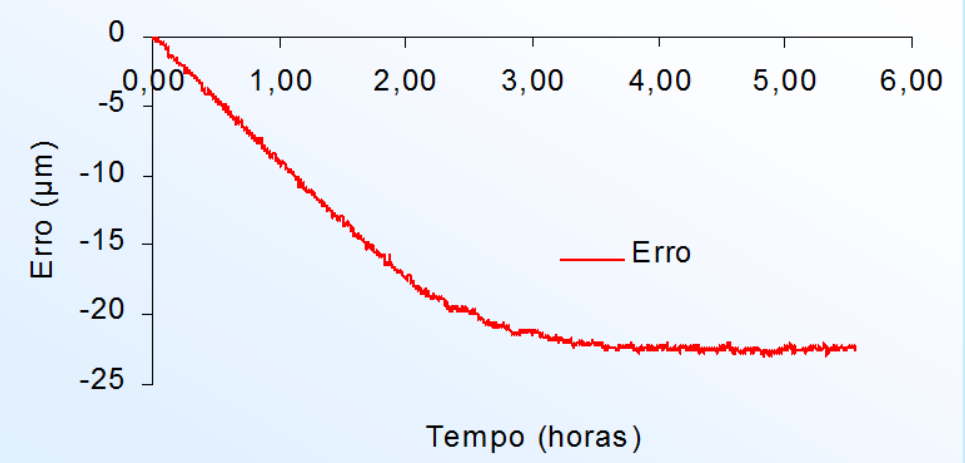

Figura 6.8 - Drift do erro de posição do eixo $Y$, no ponto zero.

A partir dos dados coletados foi determinada a constante de tempo da máquina $(\tau)$, isto é, o tempo que a máquina demora para atingir 
$63,5 \%$ da resposta final. Este valor resultou ser $1 \mathrm{~h} 35 \mathrm{~min} 20 \mathrm{~s}$. Posteriormente, foi avaliado o tempo que a máquina precisa para atingir o equilibrio térmico, sendo de $3 \mathrm{~h} 10 \mathrm{~min}$. Para tanto foi considerado que o sistema encontra-se em equilíbrio quando o erro atinge $95 \%$ da variação total.

Tomando como referência o trabalho desenvolvido por VIERA SATO (1997) pode-se concluir que a resposta da MM3C às variações de temperatura ambiente é rápida, correspondente a $2 \tau$, aproximadamente. Na Figura 6.9 observa-se que uma Máquina Ferramenta (Retificadora Cilindrica) atinge o equilíbrio térmico por volta de $9 \mathrm{~h}$ de funcionamento. Este resultado pode ser atribuído a fato desta máquina ser fabricada de ferro fundido.

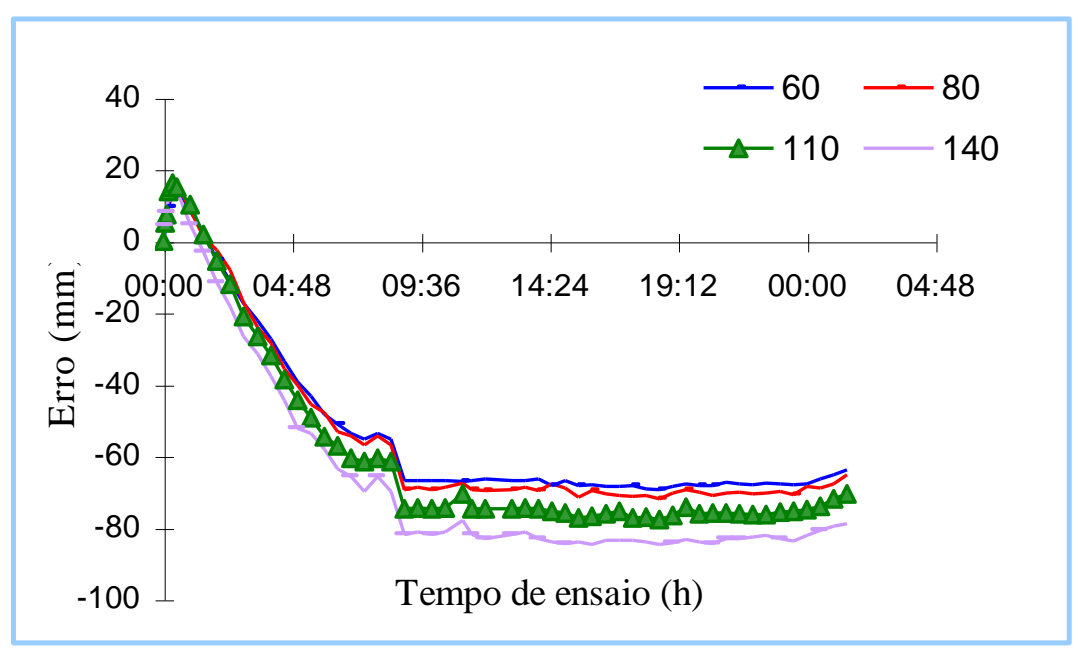

Figura 6.9 - Curvas de drift do erro de posição do eixo $X$ na Retificadora Cilindrica (VIEIRA SATO, 1998).

A rápida resposta da $\mathrm{MM} 3 \mathrm{C}$ às variações térmicas está justificada porque a maior parte dos componentes da mesma é fabricada de alumínio. Além disso, as guias e as colunas apresentam sessão transversal oca, com paredes finas, permitindo uma rápida troca de calor com o ambiente. Ainda, o desempeno que é o componente de maior massa é fabricado de granito, material cujo coeficiente de dilatação é baixo. 


\subsection{Resultados da Medição e Modelagem dos Erros Geométricos}

A seguir estão apresentados vários gráficos contendo as curvas que descrevem o comportamento dos erros de posição do eixo $X$. O primeiro gráfico mostra os erros de posição medidos para a temperatura de $20{ }^{\circ} \mathrm{C}$. Neste gráfico estão apresentadas quatro curvas que correspondem aos erros de posição nos sentidos de ida e de volta e o desvio padrão dos erros no sentido de ida. As curvas de desvio padrão do sentido de volta não estão apresentadas, pois têm comportamento similar às curvas do sentido de ida.

O segundo gráfico mostra os erros medidos nos sentidos de ida e de volta para diferentes estados de temperatura. Nestes dois gráficos as curvas contínuas pertencem aos erros medidos no sentido de ida e as pontilhadas pertencem aos erros medidos no sentido de volta. O terceiro gráfico apresenta a variação do erro nas quatro posições de observação do drift térmico.

Além dos gráficos que descrevem o comportamento do erro, são apresentados os gráficos que mostram a variação da temperatura dos diferentes termopares selecionados para a avaliação do erro em questão. Estes gráficos foram construídos com os dados de variação de temperatura obtidos durante os ensaios de drift. O tempo de ensaio (em horas) foi colocado no eixo das abscissas e, no eixo das ordenadas, a variação da temperatura dos termopares (dados em ${ }^{\circ} \mathrm{C}$ ).

São apresentadas, ainda, as equações que descrevem a variação do erro em cada uma das quatro posições de observação.

\subsubsection{Erro de posição do eixo $X$}

$\mathrm{Na}$ Figura 6.10 estão apresentadas as curvas que descrevem o comportamento do erro de posição do eixo $X$ para $20{ }^{\circ} \mathrm{C}$. Na Figura, pode- 
se observar que este erro é negativo, com desvio padrão $(99,97 \%)$ bastante pequeno. A histerese é de $14 \mu \mathrm{m}$, aproximadamente.

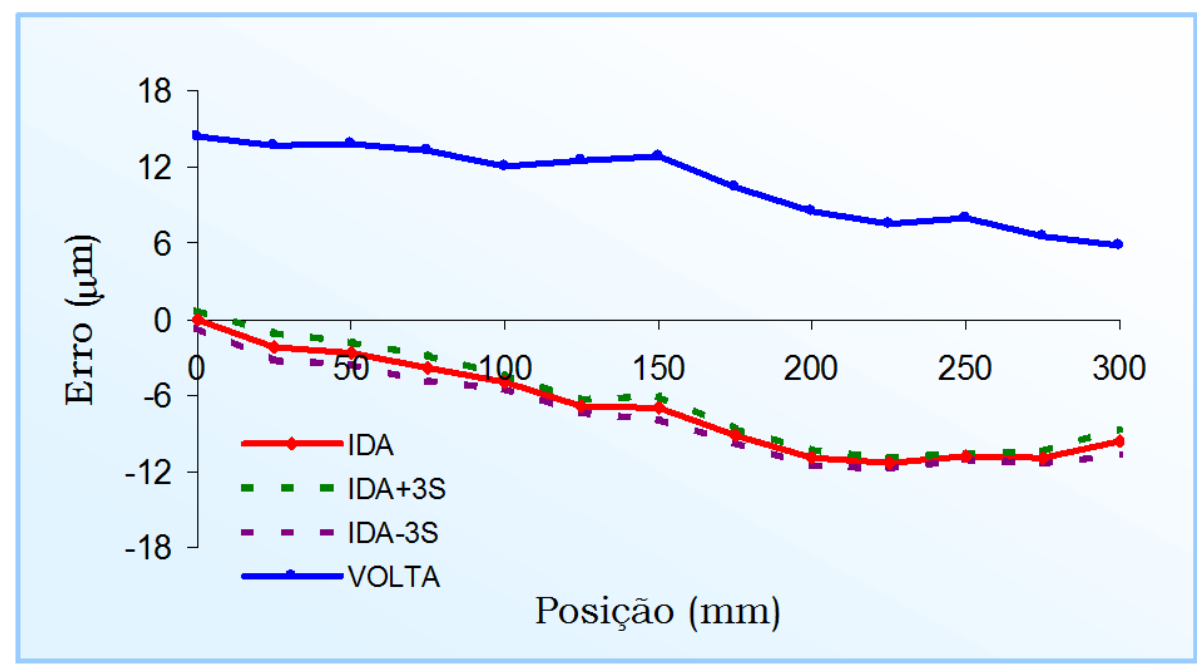

Figura 6.10 - Erro de posição do eixo $X$ para $20^{\circ} \mathrm{C}$.

Na Figura 6.11 pode-se observar que o erro apresenta a mesma tendência para os diferentes estados térmicos, decrescendo na medida em que a máquina se aquece. O erro atinge na posição $X=300 \mathrm{~mm}$ os valores de $-10,89,-14,55,-18,36$ e $-21,92 \mu \mathrm{m}$ para $20,22,24$ e $26{ }^{\circ} \mathrm{C}$, respectivamente. Ainda verifica-se que para gradientes térmicos iguais a variação do erro é aproximadamente a mesma.

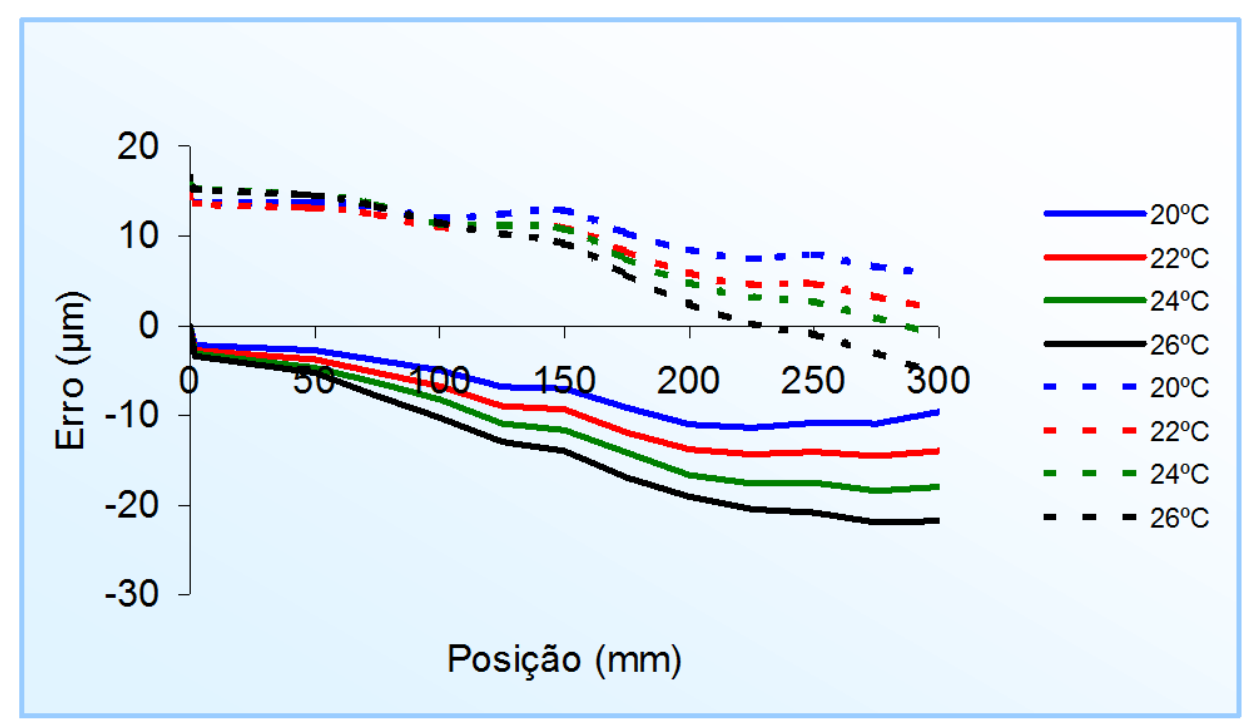

Figura 6.11 - Curvas do erro de posição do eixo $X$ para 20, 22, 24 e $26{ }^{\circ} \mathrm{C}$. 
A mudança experimentada pelo erro avaliado está estreitamente vinculada à dilatação da escala do eixo $X$, ou seja, é função do coeficiente de dilatação do vidro. Teoricamente uma escala de vidro com $300 \mathrm{~mm}$ de comprimento dilata-se $3,3 \mu \mathrm{m}$ a cada $2{ }^{\circ} \mathrm{C}$.

Na Figura 6.12 estão apresentadas as curvas que descrevem o comportamento das variações termicamente induzidas do erro de posição do eixo $X$, em cada um dos pontos de observação de drift. A primeira parte das curvas, de 0 h até $3 \mathrm{~h} 10 \mathrm{~min}$, mostra o comportamento da variação do erro durante o aquecimento, enquanto que de $3 \mathrm{~h} 10 \mathrm{~min}$ até $6 \mathrm{~h} 20 \mathrm{~min}$ apresenta a variação do erro durante o esfriamento.

Observa-se no gráfico da Figura 6.12 que o erro avaliado tem um comportamento diferente em cada posição, apresentando uma maior variação nos extremos do eixo. Uma análise efetuada a partir das curvas de drift dos erros de posição revelou que as guias e as escalas da máquina dilatam-se a partir de um local muito próximo de seus centros, provocando uma variação diferenciada ao longo do eixo (Apêndice G). Esta variação do erro diminui na medida em que os valores da coordenada $X$ aproximam-se da metade do percurso de medição nesta direção e apresenta um sinal que depende da posição de medição, isto é, do valor da coordenada $X$.

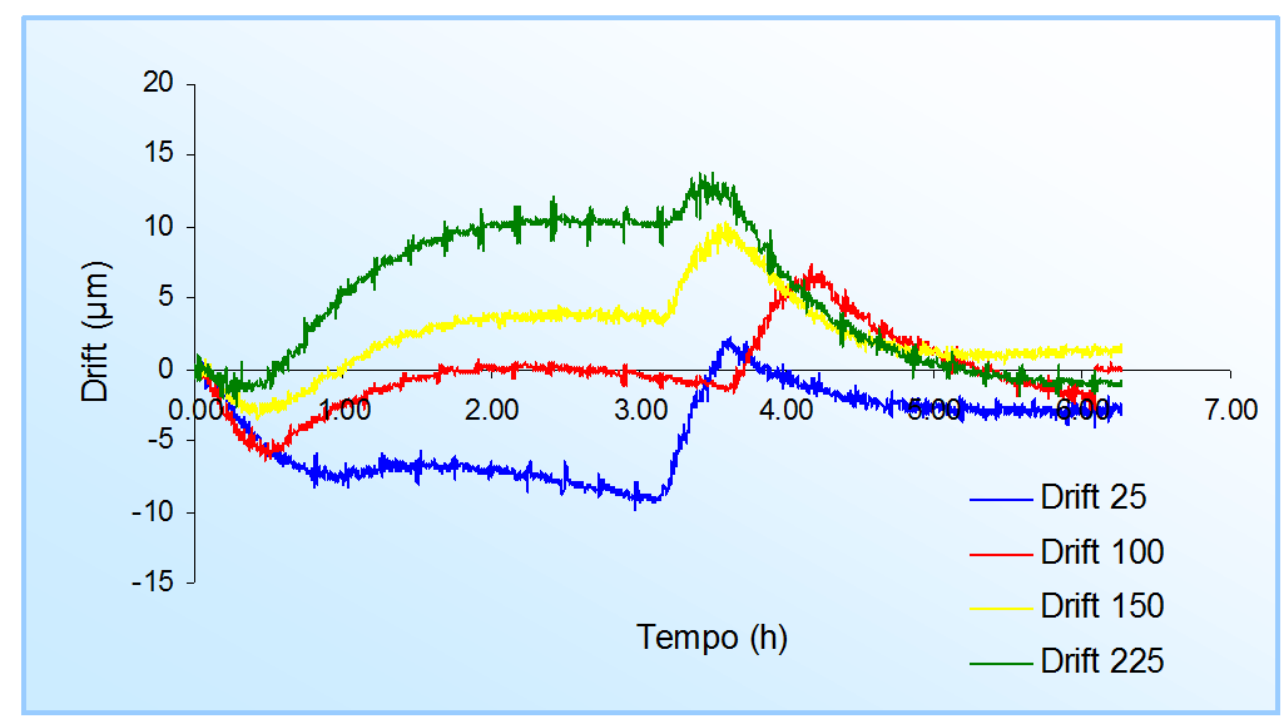

Figura 6.12 - Curvas de drift do erro de posição do eixo $X$. 
Na Figura 6.12 pode-se observar, ainda, que a variação do erro se apresenta de forma diferente durante o aquecimento e esfriamento da máquina. Apesar da tentativa de reproduzir as mesmas condições experimentais para realização dos testes de drift observou-se a presença de histerese.

A Figura 6.13 mostra uma vista frontal da máquina a fim de visualizar que durante a montagem da ponte móvel não foram impostas restrições que impeçam sua livre dilatação, na direção do eixo $X$. Assim sendo, durante o aquecimento a ponte dilata-se sem experimentar deformações termicamente induzidas.

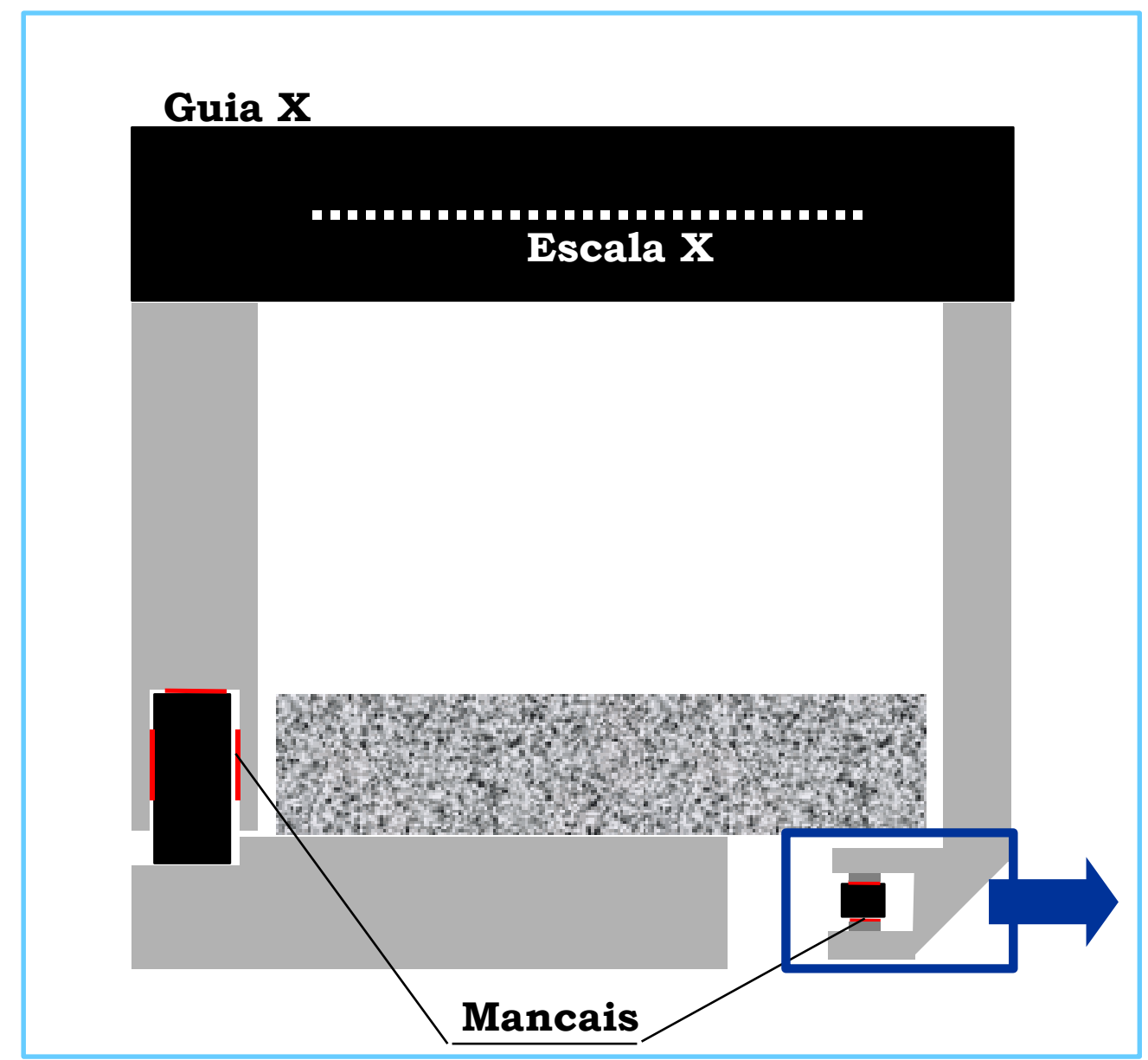

Figura 6.13 - Princípio de montagem da ponte móvel.

As variações das temperaturas, monitoradas simultaneamente à coleta dos valores de drift do erro de posição do eixo $X$, estão apresentadas na Figura 6.14 e 6.15. Na legenda estão discriminados os termopares que 
foram considerados no equacionamento do erro em cada posição de observação.

Durante os ensaios de drift do erro de posição do eixo $X$ a ponte móvel da máquina ficou parada, assim sendo, de uma posição de observação para outra somente movimentaram-se os carros dos eixos $X$ e $Z$. Portanto, as curvas que descrevem a variação das temperaturas dos seguintes termopares são iguais para todos os ensaios de drift do referido eixo: T1, T2, T3, T4, T5, T7, T8, T9, T10, T11, T15 e T17.

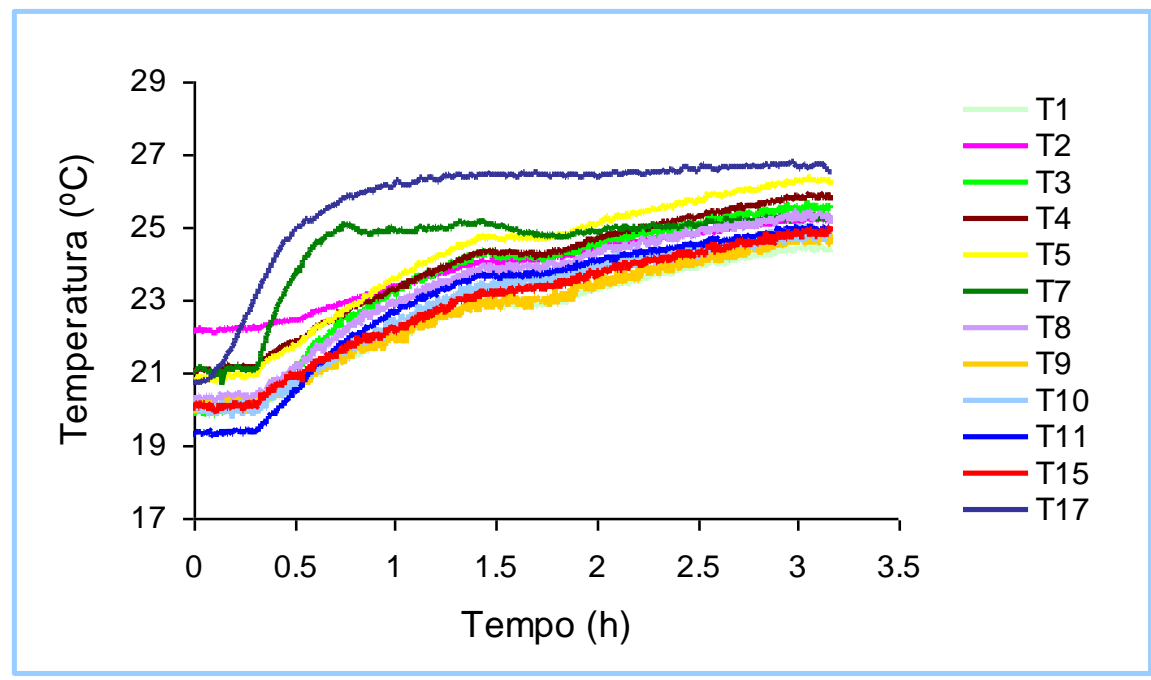

Figura 6.14 - Temperatura dos elementos fixos no drift do erro Pos $X$.

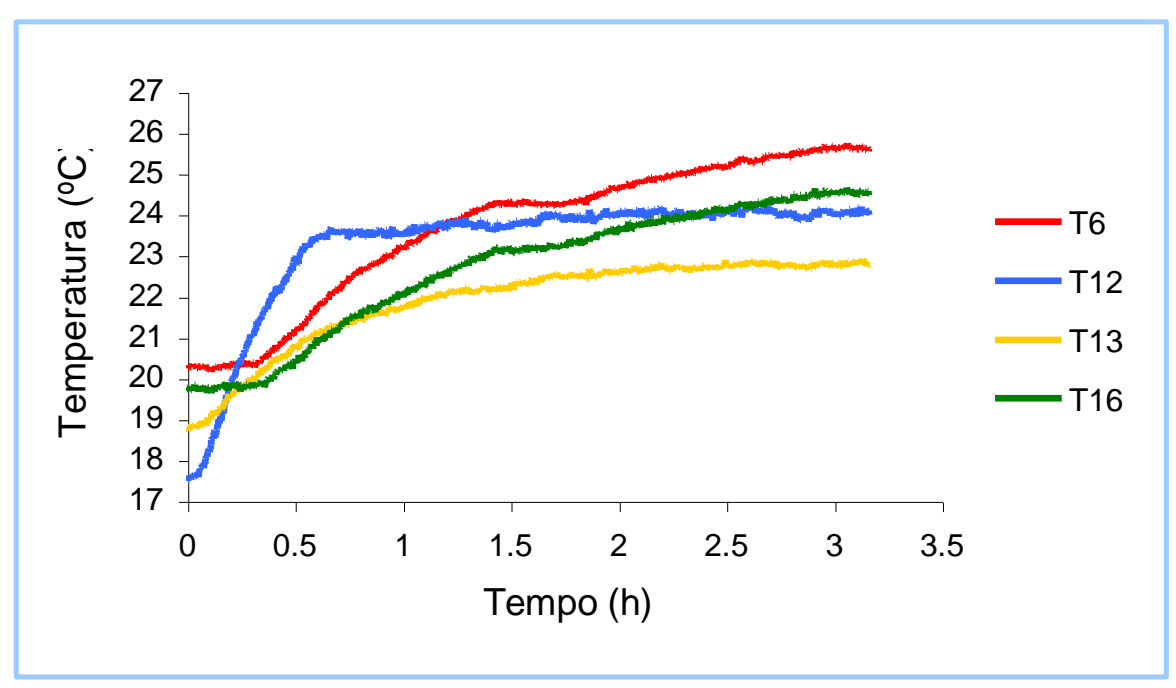

Figura 6.15 - Temperatura dos elementos móveis na posição $X=0$. 
Para mostrar a variação da temperatura dos elementos móveis está aqui apresentado apenas um gráfico, correspondente à posição de observação $X=0$, pois a variação das temperaturas nas outras posições é similar, observando-se apenas o efeito do gradiente térmico horizontal.

Com os dados obtidos e tratados de acordo com o que foi exposto no item 5.2 obteve-se, por meio de técnicas de regressão, as Eqs (6.1), (6.2), (6.3), (6.4). Tais equações descrevem a variação do erro em função da temperatura nas respectivas posições de observação $(X=0, X=75$, $X=150, X=225 \mathrm{~mm})$.

$$
\begin{aligned}
\begin{aligned}
V_{0}(T)= & 4,72 \cdot T_{1}-7,3 \cdot T_{2}+7,41 \cdot T_{4}-12 \cdot T_{6}-4,8 \cdot T_{7}+2,52 \cdot T_{9}+1,13 \cdot T_{10}- \\
& -3,4 \cdot T_{11}+4,71 \cdot T_{12}-0,5 \cdot T_{13}+4,97 \cdot T_{15}-2,1 \cdot T_{16}+5,57 \cdot T_{17}
\end{aligned} \\
\begin{aligned}
V_{75}(T)= & 10,8 \cdot T_{1}+10 \cdot T_{4}-7 \cdot T_{5}+5,85 \cdot T_{6}+1,98 \cdot T_{7}+3,24 \cdot T_{9}-28 \cdot T_{11} \\
& +2,07 \cdot T_{12}-9,2 \cdot T_{13}+19,4 \cdot T_{14}+3,81 \cdot T_{15}-26 \cdot T_{16}+14,2 \cdot T_{17}
\end{aligned} \\
\begin{aligned}
V_{150}(T)= & 8,59 \cdot T_{1}+27 \cdot T_{2}+2,96 \cdot T_{3}+5,36 \cdot T_{4}-16 \cdot T_{6}-1,6 \cdot T_{7}-2,8 \cdot T_{8}- \\
& -15 \cdot T_{11}+14,8 \cdot T_{12}-12 \cdot T_{13}-28 \cdot T_{15}-14 \cdot T_{16}+4,66 \cdot T_{17} \\
V_{225}(T)= & 0,695 \cdot T_{1}+0,39 \cdot T_{2}+0,844 \cdot T_{4}-1,6 \cdot T_{6}+0,142 \cdot T_{7}-0,26 \cdot T_{8}+0,205 \cdot T_{9}- \\
& -1,1 \cdot T_{11}+0,569 \cdot T_{12}-0,02 \cdot T_{13}-0,35 \cdot T_{14}-0,58 \cdot T_{16}+0,115 \cdot T_{17}
\end{aligned}
\end{aligned}
$$

Os coeficientes de correlação, $R^{2}$, encontrados para cada uma das curvas foram respectivamente: $99,70 \%, 97,90 \%, 98,93 \%$ e $98,84 \%$. A análise dos resíduos mostrou um comportamento aleatório, seguindo uma distribuição aproximadamente normal, com média próxima de zero e variância constante. Todos estes requisitos indicam que estas equações são adequadas para representar os dados experimentais. 
Resolvendo o sistema linear apresentado na Eq. (6.5), através do aplicativo "Matemática v. 4.0", obteve-se a expressão para a variação do erro.

$$
\left\{\begin{array}{l}
v(0, T)=V_{0}(T) \\
v(75, T)=V_{75}(T) \\
v(150, T)=V_{150}(T) \\
v(225, T)=V_{225}(T)
\end{array}\right.
$$

Somando as expressões do erro no estado de referência e a solução do sistema, Eq. (6.5), tem-se a função que descreve o comportamento do erro de Posição do eixo $X$, em qualquer estado de temperatura e posição do carro de movimentação.

\subsubsection{Erro de posição do eixo $Y$}

Pode ser observado, na Figura 6.16, que o erro de posição do eixo $Y$ é positivo, com tendência crescente e histerese de 3,7 $\mu \mathrm{m}$, permanecendo quase constante ao longo do eixo $Y$. O intervalo \pm 3 s também é pequeno.

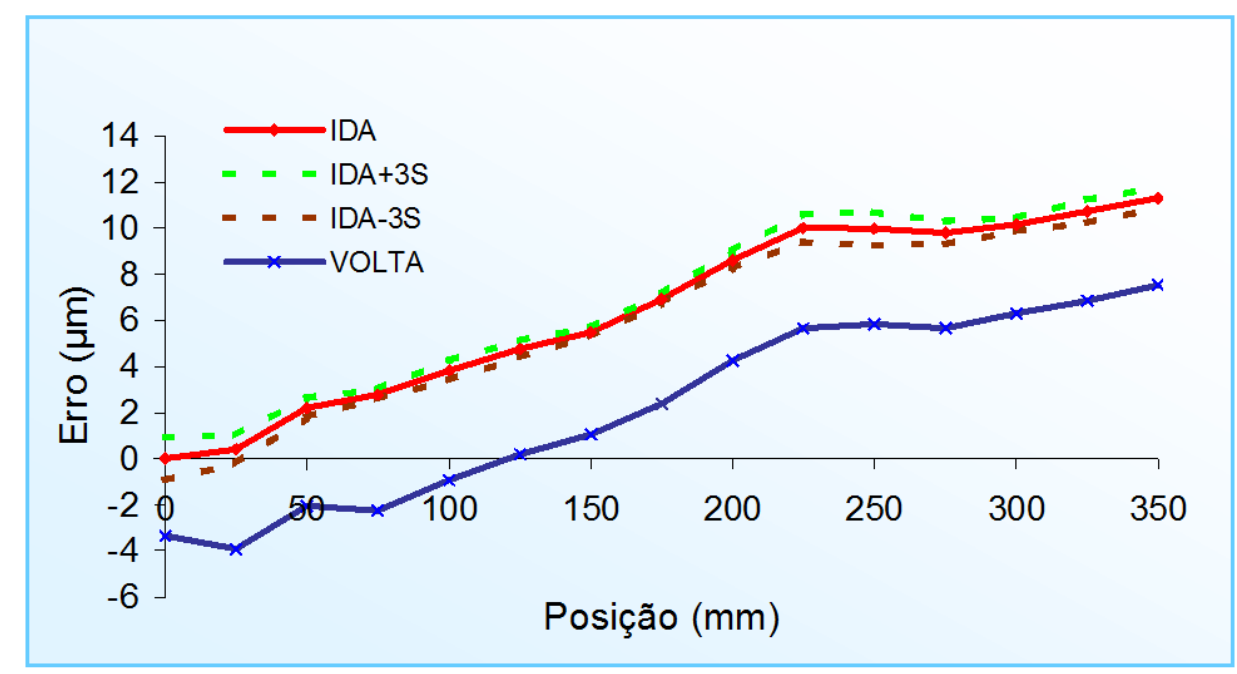

Figura 6.16 - Erro de posição do eixo $Y$ para $20^{\circ} \mathrm{C}$.

Na Figura 6.17 estão apresentadas as curvas que descrevem o comportamento do erro de posição do eixo $Y$ para diferentes temperaturas. Observa-se que na posição $350 \mathrm{~mm}$ o erro atinge os valores de 9,26; 
12,$99 ; 16,24$ e $20,46 \mu \mathrm{m}$ para as temperaturas de $20,22,24$ e $26{ }^{\circ} \mathrm{C}$, respectivamente. A variação experimentada pelo erro está estreitamente relacionada à dilatação da escala de vidro.

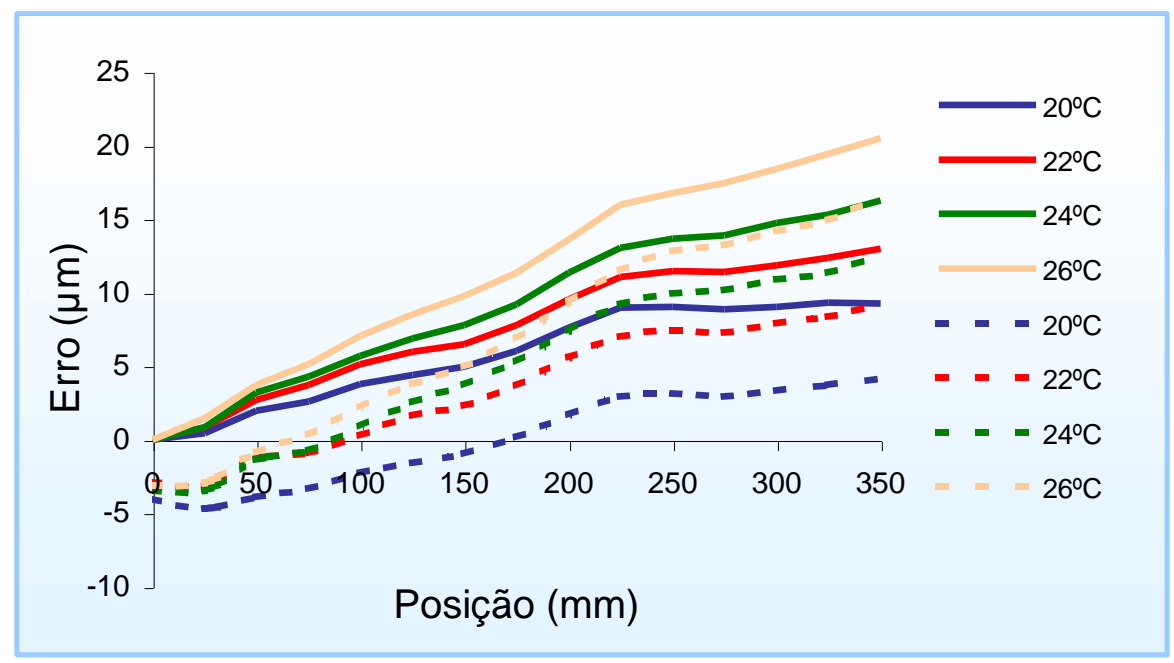

Figura 6.17 - Erro de posição do eixo $Y$ para 20, 22, 24 e $26^{\circ} \mathrm{C}$.

O gráfico da Figura 6.18 apresenta as curvas que descrevem a variação termicamente induzida do erro de posição do eixo $Y$. Excepcionalmente o drift deste erro foi observado em 5 posições com o objetivo de mostrar de forma clara o comportamento da variação do erro ao longo do eixo. Observa-se neste gráfico que o erro avaliado tem um comportamento similar ao do erro de posição do eixo $X$.

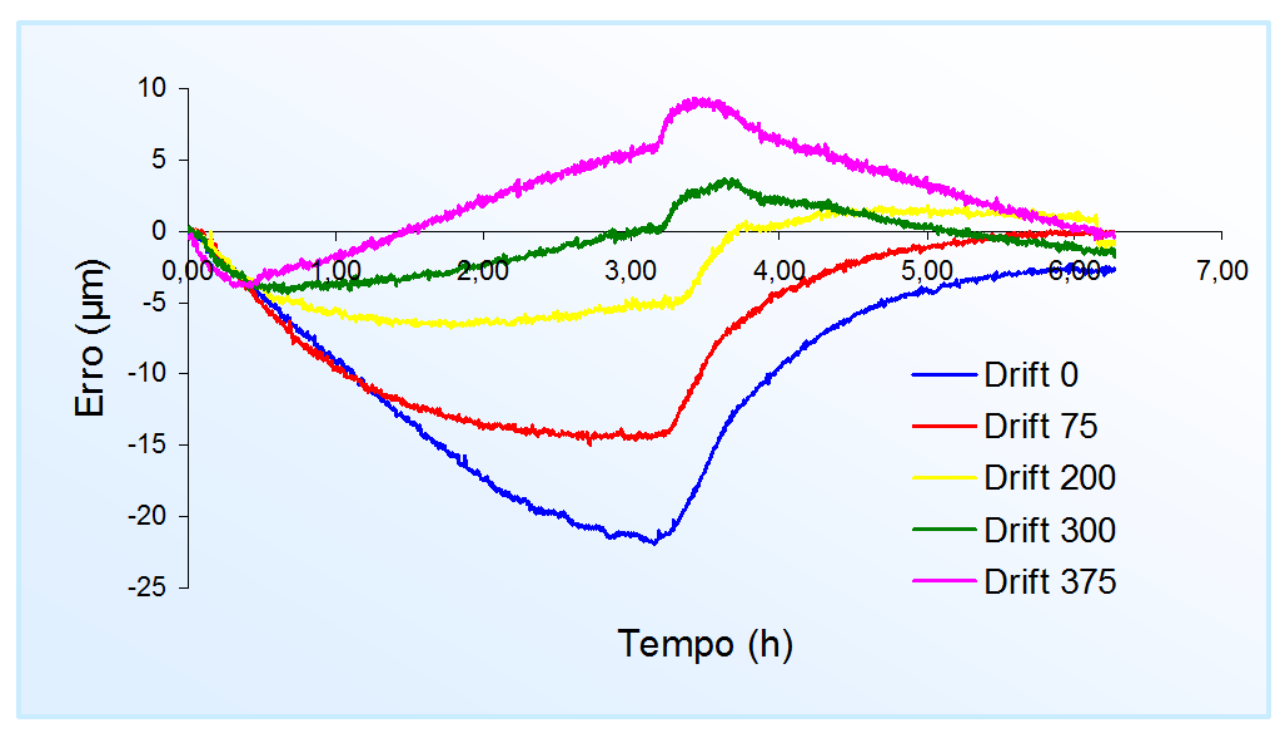

Figura 6.18 - Curvas de drift do erro de posição do eixo $Y$. 
Pode-se observar, na Figura 6.18, que em algumas posições, nos primeiros instantes do esfriamento a variação do erro apresenta uma tendência crescente. Este fato é atribuído à inércia do sistema e às condições ambientais da sala no instante da coleta dos dados. Se a umidade for alta então o sistema de aquecimento do ar terá que trabalhar mais, provocando aumentos cíclicos de temperatura.

A Figura 6.6, apresentada no item 6.1.4, mostra a variação da temperatura dos termopares colocados em elementos fixos da máquina durante o ensaio de drift do erro de posição do eixo Y. Para os elementos móveis o gráfico contendo esta variação está apresentado na Figura 6.19.

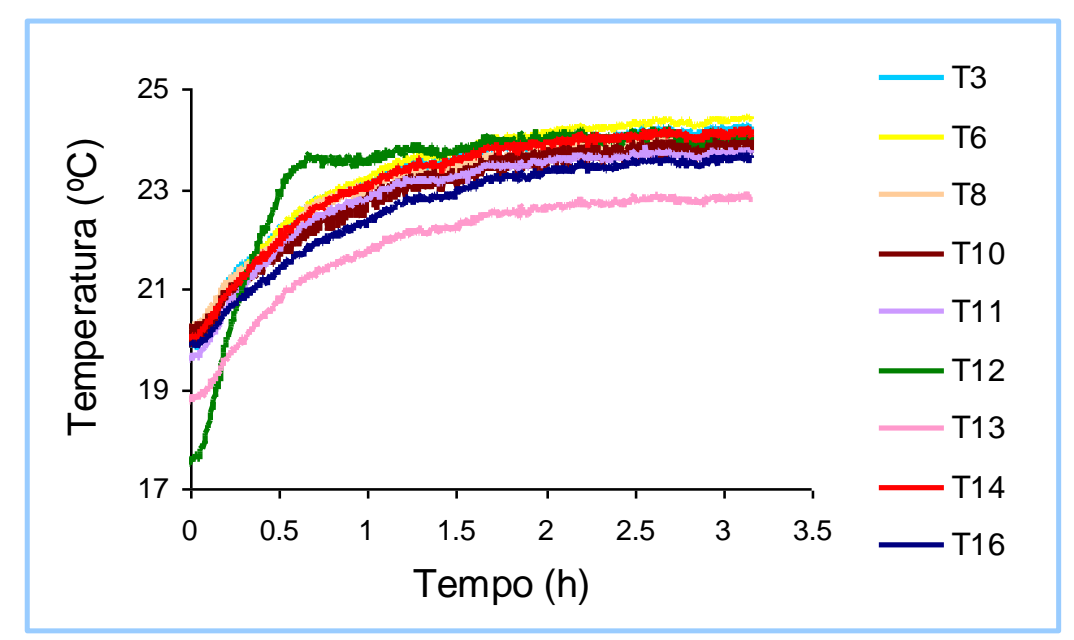

Figura 6.19 - Temperatura dos termopares em $Y=0 \mathrm{~mm}$.

Os valores de temperatura dos termopares localizados em elementos móveis experimentaram um leve incremento na medida em que a ponte passou da posição $Y=0 \mathrm{~mm}$ para as posições $Y=75,200$ e $300 \mathrm{~mm}$, respectivamente. Este fato pode ser atribuído à influência do gradiente térmico horizontal existente ao longo do eixo $Y$.

As Equações (6.6), (6.7), (6.8), (6.9) descrevem a variação do erro de posição do eixo $Y$ em função da temperatura nas respectivas posições de observação.

$$
\begin{aligned}
V_{o}(T)= & -3,5 \cdot T_{1}+19,6 \cdot T_{2}-14 \cdot T_{4}-8,5 \cdot T_{5}+8,76 \cdot T_{7}+3,2 \cdot T_{8}-1,2 \cdot T_{9}- \\
& -2,3 \cdot T_{10}+7,38 \cdot T_{11}-3 \cdot T_{12}-2,1 \cdot T_{13}+2,9 \cdot T_{14}-5,5 \cdot T_{15}-2,3 \cdot T_{16}
\end{aligned}
$$




$$
\begin{aligned}
\begin{aligned}
V_{75}(T)= & 11,7 \cdot T_{2}-1,7 \cdot T_{3}+2,75 \cdot T_{4}-7,1 \cdot T_{6}-3,8 \cdot T_{7}+0,871 \cdot T_{8}-0,97 \cdot T_{9}- \\
& -0,85 \cdot T_{10}+1,46 \cdot T_{11}-1,8 \cdot T_{12}-1,7 \cdot T_{14}-2,7 \cdot T_{15}-4,7 \cdot T_{16}
\end{aligned} \\
V_{200}(T)=12,3 \cdot T_{2}-1,8 \cdot T_{3}-3,8 \cdot T_{4}-1,9 \cdot T_{5}+1,35 \cdot T_{7}-3,4 \cdot T_{11}-2,4 \cdot T_{12}-1,3 \cdot T_{16} \\
V_{300}(T)=4,02 \cdot T_{1}+5,03 \cdot T_{2}+1,79 \cdot T_{3}+18,3 \cdot T_{4}-5,2 \cdot T_{6}+14 \cdot T_{7}-9,1 \cdot T_{8}+ \\
\quad+1,74 \cdot T_{11}-1,8 \cdot T_{12}-5,5 \cdot T_{13}-1,3 \cdot T_{14}+3,75 \cdot T_{15}+1,8 \cdot T_{17}
\end{aligned}
$$

Os coeficientes de correlação para cada uma das curvas foram de 99,89\%, 99,83\%, 99,70\% e 99,80\%, respectivamente. Os resíduos tiveram seu comportamento de acordo com os requisitos necessários para garantir boa adequabilidade das funções aos respectivos dados experimentais.

A expressão para variação do erro de posição do eixo $Y$ foi obtida somando a solução do sistema, Eq. (6.10), com o erro no estado de referência obtendo-se a função que descreve o comportamento do referido erro.

$$
\left\{\begin{array}{l}
v(0, T)=V_{0}(T) \\
v(75, T)=V_{75}(T) \\
v(200, T)=V_{200}(T) \\
v(300, T)=V_{300}(T)
\end{array}\right.
$$

\subsubsection{Erro de posição do eixo $Z$}

Na Figura 6.20 pode-se observar que o erro de posição do eixo $Z$ é positivo e mais uma vez o desvio padrão $(99,97 \%)$ é bastante pequeno. A histerese não é constante, apresentando os maiores valores na primeira metade do percurso de medição. 
A Figura 6.21 mostra que a variação experimentada por este erro está estreitamente relacionada à dilatação da escala do eixo $Z$.

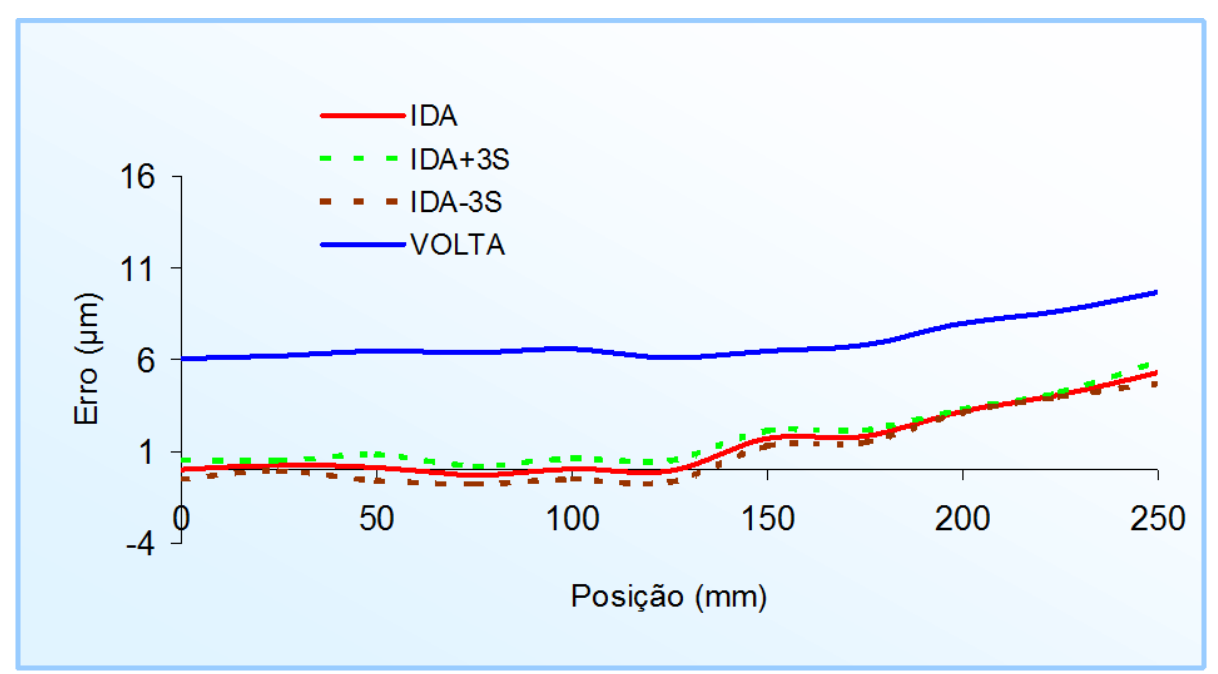

Figura 6.20 - Erro de posição do eixo $Z$ para $20^{\circ} \mathrm{C}$.

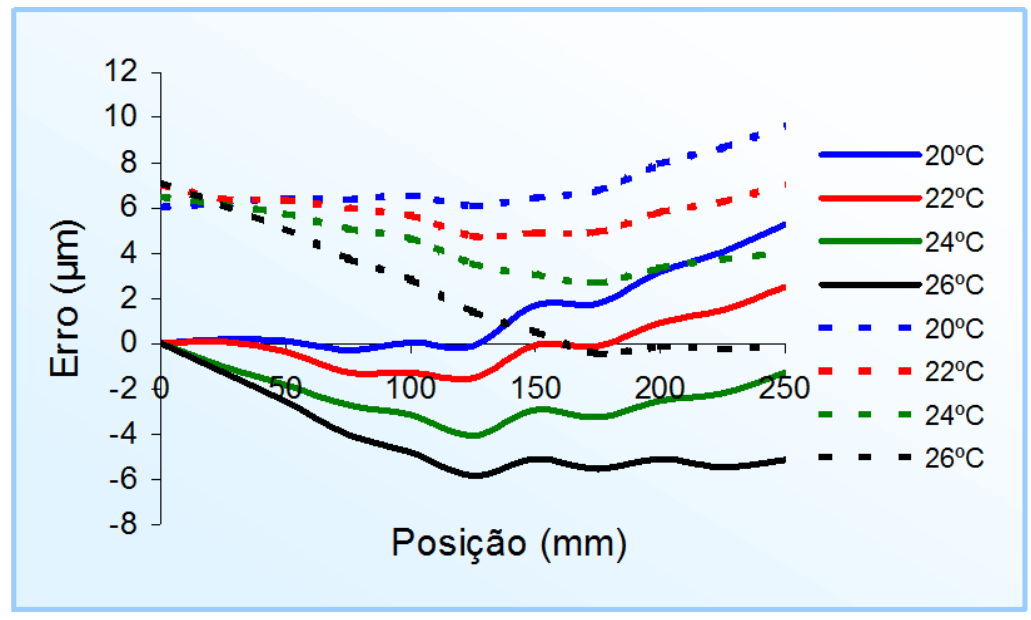

Figura 6.21 - Curvas do erro de posição do eixo $Z$ para $20,22,24$ e $26{ }^{\circ} \mathrm{C}$.

Na Figura 6.22 pode-se observar que a variação experimentada pelo erro de posição do eixo $Z$ depende da posição de observação. Porém, esta variação difere da observada anteriormente nos erros de posição dos eixos $X$ e $Y$. Na Figura observa-se que a menor variação é encontrada na posição $Z=25 \mathrm{~mm}$, isto é, próxima do desempeno da máquina e que esta variação cresce na medida em que os valores de $Z$ aumentam. Este fato 
pode ser atribuído a que na direção do eixo $Z$ a dilatação das colunas da ponte é maior que a dilatação experimentada pela escala.

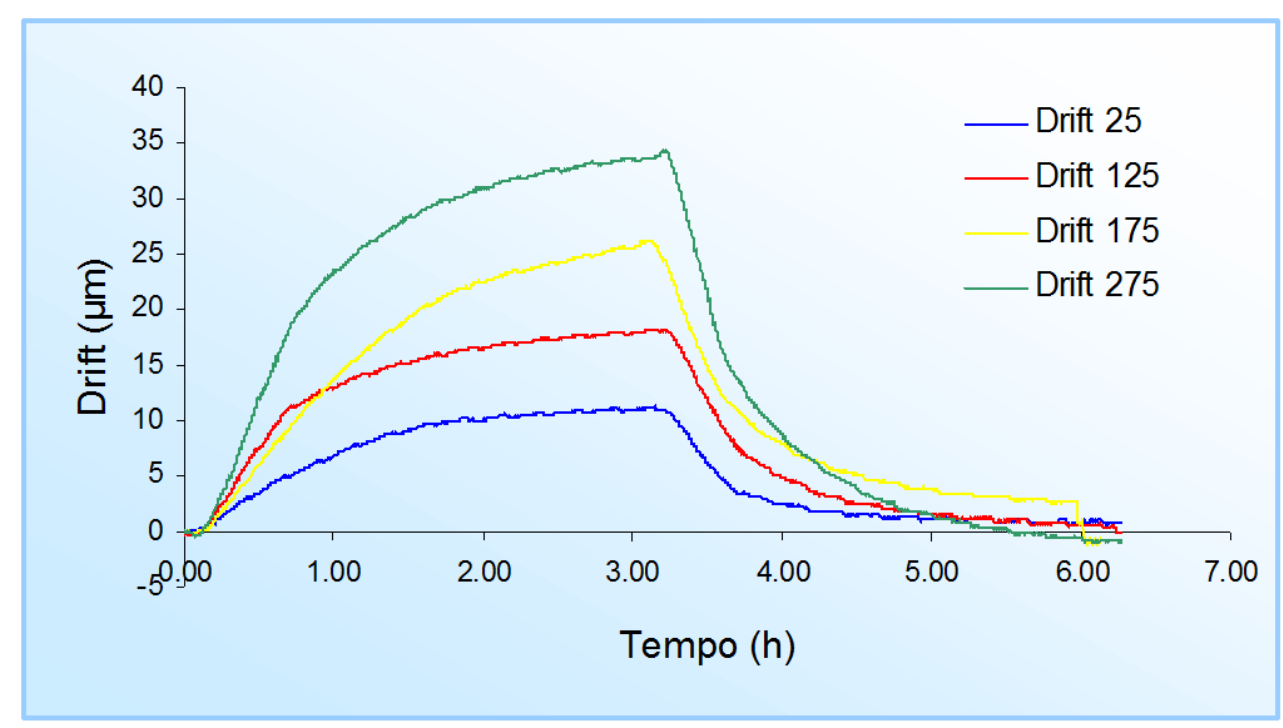

Figura 6.22 - Curvas de drift do erro de posição do eixo $Z$.

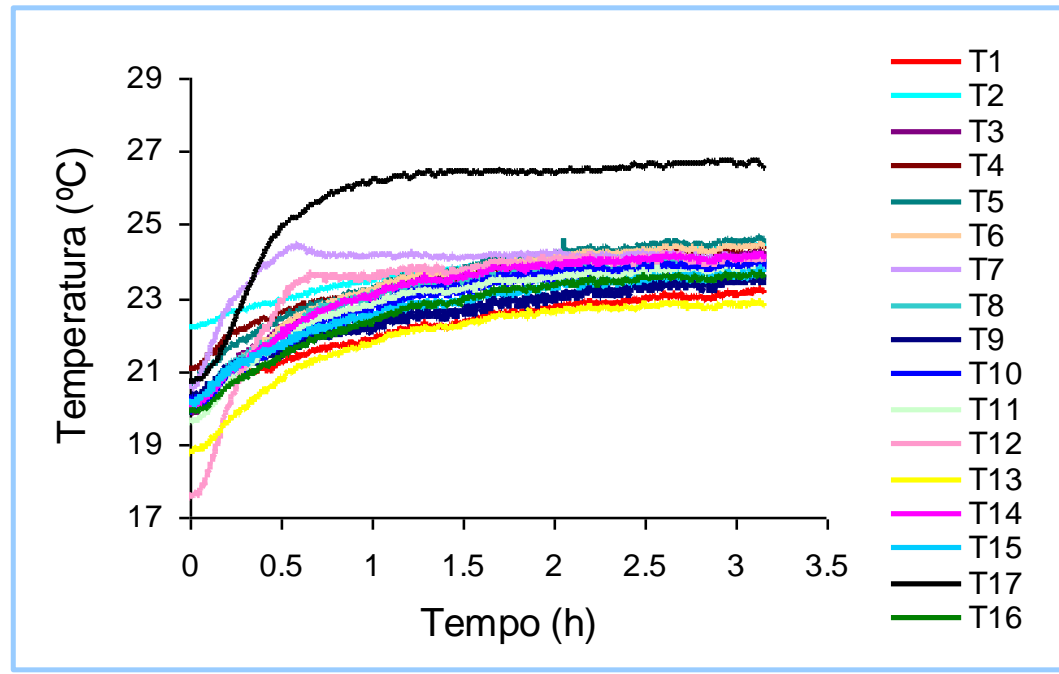

Figura 6.23 - Variação de temperatura dos termopares durante o drift do eixo $Z$.

A Figura 6.23 apresenta as curvas da variação de temperatura durante o ensaio do erro de posição do eixo $Z$. Pode-se observar no gráfico que no tempo $\mathrm{t}=0$ as temperaturas dos termopares é diferente devido à que a distribuição de temperatura na máquina não é homogênea, embora o sistema se encontre em equilíbrio térmico. 
A partir dos dados coletados e aplicando técnicas de regressão foram obtidas as Eqs (6.11), (6.12), (6.13) e (6.14). Tais equações descrevem a variação do erro em função da temperatura nas respectivas posições de observação do drift térmico.

$$
\begin{aligned}
V_{25}(T)= & -11 \cdot T_{2}+0,868 \cdot T_{3}-2,9 \cdot T_{4}+2,11 \cdot T_{5}+4,56 \cdot T_{6}-5,6 \cdot T_{7}+0,603 \cdot T_{10}- \\
& -1,1 \cdot T_{11}+1,22 \cdot T_{12}+1,16 \cdot T_{13}+2,26 \cdot T_{15}+0,988 \cdot T_{16}+1,6 \cdot T_{17} \\
V_{125}(T)= & 1,36 \cdot T_{1}-16 \cdot T_{2}+6,87 \cdot T_{4}+6,24 \cdot T_{5}+3,94 \cdot T_{6}-6,4 \cdot T_{7}-2,8 \cdot T_{8}+ \\
& +1,56 \cdot T_{10}-2,9 \cdot T_{11}+0,924 \cdot T_{12}+2,82 \cdot T_{13}-1,1 \cdot T_{14}+2,77 \cdot T_{15}+ \\
& +2,97 \cdot T_{16}+0,452 \cdot T_{17} \\
V_{175}(T)= & -9,5 \cdot T_{2}+0,872 \cdot T_{3}+3,53 \cdot T_{4}+2,2 \cdot T_{5}+3,52 \cdot T_{6}-5,4 \cdot T_{7}+ \\
& +0,525 \cdot T_{10}-1,6 \cdot T_{11}+2,16 \cdot T_{12}+0,797 \cdot T_{13}+2,06 \cdot T_{15}+1,78 \cdot T_{17} \\
V_{275}(T)= & -0,08 \cdot T_{3}+0,325 \cdot T_{5}+0,341 \cdot T_{6}-0,05 \cdot T_{7}-0,22 \cdot T_{8}-0,09 \cdot T_{9}+ \\
& +0,074 \cdot T_{10}-0,29 \cdot T_{12}+0,434 \cdot T_{13}+0,322 \cdot T_{16}+0,193 \cdot T_{17}
\end{aligned}
$$

Os coeficientes de correlação encontrados para cada uma destas curvas foram de 99,96\%, 99,92\%, 99,96\% e 99,73\%, respectivamente. A análise dos resíduos mostrou um comportamento aleatório, distribuição aproximadamente normal, com média próxima de zero e variância constante. Estes requisitos são indicativos que estas equações representam bem os dados experimentais.

O comportamento do erro em todos os estados de temperatura e posições do carro de movimentação foi determinado somando a solução do sistema apresentado na Eq. (6.15) com o erro no estado de referência.

$$
\left\{\begin{array}{l}
v(25, T)=V_{25}(T) \\
v(125, T)=V_{125}(T) \\
v(175, T)=V_{175}(T) \\
v(275, T)=V_{275}(T)
\end{array}\right.
$$


Efetuada a análise e discussão dos erros de posição de todos os eixos pode-se concluir que o princípio de montagem entre guia e escala influencia a grandeza e o comportamento destes erros quando a máquina é submetida a variações de temperatura ambiente. Na Figura 6.24 estão apresentadas duas formas de montagem de escalas em guias. Observe que na montagem superior a escala está fixa à guia em um dos extremos e expande-se ou contrai-se a partir desse ponto. Neste caso, conhece-se a priori o local a partir do qual acontece a variação do comprimento da escala.

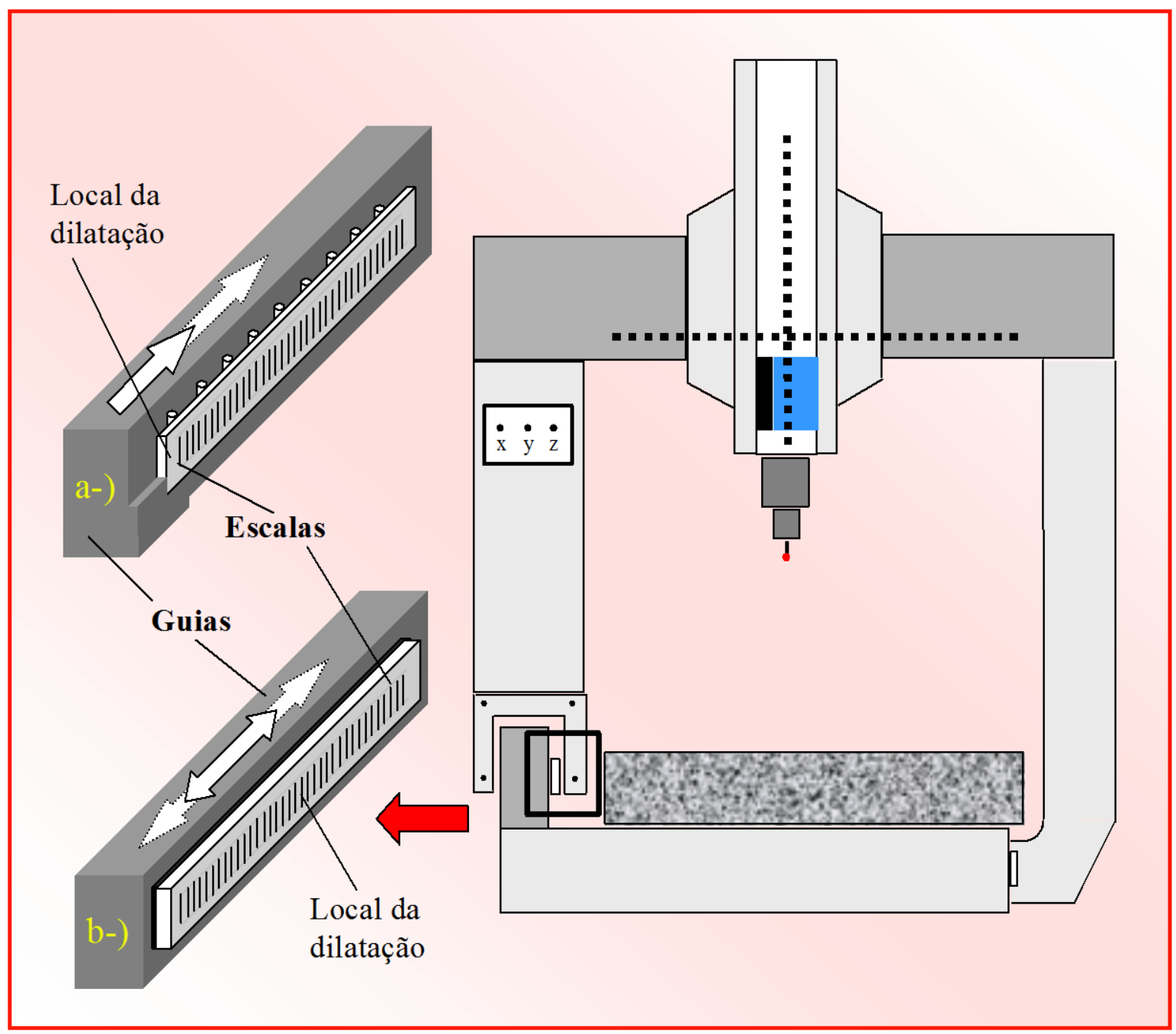

Figura 6.24 - Duas formas diferentes de montagem de escalas em guias.

Na segunda forma de montagem da Figura 6.24, correspondente à utilizada na máquina avaliada, a escala dilata-se ou contrai-se livremente 
a partir de um local muito próximo de seu centro. Desta forma, os erros menores são encontrados quando as peças a serem medidas são posicionadas próximas do centro da superfície do desempeno da máquina. Além disso, esta montagem permite que o erro de expansão diferencial seja reduzido em, aproximadamente, 50\%, portanto, pode ser considerada mais eficiente (Figura 6.25).

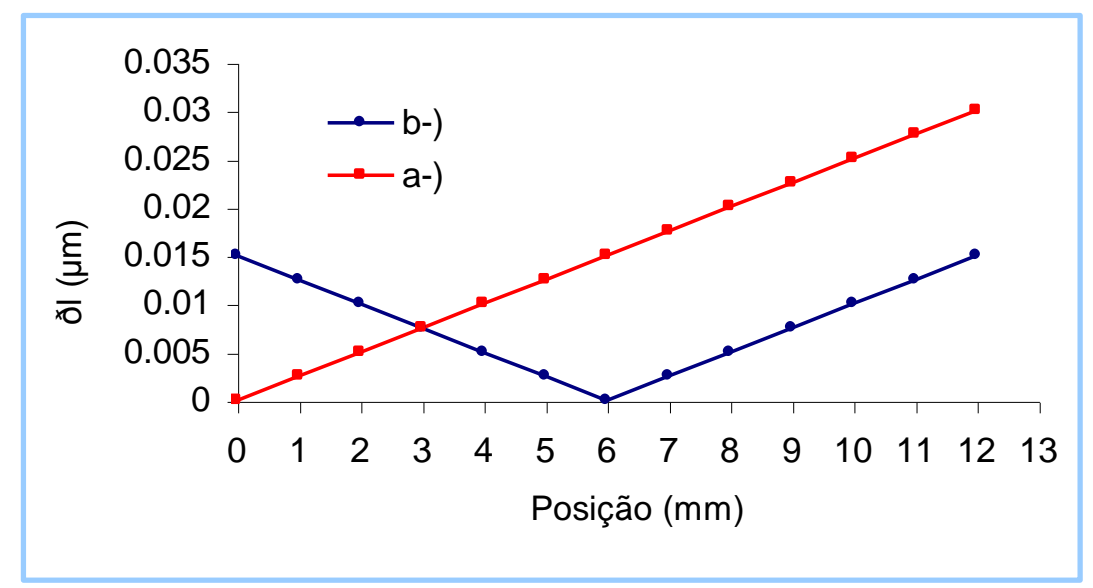

Figura 6.25 - Erros de expansão diferencial para ambos princípios de montagem.

A análise efetuada anteriormente permite ter uma idéia da influência que o projeto das Máquinas de Medir pode exercer no comportamento térmico das mesmas. Assim sendo, são reafirmados alguns critérios emitidos por cientistas sobre o assunto dentre eles (SARTORI, 1989), o qual destaca que a otimização do projeto das MM3Cs é a forma mais eficiente para evitar ou diminuir os erros termicamente induzidos.

\subsubsection{Erros de Retitude do eixo $X$}

Nas Figuras 6.26 e 6.27 estão apresentados os erros de retitude horizontal e vertical do eixo $X$. A retitude vertical apresenta valores muito 
pequenos, menores que $1 \mu \mathrm{m}$. A parcela de histerese é pequena e os erros aleatórios atingem valores $\pm 1,5 \mu \mathrm{m}$ em torno dos valores do erro.

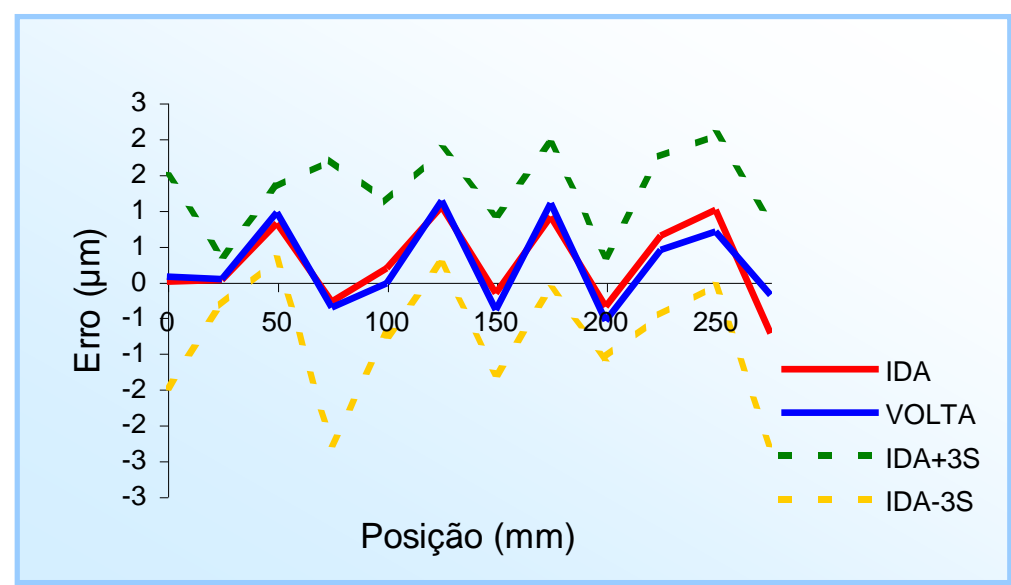

Figura 6.26 - Erro de retitude horizontal do eixo $X$ para $20^{\circ} \mathrm{C}$.

A retitude vertical alcança seu máximo valor de $4 \mu \mathrm{m}$ na posição $X=125 \mathrm{~mm}$ e apresenta uma tendência curvilinea que pode ser atribuída ao momento flexor que se produz na guia do eixo $X$ devido ao peso dos carros $X$ e $Z$ a da guia do eixo $Z$.

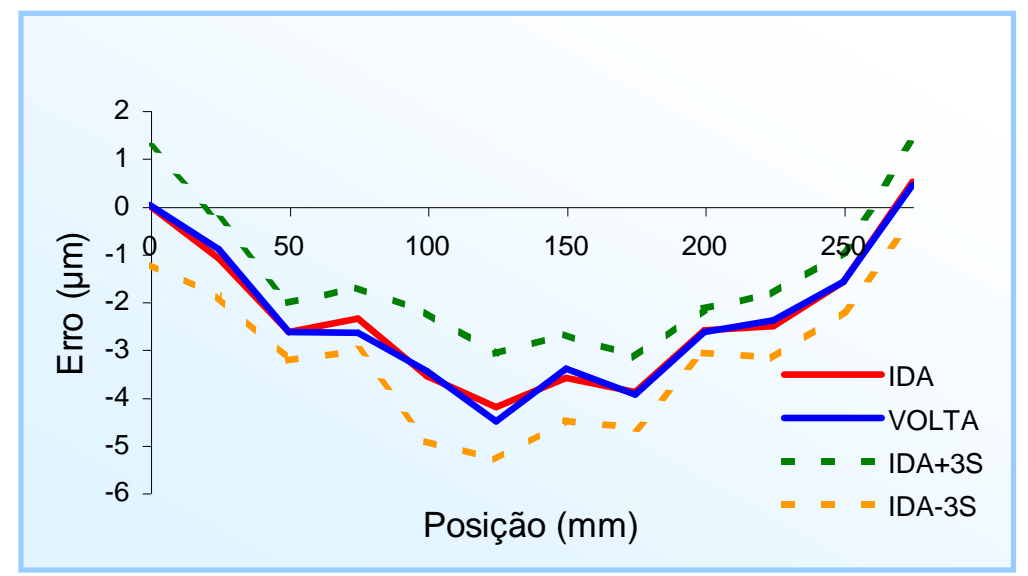

Figura 6.27 - Erro de retitude vertical do eixo $X$ para $20^{\circ} \mathrm{C}$.

As curvas descrevendo o comportamento dos erros de retitude do eixo $X$ para diferentes estados de temperatura não estão aqui 
apresentadas, pois o comportamento e a grandeza destes erros permanecem constantes durante o aquecimento e esfriamento da máquina. As pequenas variações apresentadas podem ser atribuídas aos cálculos efetuados para correção do desalinhamento, através da aplicação dos mínimos quadrados.

A Figura 6.28 apresenta as curvas de drift do erro de retitude horizontal. Como esperado a variação experimentada pelo erro independe da posição do carro de movimentação, isto significa que na direção do eixo $Y$ o ponto de controle desloca-se quantidades, aproximadamente, iguais em todas as posições.

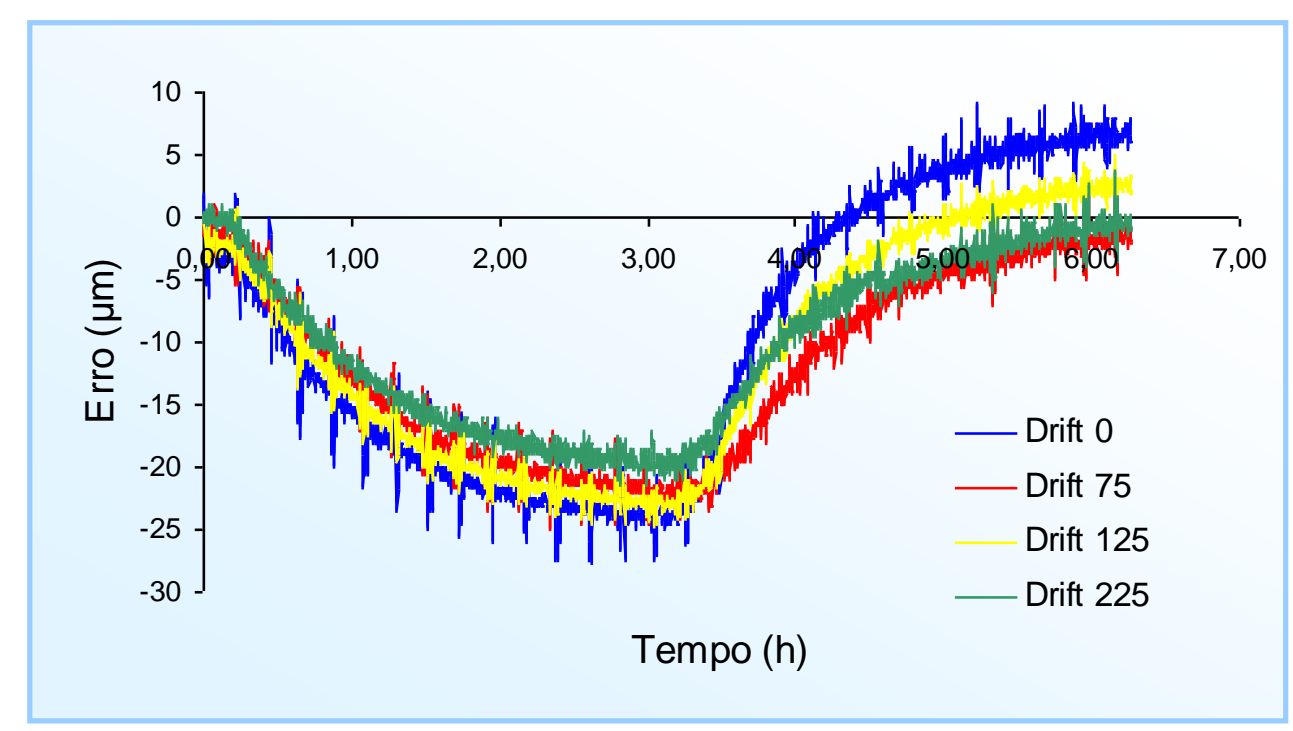

Figura 6.28 - Curvas de drift do erro de retitude horizontal do eixo $X$.

Observa-se, na Figura 6.28, uma outra variável influenciando de forma intermitente e repetitiva na variação dos erros observados. Esta influência pode ser atribuída ao compressor utilizado para comprimir o ar alimentado à máquina, pois o mesmo trabalha de forma intermitente, ficando ligado durante $2 \min 10 \mathrm{~s}$ e desligado durante $10 \mathrm{~min} 30$ s. Este compressor tem uma válvula de alivio encarregada de abrir-se, automaticamente, quando a pressão excede o valor pré-ajustado. Somente depois que as condições pré-ajustadas são alcançadas, a porta de 
exaustão é fechada e vedada. Este ciclo repete-se a cada 43s, aproximadamente, provocando o efeito observado no gráfico.

As curvas de drift do erro de retitude vertical do eixo $X$ não estão aqui apresentadas, pois a variação experimentada por este erro independe da posição de observação. Este gráfico está apresentado no Apêndice F, junto com os gráficos de drift dos demais erros de retitude e angulares.

Como os erros de retitude e angulares de todos os eixos apresentaram um comportamento similar ao longo do eixo avaliado foi possível efetuar a modelagem destes erros utilizando-se dos dados levantados em apenas um ponto de observação de drift.

O equacionamento foi efetuado através de uma regressão linear múltipla. As Eqs (6.16) e (6.17) descrevem a variação dos erros de retitude do eixo $X$ nas direções $Y$ e $Z$, respectivamente. Os coeficientes $R^{2}$ são de $99,77 \%$ e $99,60 \%$. Os resíduos para ambas as equações apresentam um comportamento aleatório.

$$
\begin{aligned}
V_{R X y}(T)= & 1,47 \cdot T_{1}+13,2 \cdot T_{2}+1,58 \cdot T_{3}-2,9 \cdot T_{4}+1,91 \cdot T_{7}-0,81 \cdot T_{9}- \\
& -1,4 \cdot T_{10}-3 \cdot T_{11}+0,88 \cdot T_{12}-2,3 \cdot T_{14}-4 \cdot T_{15}-3,6 \cdot T_{16}-2 \cdot T_{17} \\
V_{R X Z}(T)= & -2,5 \cdot T_{1}-7,6 \cdot T_{2}-2,8 \cdot T_{7}+1,48 \cdot T_{9}+6,38 \cdot T_{11}+0,69 \cdot T_{12}+ \\
& +4,14 \cdot T_{15}+1,23 \cdot T_{17}
\end{aligned}
$$

\subsubsection{Erros de Retitude do eixo $Y$.}

Os erros de retitude do eixo Y, Figuras 6.29 e 6.30, apresentam valores pequenos, menores que $2 \mu \mathrm{m}$. Em ambos os casos a histerese é pequena e os erros aleatórios oscilam na faixa $\pm 1,5 \mu \mathrm{m}$ em torno dos valores do erro.

As Equações (6.18) e (6.19) descrevem a variação dos erros de retitude do eixo $Y$ nas direções $X$ e $Z$, respectivamente. Os coeficientes $R^{2}$ são de $99,2 \%$ e 99,1\%. A análise dos resíduos mostrou que os mesmos 
apresentam um comportamento aleatório, com média zero e variância constante.

$$
\begin{aligned}
\begin{aligned}
V_{R Y x}(T) & =-21 \cdot T_{2}+6,88 \cdot T_{5}+12,8 \cdot T_{6}-6,4 \cdot T_{7}-4 \cdot T_{8}-1,8 \cdot T_{9}+2,52 \cdot T_{10}- \\
& -6,5 \cdot T_{12}+10,2 \cdot T_{13}+2,37 \cdot T_{15}+5,36 \cdot T_{16}
\end{aligned} \\
V_{R Y z}(T)=-4,1 \cdot T_{7}+5,2 \cdot T_{12}-2,8 \cdot T_{16}+2,67 \cdot T_{17}
\end{aligned}
$$

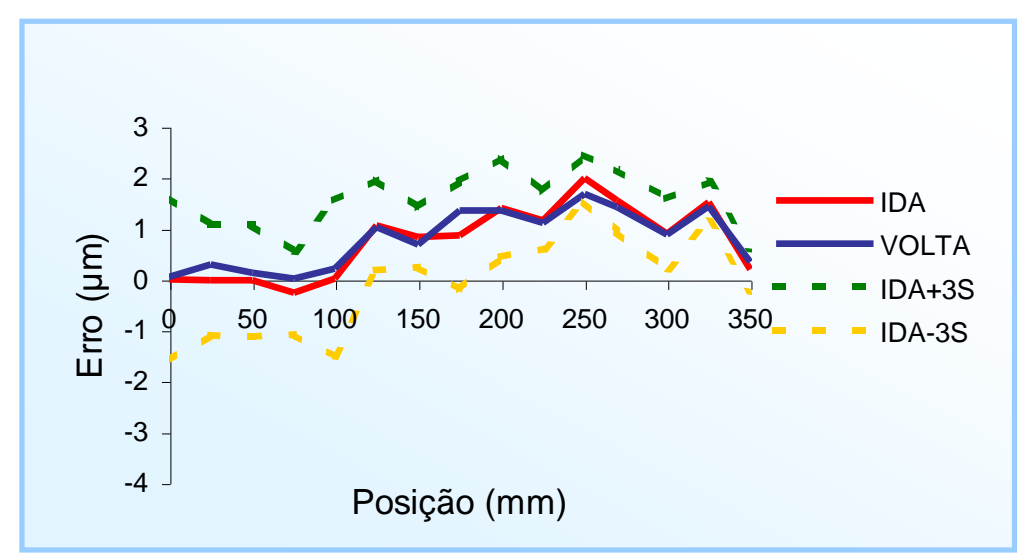

Figura 6.29 - Erro de retitude horizontal do eixo $Y$ para $20^{\circ} \mathrm{C}$.

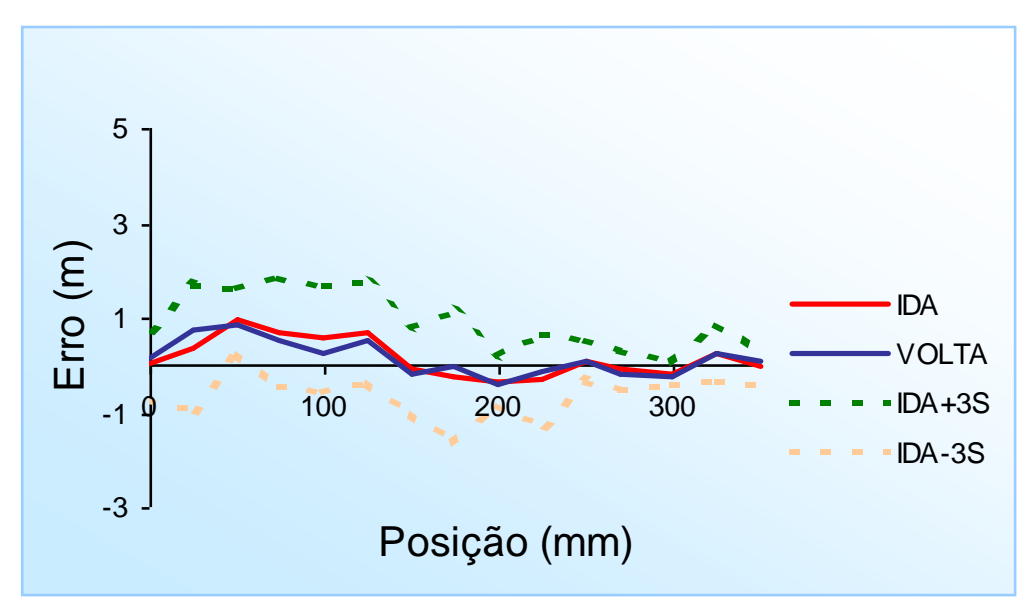

Figura 6.30 - Erro de retitude vertical do eixo $Y$ para $20^{\circ} \mathrm{C}$.

\subsubsection{Erros de Retitude do eixo $Z$}

Nas Figuras 6.31 e 6.32 estão apresentadas as curvas que descrevem o comportamento dos erros de retitude do eixo $Z$. Observe que 
os erros são muito pequenos, assim como, a parcela de histerese. Os erros aleatórios oscilam na faixa $\pm 1,7 \mu \mathrm{m}$ em torno dos valores do erro.

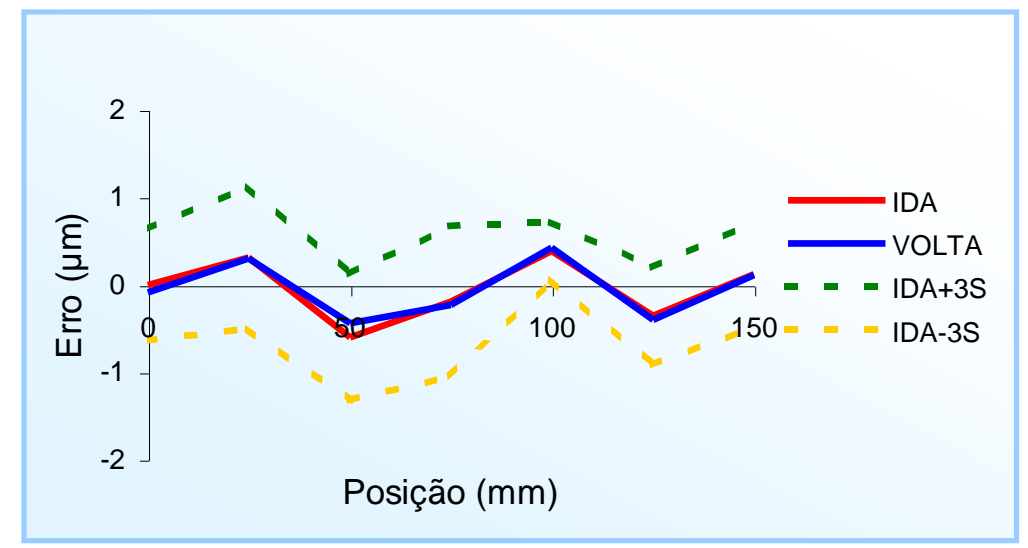

Figura 6.31 - Erro de retitude do eixo $Z$ na direção $X$ para $20{ }^{\circ} \mathrm{C}$.

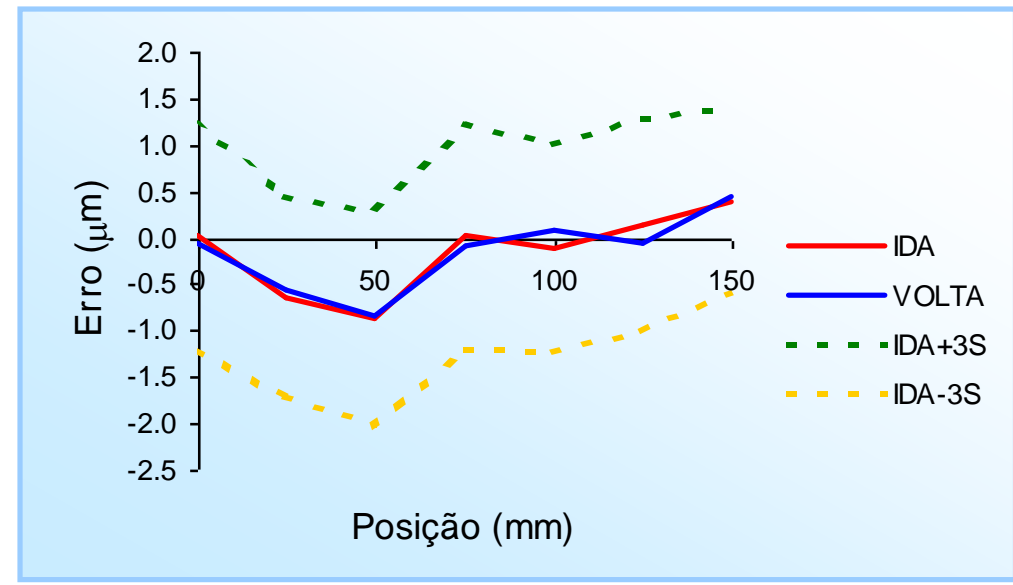

Figura 6.32 - Erro de retitude do eixo $Z$ na direção $Y$ para $20{ }^{\circ} \mathrm{C}$

As Equações (6.20) e (6.21) descrevem a variação dos erros de retitude do eixo $Z$ nas direções $X$ e $Y$, respectivamente. Os coeficientes $R^{2}$ são de $99,73 \%$ e 99,86\%.

$$
\begin{aligned}
\begin{aligned}
V_{R Z x}(T)= & 7,84 \cdot T_{2}-5,8 \cdot T_{4}-3,5 \cdot T_{5}+3,18 \cdot T_{6}+4,23 \cdot T_{7}+1,2 \cdot T_{8}-1,2 \cdot T_{9}- \\
& -4,7 \cdot T_{12}+3,16 \cdot T_{14}-2,8 \cdot T_{15}-2,6 \cdot T_{17}
\end{aligned} \\
\begin{aligned}
V_{R Z x}(T)= & 15,5 \cdot T_{2}-1,1 \cdot T_{3}-4,5 \cdot T_{4}-5,7 \cdot T_{5}-5,1 \cdot T_{6}+7,07 \cdot T_{7}+1,66 \cdot T_{8}- \\
& -1,2 \cdot T_{10}+0,727 \cdot T_{12}-2,2 \cdot T_{13}-3,2 \cdot T_{15}-2,3 \cdot T_{16}-0,55 \cdot T_{17}
\end{aligned}
\end{aligned}
$$


Uma comparação efetuada entre as curvas de drift dos erros geométricos translacionais mostrou que a variação termicamente induzida por um determinado erro, em uma determinada direção e posição, é semelhante à experimentada por outro erro em essa mesma direção e posição.

A Figura 6.33 mostra as curvas de drift do erro de posição do eixo $X$ e do erro de retitude do eixo $Z$ na direção $X$. Observa-se nesta Figura que a variação termicamente induzida destes erros apresenta grandeza e comportamento similares, portanto assume-se que descrevem o mesmo efeito. As diferenças observadas entre as curvas podem ser atribuídas às variações nas condições ambientais. Assim sendo, estes erros foram cuidadosamente tratados durante o equacionamento.

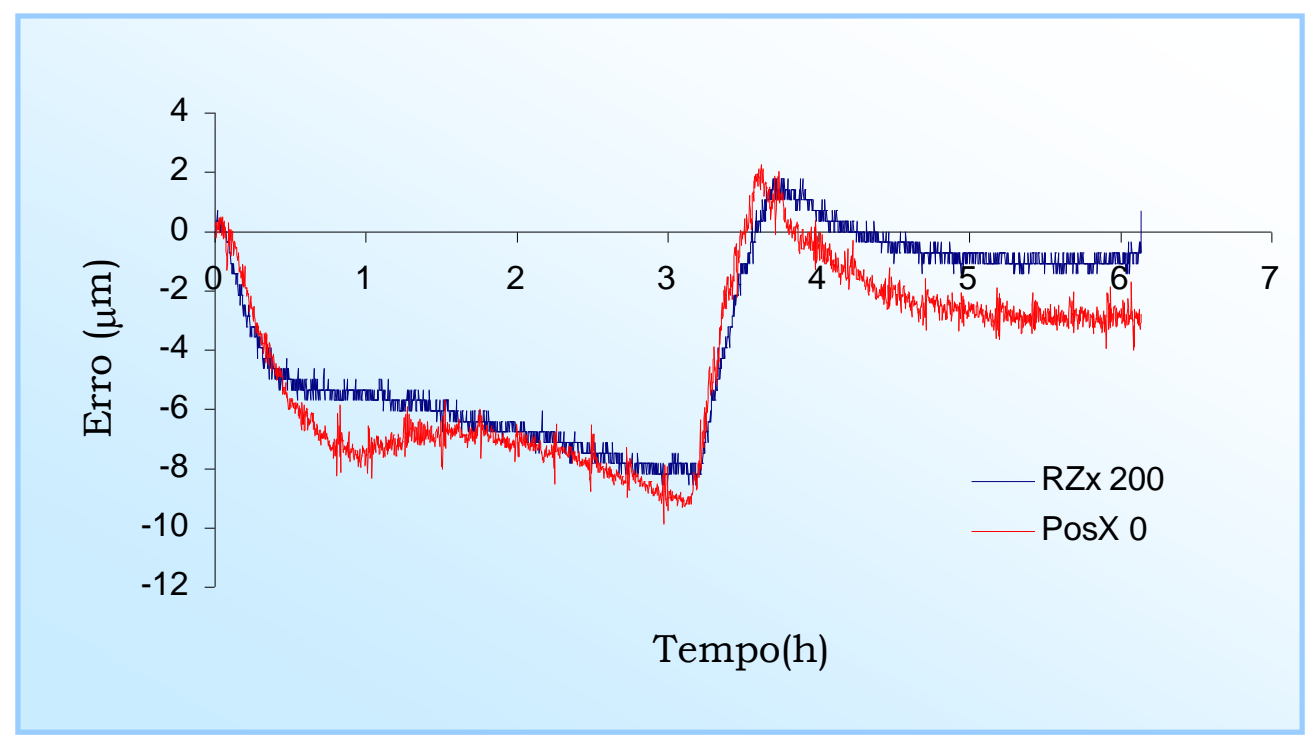

Figura 6.33 - Curvas de drift dos erros posição do eixo $X$ e retitude do eixo $Z$ na direção $X$.

Na Figura 6.34 estão apresentadas as curvas que descrevem o erro de retitude do eixo $X$ na direção $Y$ e o erro de posição do eixo $Y$. Observase nesta Figura que as curvas que descrevem a variação do erro de posição do eixo $Y$ e de retitude do eixo $X$ na direção $Y$ são semelhantes em grandeza e comportamento.

Na Figura 6.35 pode ser observado que a variação dos erros de retitude vertical dos eixos $X$ e $Y$ é similar para ambos os erros avaliados. 
Estes resultados vêm confirmando a hipóteses de que a máquina experimenta dilatações e contrações livres.

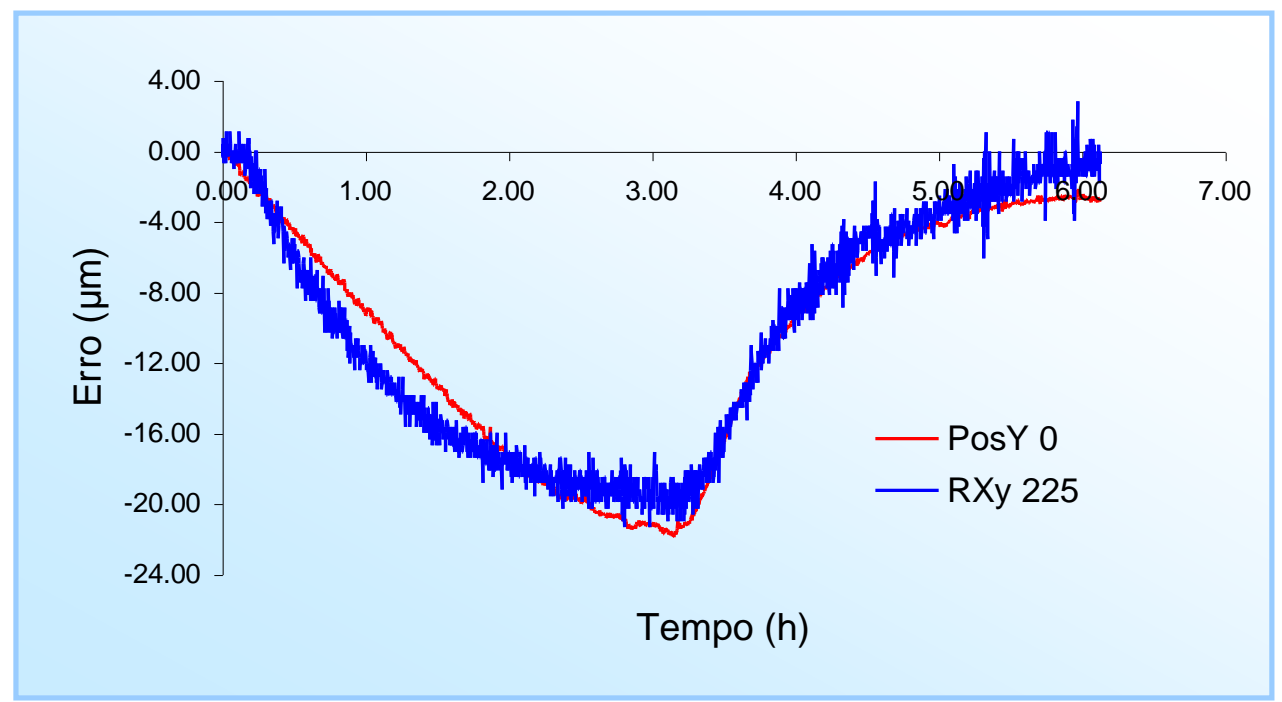

Figura 6.34 - Curvas de drift do erro posição do eixo $Y$ e retitude do eixo $X$ na direção $Y$.

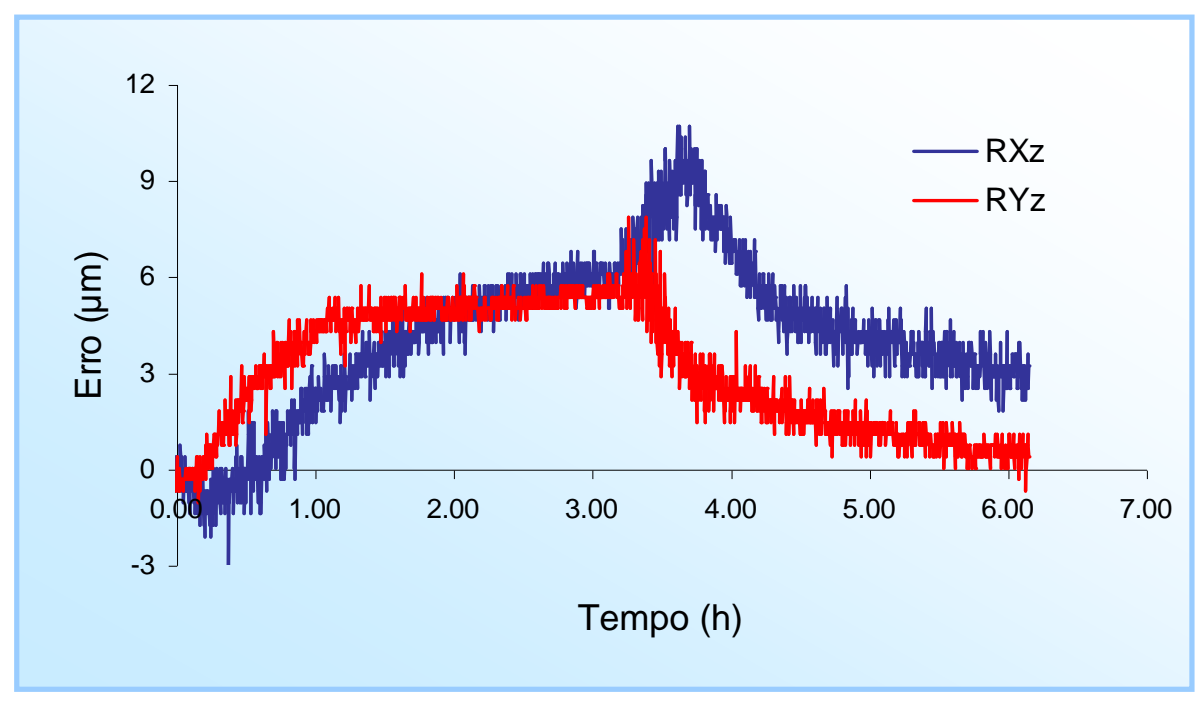

Figura 6.35 - Curvas de drift dos erros posição do eixo $Z$ e retitude dos eixos $X$ e $Y$ na direção $Z$. 


\subsubsection{Erro angular Pitch do eixo $x$}

A Figura 6.36 mostra o erro angular pitch do eixo $X$. Pode-se observar no gráfico que o erro é crescente com sinal positivo e que a diferencia entre os valores dos erros em ambos os sentidos é muito pequena, assim como os erros aleatórios.

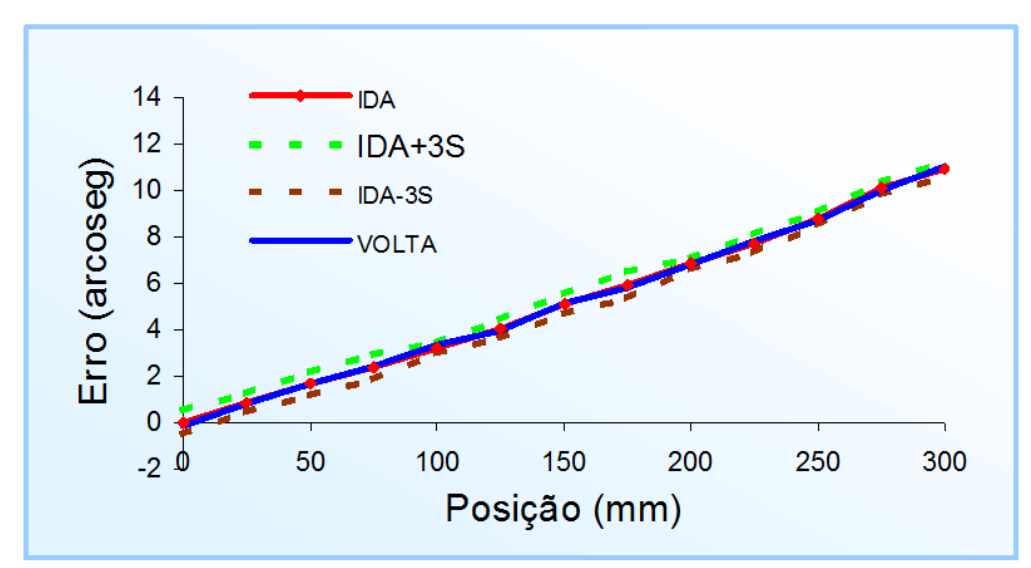

Figura 6.36 - Erro angular pitch do eixo $X$ para $20^{\circ} \mathrm{C}$.

As curvas descrevendo o comportamento dos erros angulares para diferentes estados de temperatura não estão aqui apresentadas, pois o comportamento e a grandeza destes erros permanecem constantes durante o aquecimento e esfriamento da máquina. Também, não estão apresentadas as curvas que descrevem o drift do erro angular pitch do eixo $X$. Como esperado a variação experimentada pelo erro independe da posição do carro de movimentação.

A Equação (6.22) descreve a variação termicamente induzida do erro avaliado, onde o coeficiente de correlação foi de 99,94\% e os resíduos apresentaram um comportamento aleatório, com media zero e variância constante.

$$
\begin{aligned}
V_{\text {PitchX }}(T)= & -1,5 \cdot T_{1}-11 \cdot T_{2}-0,76 \cdot T_{3}-1,7 \cdot T_{7}+0,766 \cdot T_{8}+0,909 \cdot T_{9}+0,918 \cdot T_{10}- \\
& +3,96 \cdot T_{11}-0,6 \cdot T_{12}+0,987 \cdot T_{14}+3,09 \cdot T_{15}+3,6 \cdot T_{16}+2,27 \cdot T_{17}
\end{aligned}
$$




\subsubsection{Erro angular Pitch do eixo $Y$}

A Figura 6.37 mostra o erro angular pitch do eixo Y. Pode-se observar que o erro é positivo e crescente. No início do percurso de medição até aproximadamente $Y=100 \mathrm{~mm}$, depois decresce atingindo -4 arcseg. O erro aleatório e a histerese são pequenos. Ainda, pode-se dizer que a ponte móvel da máquina gira em torno do eixo $X$ no sentido positivo, ou seja, na medida em que a ponte distancia-se da origem, a mesma inclina-se progressivamente para a posição zero do eixo $Y$.

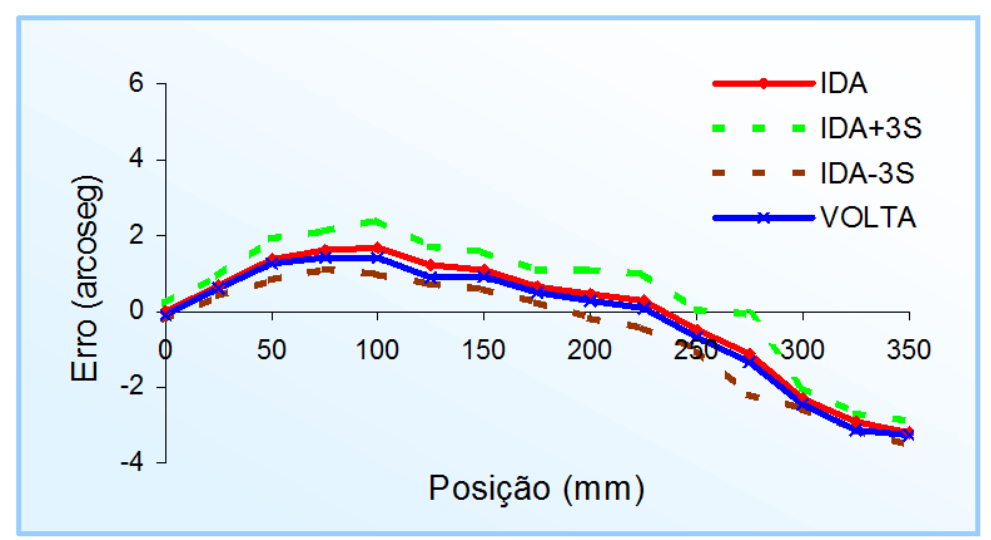

Figura 6.37 - Erro angular pitch do eixo $Y$ para $20{ }^{\circ} \mathrm{C}$.

A regressão realizada com os dados obtidos na coleta do erro pitch do eixo $Y$, durante o drift térmico, resultou na Eq. (6.23).

$$
\begin{aligned}
V_{P i t c h}(T)= & -12 \cdot T_{2}+2,6 \cdot T_{4}+3,98 \cdot T_{5}-8,18 \cdot T_{6}-12 \cdot T_{7}+3,2 \cdot T_{8}+1,37 \cdot T_{10}- \\
& -3,6 \cdot T_{11}+0,761 \cdot T_{12}+2,58 \cdot T_{13}+2,28 \cdot T_{14}+4,75 \cdot T_{15}+1,27 \cdot T_{17}
\end{aligned}
$$

O coeficiente de correlação encontrado foi de 99,76\%. O comportamento aleatório dos resíduos para a equação acima indica a adequação desta aos dados experimentais. 


\subsubsection{Erro angular pitch do eixo $Z$}

Na Figura 6.38 pode-se observar o erro angular pitch do eixo $Z$ para $20{ }^{\circ} \mathrm{C}$. Este erro apresenta valores pequenos, menores que 0,5 arcseg. A histerese atinge no máximo 0,5 arcseg.

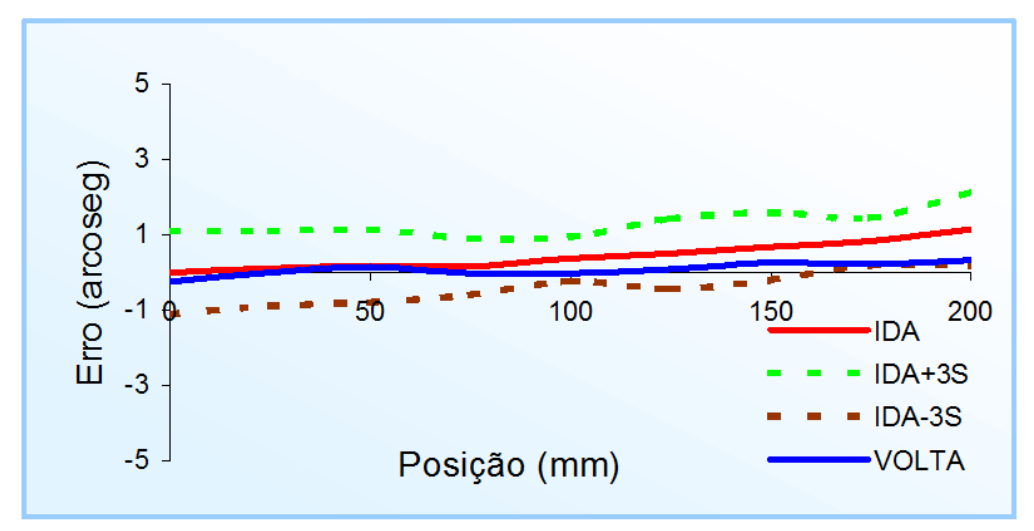

Figura 6.38 - Erro angular pitch do eixo $Z$ para $20^{\circ} \mathrm{C}$.

A Equação (6.24) descreve a variação que o erro pitch do eixo $Z$ experimentou durante o levantamento do drift térmico.

$$
\begin{aligned}
V_{\text {PitchZ }}(T)= & 1,76 \cdot T_{1}-12 \cdot T_{2}+12,8 \cdot T_{4}+6,73 \cdot T_{5}+3,75 \cdot T_{6}-14 \cdot T_{7}-0,91 \cdot T_{8}+1,02 \cdot T_{9}+ \\
& +1,13 \cdot T_{10}-7,4 \cdot T_{11}+5,37 \cdot T_{12}-2,6 \cdot T_{13}-2,6 \cdot T_{14}+5,09 \cdot T_{15}+2,69 \cdot T_{17}
\end{aligned}
$$

O coeficiente de correlação calculado foi de $99,79 \%$, os resíduos apresentaram um comportamento aleatório com media, aproximadamente, igual a zero e variância constante.

\subsubsection{Erro angular pitch do eixo $Z$}

Na Figura 6.38 pode-se observar o erro angular pitch do eixo $Z$ para $20{ }^{\circ} \mathrm{C}$. Este erro apresenta valores pequenos, menores que 0,5 arcseg. A histerese atinge no máximo 0,5 arcseg. 


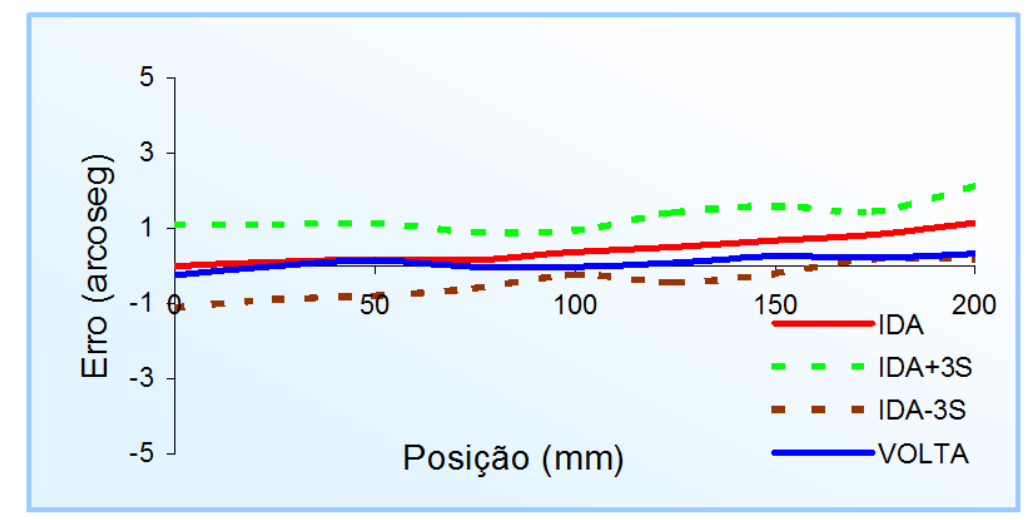

Figura 6.38 - Erro angular pitch do eixo $Z$ para $20^{\circ} \mathrm{C}$.

A Equação (6.24) descreve a variação que o erro pitch do eixo $Z$ experimentou durante o levantamento do drift térmico.

$$
\begin{aligned}
V_{\text {PichZ }}(T)= & 1,76 \cdot T_{1}-12 \cdot T_{2}+12,8 \cdot T_{4}+6,73 \cdot T_{5}+3,75 \cdot T_{6}-14 \cdot T_{7}-0,91 \cdot T_{8}+1,02 \cdot T_{9}+ \\
& +1,13 \cdot T_{10}-7,4 \cdot T_{11}+5,37 \cdot T_{12}-2,6 \cdot T_{13}-2,6 \cdot T_{14}+5,09 \cdot T_{15}+2,69 \cdot T_{17}
\end{aligned}
$$

O coeficiente de correlação calculado foi de $99,79 \%$, os resíduos apresentaram um comportamento aleatório com media, aproximadamente, igual a zero e variância constante.

\subsubsection{Erro angular yaw $X$}

A Figura 6.39 mostra as curvas do erro angular yaw do eixo $X$, para $20^{\circ} \mathrm{C}$. Observa-se que este erro é negativo e decrescente, a histerese é pequena, assim como os erros aleatórios.

A expressão que representa a variação do erro em função das temperaturas é dada na Eq. (6.25).

$$
\begin{aligned}
V_{\text {YawX }}(T) & =1.11 \cdot T_{1}+10.6 \cdot T_{2}+0.849 \cdot T_{3}+2.8 \cdot T_{7}-1.1 \cdot T_{10}-5 \cdot T_{11}-1.8 \cdot T_{14}+ \\
& -3 \cdot T_{15}-4 \cdot T_{16}-1.3 \cdot T_{17}
\end{aligned}
$$


O comportamento dos resíduos da equação (6.25) obedece às condições necessárias para adequação desta aos dados experimentais. O coeficiente de correlação foi de 99,88\% e a significância igual a zero.

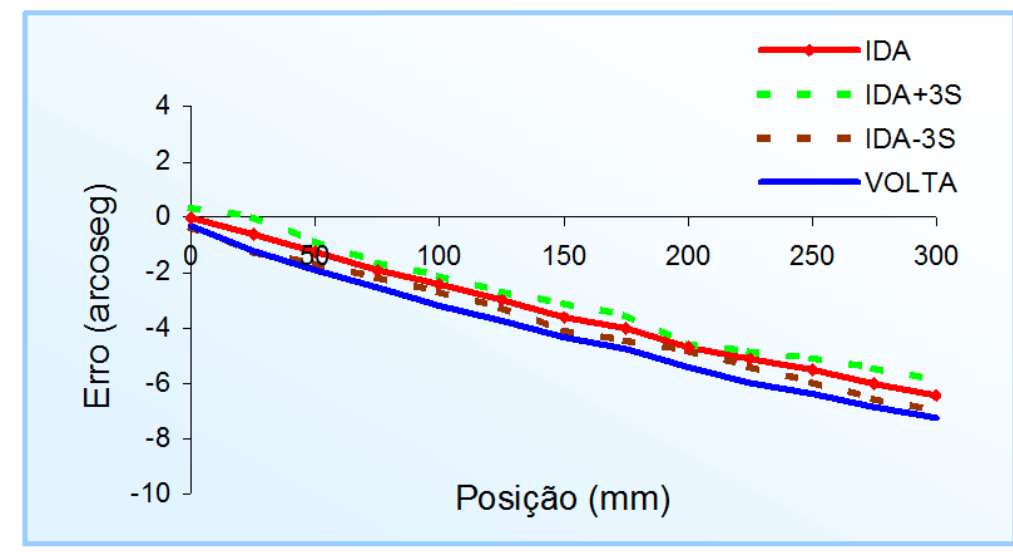

Figura 6.39 - Erro angular yaw do eixo $X$ para $20^{\circ} \mathrm{C}$.

\subsubsection{Erro angular yaw $Y$}

Na Figura 6.40 se observa que o erro yaw do eixo $Y$ para $20^{\circ} \mathrm{C}$ é positivo e crescente.

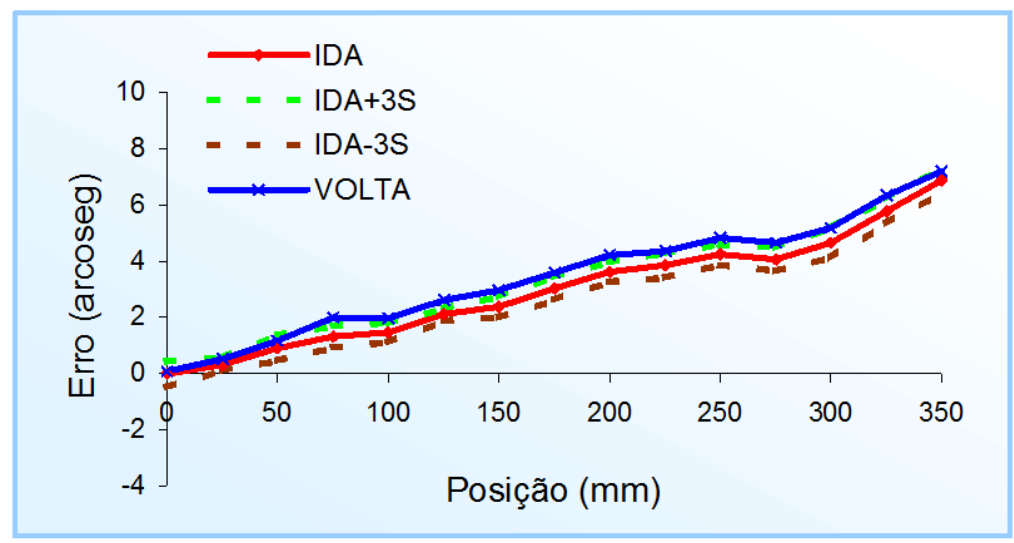

Figura 6.40 - Erro angular yaw do eixo $Y$ para $20^{\circ} \mathrm{C}$. 
Aplicando técnicas de regressão nos dados, obteve-se a Eq. (6.26).

$$
\begin{aligned}
V_{\text {YawY }}(T) & =2,81 \cdot T_{1}-21 \cdot T_{2}+9,18 \cdot T_{4}+8,99 \cdot T_{5}+3,37 \cdot T_{6}-7,3 \cdot T_{7}- \\
& -2,5 \cdot T_{8}+1,35 \cdot T_{9}+1,9 \cdot T_{10}-3,3 \cdot T_{11}+1,53 \cdot T_{13}+2,8 \cdot T_{14}+ \\
& +5,01 \cdot T_{15}+3 \cdot T_{16}+0,573 \cdot T_{17}
\end{aligned}
$$

O coeficiente de correlação para a curva acima foi de $99,86 \%$. Os resíduos tiveram seu comportamento de modo a garantir a adequação da função aos dados experimentais.

\subsubsection{Erro angular yaw $Z$}

A Figura 6.41 mostra o erro angular yaw do eixo $Z$. Observa-se que este erro é positivo, com valores menores que 1 arcoseg. A histerese é pequena, assim como os erros aleatórios.

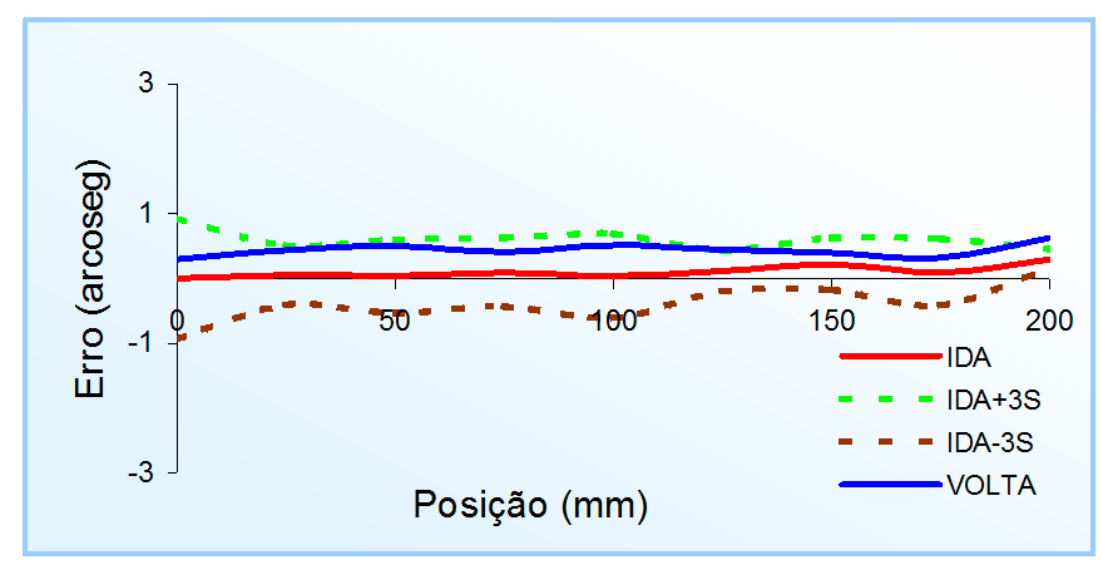

Figura 6.41 - Erro angular yaw do eixo $Z$ para $20^{\circ} \mathrm{C}$.

A expressão que representa a variação do erro em função das temperaturas é dada na Eq. (6.27).

$$
\begin{aligned}
V_{\text {YawZ }}(T)= & -1,8 \cdot T_{1}+11,1 \cdot T_{2}-12 \cdot T_{4}-4,3 \cdot T_{5}+10,9 \cdot T_{7}- \\
& -2,1 \cdot T_{9}-1,4 \cdot T_{10}-3,3 \cdot T_{11}-5,2 \cdot T_{12}+2,81 \cdot T_{13}+ \\
& +1,59 \cdot T_{14}-5,8 \cdot T_{15}+2,23 \cdot T_{16}-4 \cdot T_{17}
\end{aligned}
$$


O comportamento dos resíduos da Eq. (6.27) obedece às condições necessárias para adequação desta aos dados experimentais. O coeficiente de correlação foi de 99,81\%.

\subsubsection{Erro angular roll do eixo $X$}

A Figura 6.42 mostra as curvas que descrevem o comportamento do erro angular roll do eixo $X$ para $20{ }^{\circ} \mathrm{C}$. Observa-se nesta Figura que o erro é negativo e decrescente, com valores de histerese pequenos.

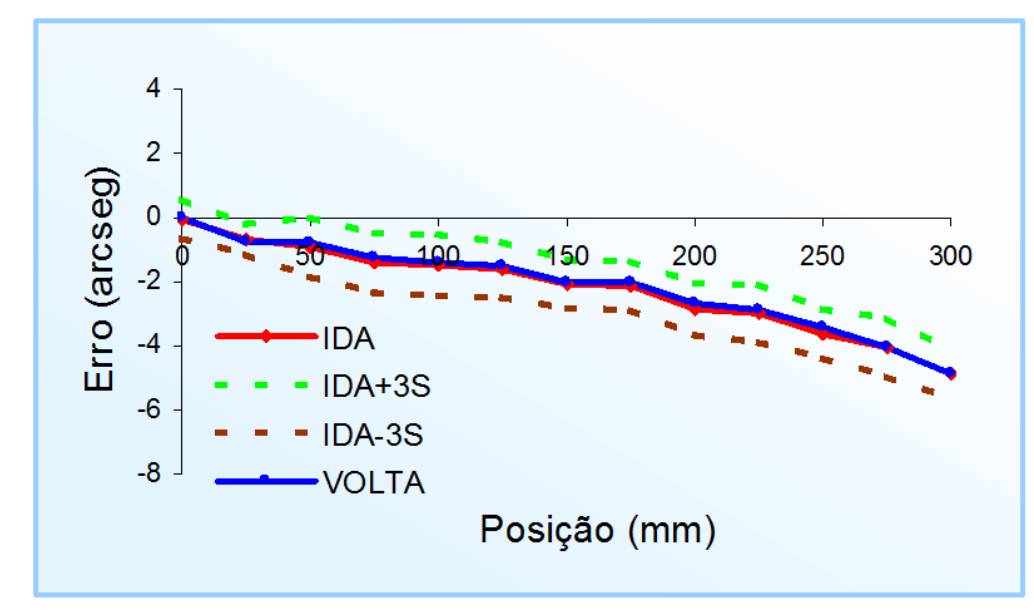

Figura 6.42 - Erro angular roll do eixo X para $20^{\circ} \mathrm{C}$.

O equacionamento da variação do erro foi efetuado através de uma regressão linear múltipla, Eq. (6.28). O coeficiente $R^{2}$ foi de $97,81 \%$. Os resíduos apresentaram um comportamento aleatório.

$$
V_{\text {RollX }}(T)=-15 \cdot T_{1}+7,23 \cdot T_{3}+14 \cdot T_{5}+9,46 \cdot T_{14}-15 \cdot T_{16}
$$




\subsubsection{Erro angular roll do eixo $Y$}

A Figura 6.43 mostra a grandeza e comportamento do erro angular roll do eixo $Y$ para $20^{\circ} \mathrm{C}$. Observa-se nesta Figura que o erro é positivo e crescente.

A Equação (6.29) descreve a variação do erro roll do eixo $Y$. O coeficiente $R^{2}$ foi de $96,61 \%$, a análise dos resíduos mostrou que os mesmos apresentam um comportamento aleatório, com média zero e variância constante.

$$
\begin{aligned}
V_{R o l l Y}(T)= & -12 \cdot T_{1}+39,6 \cdot T_{2}-44 \cdot T_{4}-26 \cdot T_{5}-27 \cdot T_{5}+14,6 \cdot T_{7}+11,8 \cdot T_{8}-5,4 \cdot T_{10}+ \\
& +25,1 \cdot T_{11}-6 \cdot T_{12}+11,8 \cdot T_{14}-9,7 \cdot T_{15}
\end{aligned}
$$

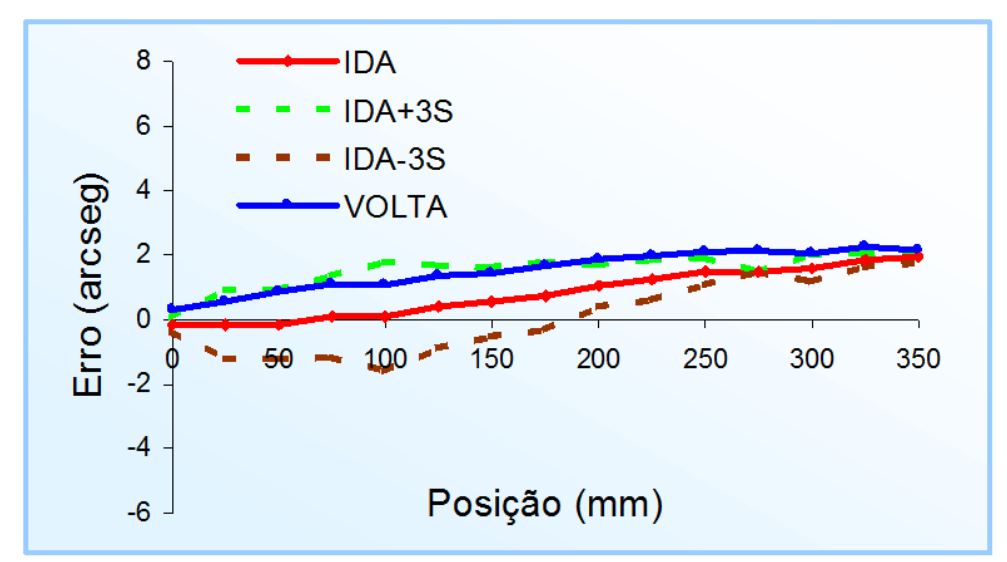

Figura 6.43 - Erro angular roll do eixo $Y$ para $20^{\circ} \mathrm{C}$.

Na Figura 6.44 observa-se que as curvas que descrevem os erros angulares yaw dos eixos $X$ e $Y$ apresentam grandeza e comportamento similares, indicando que a máquina sofre uma rotação positiva em torno do eixo $Z$. Assim sendo, o erro de perpendicularidade entre os eixos $X$ e $Y$ não deve apresentar variações quando a máquina for submetida a variações de temperatura ambiente. 


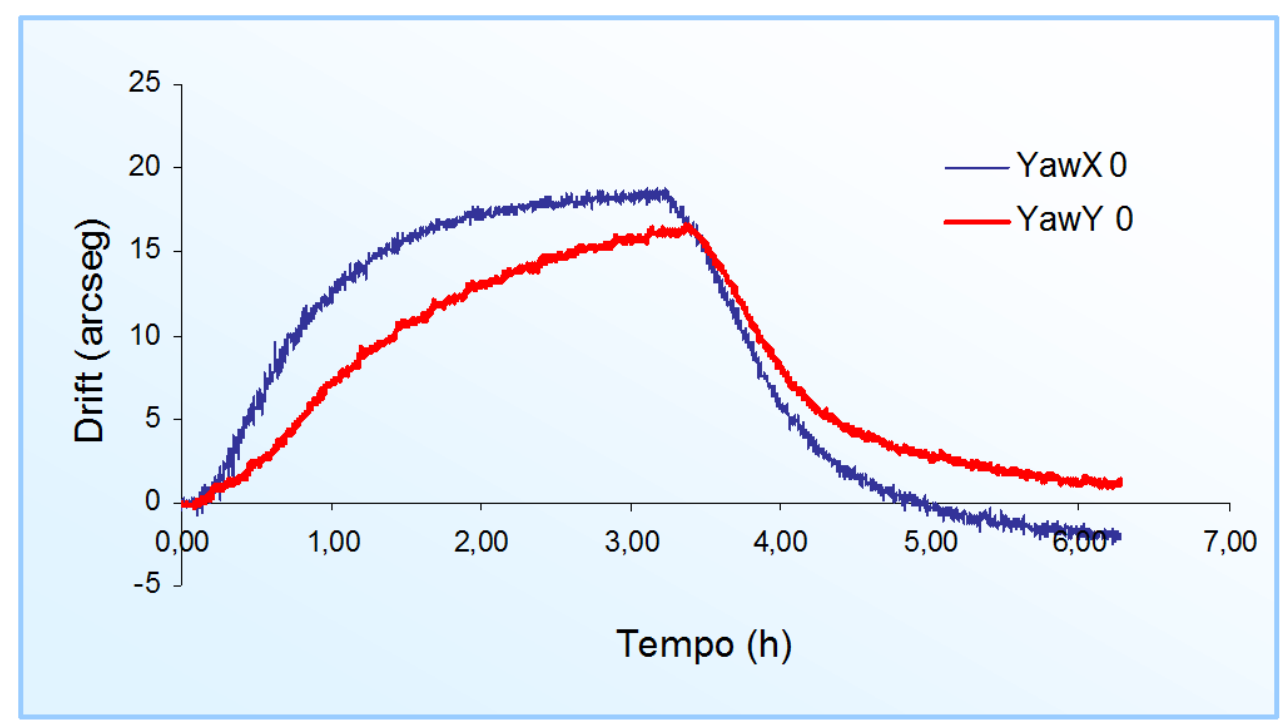

Figura 6.44-Curvas de drift dos erros yaw dos eixos $X$ e $Y$.

Na Figura 6.45 pode-se observar que os erros angulares roll do eixo $X$ e pitch do eixo $Y$, também, apresentam grandezas e comportamentos similares, indicando que a máquina sofre uma rotação positiva em torno do eixo $X$. Portanto, o erro de perpendicularidade entre os eixos $X$ e $Z$ da máquina deve permanecer constante durante o aquecimento.

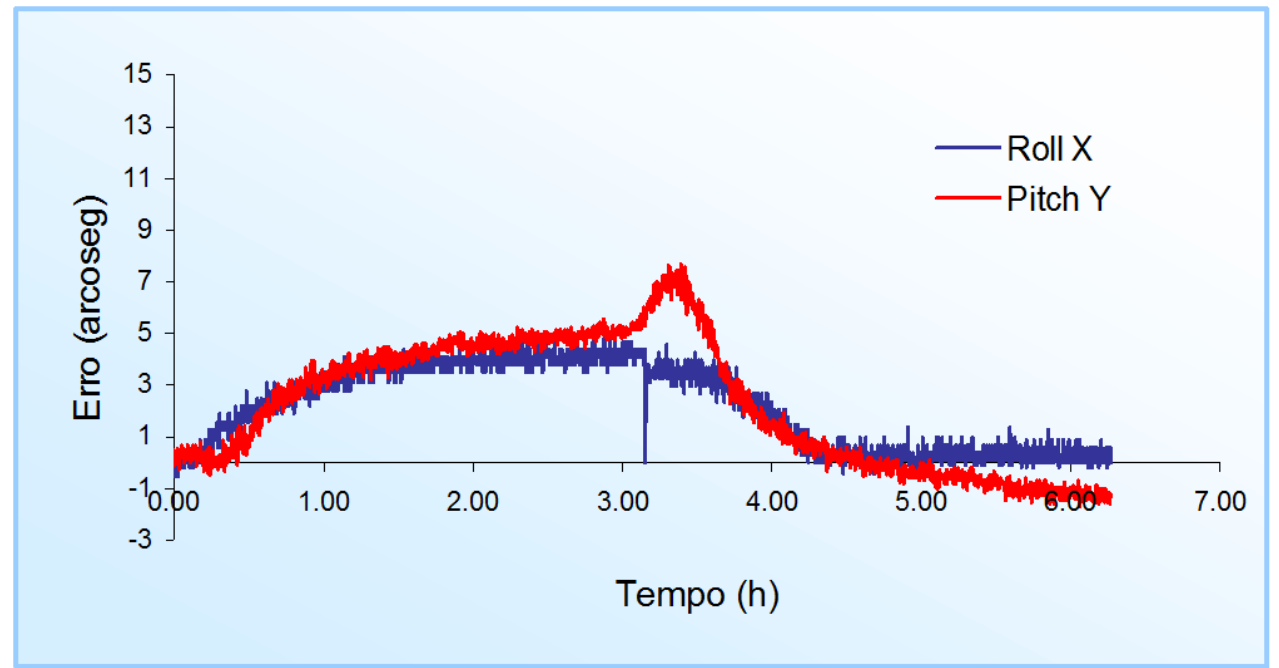

Figura 6.45 - Curvas de drift dos erros roll de $X$ e pitch de $Y$. 


\subsubsection{Erros de Perpendicularidade}

Na Tabela 6.1 são apresentados os resultados concernentes à medição dos erros de perpendicularidade para a temperatura de $20^{\circ} \mathrm{C}$.

\begin{tabular}{c|c}
\hline \multicolumn{2}{|c}{ Tabela 6.1 - Erros de perpendicularidade. } \\
\hline Ort $(\mathrm{xy})$ & $10,31 "$ \\
\hline Ort $(\mathrm{xz})$ & $20,63 "$ \\
\hline Ort $(\mathrm{yz})$ & $-185,64 "$ \\
\hline
\end{tabular}

Na Tabela 6.2 estão apresentados os resultados correspondentes à coleta do erro de perpendicularidade entre os eixos $X$ e $Y$, para diferentes estados térmicos. Pode-se observar na Tabela 6.1 que o erro de perpendicularidade avaliado tem a mesma grandeza para todos os estados.

\begin{tabular}{c|c}
\hline \multicolumn{2}{c}{ Tabela 6.2 - Erro de perpendicularidade $X Z$ para diferentes } \\
estados térmicos. \\
\hline TEMPERATURA $\left({ }^{\circ} \mathrm{C}\right)$ & ERRO DE PERPENDICULARIDADE $X Z(")$ \\
\hline 24 & 20,9264 \\
\hline 26 & 21,5940 \\
\hline 28 & 20,6075 \\
\hline
\end{tabular}

\subsection{Avaliação do Modelo}

A partir dos resultados apresentados nos item 6.2 .6 e 6.2.13 propõe-se que no modelo geométrico-térmico da MM3C não sejam consideradas algumas parcelas, correspondentes à variação termicamente induzida dos erros geométricos, por representarem o mesmo efeito. Assim sendo o modelo assume a seguinte forma, Eqs (6.30) - (6.32) 


$$
\begin{aligned}
& E x(p, T)=\operatorname{Pos}(x)+\delta[\operatorname{Pos} x(p, T)]+R y(x)+\delta[R y(x)(T)]+R z(x)+ \\
& +[\operatorname{Ort}(x y)+\operatorname{Yaw}(x)+\delta \operatorname{Yaw} x(T)] \cdot\left(Y_{34}+\delta Y_{34}\right)+ \\
& +\left[\begin{array}{l}
\operatorname{Ort}(x z)+\operatorname{Pitch}(x)+\delta[\operatorname{Pitch}(T)]+\operatorname{Yaw}(z) \\
+\delta[\operatorname{Yawz}(T)]+\operatorname{Roll}(y)+\delta[\operatorname{Rolly}(T)]
\end{array}\right] \cdot\left[-Z-\left(Z 45+\delta Z_{45}\right)\right]+ \\
& +\{\operatorname{Roll}(y)+\delta[\operatorname{Rolly}(T)]\} \cdot\left(Z_{12}+\delta Z_{12}\right) \\
& E y(p, T)=\operatorname{Pos}(y)+\delta[\operatorname{Posy}(p, T)]+R x(y)+R z(y)+\delta[R z(y)(T)] \\
& +[\operatorname{Ort}(x y)+\operatorname{Yaw}(y)+\delta[\operatorname{Yawy}(p, T)]] \cdot\left(X_{23}+\delta X_{23}+X\right)- \\
& -[\operatorname{Pitch}(y) \cdot \delta[\operatorname{Pitchy}(p, T)]] \cdot\left(Z_{12}+\delta Z_{12}\right)- \\
& -\left[\begin{array}{l}
\operatorname{Ort}(y z)+\operatorname{Roll}(x)+\delta[\operatorname{Rollx}(p, T)]+\operatorname{Pitch}(y)+ \\
+\delta[\operatorname{Pitchy}(p, T)]+\operatorname{Pitch}(z)+\delta[\operatorname{Pitch}(p, T)]
\end{array}\right] \cdot\left[-Z-\left(Z_{45}+\delta Z_{45}\right)\right] \\
& E z=\operatorname{Pos}(z)+\delta[\operatorname{Pos} z(p, T)]+R x(z)+\delta[R x(z)(T)]+R y(z)- \\
& -[\operatorname{Roll}(y)+\delta[\operatorname{Rolly}(p, T)]] \cdot\left(X_{23}+\delta X_{23}+X\right)- \\
& -[\operatorname{Roll}(x)+\delta[\operatorname{Rollx}(p, T)]+\operatorname{Pitch}(y)+\delta[\operatorname{Pitchy}(p, T)]] \cdot\left(Y_{34}+\delta Y_{34}\right)
\end{aligned}
$$

\section{Comparação entre os erros encontrados na medição de peças e os sintetizados}

Inicialmente, são apresentados os resultados concernentes à avaliação do modelo geométrico da MM3C. A Figura 6.46 mostra os valores dos erros encontrados na medição do diâmetro do anel padrão, em diferentes posições, para $20{ }^{\circ} \mathrm{C}$. Para as coordenadas dos pontos de medição os valores das componentes do erro volumétrico foram sintetizados e então compensados. A diferença entre o erro de medição e o sintetizado é o erro residual mostrado na Figura 6.46. As posições de medição do anel padrão, no volume de trabalho da máquina estão mostradas na Figura 6.47.

Verifica-se na Figura 6.46 que os erros encontrados durante a medição do diâmetro do círculo para $20{ }^{\circ} \mathrm{C}$, isto é, a diferença entre o valor medido e o padrão, é igual ou menor que 16,0 $\mu \mathrm{m}$ em todos os casos, enquanto os erros após a compensação não ultrapassam 2,3 $\mu \mathrm{m}$. O modelo geométrico permitiu reduzir os erros de medição em pelo menos 74\%. Estes resultados podem ser considerados bons, pois a medição do 
anel padrão incorpora o sistema de apalpamento o qual não foi utilizado durante o levantamento dos erros geométricos. Sempre são atribuídos erros ao sistema de apalpamento, embora a sonda utilizada apresente boa repetibilidade.

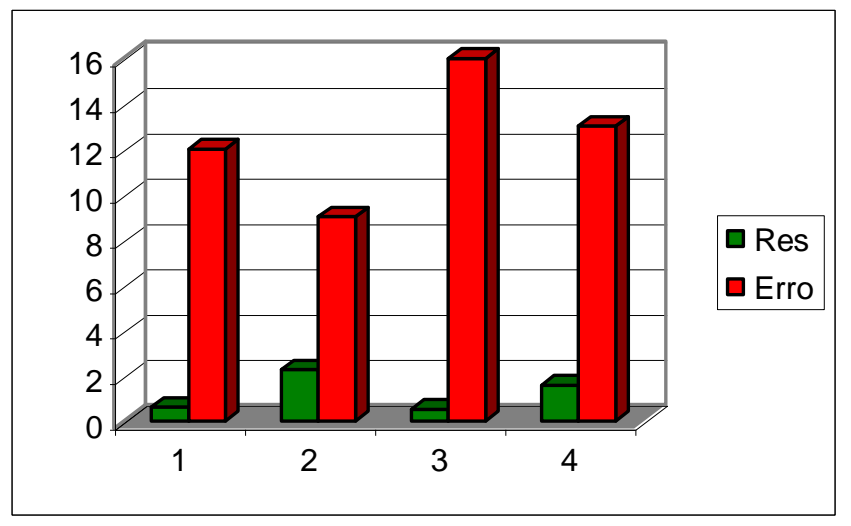

Figura 6.46 - Erros de medição e residuais para $20^{\circ} \mathrm{C}$.

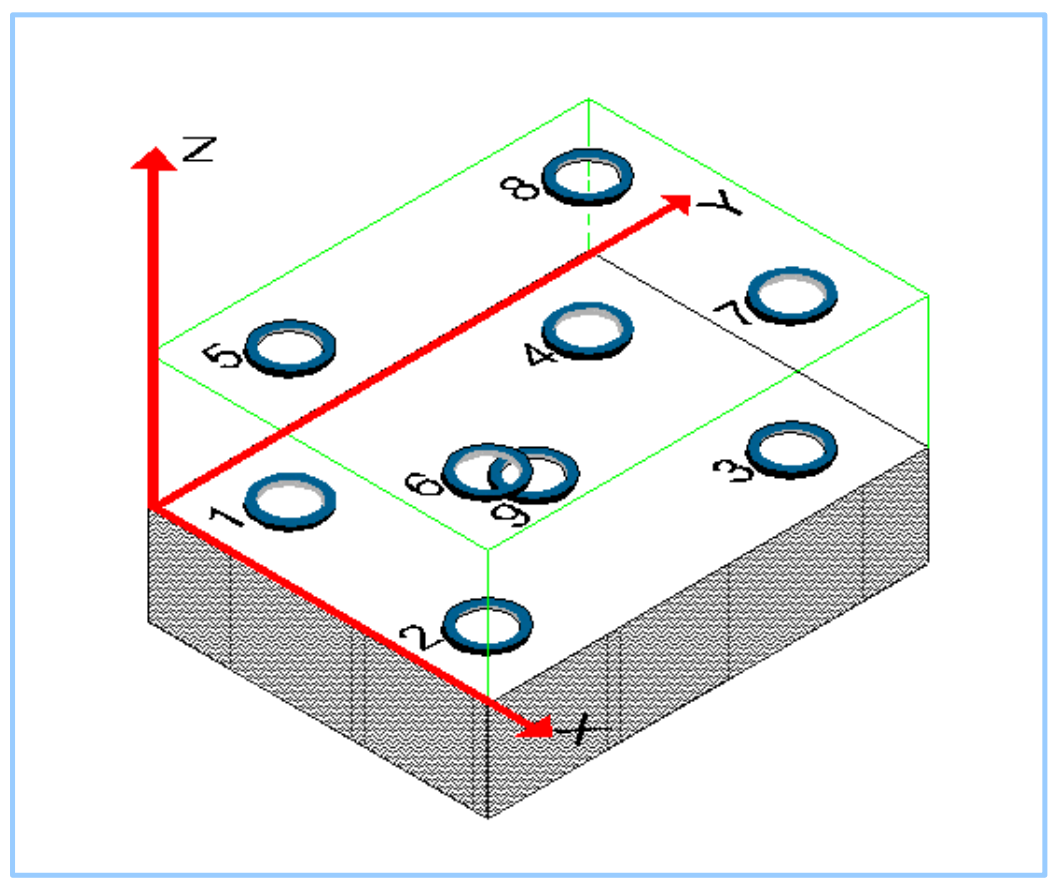

Figura 6.47 - Posições de medição do anel padrão. 
A Tabela 6.3 mostra os valores dos diâmetros medidos e os sintetizados utilizando-se do modelo geométrico da máquina, assim como, os erros residuais e a porcentagem de redução do erro.

Tabela 6.3 - Resultados da avaliação do modelo geométrico.

\begin{tabular}{c|c|c|c|c|c}
\hline POS. & TEMP. ${ }^{\circ} \mathrm{C}$ & D. MEDIDO & D. SINTETIZADO & ERRO RES. & PORCENTAGEM \\
\hline 1 & 20 & 180,000 & 180,0126 & 0,60 & 94,96 \\
\hline 2 & 20 & 180,003 & 180,0143 & 2,26 & 74,85 \\
\hline 3 & 20 & 179,996 & 180,0115 & $-0,52$ & 96,74 \\
\hline 4 & 20 & 179,999 & 180,0136 & 1,59 & 87,77 \\
\hline
\end{tabular}

A Figura 6.48 mostra os resultados obtidos durante a avaliação do modelo para $26^{\circ} \mathrm{C}$. Pode-se observar que os erros geométrico-térmicos nas posições 1-4 presentes na Figura 6.48 são muito maiores que os erros geométricos da Figura 6.46. Isto confirma a importância do efeito das variações de temperatura no resultado das medições. Os erros residuais para todas as posições são pequenos, iguais ou menores que $3 \mu \mathrm{m}$. Nas posições 1-4, próximas do desempeno, os erros foram reduzidos em pelo menos $90 \%$. Para as posições $5-8$, onde os erros são menores, a correção foi maior que $74 \%$.

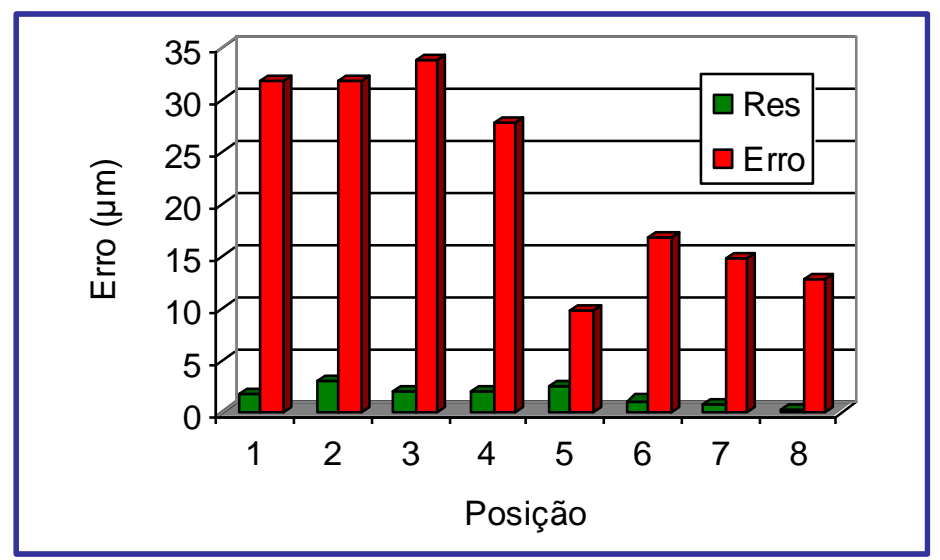

Figura 6.48 - Erros de medição e residuais para $26^{\circ} \mathrm{C}$.

A Tabela 6.4 mostra os valores dos diâmetros medidos e os sintetizados através do modelo geométrico-térmico proposto, assim como, os resíduos e a porcentagem da redução do erro. 
Tabela 6.4 - Resultados da avaliação do modelo geométrico-térmico para $26^{\circ} \mathrm{C}$.

\begin{tabular}{c|c|c|c|c|c}
\hline Pos. & TEMP. $^{\circ} \mathrm{C}$ & D. MEDIDO & D. SINTETIZADO & ERRO RES. & PORCENTAGEM \\
\hline 1 & 26 & 179,982 & 180,0119 & $-1,81$ & 94,28 \\
\hline 2 & 26 & 179,982 & 180,0107 & $-2,96$ & 90,66 \\
\hline 3 & 26 & 179,980 & 180,0116 & $-2,11$ & 93,72 \\
\hline 4 & 26 & 179,986 & 180,0117 & $-2,02$ & 92,71 \\
\hline 5 & 26 & 180,004 & 180,0112 & $-2,49$ & 74,26 \\
\hline 6 & 26 & 179,997 & 180,0149 & 1,17 & 92,98 \\
\hline 7 & 26 & 179,999 & 180,0129 & $-0,76$ & 94,80 \\
\hline 8 & 26 & 180,001 & 180,0140 & 0,34 & 97,26 \\
\hline
\end{tabular}

Para $20{ }^{\circ} \mathrm{C}$ o desvio padrão das medições é de $2,8 \mu \mathrm{m}$, após a correção dos erros este desvio é de 1,6 $\mu \mathrm{m}$. Para a temperatura de $26{ }^{\circ} \mathrm{C}$ o desvio padrão das medições é de 9,8 $\mu \mathrm{m}$ e após a correção de 1,4 $\mu \mathrm{m}$. Pode-se observar que a dispersão após a compensação é mais compacta para $26^{\circ} \mathrm{C}$.

A partir dos diâmetros medidos se comprovou que quando o anel padrão foi posicionado no centro da superficie do desempeno da máquina os erros induzidos termicamente foram menores. Estes resultados são atribuídos ao princípio de montagem das escalas nas guias, permitindo a livre dilatação das mesmas a partir de um local próximo de seus centros.

A Tabela 6.5 mostra os valores dos diâmetros do círculo medidos durante o aquecimento da máquina de 20 para $26{ }^{\circ} \mathrm{C}$. Nesta Tabela a quarta coluna (erro) representa o erro encontrado durante a medição do círculo, para 20 e $26^{\circ} \mathrm{C}$, respectivamente. Enquanto a quinta coluna (drift) corresponde ao valor do erro termicamente induzido.

\begin{tabular}{c|c|c|c|c}
\hline \multicolumn{5}{|c}{ Tabela 6.5 - Erros termicamente induzidos. } \\
\hline POS. & TEMP. $\left({ }^{\circ} \mathrm{C}\right)$ & D. MEDIDO & ERRO $(\mu \mathrm{M})$ & DRIFT $(\mu \mathrm{M})$ \\
\hline 1 & 20 & 180,000 & 12 & \\
\hline 2 & 20 & 180,003 & 9 & \\
\hline 3 & 20 & 179,996 & 16 & \\
\hline 4 & 20 & 179,999 & 13 & \\
\hline 9 & 20 & 180,003 & 9 & \\
\hline 1 & 26 & 179,982 & 32 & 20 \\
\hline 2 & 26 & 179,982 & 32 & 23 \\
\hline 3 & 26 & 179,980 & 34 & 18 \\
\hline 4 & 26 & 179,986 & 28 & 15 \\
\hline 9 & 26 & 179,998 & 16 & 7 \\
\hline
\end{tabular}


Observe que na posição 9, centro do desempeno, a variação termicamente induzida experimentada pelos valores do diâmetro é $50 \%$ menor que nas outras posições, Isto confirma que os erros menores ocorrem quando as peças são posicionadas no centro da superfície do desempeno, Assim sendo, recomenda-se que nestes tipos de máquinas as peças a serem medidas, sob variações de temperatura ambiente, sejam posicionadas no centro do desempeno, onde os efeitos térmicos são os menores,

\subsection{CÁlculo da INCERTEZA AsSOCIAdA Às COMPONENTES do ERRO VOLUMÉTRICO}

A Tabela 6.6 apresenta os dados referentes ao cálculo da incerteza do erro de posição do eixo $X$ para $20^{\circ} \mathrm{C}$, usado neste capítulo para efeito de ilustração e discussão geral do método aplicado. Pode-se observar que a incerteza padrão combinada é de 0,348 $\mu \mathrm{m}$, enquanto a incerteza expandida é de 0,700 $\mu \mathrm{m}$. Assim sendo, o resultado da incerteza de medição do erro de posição do eixo $X$ na posição $X=275 \mathrm{~mm}$ é:

$$
\operatorname{ErroPos}\left(X_{275}\right)=\operatorname{Valor}\left(\operatorname{ErroPos}\left(X_{275}\right)\right) \pm 0,348 \mu m
$$

\begin{tabular}{|c|c|c|c|c|c|c|c|}
\hline \multicolumn{8}{|c|}{ Tabela 6.6 - Incerteza do Erro de Posição do eixo $X_{275}$ para $20^{\circ} \mathrm{C}$} \\
\hline $\begin{array}{c}\text { Grandeza } \\
X_{\mathrm{i}} \\
\end{array}$ & $\begin{array}{c}\text { Estimativa } \\
\mathrm{x}_{\mathrm{i}}\end{array}$ & \begin{tabular}{c|} 
Inc. \\
Padronizada
\end{tabular} & Unidade & $\begin{array}{l}\text { Dist. de } \\
\text { Probab. }\end{array}$ & $\begin{array}{l}\text { Coef. de } \\
\text { Sensib. } \\
\end{array}$ & $\begin{array}{l}\text { Incert. } \\
\text { padrão }\end{array}$ & $\begin{array}{l}\text { Grau de } \\
\text { liberdade }\end{array}$ \\
\hline $\mathrm{M}$ & 0,23 & 0,289 & $\mu \mathrm{m}$ & Normal & 1 & 0,289 & 4 \\
\hline $\mathrm{R}_{\mathrm{MM}}$ & 0,002 & 0,001 & $\mu \mathrm{m}$ & Retan. & 1 & 0,001 & $\infty$ \\
\hline Rlaser & 0 & 0,058 & $\mu \mathrm{m}$ & Retan. & 1 & 0,058 & $\infty$ \\
\hline$\alpha_{\mathrm{E}}$ & 0 & $3,06 \mathrm{E}-08$ & ${ }^{\circ} \mathrm{C}$ & Retan. & $-0,0064$ & $-1,95^{*} \mathrm{E}-10$ & $\infty$ \\
\hline $\mathrm{C}_{\text {laser }}$ & 0 & $8,08 \mathrm{E}-05$ & ${ }^{\circ} \mathrm{C}$ & Retan. & 0,014 & $1,13^{*} \mathrm{E}-6$ & $\infty$ \\
\hline$\delta \mathrm{T}$ & 0 & 0,202 & ${ }^{\circ} \mathrm{C}$ & Retan. & $-0,53^{*} \mathrm{E}-7$ & $-1,07^{*} \mathrm{E}-8$ & $\infty$ \\
\hline \multirow[t]{2}{*}{$\Delta \mathrm{T}$} & 0 & 0,370 & ${ }^{\circ} \mathrm{C}$ & Retan. & $-0,000139$ & $-5,17^{*} \mathrm{E}-5$ & $\infty$ \\
\hline & & & & & $\mathrm{k}=2,00$ & 0,348 & $v_{e f}=124$ \\
\hline \multicolumn{6}{|c|}{ Incerteza expandida } & 0,700 & \\
\hline
\end{tabular}


$\mathrm{Na}$ Tabela anterior $\mathrm{k}=2,00$ é o coeficiente de sensibilidade e $v_{e f}$ $=124$ é o grau de liberdade efetivo.

\section{Incerteza associada às componentes do erro volumétrico}

Uma vez concluído o cálculo das incertezas associadas a cada um dos erros geométricos e dos braços da máquina, procede-se à combinação adequada destas para obtenção das incertezas associadas às componentes do erro volumétrico. Na Tabela 6.7 são apresentados os valores da incerteza padrão combinada associada às componentes Ex, Ey e Ez.

\begin{tabular}{c|c}
\hline $\begin{array}{c}\text { Tabela } 6.7-\text { Incerteza associada às componentes } \\
\text { do Erro Volumétrico. }\end{array}$ \\
\hline COMPONENTE & INCERTEZA $(\mu \mathrm{m})$ \\
\hline$U C_{E X}$ & 3,48 \\
\hline$U C_{E Y}$ & 4,88 \\
\hline$U C_{E Z}$ & 2,63 \\
\hline
\end{tabular}

Os valores de incerteza apresentados na Tabela 6.7 indicam que em qualquer ponto do volume de trabalho da máquina as componentes do erro volumétrico apresentam valores de incerteza próximos de 3,48, 4,88 e $2,63 \mu \mathrm{m}$, respectivamente. Estes resultados são similares àqueles obtidos por VIEIRA SATO (2001) e podem ser considerados adequados. 


\section{CAPÍTULO 7}

\section{Conclusões e Propostas para Trabalhos FUTUROS}

Neste trabalho foi apresentado o equacionamento matemático das componentes do erro volumétrico em uma Máquina de Medir a Três Coordenadas do tipo Ponte Móvel, considerando as influências térmicas. Para tanto foi desenvolvido um modelo geométrico-térmico, o modelo geométrico foi obtido através da utilização das transformações homogêneas, enquanto o modelo térmico combina técnicas de regressão e o método dos mínimos quadrados.

Para obtenção do modelo foi necessário o levantamento dos erros geométricos e da variação termicamente induzida destes erros. Simultaneamente à calibração foi efetuado o monitoramento das temperaturas em vários pontos da estrutura da máquina. A eficiência do modelo foi verificada através da comparação dos resultados obtidos durante a medição de um artefato padrão e aqueles sintetizados utilizando-se do modelo proposto.

Após a avaliação e discussão dos resultados as seguintes conclusões podem ser feitas: 
O computador, o ar fornecido à máquina, os cabos de alimentação e o operador constituem fontes localizadas de calor. Portanto, devem ser cuidadosamente localizadas para assim evitar ou diminuir seus efeitos. Destaca-se, também, a importância da correta manipulação da peça durante as medições.

As fontes localizadas de calor provocam uma distribuição não homogênea das temperaturas na estrutura da máquina, gerando gradientes térmicos espaciais.

> A resposta da máquina às perturbações térmicas pode-se considerar como rápida, pois após $3 \mathrm{~h}$ aproximadamente, de introduzida uma perturbação térmica o equilíbrio térmico é atingido. Isto deve-se ao fato que a máquina é fabricada, majoritariamente, de alumínio. Máquinas Ferramentas (Retificadora Cilíndrica, fabricada de ferro fundido) podem demorar até $9 \mathrm{~h}$ para atingir o equilíbrio térmico (VIEIRA SATO, 1998).

A variação termicamente induzida dos erros de posição depende da temperatura, do material da guia e da escala e do princípio de montagem entre ambos.

Não foi possivel adotar um modelo linear para descrever a variação termicamente induzida dos erros de posição, pois a distribuição da temperatura na máquina não é homogênea.

O comportamento térmico dos erros de retitude e angulares de todos os eixos não depende da posição do carro de movimentação, correspondente, portanto, durante a coleta do drift térmico estes erros podem ser levantados em apenas um ponto. Enquanto, VIEIRA SATO, (1998) propõe o levantamento do drift destes erros em quatro pontos ao longo do eixo avaliado.

Os erros de perpendicularidade não mudam de comportamento durante os transientes térmicos.

A MM3C avaliada dilata-se livremente durante o aquecimento, pois não foram impostas restrições à dilatação. Assim sendo, 
pode-se concluir que durante o projeto e montagem dos componentes da máquina foram considerados os efeitos térmicos. Pode-se dizer que a MM3C avaliada possui uma estrutura metrológica correta.

$\mathrm{O}$ método dos mínimos quadrados mostrou-se eficiente para o equacionamento da variação termicamente induzida dos erros de posição em qualquer estado de temperatura e posição do carro de movimentação, correspondente.

O modelo proposto mostrou-se eficiente permitindo reduzir os valores de erro volumétrico, maiores que $10 \mu \mathrm{m}$, em pelo menos $90 \%$. Para valores de erro volumétrico, menores que $10 \mu \mathrm{m}$, a redução foi maior que $75 \%$. A seguir são citados alguns trabalhos a modo de comparação. O modelo desenvolvido por KRENG et al. (1994) em um centro de usinagem de três eixos, além de não prever adequadamente o erro da máquina fria, somente permitiu compensar $75 \%$ do erro quando a máquina estava aquecida, sendo que os erros presentes nesta máquina eram da ordem de $100 \mu \mathrm{m}$. O modelo desenvolvido por SARTORI (1989), usando elementos finitos, permitiu compensar de 65 a $75 \%$ dos erros. BALSAMO et al. (1990) conseguiu descrever $70 \%$ das deformações térmicas em uma MMC.

O modelo proposto se mostrou eficiente durante a compensação dos erros encontrados na medição de peças para diferentes temperaturas, apesar de ser obtido a partir de dados que não incluíam o sistema de apalpamento.

Comprovou-se, experimentalmente, que a grandeza dos erros termicamente induzidos é menor quando as peças são posicionadas no centro do desempeno da máquina.

Na maioria das posições de medição a parcela correspondente aos erros termicamente induzidos é até $200 \%$ maior que a parcela dos erros geométricos. Assim sendo, verifica-se como as variações de temperatura ambiente afetam o resultado das medições. 
A partir destas observações e conclusões, algumas propostas de trabalhos futuros estão delineadas a seguir.

Implementar um sistema de compensação de erros nas MM3Cs tipo Ponte Móvel utilizando as equações obtidas através do presente trabalho.

Incorporar ao equacionamento os efeitos da peça e do sistema apalpador.

Estender a metodologia a outros tipos de Máquinas de Medir.

Efetivar o cálculo da incerteza de medição considerando as influências térmicas. 


\section{REFERÊNCIAS BIBLIOGRÁFICAS}

ABACKERLI, A.; MIGUEL, P.A.C. (1997). Máquina virtual: Uma solução viável para a estimativa de incertezas na medição por coordenadas. Máquinas e Metais. Abril/maio.

AMERICAN NATIONAL STANDARDS INSTITUTE / AMERICAN SOCIETY OF MECHANICAL ENGINEERS. (1973). B 89.6.2 - Temperature and humidity environment for dimensional inspection. Washington.

. (1990). B 89.1.12M - Methods for performance evaluation of coordinate measuring machines. Washington.

BALSAMO, A.; MARQUES, D.; SARTORI, S. (1990). A Method for thermaldeformation corrections of CMMs. Annals of the CIRP, Paris, v.39, n.1, p. 557-560.

BOSCH, J.A. (1995). Coordinate measuring machines and systems. New York. Marcel Dekker, Inc.

BREYER K.H.; PRESSEL H.G. (1991). Paving the way to thermally stable coordinate measuring machines. Progress in Precision Engineering, Braunschweig, p.56-76, May.

BRYAN, J.B. (1967). International status of thermal error research. Annals of the CIRP, Paris, v.16, p.203-215.

, J.B. (1990). International status of thermal error research. Annals of the CIRP, Paris, v.39, n.2, p.645-656.

J.B. (1995). Temperature fundamentals. In: BOSCH, J.A. Coordinate measuring machines and systems. New York: Marcel Dekker. Cap.8, p.227-264. 
BS 6808, (1989) - Coordinate measuring machines. Parte III Code of pratice. British standards institution.

CARDOZA, J.A.S. (1995) Máquinas virtuais de medir a três coordenadas. 225 p. Tese (Doutorado) - Escola de Engenharia de São Carlos, Universidade de São Paulo, São Carlos, 1995.

CHEN J.S. et al. (1993). Real-time compensation for time-variant volumetric errors on a machining. Journal of Engineering for Industry, v.115, p.472-479, Nov.

CMMA: Coordinate Measuring Machines Manufacturing Association. London, 1989.

CPIM: COMITÉ INTERNATIONAL DES POIDS ET MESURES Recomendação INC-1. 1980.

DECKER, J.E.; PEKELSKY, J.R. (1999). Gauge Block Calibration and the expression of associated measurement uncertainties, Anais III Seminário de Metrologia Aeroespacial, Julho, p. 1-10.

DI GIACOMO, B.; SATO, D.P.V. \& ORREGO, R.M.M, (1997). Second order terms influence in mathematical models of machine tools, Proceedings of $12^{\text {th }}$ Annual Meeting the American Society for Precision Engineering, p.5356.

DI GIACOMO, B.; ARENCIBIA, R.V. (2002). Estudo do comportamento térmico de máquinas de medir de tres coordenadas. Revista Internacional Información Tecnológica, Chile, v.13, n.6, p.111-6.

DI GIACOMO, B.; ARENCIBIA, R.V.; MARQUES, A. (2002). Estudo do comportamento térmico das MM3Cs. In: CONGRESSO DE ENGENHARIA MECÂNICA, 2., 2002, João Pessoa. Anais Paraíba. 
DONMEZ, M.A. et. al. (1986). A General methodology for machine tool accuracy enhancement by error compensation. Precision Engineering, Guildford, v.8, n.4, p.187-196.

DONMEZ, M.A. et. al. (1982). Statistical analysis of positioning error of a CNC milling machine. Journal of Manufacturing Systems. v.1, n.1, p.3341.

DRAFT BRITISH STANDARD (1987). BSI coordinate measuring machines. Parte 1, Glossary of terms.

DRAPER, N.R.; SMITH, H. (1986). An Introduction to nonlinear estimation. In: Applied regression analysis. 2.ed. New York: Wiley. Cap.10, p.458-529.

FERREIRA, P.M.; LIU, C.R.B. (1986a). An Analytical quadratic model for the geometric error of a machine tool. Journal of Manufacturing Systems, Dearborn, v.5, n.1, p.51-62, Apr.

- (1986b). A Contribution to the analysis and compensation of the geometric error of a machining center. Annals of the CIRP, Paris, v.35, n.1, p.259-262.

GROBMANN, K. e JUNGNICKEL, G. (2002). Correção de erros gerados por fatores térmicos em máquinas-ferramenta. Máquinas e Metais, p.38-61. nov.

ISO. Proposed draft standart, (1989). Part $1-(\mathrm{E})$, Doc ISI/TC 3/WG10/N77.

ISO TAG 4/WG 3 - (1993). Guide to the Expression of Uncertainty in measurement, Geneva Switzerland. 
ISO 10360-2: (1994). Methods for the assessment of the performance and verification of co-ordinate measuring machines.

INMETRO. (1998). Guia para expressão das incertezas de medição.

JEDRZEJEWSKI, J.; MODRZYCKI, W. (1992). A New approach to modeling thermal behavior of a machine tool under service conditions. Annals of the CIRP, Paris, v.41, n.1, p.455-8.

JIS B 7440. (1997). Test Code for accuracy of Coordinate Measuring Machines.

KRENG, V.B.; LIU, C.R.; CHU, C.N. (1994). A Kinematic model for machine tool accuracy characterization. International Journal of Advanced Manufacturing Technology, London, n.9, p.79-86.

KRULEWICH, D.A. (1998). Temperature integration model and measurement point selection for thermally induced machine tool errors, Mechatronics 8 pp.395-412 in RAMESH, R. M.A. MANNAN and A.N. Poo, (2000) Error Compensation in Machine Tools - A Review. Part II: Thermal Errors. International Journal of Machine Tools \& Manufacture. Vol.40 pp.1257-1284.

KRUTH, J.P; VANHERCK, P.; VAN DEN BERGH, C. (2001). Compensation of static and transient thermal errors on CMMs. Annals of the CIRP, Paris, v.50, n.1, p.377-380.

KRUTH, J.P. et al. (2002). Interaction between workpiece and CMM during geometrical quality control in non-standard thermal conditions. Precision Engineering, Guildford, v.26, p.93-98. 
KUNZMAN, H.; TRAPET, E.; WÄLDELE, F. (1993). Concept for the traceability of measurements with coordinate measuring machines. Proceedings of the $7^{\text {th }}$ International Precision Engineering Seminar. Kobe. Japan, may. 40-52.

KUNZMAN, H.; et al., (1994). Já há como rastrear as medições com máquinas de coordenadas. Máquinas e Metais. Agosto. p. 74-85.

KUNZMANN, H; WÄLDELE, F; NI, J. (1995). Accuracy Enhancement, in: BOSCH, J.A.: Coordinate Measuring Machines and Systems, New York, Marcel Dekker, Inc., 1995.

LINGARD, P.S. et al. (1991). Temperature perturbation effects in a high precision CMM. Precision Engineering, v.13, n.1, p.41-51.

LINK, W. (1997). Metrologia mecânica: expressão da incerteza de medição. p. 174 .

LO, et al., (1995). in RAMESH, R. M.A. MANNAN and A.N. Poo, (2000) Error Compensation in Machine Tools - A Review. Part II: Thermal Errors. International Journal of Machine Tools \& Manufacture. Vol.40 pp.12571284.

LOTZE, W. (1996). ScanMax- a novel 3D coordinate measuring machine for the shop-floor environment. New York: John Wiley.

MARTINEZ ORREGO, R. (1997). Avaliação e qualificação de Maquinas de medir por coordenadas. Relatório FAPESP - Escola de Engenharia de São Carlos, Universidade de São Paulo, São Carlos, 1997.

- (1999). Método de calibração direta para Maquinas de Medir a Três Coordenadas. Tese (doutorado) - Escola de Engenharia de São Carlos, Universidade de São Paulo, São Carlos, 1999. 
MONGOMERY, D.C.; RUNTER, G.C.; MONTGOMERY, D. (1996). Applied statistics and probability for engineers measurement. IMM Ingenieurbuero fur Moderne Messtechnik, Dresden, v.18, n.1, p.17-25.

MOU et al., (1995). in RAMESH, R. M.A. MANNAN and A.N. Poo, (2000) Error Compensation in Machine Tools - A Review. Part II: Thermal Errors. International Journal of Machine Tools \& Manufacture. Vol.40 pp.12571284.

MURTHY, R.L. (1980) Thermal deformation on a semi-automatic machine: a case study. Precision Engineering, v. 2, n.1, p. 17-21.

NI, J. (1995). Environmental Control, in: BOSH, J.A. Coordinate Measuring Machines and Systems, New York, Marcel Dekker, Inc.

NIST TECNICAL NOTE 1297. (1994). Guide lines for evaluating and expressing the uncertainty of NIST measurement results. National Institute of standards and technology.

OMEGA ENGINEERING (1996). Temperature measurements handbook: the thermocouples. Stanford: Connecticut. Book 1, v.29, p.Z13-Z24.

OKUSHIMA, K.; KAKINO, Y. (1975). An analysis of methods used in minimizing thermal deformations of machine tools. Proceedings of $16^{\text {th }}$ MTDR CONFERENCE, 16. Proceedings. p.195-201.

PEREIRA, P.H. (1995). Levantamento e modelamento dos erros térmicos de uma retificadora cilindrica CNC. 156 p. Dissertação (Mestrado) - Escola de Engenharia de São Carlos, Universidade de São Paulo, São Carlos, 1995.

PHILLIPS, S.D. (1995). Performance evaluations. In BOSCH, J.A. (1995). Coordinate measuring machines and systems. New York. Marcel Dekker, Inc. 
PIRATELI FILHO, A. (1997). Método para avaliação do desempenho de máquinas de medir a três coordenadas através do planejamento de experimentos. 225 p. Tese (Doutorado) - Escola de Engenharia de São Carlos, Universidade de São Paulo, São Carlos, 1997.

RAMESH, R.; M.A. MANNAN.; POO, A.N. (2000). Error compensation in machine tools - a review. Part II: Thermal errors. International Journal of Machine Tools \& Manufacture, v.40, p.1257-1284.

RESHETOV, D.N.; PORTMAN, V.T. (1988). Accuracy of machine tools. American Society of Mechanical Engineers.

SARTORI, S.K. et al., (1989). A method for the identification and correction of thermal deformations in a three coordinate measuring machine. VDI Berichte, 761.

SATA, T.; TAKEUCHI, Y.; OKUBO, N. (1975). Control of the thermal deformation of a machine tool. In: MTDR CONFERENCE, 16., Proceedings. p.203-208.

SATA, T. et al. (1972). Analysis of thermal deformation of machine tool by the finite element method. Annals of the CIRP, Paris, v.21, n.1.

(1973). Analysis of thermal deformation of machine tool structure and its application. In: MTDR CONFERENCE, 14. Proceedings. p.275280.

SHIVASWAMY, S.C. (1992). Error analysis of a three axis machine tool. UNC Charlotte.

SOONS, J.A. et al. (1992). Modeling the errors of multi-axis machines: a general methodology. Precision Engineering, Guildford, v.14, n.1, p.5-19, Jan. 
SPUR, G. et al. (1988). Thermal behavior optimization of machine tools. Annals of the CIRP, Paris, v.37, n.1, p.401-405.

TRAPET, E., WÁLDELE, F., (1989) Coordinate measuring machines in the production line: influence of temperature and measuring uncertainties. IV Congress INTL. Metrologia Industrial, Zaragosa, Nov.

VALDÉS, A.R. (1999). Equacionamento das Componentes do Erro Volumétrico em Máquinas de Medir a Três Coordenadas, Dissertação (Mestrado) - Escola de Engenharia de São Carlos, Universidade de São Paulo, São Carlos, 1999.

VDI/VDE 2617 (1986). Parte I Accuracy of coordinate measuring machines, Characteristics and their checking. Verein Deutscher Ingenieure Verband Deutscher Elektro-Techniker.

VENUGOPAL, R.; BARASH, M. (1986). Thermal effects on the accuracy of numerically controlled machine tools. Annals of the CIRP, Paris, v.35, n.1, p.255-258.

VIEIRA SATO, D.P. (1998). Uma Contribuição ao modelo de sintetização de erros em máquinas ferramentas. 198 p. Tese (Doutorado) - Escola de Engenharia de São Carlos, Universidade de São Paulo, São Carlos, 1998.

. (2001). Determinação da incerteza de medição a três coordenadas. São Carlos: Escola de Engenharia de São Carlos, Universidade de São Paulo, São Carlos. Relatório FAPESP.

WANG Y.G.; ZHANG, K.S.; MOON, J.S. (1998). Compensation for the thermal errors of a multi-axis machining center. ASME Transactions Journal of Materials Processing Technology, v.75, p.45-53. 
WECK, M.; ZANG, L. (1975). Computing the thermal behaviour of machine tools using the finite element methods - possibilities and limitations. In: MTDR CONFERENCE, 16. Proceedings. p.185-194.

WECK, M. (1984). Handbook of machine tools - metrological analysis and performance tests. London: John Wiley. v.4.

WECKENMANN, A.; KNAUER, M.; KILLMAIER, T. (2001). Uncertainty of coordinate measurements on sheet-metal parts in the automotive industry. Journal of Materials Processing Technology, Amsterdam, v.115, p.9-13.

YUAN, M. and NI, J. (1998). Measurement and prediction of thermal errors of a CNC machining center using two spherical balls. Journal of Materials Processing Technology. v. 75, Issue: 1-3, March 1, p. 180-189. 


\section{APÊNDICE A}

\section{Procedimento estatístico Para escolha De VARIÁVEIS NA REGRESSÃO}

Existem vários procedimentos propostos para a escolha da melhor equação de regressão e um deles, muito utilizado, é o procedimento de regressão stepwise.

Este procedimento consiste basicamente em escolher dentre todas as variáveis independentes quais estão mais altamente correlacionadas com a resposta (variável dependente) e determinar a equação que relaciona a variável dependente com as variáveis independentes. Segundo DRAPER e SMITH (1981), este é um dos melhores métodos para seleção de variáveis e são apresentados a seguir os passos básicos para a sua aplicação.

Como primeiro passo todos os conjuntos de variáveis possíveis devem ser determinados. Por exemplo, para modelos com 4 variáveis independentes $\left(x_{1}, x_{2}, x_{3}, x_{4}\right)$ tem-se 24 conjuntos que são dados por:

$\mathrm{Z}_{1}=\left\{\mathrm{x}_{1}, \mathrm{x}_{0}\right\}$ onde $x_{0}=1$, variável associada ao termo independente.

$\mathrm{Z}_{2}=\left\{\mathrm{x}_{2}, \mathrm{x}_{0}\right\}$

$\mathrm{Z}_{3}=\left\{\mathrm{x}_{3}, \mathrm{x}_{0}\right\}$

$\mathrm{Z}_{4}=\left\{\mathrm{x}_{4}, \mathrm{x}_{0}\right\}$

$\mathrm{Z}_{\mathrm{n}}=\left\{\mathrm{x}_{\mathrm{i}}, \mathrm{x}_{\mathrm{j}}, \mathrm{x}_{0}\right\} \quad \mathrm{i}, \mathrm{j}=1, \ldots, 4, \mathrm{i} \neq \mathrm{j} \quad(\mathrm{n}=5,6, \ldots, 10)$ 


$$
\begin{aligned}
& \mathrm{Z}_{\mathrm{n}}=\left\{\mathrm{x}_{\mathrm{i}}, \mathrm{x}_{\mathrm{j}}, \mathrm{x}_{\mathrm{k}}, \mathrm{x}_{0}\right\} \\
& \mathrm{Z}_{15}=\left\{\mathrm{x}_{1}, \mathrm{x}_{2}, \mathrm{x}_{3}, \mathrm{x}_{4}, \mathrm{x}_{0}\right\} \\
& \mathrm{Z}_{16}=\left\{\mathrm{x}_{0}\right\}
\end{aligned}
$$$$
i, j, k=1, \ldots 4, i \neq j, i \neq k, j \neq k \quad(n=11, \ldots 14)
$$

2) Escolhe-se um nível de significância. Normalmente, usa-se um nível de significância fixo para todos os passos, tal como 95\% ( $\alpha=0.05)$.

3) Escolhe-se um conjunto $Z$ mais correlacionado com $Y$ (variável dependente).

4) A correlação de todas as variáveis independentes com a variável dependente é calculada. Escolhe-se como a primeira variável a entrar na regressão a mais altamente correlacionada com a resposta. Seja $x_{k}$ esta variável.

5) A regressão de $Y$ em função de $x_{k}$ é realizada e a equação de mínimos quadrados obtida. $O$ teste $F$ deve ser executado para verificar se a equação de regressão é significante. Se for a variável $x_{k}$ deve ser mantida.

6) O coeficiente de correlação parcial de todas as variáveis que não estão na regressão com $Y$ deve ser calculado.

7) Repita

A) Escolha como próxima variável a entrar na regressão aquela que esta mais altamente correlacionada com a resposta.

B) Encontre a equação de Mínimos Quadrados e obtenha Y em função das variáveis que estão no modelo.

C) Determine $R^{2}$ e verifique se a equação é significante.

D) Calcule o $F$ parcial de todas as variáveis que estão no modelo.

Enquanto $F_{\text {calculado }}<F_{\text {tabelado }}$ para alguma variável faça:

i) a respectiva variável é rejeitada e deve sair do modelo

ii) faça nova regressão com as variáveis restantes

iii) calcule $F$ parcial de todas as variáveis que estão no modelo para verificar se todas são significativas

até que todas as variáveis tenham sido testadas. 


\section{APÊNDICE B}

\section{MEDIÇÃO DOS ERROS GEOMÉTRICOS}

O levantamento dos 21 erros geométricos foi realizado através da calibração direta. Cada erro geométrico foi medido de forma individual. Todas as calibrações obedeceram aos seguintes critérios: os intervalos de medição para os três eixos foram de $25 \mathrm{~mm}$; o processo de medição foi passo a passo e a coleta de dados automática.

\section{Medição do Erro de Posição.}

O arranjo experimental para medição do erro de posição está apresentado na Figura B.1. Pode-se observar que o interferômetro linear está fixo à estrutura da máquina enquanto o refletor está fixo no lugar da sonda, no eixo $Z$. 


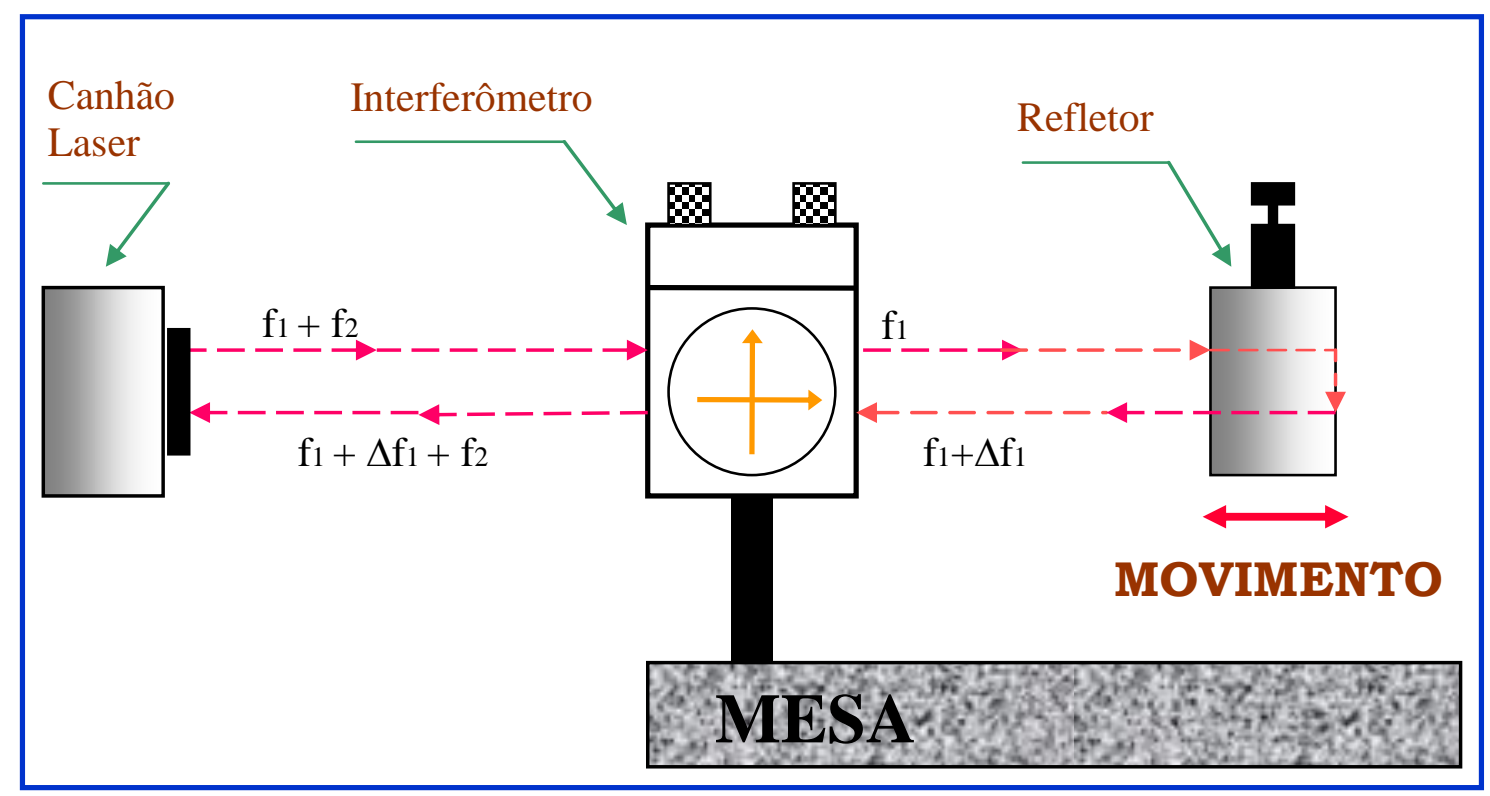

Figura B.1 - Montagem do sistema interferométrico para medição do erro de posição dos eixos $X$ e $Y$.

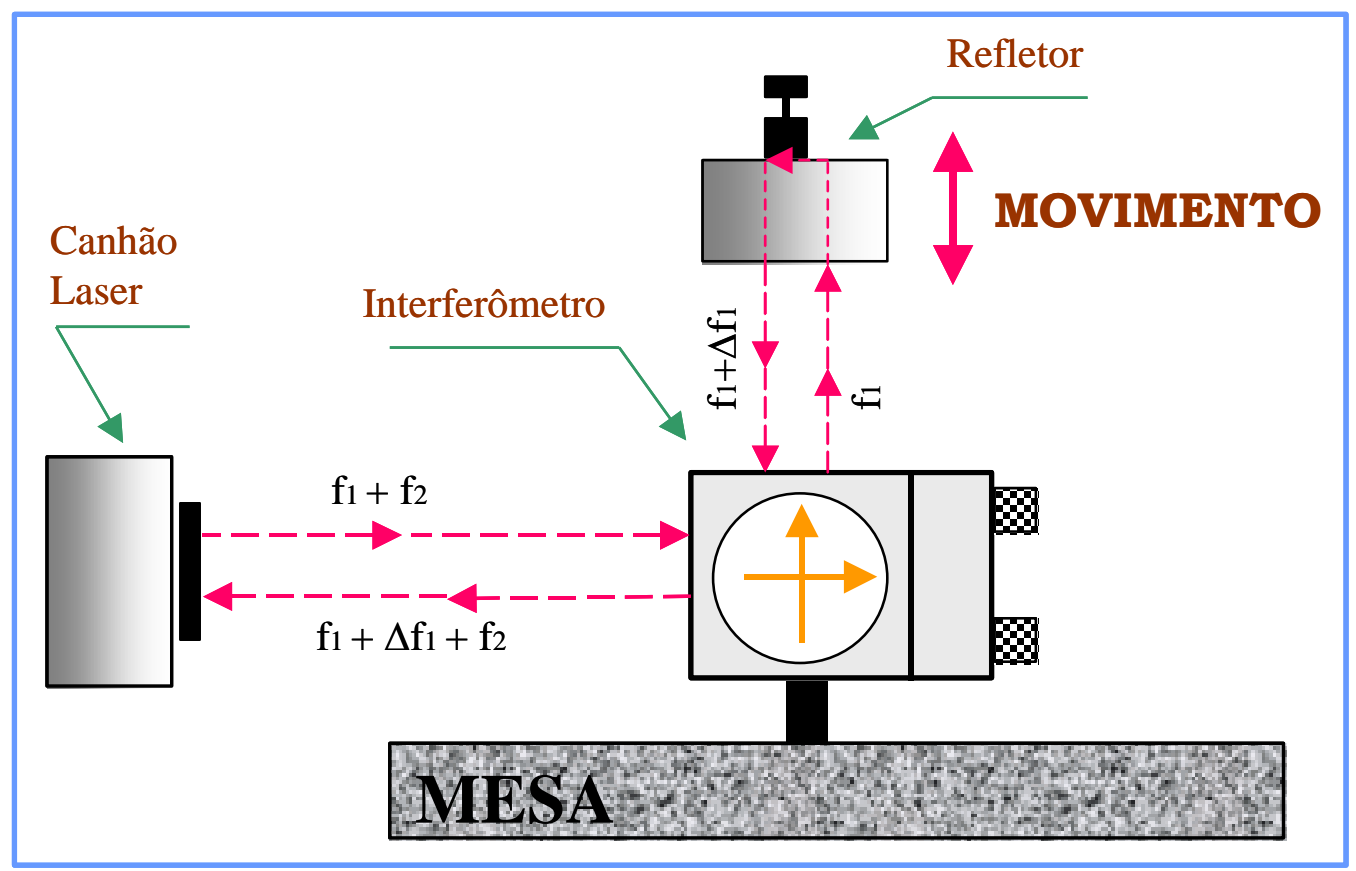

Figura B.2 - Montagem do sistema interferométrico para medição do erro de posição do eixo $Z$.

O canhão laser emite um feixe de luz com duas freqüências $f 1$ e $f 2$ muito próximas. $\mathrm{O}$ feixe laser $(f 1+f 2)$ atinge o interferômetro e as 
freqüências $f 1$ e $f 2$ se separam, percorrendo caminhos diferentes. Um dos feixes atinge o espelho refletor enquanto o outro é refletido internamente para ser utilizado como feixe de referência. Estes feixes são recombinados no interferômetro e retornam à unidade laser, onde são captados por fotosensores. Visto que os dois feixes percorrem caminhos diferentes, ocorre uma variação de fase entre o feixe de referência e o de medição. A variação de sinal resultante é detectada e transformada em variação de distância a partir de cálculos realizados tendo como base o comprimento de onda do laser utilizado. O erro de posição é calculado como sendo a diferença entre o valor indicado pela máquina e o valor indicado pelo laser, onde $E_{i}$ representa as componentes $E x, E y$ ou $E z$, segundo o caso.

$\mathrm{E}_{\mathrm{i}}=$ Erro de posição=Leitura da máquina-Leitura do laser

Cada geratriz foi medida 5 vezes no sentido de ida e cinco vezes no sentido de volta. A partir destes dados foram construídas as superficies de erros para cada plano de medição. As Figuras B.1 e B.2 apresentam a montagem para a medição dos erros de posição dos eixos $X$ e $Z$, respectivamente.

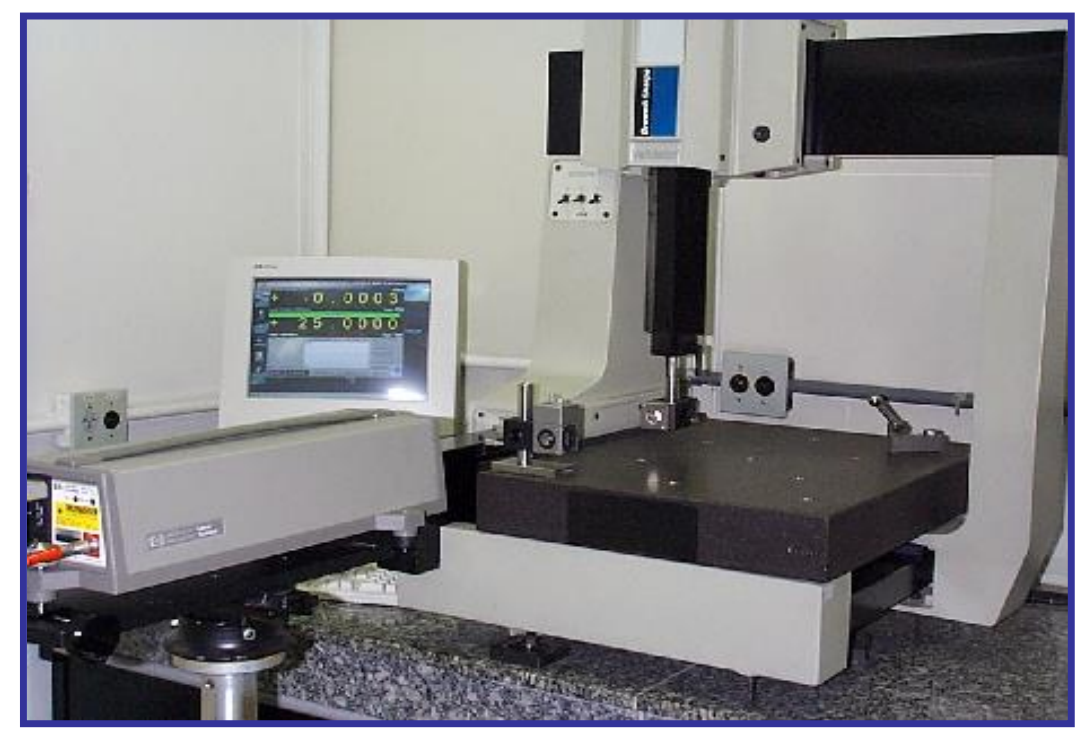

Figura B.3 - Montagem experimental para a medição do erro de posição do eixo $Y$.

Na Figura B.3 está apresentada uma fotografia da montagem experimental para a medição do erro de posição do eixo $Y$. Nesta 
montagem tem-se uma base fixa ao desempeno contendo uma haste que suporta o interferômetro. O refletor fica preso no lugar da sonda, permitindo que este se movimente ao longo de uma linha reta paralela ao eixo $Y$. Os valores das coordenadas $X$ e $Z$ devem permanecer constantes. As montagens experimentais para a medição dos erros de posição dos eixos $X$ e $Z$ são similares à utilizada para o eixo $Y$.

\section{Medição do Erro de Retitude}

O erro de retitude, também, pode ser medido através da utilização do sistema interferométrico laser, apresentado na Figura B.4. Embora o princípio de medição utilizado para o levantamento deste erro seja muito similar ao da medição do erro de posição, existem algumas diferenças na configuração óptica. Esta diferença está dada na utilização de um interferômetro que contém um prisma de Wollastón, além, de dois espelhos refletores montados sob determinado ângulo. O interferômetro é colocado no elemento móvel da máquina e os espelhos fixos ao desempeno.

$O$ feixe emitido pela unidade laser, de freqüências $f 1$ e $f 2$, ao atingir o interferômetro prisma de Wollaston é dividido em dois feixes que incidem perpendicularmente nos espelhos do retrorefletor. Depois da reflexão estes feixes voltam ao interferômetro com o mesmo ângulo de incidência, onde são recombinados. Devido ao movimento relativo entre o prisma de Wollaston, o interferômetro e o espelho, são observadas variações de freqüência. Estes sinais são processados eletronicamente pela fotocélula na unidade laser e convertidos em deslocamentos transversais à direção preferencial. A referência para a retitude é a bissetriz do ângulo entre os espelhos.

O processo de alinhamento do laser para a medição do erro de retitude é relativamente complicado, por tal motivo, os valores indicados pelo interferômetro não são os valores reais do erro de retitude. Neste caso, os resultados da medição incluem deslocamentos devido ao desalinhamento entre o feixe de luz e a direção de movimento. A Figura 
B.5 ilustra este fato. Antes de efetuar a interpretação dos dados este efeito deve ser corrigido.

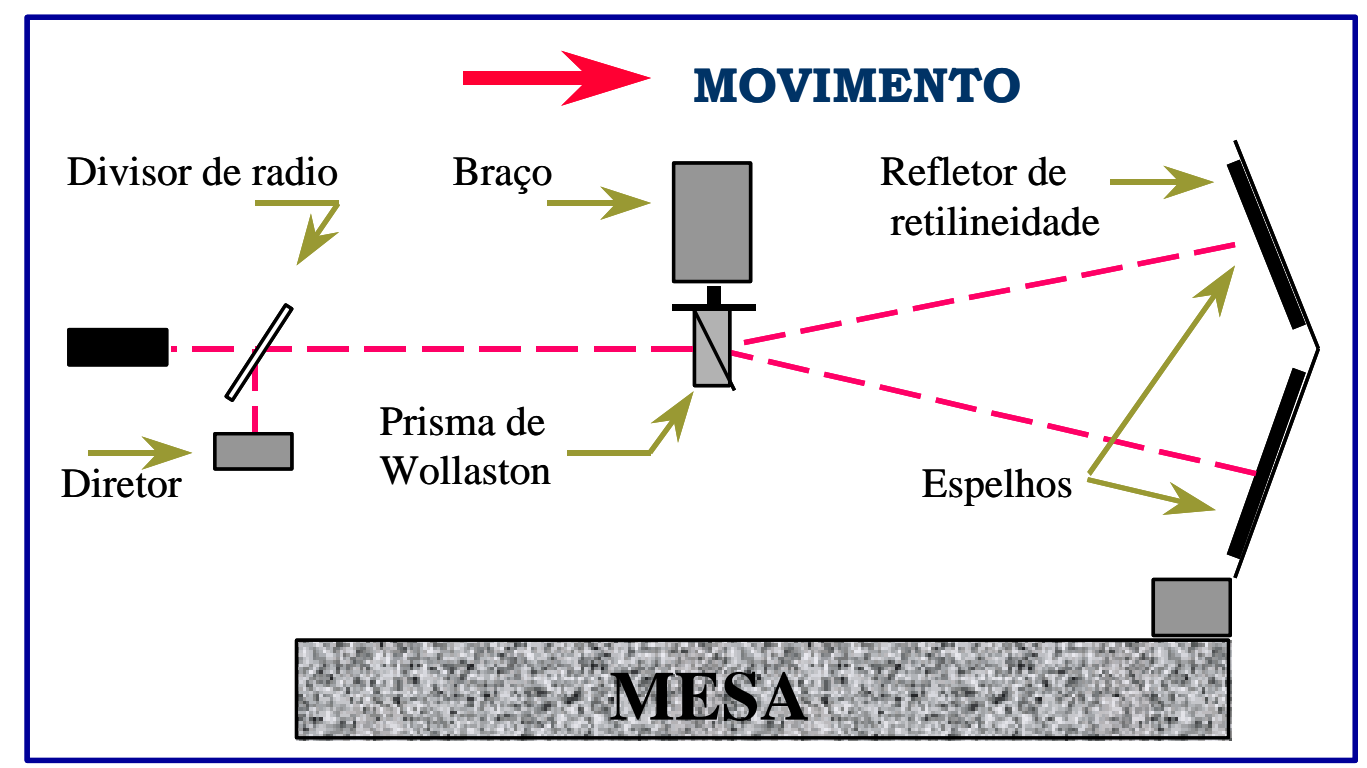

Figura B.4 - Interferômetro Laser com o prisma de Wollaston.

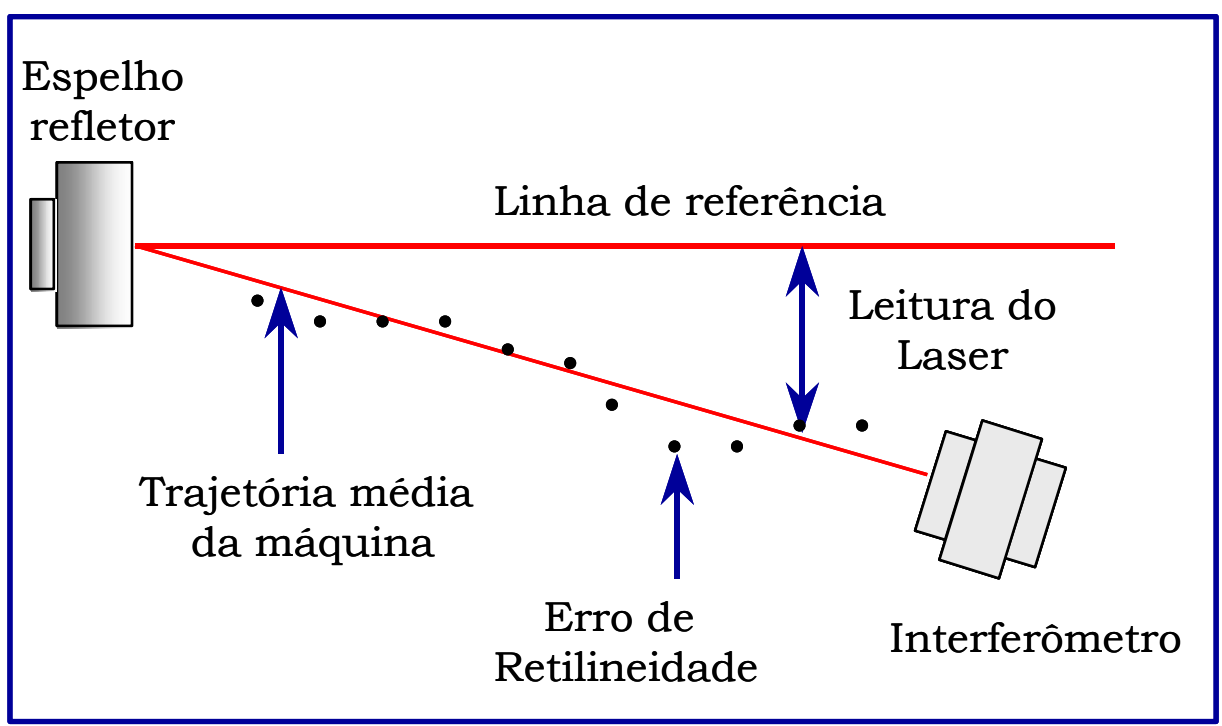

B.5 - Efeitos de desalinhamento na medição dos erros

Figura de retitude (VIEIRA SATO, 1998).

Para corrigir o desalinhamento foram utilizados uma regressão linear e o método dos mínimos quadrados, onde a partir dos dados obtidos determinou-se a direção média de movimento da máquina. Em seguida estes valores foram subtraídos dos valores do erro medido. O 
resultado desta diferença pode ser interpretado como sendo o erro de retitude procurado, equação (B.2).

$$
\left(\begin{array}{l}
\text { Erro de } \\
\text { Re tilineidade }
\end{array}\right)=\left(\begin{array}{c}
\text { Valor indicado } \\
\text { no laser }
\end{array}\right)-\left(\begin{array}{l}
\text { Valor encontrado através da } \\
\text { equação de desaliniamento }
\end{array}\right)
$$

Na fotografia da Figura B.6 pode ser observada a disposição física dos equipamentos utilizados na medição do erro de retitude horizontal do eixo Y. Nesta Figura pode se observar que o interferômetro, montado no lugar da sonda, se encontra entre a unidade laser e o refletor, este último fixo ao desempeno.

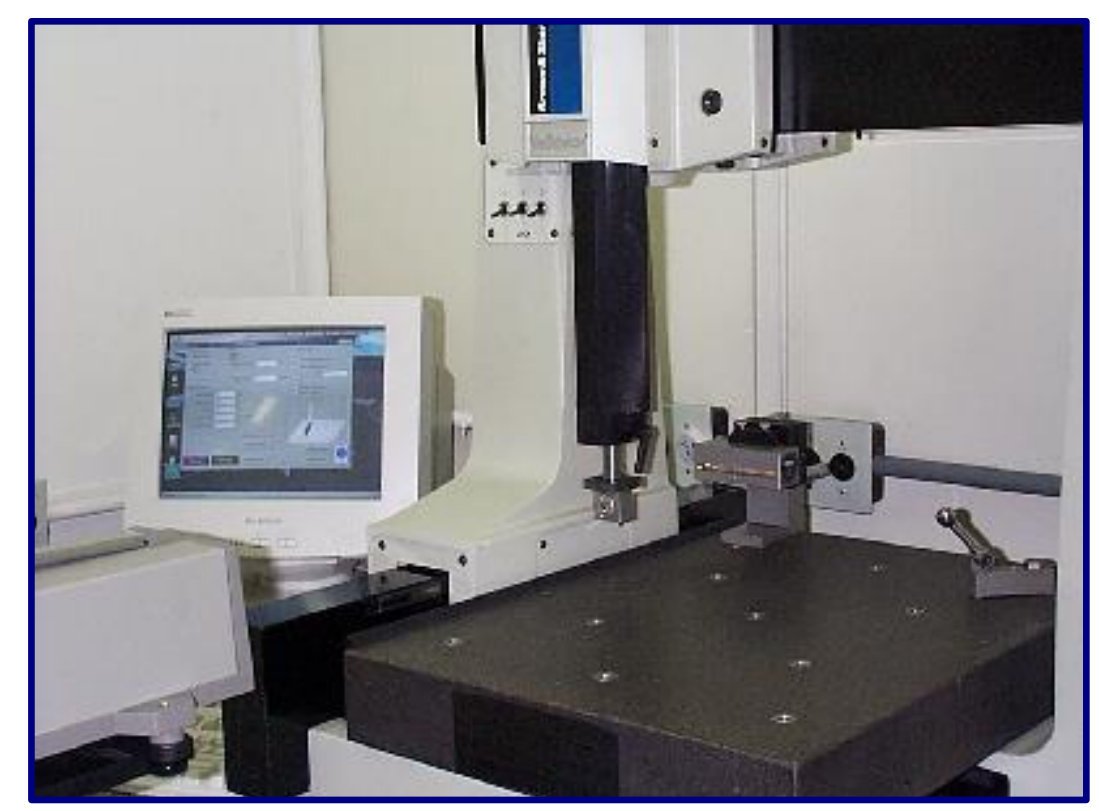

Figura B.6 - Montagem experimental da medição do erro de retitude do eixo $Y$ na direção $X$.

Para a medição do erro de retitude na direção do eixo $Z$, devido ao movimento na direção do eixo $Y$, deve ser utilizado um arranjo físico semelhante ao anterior, com a única diferença que o refletor deve ser girado $90^{\circ}$. De forma análoga à adotada para o eixo $Y$ podem ser medidos os erros de retitude vertical e horizontal para os eixos $X$ e $Z$. 


\section{Medição dos Erros Angulares.}

Os erros angulares pitch e yaw são medidos utilizando-se o interferômetro laser, enquanto que, na medição do roll, se faz necessário a utilização de um nível eletrônico e outro de bolha.

A Figura B.7 ilustra o princípio de medição dos erros angulares pitch e yaw utilizando o sistema interferométrico. Neste caso o interferômetro angular utilizado fica preso a estrutura da máquina e o conjunto de espelhos refletores é colocado no eixo $Z$.

O feixe emitido pelo canhão laser é dividido em dois feixes paralelos com freqüências $f 1$ e $f 2$ ao atravessar o interferômetro angular. Ambos os feixes caminham até o refletor angular, retornando para o interferômetro, onde são recombinados. Variações no padrão de interferência dos feixes de volta indicam diferenças no comprimento do caminho percorrido por eles. Essas variações de comprimento divididas pela distância entre os espelhos retrorefletores são as variações de pitch e yaw.

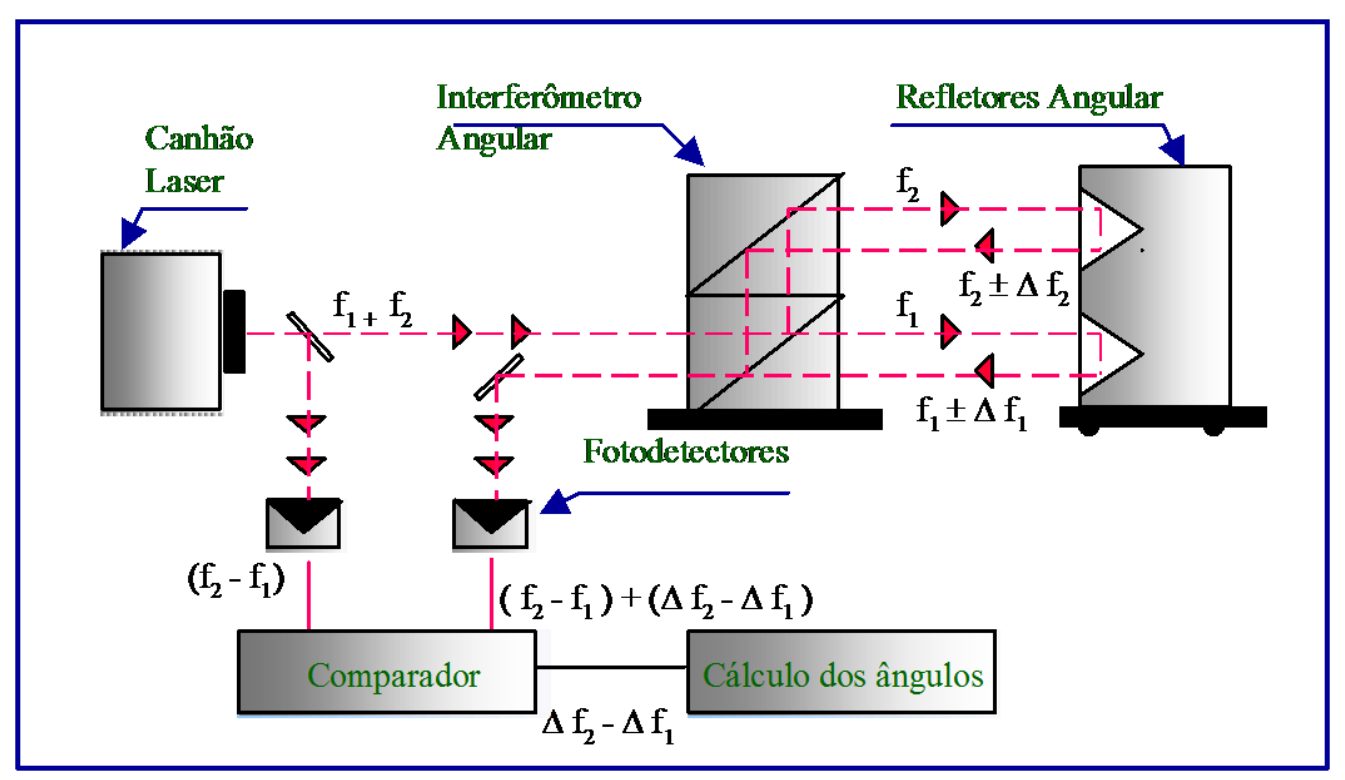

Figura B.7 - Interferômetro angular laser (BARREIRA, 1998).

O arranjo experimental utilizado para a medição do erro angular denominado yawX, isto é, rotações que o carro $X$ experimenta em torno do eixo $Z$, está mostrado na Figura B.8. Pode-se observar que o interferômetro angular fica fixo ao desempeno, enquanto que o 
retrorefletor angular está preso ao eixo $Z$. Durante a medição o eixo $X$ se movimenta a partir do ponto de referência e os eixos $Y$ e $Z$ permanecem constantes.

De forma semelhante são medidos os erros angulares do eixo $Y$. Para este eixo têm-se rotações em torno do eixo $X$ e do eixo $Z$, chamadas pitch e roll, respectivamente. Já para o eixo $Z$ o arranjo experimental para a medição dos erros angulares apresenta uma pequena diferença quando comparado aos eixos $X$ e $Y$. Neste caso o interferômetro permanece solidário ao desempeno, enquanto o retrorefletor angular está preso ao eixo $Z$.

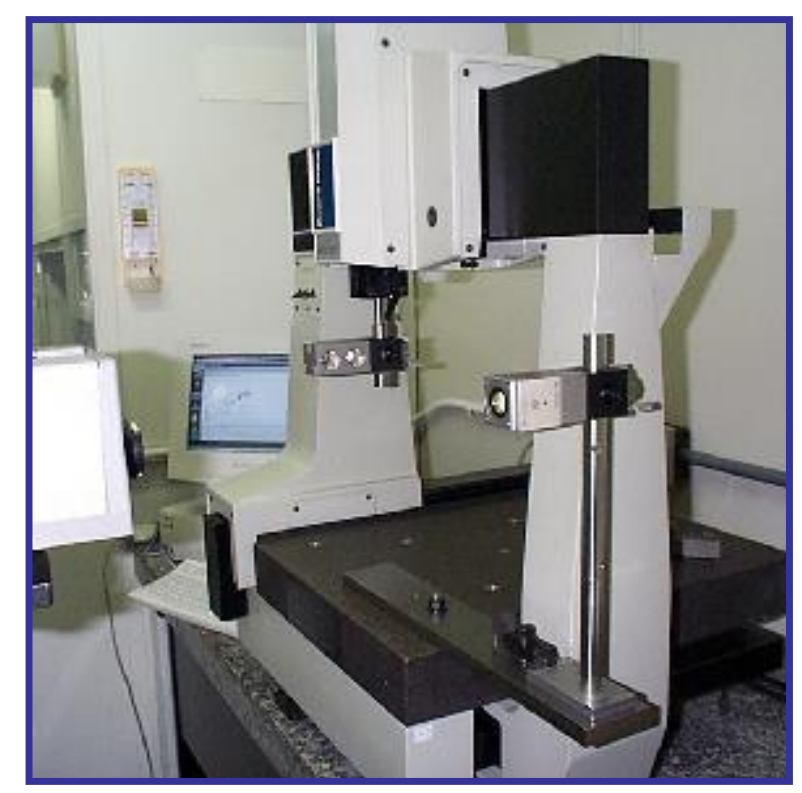

Figura B.8 - Sistema de medição do erro angular yawX.

\section{Medição do erro roll.}

$\mathrm{Na}$ medição do roll são utilizados dois níveis, um eletrônico e um outro de bolha. Isto se faz necessário, devido a movimentos que a estrutura da máquina pode experimentar durante a movimentação dos carros. 
O principio de funcionamento deste nivel é apresentado na Figura B.9.

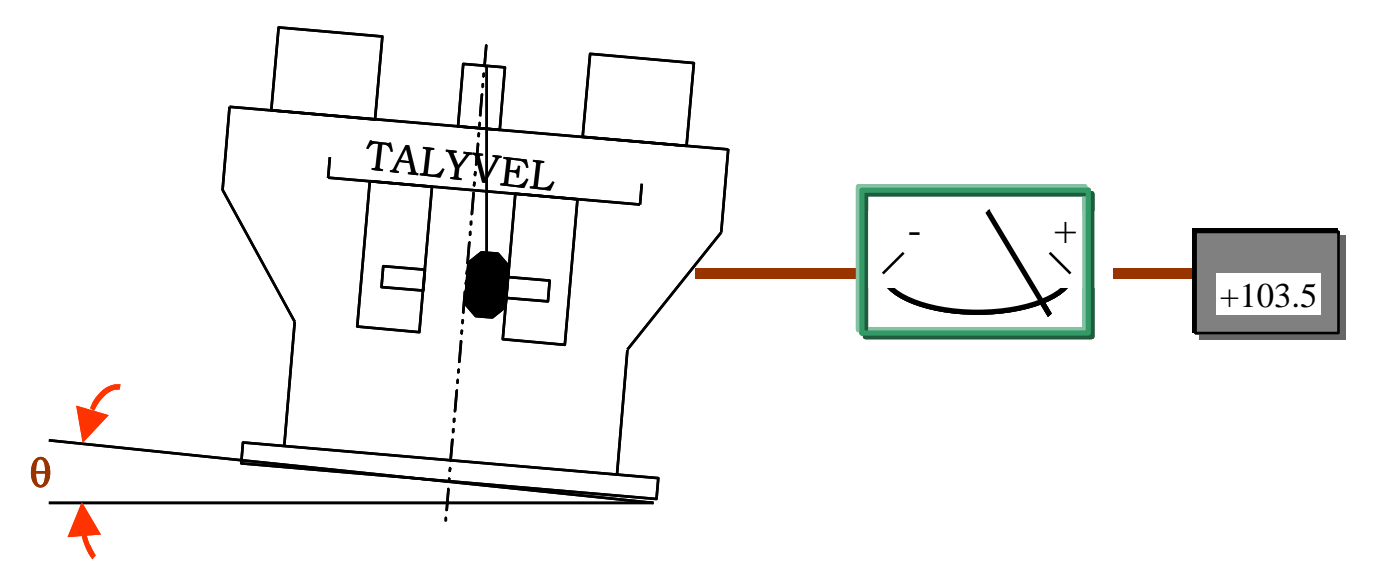

\section{UNIDADE DO NÍVEL INCLINADO NO SENTIDO HORÁRIO A INCLINAÇÃO É POSITIVA}

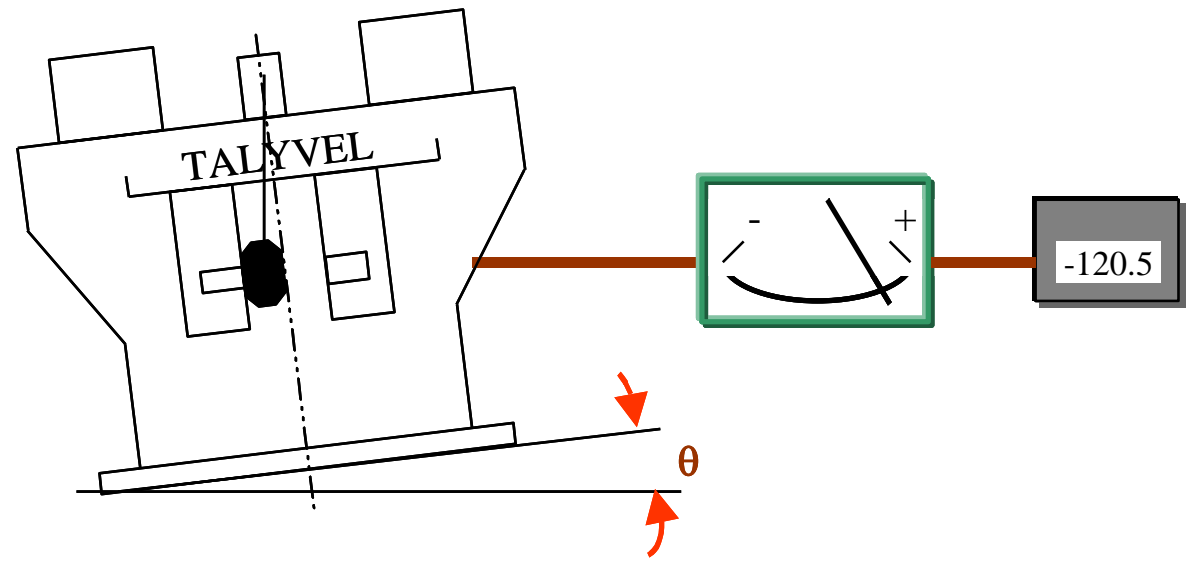

UNIDADE DO NÍVEL INCLINADO NO SENTIDO ANTI-HORÁRIO A INCLINAÇÃO É NEGATIVA

Figura B.9 - Medição com o nível eletrônico.

O nivel eletrônico é um instrumento constituído basicamente por um pêndulo que é o encarregado de detectar o sinal, proporcional à inclinação experimentada, que depois de tratado é apresentado no mostrador ou disponivel numa interface de saída.

O nivel de bolha é um instrumento de uso comum em metrologia. Uma vez colocado na superficie a ser avaliada, deve ser zerado através do parafuso de ajuste e do visor indicador. 
No arranjo experimental para medir o erro angular roll do eixo $Y$, o nível eletrônico fica fixo ao eixo $Z$, enquanto, o nível de bolha permanece sobre o desempeno. Durante a medição deste erro o eixo $Y$ se movimenta a partir do ponto de referência e os eixos $X$ e $Z$ devem permanecer estáticos. De forma análoga é medido o erro angular roll no eixo $X$, basta ter o cuidado de posicionar os níveis numa direção paralela ao eixo $Y$.

\section{Medição dos erros de perpendicularidade.}

Os erros de perpendicularidade foram medidos utilizando-se o esquadro de granito, conhecido também, como esquadro mecânico. Este é utilizado conjuntamente com um comparador eletrônico do tipo LVDT e é colocado no plano da mesa da máquina com os seus lados alinhados com os eixos dá maquina. Os lados alinhados são então percorridos pelo sensor da máquina, fazendo quatro medições, duas medições em cada lado, diagnosticando-se o desvio. A exatidão da medição utilizando o esquadro mecânico é geralmente dificil porque alguns problemas dificultam a exatidão do processo, entre eles, desgaste de suas faces, por tal motivo, recomenda-se utilizar a técnica de reversão.

Na Figura B.10 está apresentada a técnica de reversão para a medição do erro de perpendicularidade entre os eixos $X$ e $Z$. Pode-se observar que o esquadro mecânico em $L$ está apoiado sobre o desempeno através de uma de suas arestas, enquanto a outra aresta, fica livre. Para isto, é necessário fixar um comparador no eixo $Z$ e, em seguida, efetuar o levantamento do desvio entre o deslocamento do eixo $Z$ e a aresta. Através da utilização de ferramentas estatísticas e matemáticas é possível determinar o ângulo $\theta 1$ para a posição 1. A seguir, o esquadro é girado $180^{\circ}$ sobre o plano $X Y$ eliminando-se, assim, o erro do esquadro. Este arranjo é denominado de posição 2 e permite realizar as medições através das quais será calculado o ângulo $\theta 2$. O erro de perpendicularidade do eixo $Z$ é dado por:

$$
\theta_{E}=\theta_{1}-\theta_{2}
$$


Caso o eixo $Z$ não apresente erro de perpendicularidade, os valores absolutos dos ângulos avaliados $\theta 1$ e $\theta 2$ serão iguais entre si e representarão o erro de perpendicularidade entre as duas faces do esquadro. Caso o eixo $Z$ possua erro de perpendicularidade, os valores absolutos de $\theta 1$ e $\theta 2$ serão diferentes e em conjunto com o sinal de rotação adotado fornecerão o desvio de perpendicularidade entre os eixos $X$ e $Z$.

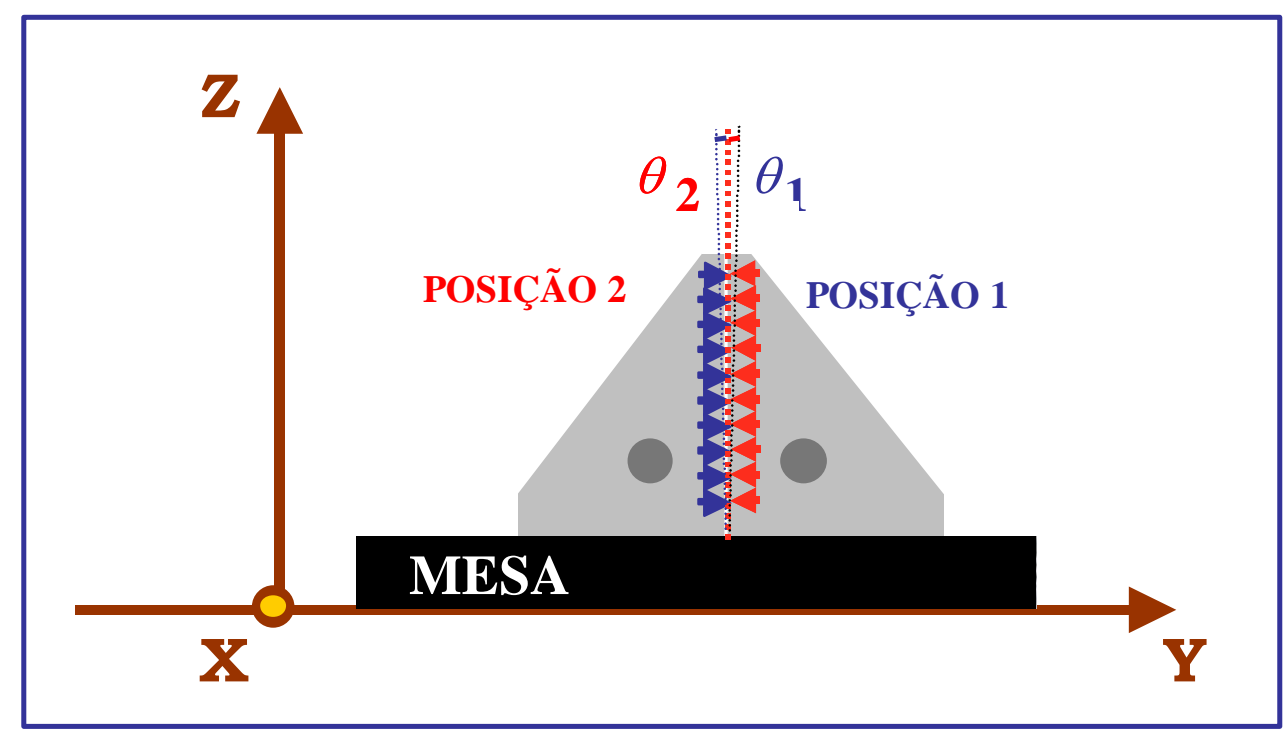

Figura B.10 - Esquema básico de medição do erro de perpendicularidade entre dois eixos.

Os arranjos experimentais para medir o erro de perpendicularidade entre os eixos $X$ e $Z$ e entre os eixos $Y$ e $Z$ estão apresentados nas Figuras B.11 e B.12. Os critérios de medição são os mesmos que foram adotados no caso anterior.

Para medição do erro de perpendicularidade entre os eixos $X$ e $Y$ a linha de referência de medição é o eixo $X$ e, portanto, alinha-se a aresta do esquadro paralelamente ao eixo $X$ da máquina. Em seguida o apalpador percorre a outra aresta do esquadro e determina-se a caminho da máquina sobre dita aresta. Com estas informações determina-se o desvio angular na posição 1. Para determinar a posição 2 o esquadro é girado $180^{\circ}$ em torno do eixo $X$, tendo-se o cuidado de que o mesmo seja apoiado sobre a mesma área do desempeno que foi utilizada na posição anterior. 
Desta forma, é eliminada a possivel interferência do desempeno no resultado das medições. Em seguida alinha-se o eixo $X$ e determina-se o desvio angular na posição 2. De posse dos desvios angulares na posição 1 e 2, obtém-se facilmente o erro de perpendicularidade entre os eixos $X$ e $Y$.

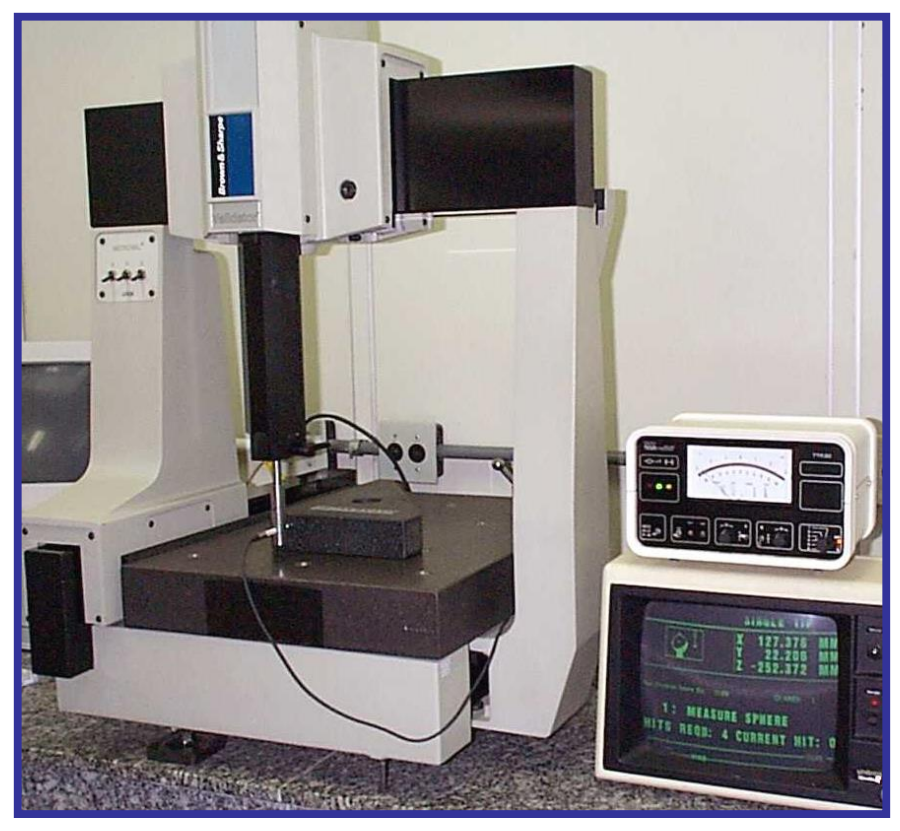

Figura B.11 - Montagem do sistema para medição do erro de perpendicularidade entre os eixos $X$ e $Z$.

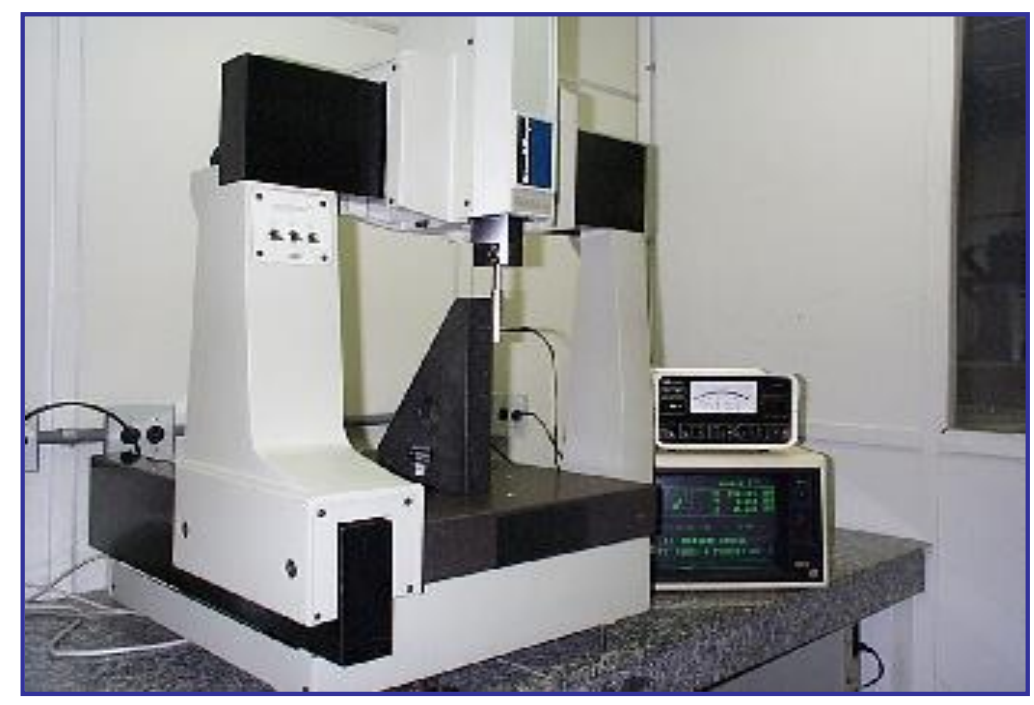

Figura B.12 - Montagem do sistema para medição do erro de perpendicularidade entre os eixos $Y$ e $Z$. 
$\mathrm{Na}$ procura de uma maior exatidão na medição dos erros de perpendicularidade foi utilizado o interferômetro laser conjuntamente com o esquadro óptico.

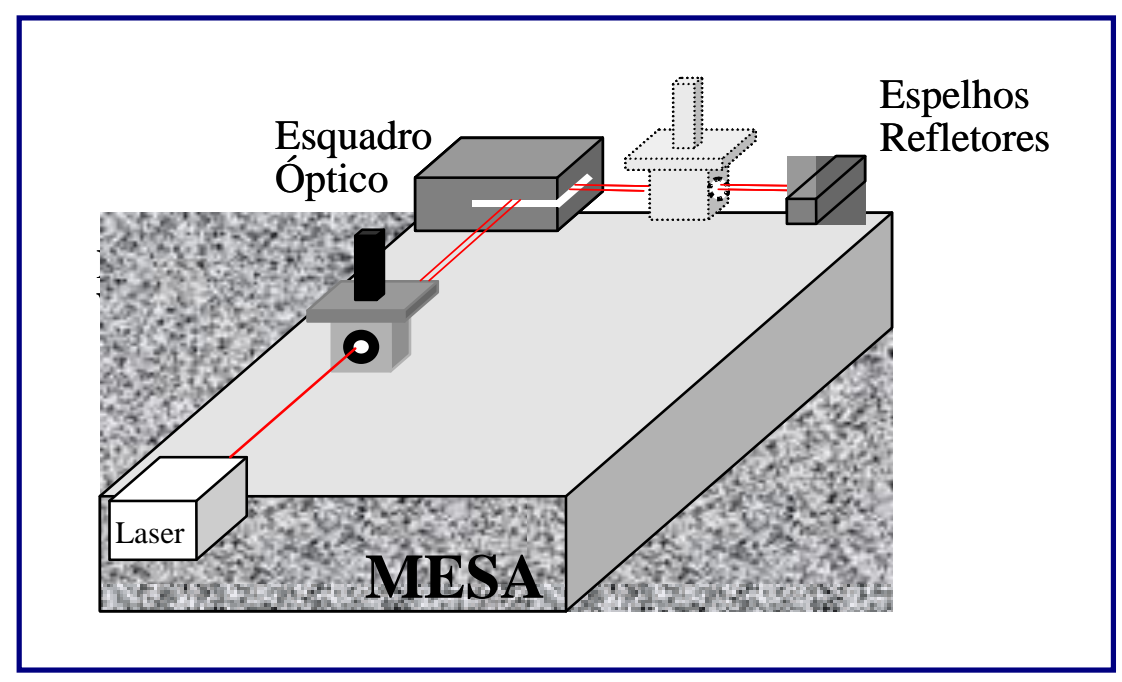

Figura B.13 - Arranjo experimental para levantamento do erro de perpendicularidade usando o esquadro óptico.

A Figura B.13 mostra o arranjo experimental para medição do erro de perpendicularidade entre os eixos $X$ e $Y$. Observa-se que o erro em questão foi determinado a partir da medição dos erros de retitude horizontal dos eixos $X$ e $Y$, respectivamente.

Foram efetuados cinco trajetos de ida e cinco de volta, para diferentes estados térmicos estacionários. O erro numa determinada posição foi considerado como a média de 15 valores espaçados $64 \mu \mathrm{m}$. A medição dos erros de perpendicularidade entre os eixos $X Z$ e $Y Z$ não foi efetuada devido à impossibilidade de montagem. 


\section{APÊNDICE C}

\section{ESPECIFICAÇÕES TÉCNICAS DOS INSTRUMENTOS UTILIZAdOS Na CALIBRAÇÃo DA MM3C}

Neste apêndice são apresentadas as especificações técnicas dos instrumentos utilizados na calibração da MM3C.

\begin{tabular}{|c|c|c|c|c|}
\hline ERRO & INSTRUMENTO & FAIXA & RESOLUÇÃO & INCERTEZA \\
\hline Posição & Laser & $40 \mathrm{~m}$ & $0,01 \mu \mathrm{m}$ & $\pm 0,1 \mathrm{PPM}$ \\
\hline Retitude & Laser & $1,5 \mathrm{~mm}$ & $0,01 \mu \mathrm{m}$ & $\pm 3,5 \%$ \\
\hline Pitch e Yaw & Laser & \pm 36000 & $0,1 ”$ & $\pm 0,05 \% / \mathrm{m}$ \\
\hline $\begin{array}{l}\text { Ortogonali- } \\
\text { dade }\end{array}$ & $\begin{array}{l}\text { Esq. mecânico } \\
\text { de granito }\end{array}$ & $220 \times 150 \mathrm{~mm}$ & & $\begin{array}{l} \pm(2+\mathrm{L} / 100) \\
\mu \mathrm{m}\end{array}$ \\
\hline Roll & $\begin{array}{l}\text { Nivel eletrônico } \\
\text { Nivel de bolha }\end{array}$ & $\begin{array}{l} \pm 600^{\prime \prime} \\
10^{\prime}\end{array}$ & $\begin{array}{l}0,1 ” \\
1 ”\end{array}$ & $\begin{array}{l} \pm 0,2 " \\
\pm 1 ”\end{array}$ \\
\hline Erro Volum. & Laser & $40 \mathrm{~m}$ & $0,01 \mu \mathrm{m}$ & $\pm 0,1 \mathrm{PPM}$ \\
\hline
\end{tabular}




\section{APÊNDICE D}

\section{TEMPERATURAS DURANTE a MEDIÇÃO DOS ERROS GEOMÉTRICOS}

Neste apêndice são apresentadas as temperaturas em que os erros geométricos foram medidos.

\begin{tabular}{|c|c|c|c|}
\hline ERRO MEDIDO & \multicolumn{3}{|c|}{ TEMPERATURA ${ }^{\circ} \mathrm{C}$} \\
\hline Posição $X, Y$ e $Z$ & 20,64 & 20,57 & 20,52 \\
\hline Retitude $X y$ e $X z$ & 20,81 & \multicolumn{2}{|c|}{20,80} \\
\hline Retitude $Y x$ e $Y z$ & 20,33 & \multicolumn{2}{|c|}{20,54} \\
\hline Retitude $Z x$ e $Z y$ & 20,61 & \multicolumn{2}{|c|}{20,72} \\
\hline Pitch $X, Y$ e $Z$ & 20,00 & 20,75 & 20,94 \\
\hline Yaw $X, Y$ e $Z$ & 20,60 & 20,73 & 20,15 \\
\hline Roll $X$ e $Y$ & 20,72 & \multicolumn{2}{|c|}{20,78} \\
\hline Ort $X Y, X Z$ e $Y Z$ & 20,67 & 20,80 & 20,75 \\
\hline
\end{tabular}




\section{APÊNDICE E}

\section{CÁlCUlo das Características do CírCUlo}

A equação de um círculo de centro $\mathrm{C}=\left(\mathrm{X}_{0}, \mathrm{Y}_{0}\right)$ e raio $\mathrm{r}>0$ é dada pela equação (E.1).

$$
\left(x-x_{c}\right)^{2}+\left(y-y_{c}\right)^{2}=r^{2}
$$

Aplicando-se o método dos Mínimos Quadrados é possível estimar as coordenadas do centro e o raio do círculo, para tanto deve-se minimizar a expressão dada pela equação (E.2).

$$
\sum \varepsilon_{\mathrm{i}}^{2}=\sum\left(\mathrm{r}_{\mathrm{i}}^{2}-\mathrm{r}^{2}\right)^{2}=\sum\left[-2 \cdot \mathrm{x}_{\mathrm{i}} \cdot \mathrm{x}_{\mathrm{c}}-2 \cdot \mathrm{y}_{\mathrm{i}} \cdot \mathrm{y}_{\mathrm{c}}+\left(\mathrm{x}_{\mathrm{i}}^{2}+\mathrm{y}_{\mathrm{i}}^{2}\right)+\left(\mathrm{x}_{\mathrm{c}}^{2}+\mathrm{y}_{\mathrm{c}}^{2}-\mathrm{r}^{2}\right)\right]^{2}
$$

Fazendo as mudanças de variáveis dadas em (E.3), pode-se reescrever a expressão (E.1) de forma linear, equação (E.4).

$$
\begin{array}{lcl}
\mathrm{a}=-2 \cdot \mathrm{x}_{\mathrm{c}} \quad \mathrm{b}=-2 \cdot \mathrm{y}_{\mathrm{c}} & \mathrm{c}=\mathrm{x}_{\mathrm{c}}^{2}+\mathrm{y}_{\mathrm{c}}^{2}-\mathrm{r}^{2} \\
\mathrm{MQ}=\sum\left[\mathrm{a} \cdot \mathrm{x}_{\mathrm{i}}+\mathrm{b} \cdot \mathrm{y}_{\mathrm{i}}+\left(\mathrm{x}_{\mathrm{i}}^{2}+\mathrm{y}_{\mathrm{i}}^{2}\right)+\mathrm{c}\right]^{2} &
\end{array}
$$

Os coeficientes de mínimos quadrados são determinados fazendo as derivadas parciais de MQ com relação às variáveis a, b e c iguais a zero, (E.5)-(E.7). 


$$
\begin{aligned}
& \frac{\partial \mathrm{MQ}}{\partial \mathrm{a}}=2 \cdot \sum\left[\mathrm{a} \cdot \mathrm{x}_{\mathrm{i}}+\mathrm{b} \cdot \mathrm{y}_{\mathrm{i}}+\left(\mathrm{x}_{\mathrm{i}}^{2}+\mathrm{y}_{\mathrm{i}}^{2}\right)+\mathrm{c}\right] \cdot\left(\mathrm{x}_{\mathrm{i}}\right)=0 \\
& \frac{\partial \mathrm{MQ}}{\partial \mathrm{a}}=2 \cdot \sum\left[\mathrm{a} \cdot \mathrm{x}_{\mathrm{i}}+\mathrm{b} \cdot \mathrm{y}_{\mathrm{i}}+\left(\mathrm{x}_{\mathrm{i}}^{2}+\mathrm{y}_{\mathrm{i}}^{2}\right)+\mathrm{c}\right] \cdot\left(\mathrm{y}_{\mathrm{i}}\right)=0 \\
& \frac{\partial \mathrm{MQ}}{\partial \mathrm{c}}=2 \cdot \sum\left[\mathrm{a} \cdot \mathrm{x}_{\mathrm{i}}+\mathrm{b} \cdot \mathrm{y}_{\mathrm{i}}+\left(\mathrm{x}_{\mathrm{i}}^{2}+\mathrm{y}_{\mathrm{i}}^{2}\right)+\mathrm{c}\right] \cdot 1=0
\end{aligned}
$$

Reescrevendo as equações (E.5)-(E.7) na forma matricial tem-se o sistema linear (E.8).

$$
\left[\begin{array}{ccc}
\sum \mathrm{x}_{\mathrm{i}}^{2} & \sum \mathrm{x}_{\mathrm{i}} \cdot \mathrm{y}_{\mathrm{i}} & \sum \mathrm{x}_{\mathrm{i}} \\
\sum \mathrm{x}_{\mathrm{i}} \cdot \mathrm{y}_{\mathrm{i}} & \sum \mathrm{y}_{\mathrm{i}}^{2} & \sum \mathrm{y}_{\mathrm{i}} \\
\sum \mathrm{x}_{\mathrm{i}} & \sum \mathrm{y}_{\mathrm{i}} & \mathrm{N}
\end{array}\right] \cdot\left[\begin{array}{l}
\mathrm{a} \\
\mathrm{b} \\
\mathrm{c}
\end{array}\right]=\left[\begin{array}{c}
-\sum\left(\mathrm{x}_{\mathrm{i}}^{3}+\mathrm{x}_{\mathrm{i}} \cdot \mathrm{y}_{\mathrm{i}}^{2}\right) \\
-\sum\left(\mathrm{x}_{\dot{j}}^{2} \cdot \mathrm{y}_{\mathrm{i}}+\mathrm{y}_{\mathrm{i}}^{3}\right) \\
-\sum\left(\mathrm{x}_{\mathrm{i}}^{2}+\mathrm{y}_{\mathrm{i}}^{2}\right)
\end{array}\right]
$$

Utilizando as notações representadas em (E.9)-(E.13) tem-se que a solução do sistema de equações normais (E.8) é dada pelas expressões (E.14)-(E.16).

$$
\begin{aligned}
& \mathrm{D}=\sum \mathrm{x}_{\mathrm{i}}^{2} \cdot \sum \mathrm{y}_{\mathrm{i}}-\sum \mathrm{x} \cdot \sum \mathrm{x}_{\mathrm{i}} \cdot \mathrm{y}_{\mathrm{i}} \\
& \mathrm{E}=-\sum \mathrm{x}_{\mathrm{i}} \cdot \mathrm{y}_{\mathrm{i}} \cdot\left[-\sum\left(\mathrm{x}_{\mathrm{i}}^{3}+\mathrm{x}_{\mathrm{i}} \cdot \mathrm{y}_{\mathrm{i}}^{2}\right)\right\rfloor+\sum \mathrm{x}^{2} \cdot\left\lfloor-\sum\left(\mathrm{x}_{\mathrm{i}}^{2} \cdot \mathrm{y}_{\mathrm{i}}+\mathrm{y}_{\mathrm{i}}^{3}\right)\right\rfloor \\
& \mathrm{F}=\sum \mathrm{x}_{\mathrm{i}}^{2} \cdot \sum \mathrm{y}_{\mathrm{i}}^{2}-\left(\sum \mathrm{x}_{\mathrm{i}} \cdot \mathrm{y}_{\mathrm{i}}\right)^{2} \\
& \mathrm{G}=\sum \mathrm{x}_{\mathrm{i}}^{2} \cdot\left[-\sum\left(\mathrm{x}_{\mathrm{i}}^{2}+\mathrm{y}_{\mathrm{i}}^{2}\right)\right]-\sum \mathrm{x}_{\mathrm{i}} \cdot\left\lfloor-\sum\left(\mathrm{x}_{\mathrm{i}}^{3}+\mathrm{x}_{\mathrm{i}} \cdot \mathrm{y}_{\mathrm{i}}^{2}\right)\right] \\
& \mathrm{H}=\mathrm{N} \cdot \sum \mathrm{x}_{\mathrm{i}}^{2}-\left(\sum \mathrm{x}_{\mathrm{i}}\right)^{2} \\
& \mathrm{c}=(\mathrm{D} \cdot \mathrm{E}-\mathrm{F} \cdot \mathrm{G}) \div\left(\mathrm{D}^{2}-\mathrm{H} \cdot \mathrm{F}\right) \\
& \mathrm{b}=(\mathrm{G}-\mathrm{H} \cdot \mathrm{c}) \div \mathrm{D} \\
& \mathrm{a}=-\left[\left(\sum \mathrm{x}_{\mathrm{i}}\right) \cdot \mathrm{c}+\left(\sum \mathrm{x}_{\mathrm{i}} \cdot \mathrm{y}_{\mathrm{i}}\right) \cdot \mathrm{b}+\sum\left(\mathrm{x}_{\mathrm{i}}^{3}+\mathrm{x}_{\mathrm{i}} \cdot \mathrm{y}_{\mathrm{i}}^{2}\right)\right\rfloor \div \sum \mathrm{x}_{\mathrm{i}}^{2}
\end{aligned}
$$


Calculados os coeficientes de mínimos quadrados, determinam-se os parâmetros do círculo. Tais expressões estão apresentadas em (E.17).

$$
\mathrm{x}_{\mathrm{c}}=\frac{-\mathrm{a}}{2}, \quad \mathrm{y}_{\mathrm{c}}=\frac{-\mathrm{b}}{2}, \quad \mathrm{r}=\sqrt{\mathrm{x}_{\mathrm{c}}^{2}+\mathrm{y}_{\mathrm{c}}^{2}-\mathrm{c}}
$$




\section{APÊNDICE F}

\section{CURVAS DE DRIFT DOS ERROS DE RETITUDE E}

\section{ANGULARES}

\section{Curvas de drift dos erros de retitude}

Na Figura F.1 - F.5 observa-se que os erros de retitude de todos os eixos não mudam de comportamento quando a máquina é submetida a variações de temperatura ambiente. Assim sendo, é possivel levantar o drift em apenas um ponto de observação e efetuar a modelagem destes erros utilizando-se os dados levantados no ponto escolhido.

As Figuras F.4 e F.5 apresentam as curvas de drift dos erros de retitude do eixo $Z$. Ambos os erros foram observados em somente duas posições devido a que o percurso no qual os erros de retitude do eixo $Z$ podem ser medidos com o interferômetro laser é pequeno. 


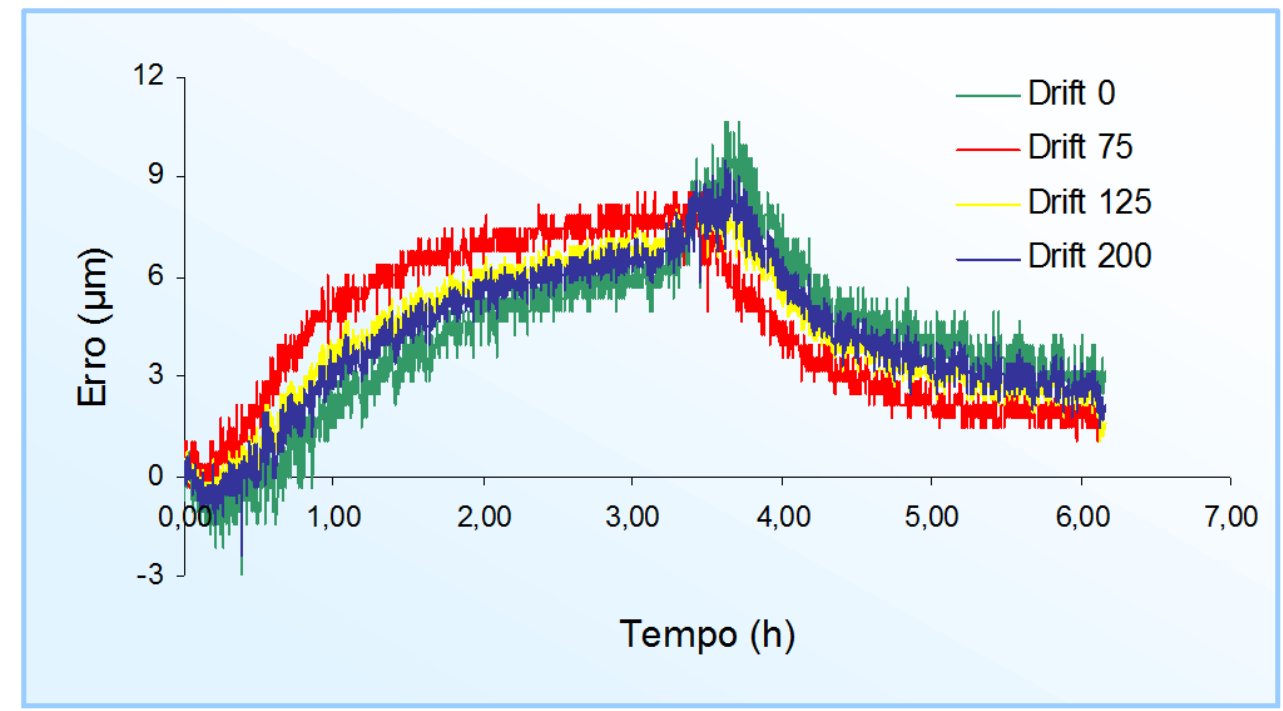

Figura F.1 - Curvas de drift do erro de retitude vertical do eixo $X$.

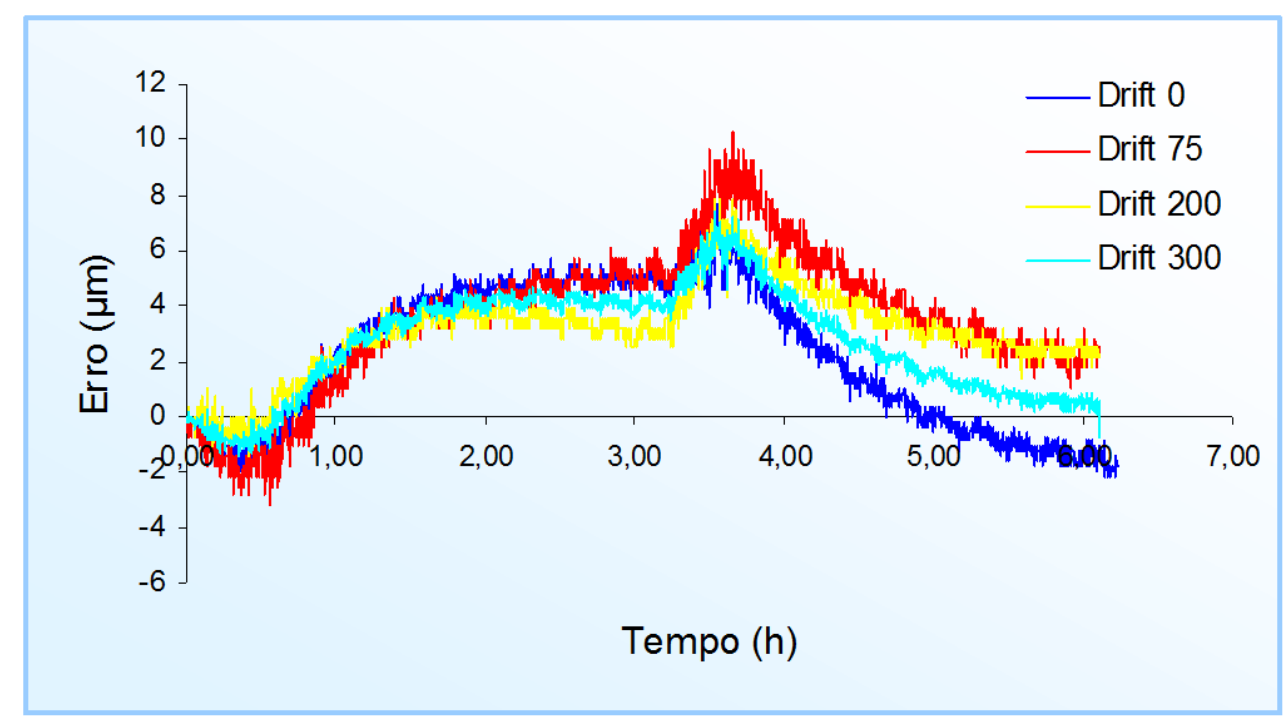

Figura F.2 - Curvas de drift do erro de retitude do eixo $Y$ na direção $X$. 


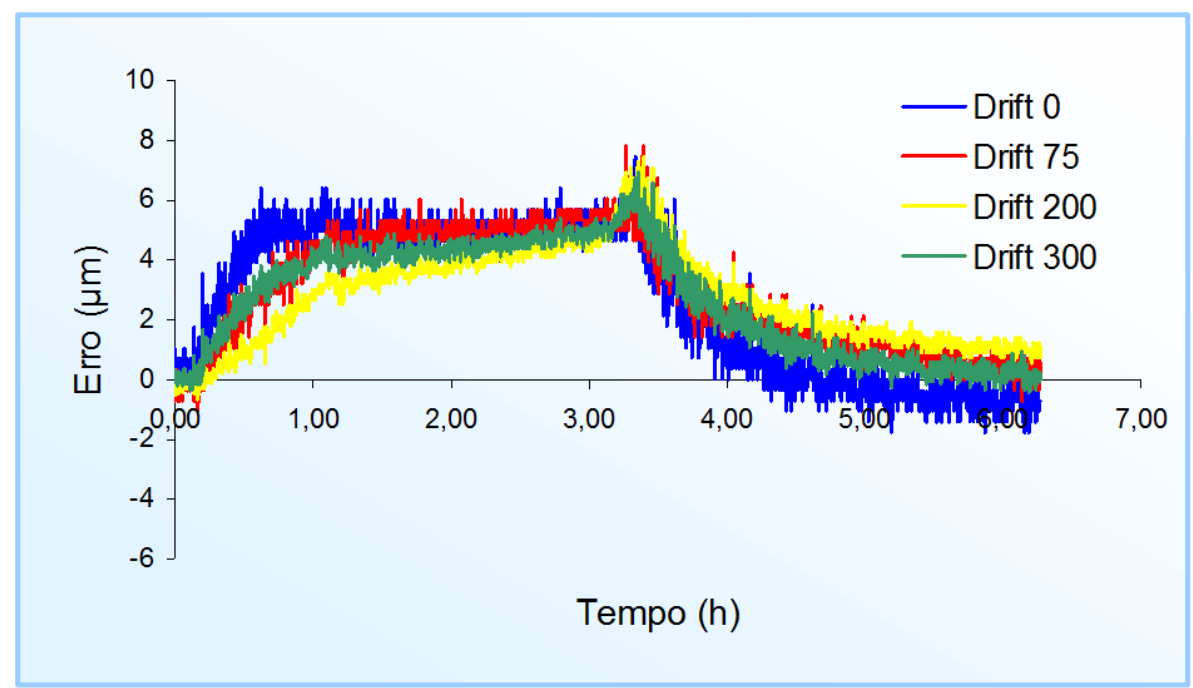

Figura F.3 - Curvas de drift do erro de retitude do eixo $Y$ na direção $Z$.

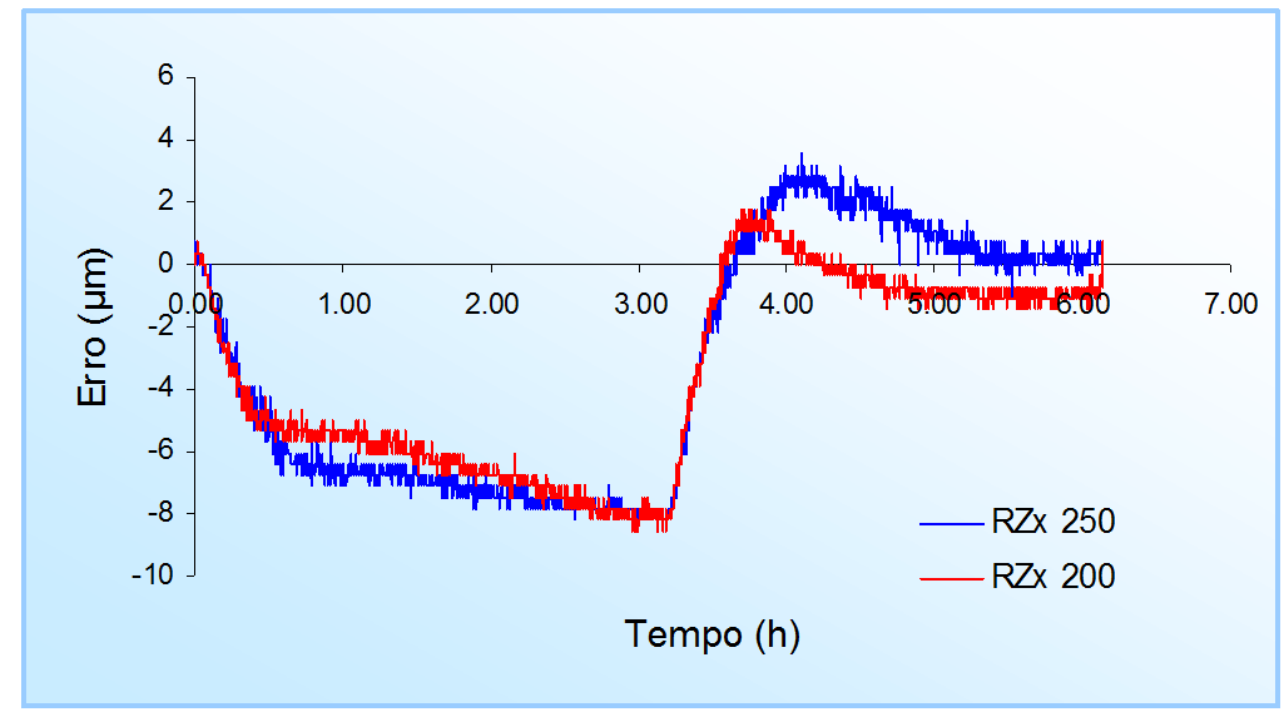

Figura F.4 - Curvas de drift do erro de retitude do eixo $Z$ na direção $X$. 


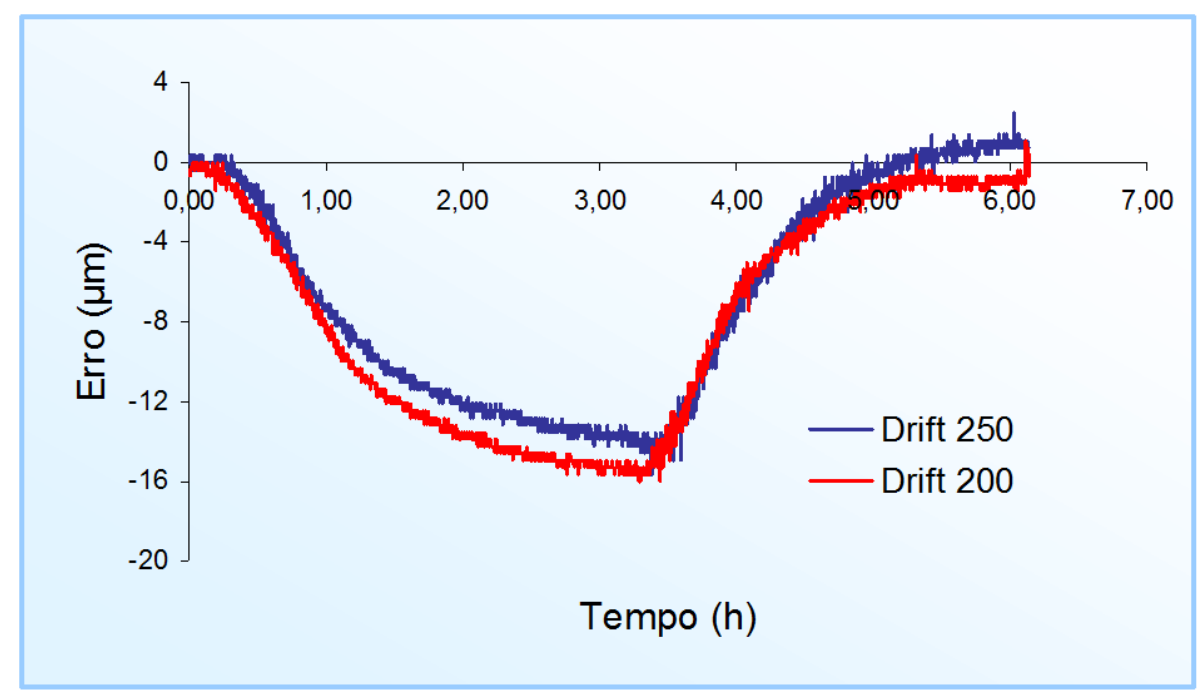

Figura F.5 - Curvas de drift do erro de retitude do eixo $Z$ na direção $Y$.

\section{Curvas de drift dos erros angulares}

As curvas descrevendo o comportamento dos erros angulares pitch, yaw e roll de todos os eixos estão apresentadas nas Figuras F.6 F.13. Observe que o comportamento e a grandeza destes erros, também permanecem constantes durante o aquecimento e esfriamento da máquina.

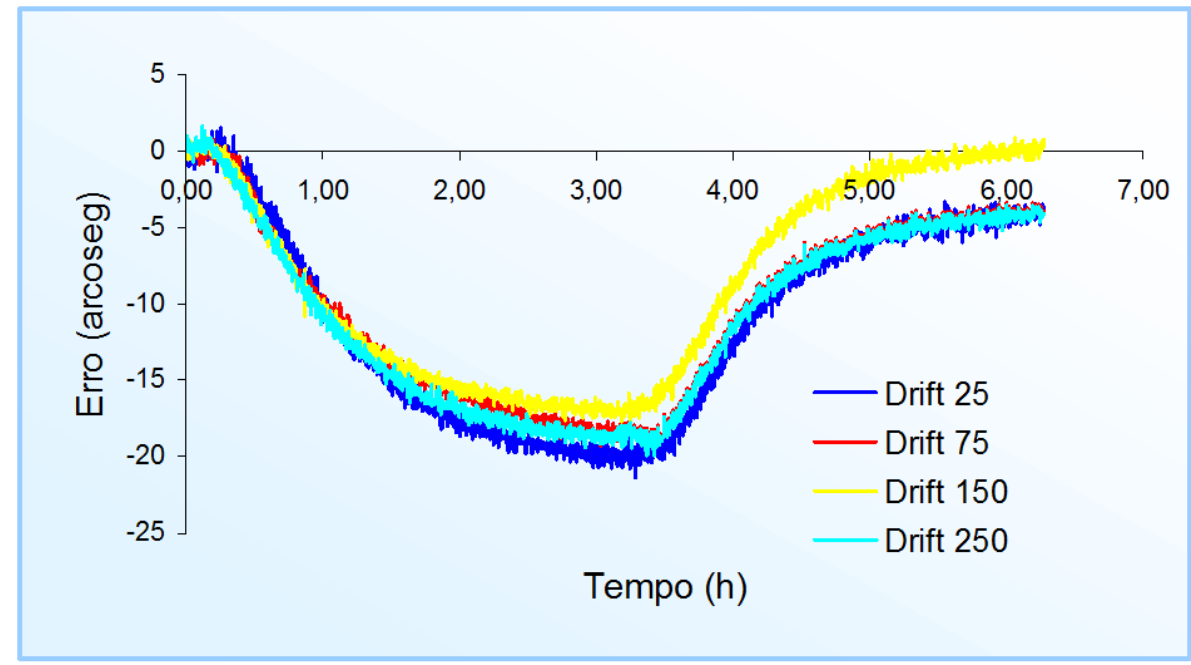

Figura F.6 - Curvas de drift do erro pitch do eixo $X$. 


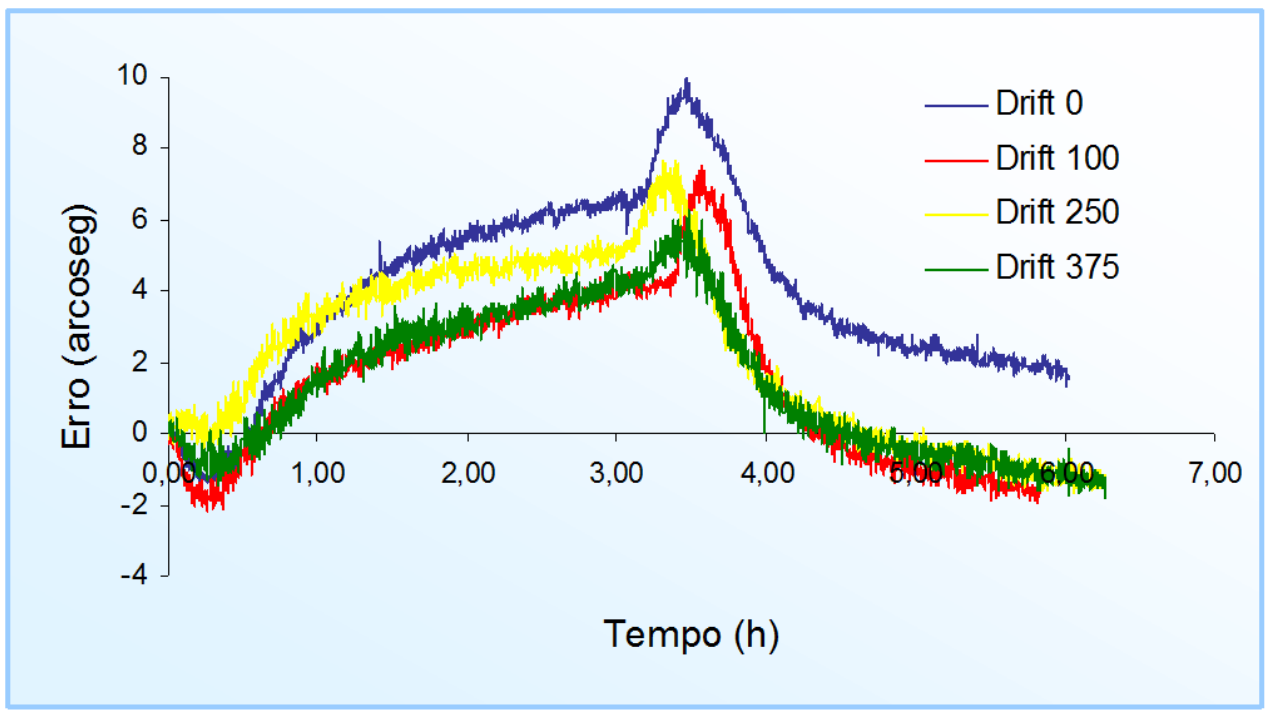

Figura F.7 - Curvas de drift do erro pitch do eixo $Y$.

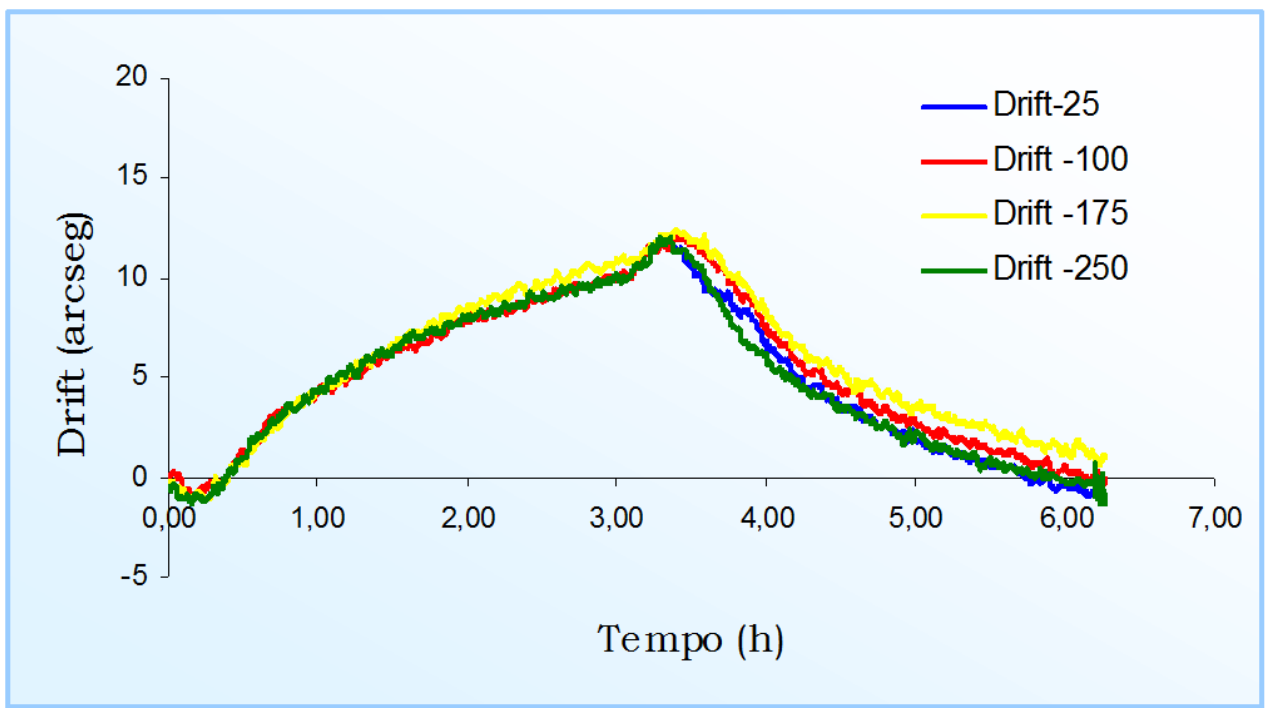

Figura F.8 - Curvas de drift do erro angular pitch do eixo $Z$.

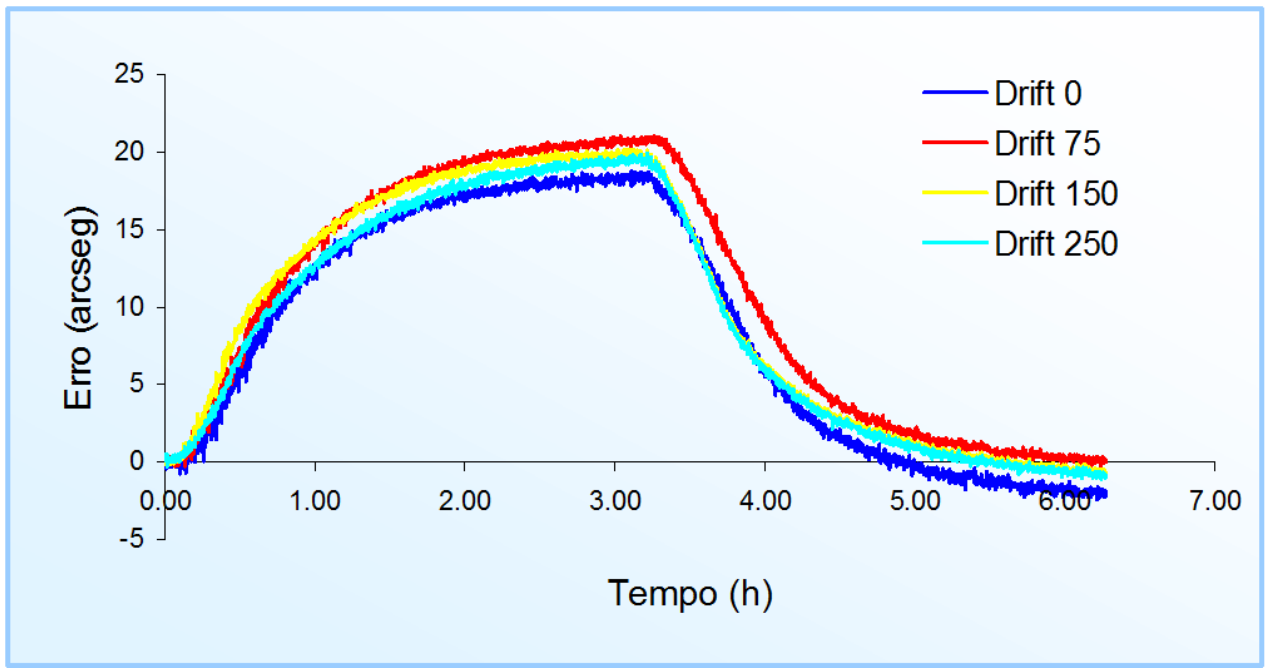

Figura F.9 - Curvas de drift do erro angular yaw do eixo $X$. 


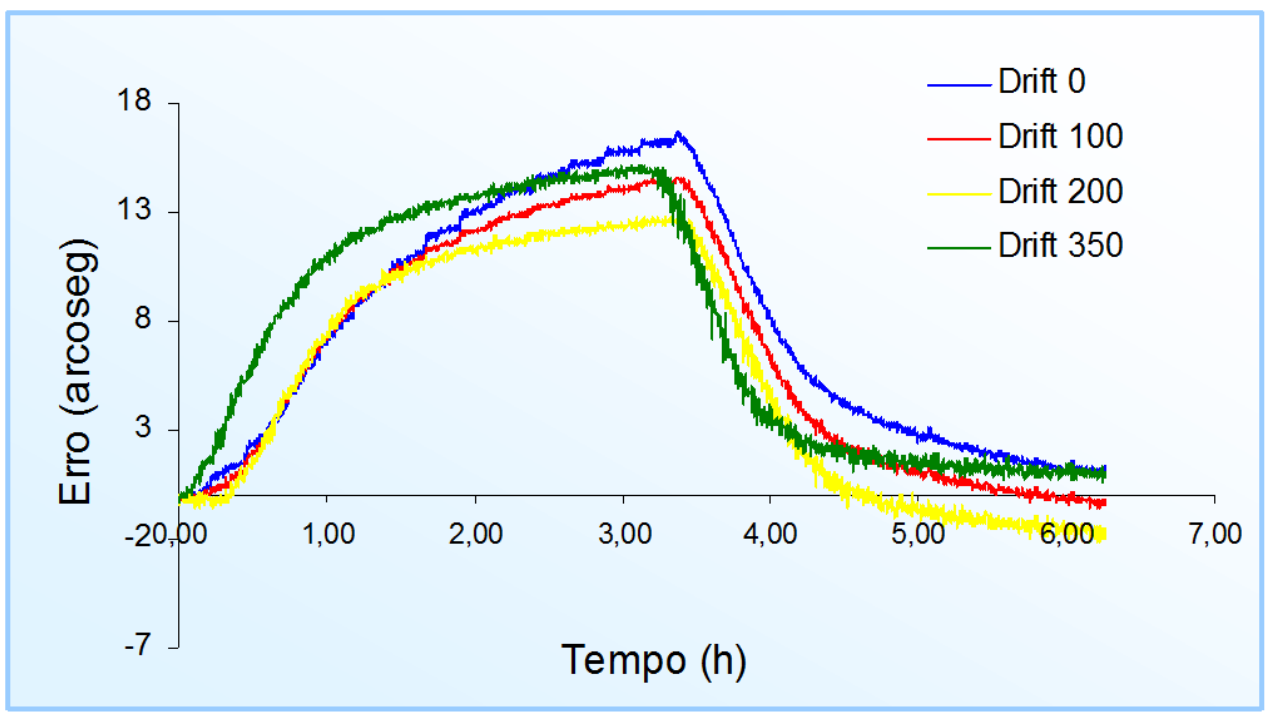

Figura F.10 - Curvas de drift do erro angular yaw do eixo $Y$.

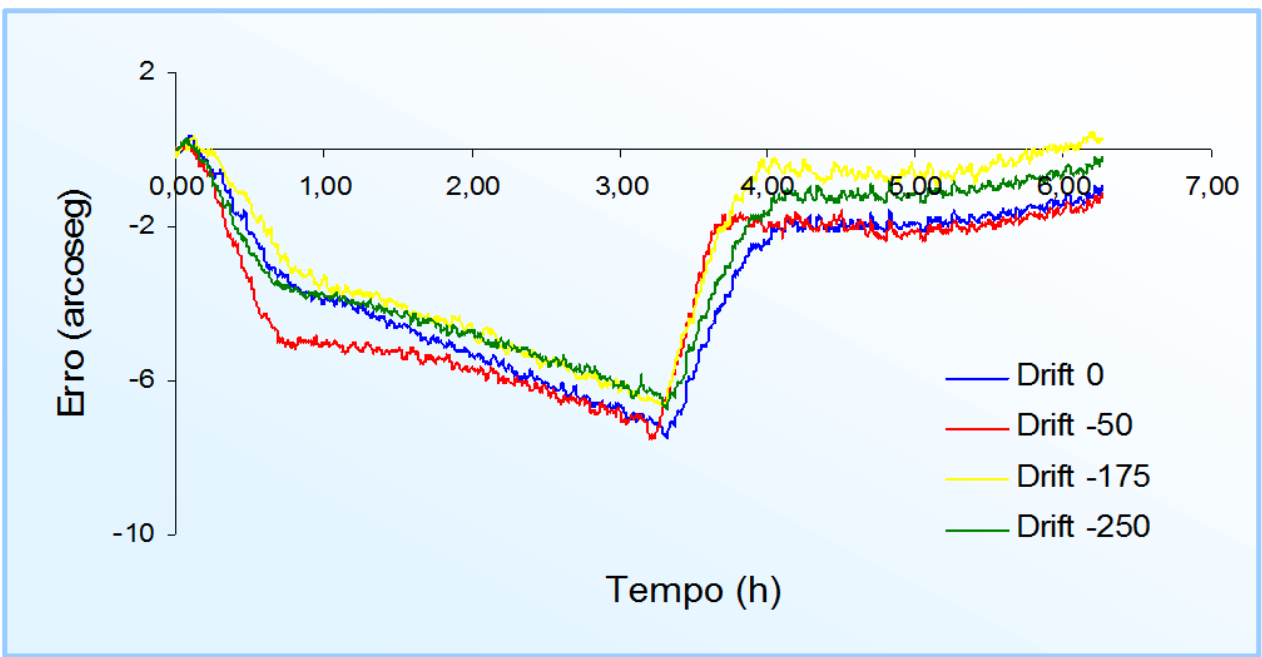

Figura F.11 - Curvas de drift do erro yaw do eixo $Z$.

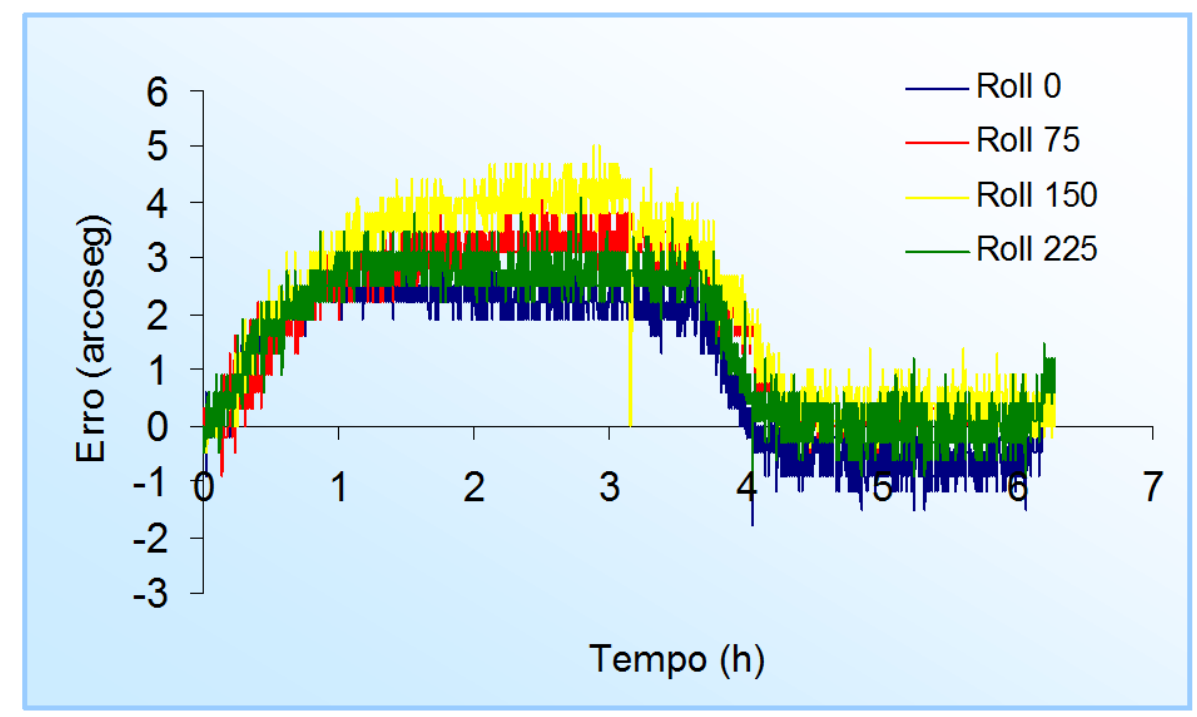

Figura F.12 - Curvas de drift do erro roll do eixo $X$. 


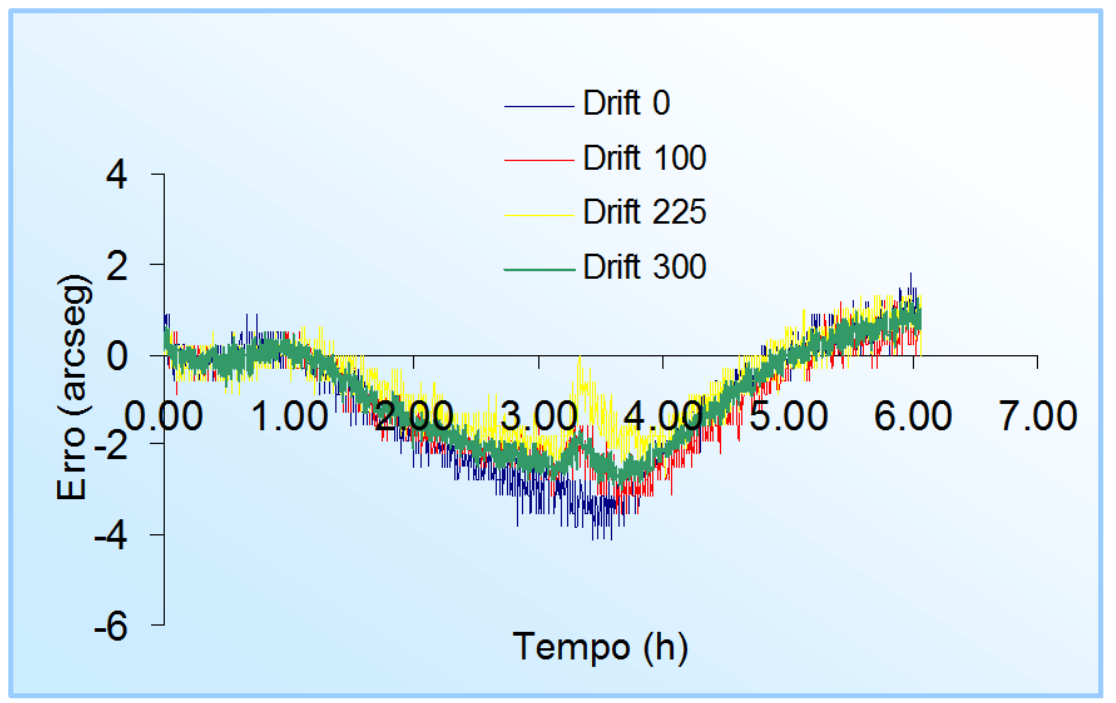

Figura F.13 - Curvas de drift do erro roll do eixo $Y$. 


\section{APÊNDICE G}

\section{Estudo do PRINCÍPIO de Montagem Escala-GuIa}

Uma análise efetuada a partir das curvas da Figura 6.17 permitiu determinar o ponto a partir do qual guia e escala dilatam-se. Primeiramente, foi calculado o coeficiente de dilatação do vidro a partir das curvas dos erros de posição para 20 e $22{ }^{\circ} \mathrm{C}$, sendo de $5,3 \times 10^{-6}{ }^{\circ} \mathrm{C} / \mathrm{m}$. Em seguida foram estimados os erros de posição para diferentes estados térmicos, considerando-se que os mesmos apresentam variação linear. Os resultados estão mostrados na Figura G.1.

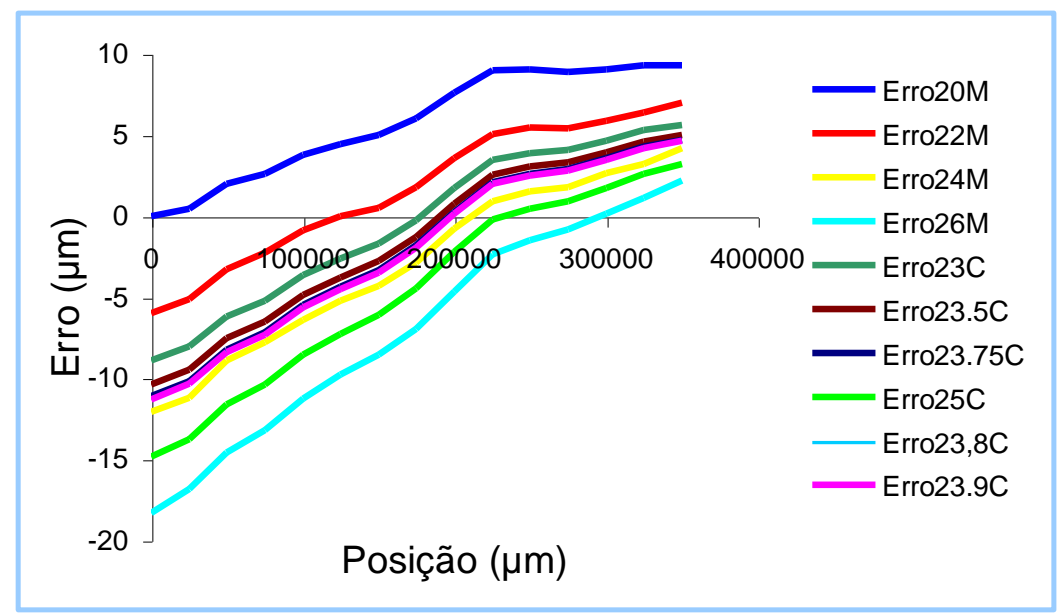

Figura G.1 - Curvas do erro de posição do eixo $Y$. 
$\mathrm{Na}$ Figura anterior pode-se observar que a distância entre interceptos varia, mesmo para gradientes térmicos iguais. Isto pode ser observado na Figura G.2. Verifica-se, ainda, que a distância entre estes interceptos decresce na primeira metade do eixo $Y$, enquanto que na segunda metade cresce. $O$ valor da coordenada $Y$ para a qual muda a tendência da curva é de 230,5 mm. Este valor está próximo dos valores que representam a metade da escala e da guia do eixo $Y$.

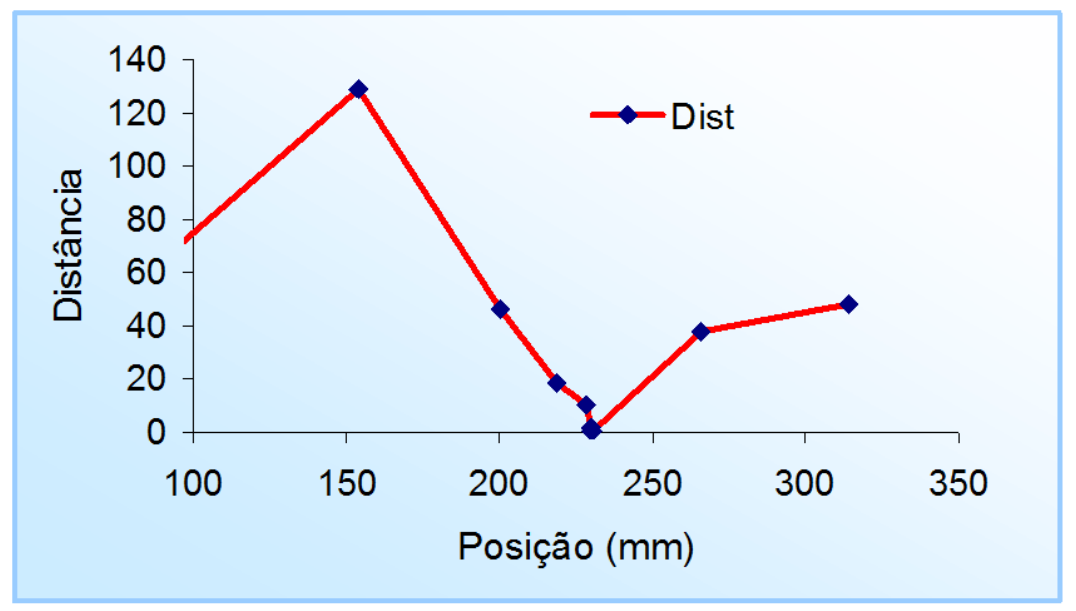

Figura G.2 - Curva representando a distância entre interceptos.

Apesar da variação do erro apresentar um comportamento, aproximadamente, linear e este comportamento estar estreitamente ligado à dilatação do vidro, isto é a escala, não foi possível adotar um modelo linear, pois os resíduos apresentaram tendências. Este fato está justificado pela distribuição não homogênea das temperaturas na estrutura da máquina. Por outra parte, a estimação do coeficiente de dilatação térmica da escala a partir dos valores do erro de posição coletados utilizando o interferômetro laser se mostrou eficiente somente para o eixo $Y$.

Outro aspecto de interesse está no fato de que a distância entre interceptos para valores menores que $230,5 \mathrm{~mm}$ são menores que para os maiores que $230,5 \mathrm{~mm}$. Isto devido a que durante a coleta dos dados impõe-se que no ponto zero o erro é zero. 
No caso específico da máquina avaliada, a escala é colada na guia, permitindo que ela se dilate livremente. Desta forma, os componentes que mais influenciam os valores dos erros de posição são a escala e a guia.

Observando a posição relativa dos componentes escala $Y$, guia $Y$ e desempeno, Figura G.3, verifica-se que a disposição dos elementos guiaescala-desempeno não é simétrica. O eixo $Z$, com a sonda de medição, está situado na parte dianteira da ponte e a escala móvel do eixo $Y$ está mais ou menos no centro da coluna esquerda da ponte. Portanto, existe um braço entre a linha do eixo $Z$ e o local de leitura das escalas. Conseqüentemente, o desempeno foi colocado assimetricamente, deslocado em direção ao extremo dianteiro da guia do eixo $Y$, enquanto que a escala está deslocada na direção do outro extremo da guia. Desta forma, a sonda tem acesso a todos os pontos do volume que estão acima do desempeno.

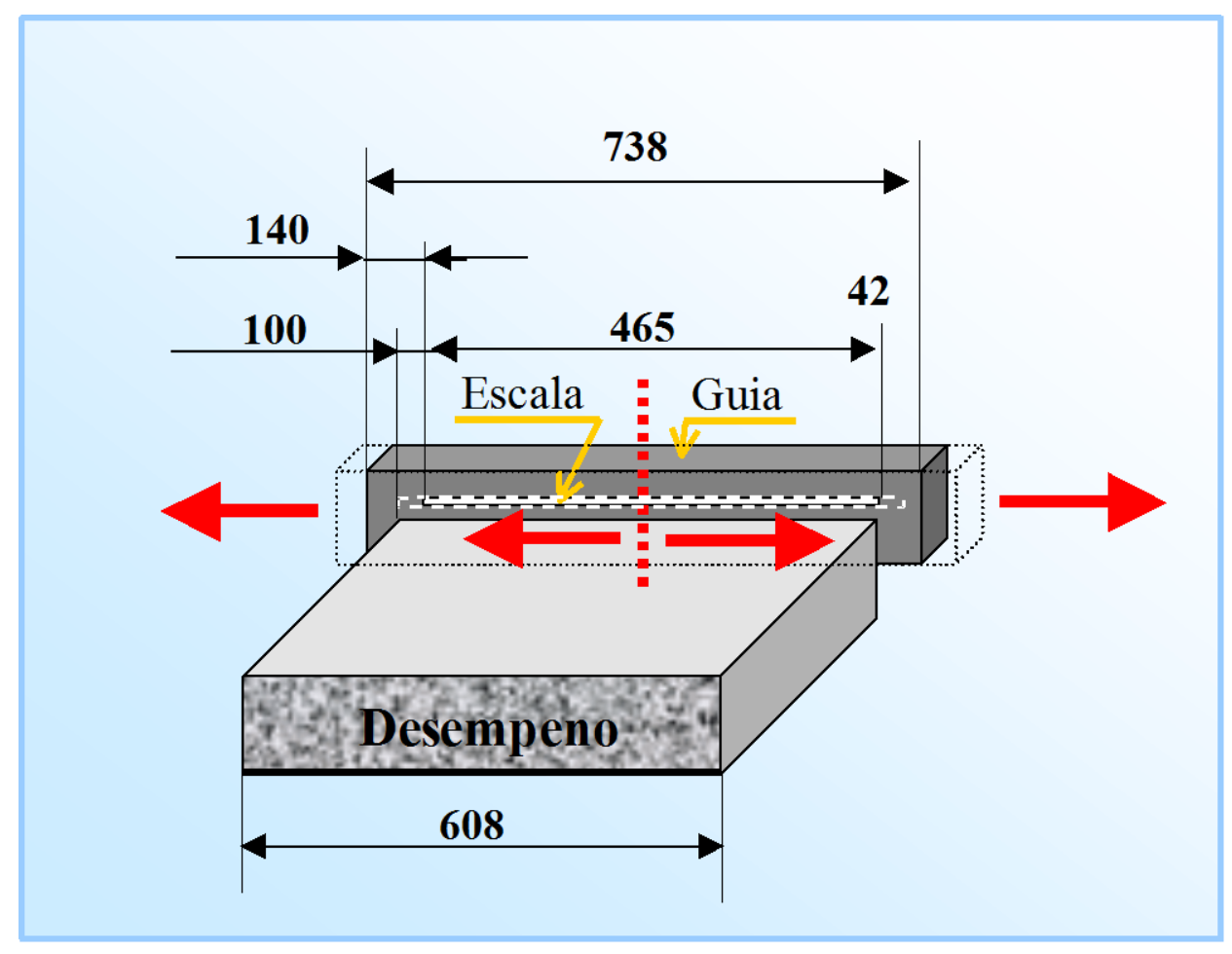

Figura G.3 - Posição relativa entre componentes.

Cabe lembrar que os valores de drift foram coletados com o eixo $Y$ fechado, de forma que a ponte móvel da máquina fica presa à guia e deve 
acompanhar a dilatação da mesma. Desta forma o valor de drift coletado deve ser uma mistura das dilatações experimentadas pela guia e escala do eixo $Y$.

Do anterior pode-se concluir que a variação experimentada pelo erro de posição do eixo $Y$ está estreitamente relacionada com os materiais utilizados na fabricação da escala e da guia, com o comprimento destes componentes, com o princípio de montagem utilizado e logicamente com a variação da temperatura. 


\section{APÊNDICE H}

\section{CÁLCULO do COEFICIENTE de CORREÇÃo do LASER}

O sistema interferométrico laser tem seu princípio de medição baseado no comprimento de onda da luz. Assim sendo, variações na temperatura ambiente provocam mudanças no comprimento de onda da luz, introduzindo erros nas medições. A equação que relaciona o comprimento de onda, a freqüência e a velocidade da luz é dada a seguir:

$$
\lambda=\frac{v}{f}
$$

onde

$\lambda$ - comprimento de onda

$v$ - velocidade da luz

f - freqüência

A velocidade da luz é constante no vácuo, porém, no ar, varia em função da temperatura deste, da pressão e da umidade. Como a freqüência do laser é constante, o comprimento de onda da luz variará com a variação da velocidade da luz.

A distância mostrada no display de medição da unidade laser é igual ao número de comprimento de ondas $N$, multiplicado por um fator 
de compensação $C$ e, este resultado é então multiplicado pelo comprimento de onda no ar $\lambda_{A}$ conforme equação:

$$
D=N \cdot C \cdot \lambda_{A}
$$

A seguinte equação permite calcular o fator de compensação $C$.

$$
C=\frac{10^{12}}{N+10^{-6}}-999000
$$

$\mathrm{N}$ é o comprimento de onda do movimento e pode ser calculado por:

$$
N=0.3836391 \cdot P \cdot\left[\frac{1+10^{-6} \cdot P(0.817-0.0133 \cdot T)}{1+0,003661 \cdot T}\right]-3,033 \cdot 10^{-3} H\left(e^{0.057626 T}\right)
$$

onde $\mathrm{H}$ é a umidade e $\mathrm{P}$ a pressão. 